II. Italienische Dokumente (Nr. 16-29)

\title{
Dokument 16
}

\section{Bericht von General Efisio Marras 1 über seine Inspektionsreise zur 8. italienischen Armee vom 26. September bis 5. Oktober 1942}

Italienische Militärmission

den 7. Oktober 1942-XX²

in Deutschland

Nr. 786/G

Bezug: Besuch bei der 8 . Armee

An das

Comando Supremo

Feldpost Nr. 21

Am vergangenen 26. September besuchte ich das Oberkommando der 8 . Armee und blieb in jenem Abschnitt bis zum 5. Oktober, wobei ich auch Kontakt zum Oberkommando der Heeresgruppe B in Starobelsk aufgenommen habe.

Zweck der Reise war, Kontakt zum Armeeoberkommando aufzunehmen und auf der Grundlage dessen, was mir das Oberkommando des deutschen Heeres mitgeteilt hatte, zusammen mit den Organen des Oberkommandos der Heeresgruppe die Transport- und Versorgungslage zu prüfen. Ich nutzte die Gelegenheit, um den Sektor der Armee kennenzulernen und so über das Gelände, die taktische Situation und die Verteidigungsorganisation unterrichtet zu werden.

In Ergänzung zu den bereits abgesandten diesbezüglichen Telegrammen ${ }^{3}$ werde ich kurz über die Transport- und Versorgungsfrage berichten sowie einige

1 Efisio Marras (1888-1981), Generale di Corpo d'Armata, 1912-1915 als Oberleutnant bei den Besatzungsstreitkräften auf Rhodos, 1915-1918 Teilnahme am Ersten Weltkrieg, Generalstabsausbildung, Mitglied der Untersuchungskommission über die Ursachen der italienischen Niederlage bei Caporetto, 1921-1936 verschiedene Stabsverwendungen und Truppenkommandos, u.a. Büroleiter von Generalstabschef Pietro Badoglio, 1936-1939 als Oberst bzw. Brigadegeneral Militärattaché in Berlin (mit Akkreditierung in Dänemark, Schweden und Litauen), Juli - November 1939 Artillerieführer des in Rom stationierten Armeekorps bzw. Chef des Stabes der 5. Armee in Libyen, seit November 1939 erneut Militärattaché in Berlin und seit November 1940 Chef der italienischen Militärmission in Deutschland, 1940 zum Generale di Divisione, 1943 zum Generale di Corpo d'Armata befördert, am 9. 9.1943 in Deutschland interniert und an die RSI ausgeliefert, im August 1944 Flucht in die Schweiz, Rückkehr im Mai 1945, 1945-1947 Kommandeur des Comando Militare Territoriale Mailand, 1947-1950 Chef des Generalstabs des Heeres, 1950-1954 Chef des Generalstabs der italienischen Streitkräfte.

2 Die römischen Ziffern im Datum beziehen sich auf die Zeitrechnung des faschistischen Regimes nach dem sogenannten Marsch auf Rom.

3 AUSSME, DS II 1480, Fernschreiben von Efisio Marras an das Comando Supremo vom 5. 10., 6. 10. (15.30 Uhr) und 6. 10. 1942 (16.00 Uhr) als Anlagen Nr. 370, Nr. 371 und Nr. 372 zum KTB des Comando Supremo für Oktober 1942. 
Nachrichten und Eindrücke übermitteln, die ich auf meiner Rundreise gewonnen habe.

\section{Transport und Versorgung}

Die Frage ist unter Teilnahme von Vertretern des Oberkommandos der 8. Armee und der Heeresgruppe B in einer Besprechung am 27. September in Millerowo erörtert worden. Gemäß der Lage, wie sie sich nach der Besprechung ergeben hat, habe ich dann am 4. Oktober ${ }^{4}$ mit dem Oberkommando der Heeresgruppe und insbesondere mit General von Weichs ${ }^{5}$ Rücksprache gehalten, um zu vervollkommnen, was bereits vereinbart worden warb.

Die Lage stellt sich im wesentlichen wie folgt dar: Die Eisenbahntransporte an die russische Front befinden sich in einem chronischen Krisenzustand, was zum Teil an der Unzulänglichkeit der Anlagen liegt und zu einem großen Teil an den Schwierigkeiten, die die Partisanen im rückwärtigen Gebiet verursachen. Als Folge dieser Situation erfährt die von der deutschen Transportleitung vorgesehene Zahl der Züge unkalkulierbare, erhebliche Einschränkungen, die im Monat September den hohen Satz von 36 Prozent erreicht haben; in gewissen Phasen und in bestimmten Abschnitten ist dieser Prozentsatz bis auf 50 Prozent angestiegen. Ich referiere die Daten, die mir mitgeteilt worden sind, aber ich muß sofort hinzufügen, daß, wenn man um Informationen zur allgemeinen Lage bittet, geantwortet wird, es sei alles in Ordnung, und die Partisanen würden wirksam niedergehalten; spricht man andererseits von der Versorgung, bekommen die Aktivitäten der Partisanen ein völlig anderes Gewicht.

Auf jeden Fall muß man auch bedenken, daß die Fortdauer der Operationen gegen Stalingrad die Krise verschärft hat, da sie eine Intensivierung der Transporte zu den beiden in jenem Bereich eingesetzten deutschen Armeen erforderlich machte. Diese Situation hat sich auf die Transporte für die übrigen Armeen der Heeres-

4 Eine Aufzeichnung über dieses Gespräch findet sich im AUSSME, DS II 1333 a.

5 Maximilian Reichsfreiherr von und zu Weichs an der Glon (1881-1954), Generalfeldmarschall, 1914-1918 Teilnahme am Ersten Weltkrieg, 1919 Übernahme in die Reichswehr, seit 1937 als General der Kavallerie Kommandierender General des XIII. Armeekorps, seit Oktober 1939 Oberbefehlshaber der 2 . Armee, seit Juli 1940 Generaloberst, 1942/1943 Oberbefehlshaber der Heeresgruppe B, seit Januar 1943 Generalfeldmarschall, im August 1943 zum Oberbefehlshaber Südost und der Heeresgruppe F ernannt, nach 1945 im Nürnberger Prozeß gegen die "Südost-Generale“ angeklagt, jedoch noch während des Prozesses aus gesundheitlichen Gründen entlassen.

6 Diese Frage, die sowohl die laufende Versorgung der 8. Armee als auch den Ausbau der geplanten Winterstellung am Don betraf, stand seit August 1942 im Raum und drohte im September zu eskalieren. Die wichtigsten italienischen Forderungen betrafen die Zuteilung von 402 Zügen zwischen dem 1. 9. und dem 15. 11.1942 sowie die Zuteilung von $500 \mathrm{~m}^{3}$ Treibstoff täglich; die zuständigen deutschen Stellen wollten zwischen dem 10. 9. und dem 15. 11. 1942 dagegen nur 260 Züge und $200 \mathrm{~m}^{3}$ Treibstoff bereitstellen. AUSSME, L 14/88-10, Generalstab des italienischen Heeres (Nr. 230620 di. prot. segreto - gez. Francesco Rossi) an den Generalquartiermeister des deutschen Heeres vom 31.8. 1942 und Oberquartiermeister/Heer (Nr. 9911/42 geheim - gez. Major i.G. Weller), an den Oberquartiermeister im italienischen Heeresgeneralstab vom 29.11. 1942. Zu den Spannungen zwischen den Verbündeten und zum vermittelnden Gespräch von Marras am 27.9. 1942 vgl. BA-MA, MFB4 41403, Bl. 1025, Bl. 1033 und Bl. 1035, KTB des Deutschen Generals beim italienischen AOK 8, Einträge vom 2. 9., 23. 9. und 27. 9. 1942. 
gruppe B (8. italienische, 2. ungarische, 2. deutsche) und folglich auch auf den Zufluß von Betriebsstoff ausgewirkt, so daß unsere Armee in äußerste Schwierigkeiten geraten ist und nicht, wie es wünschenswert gewesen wäre, die trockene Jahreszeit nutzen konnte, um Material und Vorräte nach vorne zu bringen. Das deutsche Oberkommando wie auch das Oberkommando der Heeresgruppe glauben, nachdem sie Druck von allen Seiten erhalten haben, die Frage vorübergehend durch die Zuweisung von täglich fünfeinhalb Zügen und $300 \mathrm{~m}^{3}$ Betriebsstoff an die 8 . Armee geregelt zu haben ${ }^{7}$. Gegenüber dem von der Intendenza der 8. Armee gemeldeten Bedarf gibt es somit einen Fehlbestand von einem Zug und $200 \mathrm{~m}^{3}$.

Von deutscher Seite wird versichert, daß nicht mehr möglich sei, und wenn die Daten richtig sind, die mir das Oberkommando der Heeresgruppe geliefert hat, müßte man tatsächlich einräumen, daß die fünfeinhalb Züge täglich, wenn sie beibehalten werden, einen günstigen Satz darstellen. In der Tat belaufe sich die Zahl der Züge, die der Heeresgruppe täglich zur Verfügung gestellt würden, insgesamt gerade auf 19. Andererseits habe ich den Eindruck gewonnen, daß die logistische $\mathrm{Si}_{\text {- }}$ tuation der Armee sich erheblich bessern würde, behielte man die Zahl der Züge bei, weil es ihr möglich würde, den Rest der trockenen Jahreszeit, die dieses Jahr glücklicherweise länger als gewohnt anhält, voll und ganz zu nutzen.

Einen erheblichen Nachteil stellt der Umstand dar, daß dreieinhalb Züge über Ostrogoshsk kommen und folglich umgeschlagen werden müssen ${ }^{8}$. Von deutscher Seite ist zugesichert worden, daß der Bau der Eisenbahnverbindung Ostrogoshsk Jewdakowo mit allen Mitteln beschleunigt wird, deren Fertigstellung für ungefähr Mitte November vorgesehen ist; es ist auch zugesichert worden, später den Anteil der Züge zu vergrößern, die über Starobelsk herangeführt werden sollen.

Ein anderes Element, das die Versorgung der Armee betrifft, ist die Verfügbarkeit von Karren für Zugtiere. Das deutsche Kommando hat bereits angeordnet, eine bestimmte Zahl an landesüblichen Karren und Zugtieren abzugeben, deren Zahl nach Abschluß der Erntearbeiten erhöht wird'.

Zusammenfassend bin ich der Meinung, daß es zur Zeit nicht möglich ist, von deutscher Seite mehr zu erlangen ${ }^{10}$, und $\mathrm{da} ß$ es notwendig ist, auf die Einhaltung

7 Daß sich die deutsche Seite schließlich auf diesen entgegenkommenden Kompromiß einließ, war laut Marras nicht zuletzt auf eine Intervention Hitlers zurückzuführen; AUSSME, DS II 1480, Fernschreiben von Efisio Marras an das Comando Supremo vom 5. 10. 1942 (Anlage Nr. 370 zum KTB des Comando Supremo für Oktober 1942).

8 Ostrogoschsk war deshalb ungünstig, weil dort keine Möglichkeit bestand, die Züge auf die von Norden nach Süden verlaufende Bahnlinie Jewdakowo - Millerowo - Kamensk weiterzuleiten. Menschen und Material mußten daher zunächst auf Kraftfahrzeuge und bei Jewdakowo erneut auf die Schiene verladen werden. Eine Linie von Ostrogoschsk nach Jewdakowo befand sich im Bau.

${ }^{9}$ Dies hatte Marras dem Comando Supremo bereits in einem Fernschreiben am 24. 9.1942 mitgeteilt (AUSSME, DS II 4007); allerdings wollte sich die deutsche Seite noch nicht auf die Zuweisung der geforderten 2500 "Panjewagen " festlegen und erklärte auch, es sei noch nicht klar, wie viele von den 10000 Schlitten mit den dazugehörigen Pferden, die man zu beschlagnahmen gedenke, der 8. Armee überlassen werden könnten. AUSSME, L 14/88-10, Oberquartiermeister/Heer (Nr. 9911/42 geheim - gez. Major i.G. Weller) an den Oberquartiermeister im italienischen Heeresgeneralstab vom 29.11. 1942.

$10 \mathrm{Daß}$ die zuständigen deutschen Stellen den Verbündeten zumindest auf dem Papier weit entgegengekommen waren, zeigt die Tatsache, daß ${ }_{n}$ der 6 . Armee im Oktober [1942] trotz bevorzugter Versorgung im Tagesdurchschnitt nur $4 \frac{1}{2}$ Züge statt, wie vorgesehen, 8 bis 
der eingegangenen Verpflichtungen zu achten, anstatt auf neue Zugeständnisse zu drängen.

\section{Der Einsatzbereich der Armee}

Mit Erlaubnis des Oberkommandos der Armee habe ich den gesamten von unseren Truppen besetzten Sektor besuchen dürfen. Dieser in einigen Abschnitten sehr ins Detail gehende Besuch hat es mir ermöglicht, eine Vorstellung von den Geländebedingungen, Verbindungswegen, der Verteidigungsorganisation und der taktischen Situation zu gewinnen sowie mir vor Ort ein genaueres Bild von den jüngsten Operationen in den Abschnitten des XXXV. und des II. Armeekorps zu machen'1.

Obgleich das Gelände westlich des Don im von unseren Truppen gehaltenen Gebiet die allgemeinen Merkmale einer Flachlandregion zeigt, wie sie für die ganze Ukraine typisch sind, weist es zahlreiche weitgeschwungene Anhöhen auf, die sich zuweilen zu niedrigen Hügeln erheben, was in den Senken die Möglichkeit von Bereitstellungen und Bewegungen bietet, die der Beobachtung vom Boden aus verborgen bleiben. In der Region mangelt es vor allem im südlichen Abschnitt an Wäldern, und die wenigen Wälder, die es gibt, sind im allgemeinen in ihrer Ausdehnung begrenzt. Der Boden wird zum Getreideanbau und als Weideland genutzt; weitläufig sind auch die Sonnenblumenplantagen. Dort, wo die Ernte noch nicht eingebracht worden ist, bieten sich deshalb für Männer im Gelände Deckungsmöglichkeiten. Einige Landstriche sind unbebaut. Die ganze Landschaft zeigt sich in dieser Jahreszeit in einem steppenartigen Gewand.

Ortschaften sind selten, die Häuser armselig, abgesehen von einigen Gebäuden, die als Schulen, Behörden oder zu industriellen Zwecken dienen. Wasser ist rar. Das Niveau der Lebenshaltung ist niedriger als in der Westukraine.

Das von unseren Truppen gehaltene rechte Donufer beherrscht im allgemeinen das gegenüberliegende Ufer; es fällt mit einer zwischen 20 und $50 \mathrm{~m}$ hohen Böschung zum Fluß hin ab; der Fluß liegt etwa $70 \mathrm{~m}$ hoch, die größeren Anhöhen dahinter erreichen bis zu $220 \mathrm{~m}$. Der Böschung geht zum Fluß hin eine Niederungszone von unterschiedlicher Tiefe voraus, und sie wird häufig von großen (mit dem Namen balka bezeichneten) Schluchten durchbrochen, die ins Landesinnere reichen, wobei sie sich in kleinere Einkerbungen verzweigen und dem Feind die besten Wege zur Infiltration bieten, wenn es ihm gelingt, den Fluß zu überqueren. Diese balkas sind dann vom Feind bei seinen jüngsten Operationen tatsächlich genutzt worden. Sie werden jetzt nach und nach mit Minen und Hindernissen gesperrt. Der Sektor der Armee weist mit dem Tal der Tschernaja Kalitwa, eines rechten Nebenflusses des Don, auch einen ebenen Abschnitt auf, den zur Zeit die „Cuneense" hält, die ihn später an die "Cosseria" abgeben wird ${ }^{12}$.

Das linke Donufer ist im allgemeinen flach und wird folglich von uns beherrscht; allerdings bietet es dem Feind gute Deckungsmöglichkeiten, da es ausgedehnte

10 Züge zugeführt werden “ konnten. Wegner, Krieg gegen die Sowjetunion, in: DRZW 6, S. 989.

$11 \mathrm{Zu}$ den Kampfhandlungen vom 20.8.-12.9. 1942 vgl. Operazioni delle unità italiane al fronte russo, S. 250-300.

12 Seit Ende September 1942 bildete die Tschernaja Kalitwa die Grenze zwischen dem Alpinikorps und dem II. Armeekorps; vgl. ebenda, Abbildung 33. 
Waldgebiete gibt, die bis zum Fluß reichen. Der Don selbst stellt kein Hindernis von großer Bedeutung dar; er ist ungefähr $150 \mathrm{~m}$ breit, doch verengt er sich dort, wo der Wasserlauf sich teilt und kleine Inseln bildet, die alle vom Feind besetzt sind; an einigen Stellen gibt es Furten. Die Sowjets bedienen sich für ihre Erkundungen verschiedener Wasserfahrzeuge; gegenüber dem sowjetischen Brückenkopf von Krutowskij, an der Nahtstelle zur 6. deutschen Armee, sind einige Brücken errichtet worden. Manche - auch sehr ausgedehnte - Ortschaften befinden sind auf beiden Ufern in der Nähe des Flusses. So erstreckt sich z. B. die Ortschaft Gorochowka im Abschnitt des II. Korps auf dem sowjetischen Ufer über ungefähr neun km.

Im Abschnitt unserer Armee ist das gesamte an den Don grenzende Gebiet in einer Tiefe von ungefähr fünf $\mathrm{km}$ von der Bevölkerung geräumt worden. Bei der ungarischen Armee ist man ebenso verfahren. Die geräumten Ortschaften bieten einige Unterbringungsmöglichkeiten und die in der Nähe des Flusses auch Holz und Befestigungsmaterial sowie verschiedene Materialien zur Einrichtung von Unterständen (Balken, Türen, Fenster usw.).

\section{Die Einwohner und die lokalen Ressourcen}

Die Einwohner verhalten sich im allgemeinen ruhig; man verspürt im Vergleich zu den deutschen Truppen und Dienststellen eine gewisse Präferenz für uns. Das Niveau der Lebenshaltung ist niedrig, doch die allgemeinen Lebensbedingungen der Landbevölkerung erweisen sich als gut, vor allem hinsichtlich der Ernährung; hingegen sind die Lebensbedingungen in den dichter bevölkerten Zentren schlechter, wo die Grundnahrungsmittel rationiert und nur den Arbeitern garantiert sind (die Brotration schwankt zwischen 200 und 250 gr.). Es gibt zahlreiche Flüchtlinge, die in verschiedene Richtungen ziehen; es handelt sich dabei um Personen, die man aus der frontnahen Zone entfernt hat, oder auch um Personen, die früher im rückwärtigen Gebiet evakuiert worden sind und nun zu ihren ursprünglichen Wohnsitzen zurückkehren, die die Kampfeinheiten hinter sich gelassen haben. Während von seiten der Wirtschaftsorgane nachdrücklich empfohlen wird, die Bauern nicht von ihrer Arbeit abzuziehen, ist festzuhalten, daß andererseits die Arbeitskräfte von den deutschen Behörden zu Hilfsdiensten und auch zu Straßenarbeiten herangezogen werden; gleichzeitig vollzieht sich die Rekrutierung von ins Reich zu transportierenden, insbesondere weiblichen Arbeitskräften, wobei die jüngeren und kräfrigeren bevorzugt werden ${ }^{13}$. Typisch sind die Aktivitäten der Organisation Todt, die entlang einiger großer Straßen (ich habe dies auf der Straße Kantemirowka - Bogutschar beobachtet) einfache Assistenten einsetzt, die vor Ort Arbeitskräfte und Gerätschaften requirieren und dabei zuweilen unsere Truppenteile um Unterstützung ersuchen.

Die landwirtschaftlichen Ressourcen des Gebietes sind beträchtlich ${ }^{14}$, wenngleich weniger reichhaltig als in der Westukraine; unsere Armee kann darauf zu-

${ }^{13}$ Zur Rekrutierung sowjetischer Arbeitskräfte für die deutsche Kriegswirtschaft im rückwärtigen Gebiet der 8. italienischen Armee vgl. die Berichte der Etappenkommandos, die wiederholt den negativen Einfluß dieser Maßnahme auf das Verhältnis von Besetzten und Besatzern betonten; ASD, DGAP 1931-1945 (URSS), 39/2.

14 Detaillierte Übersichten über die Ressourcen des rückwärtigen Gebietes der 8. Armee finden sich im AUSSME, DS II 1557/8. 
rückgreifen, freilich unter all den Schwierigkeiten, die der Mangel an Transportmitteln, die geringe Zahl an Mühlen und die von den deutschen Wirtschaftsorganen verhängten Beschränkungen mit sich bringen ${ }^{15}$. Wie bereits von der Intendenza der 8. Armee mitgeteilt ${ }^{16}$, haben die deutschen Stellen 70 Prozent des Getreides für die Ernährung der Zivilbevölkerung und für die Saat reserviert, zwei Drittel des Tierfutters für die Zivilbevölkerung und 80 Prozent des Viehs für die Bevölkerung, für die Herstellung von Milchprodukten und für die Zucht. Das Bemühen, nicht nur die Ernährung der Zivilbevölkerung sicherzustellen, sondern auch möglichst viel zur Ernährung der deutschen Truppen an anderen Abschnitten der russischen Front herauszuziehen und zur Ernährung der deutschen Bevölkerung beizutragen, ist offensichtlich. Eine amtliche Meldung, die darauf hinweist, daß die jüngste Erhöhung der Brotration auf den Beitrag der in Rußland besetzten Gebiete zurückzuführen ist, bestätigt dies indirekt.

\section{Die Unterbringung der Truppen und die Organisation der Verteidigung}

Alle Verbände haben eine intensive Tätigkeit sowohl bei den Arbeiten an den Verteidigungsanlagen als auch beim Bau von Unterständen, beim Umbau von Unterkünften und bei der Instandsetzung der Verbindungswege entfaltet. Dem Mangel an Nachschubgütern begegnete man mit der Ausbeutung der Ressourcen vor Ort.

Bei der Organisation der Verteidigung setzte man auf die Anlage von Stützpunkten und Widerstandsnestern in unterschiedlichen Abständen, deren Bau in einigen Abschnitten ziemlich weit fortgeschritten ist ${ }^{17}$. Parallel dazu gewinnt die Verteidigungsstellung eine gewisse Tiefe. Von deutscher Seite ist empfohlen worden, die vordere Linie [möglichst] widerstandsfähig auszubauen; man hat gar darauf bestanden, die Kampflinie in Ufernähe zu errichten. Dieser Grundsatz schien angesichts der Chance, die Böschung soweit als möglich als Panzersperre zu nutzen, ohne damit selbstverständlich auf die direkte Beobachtung des Flusses zu verzichten, vielfach fragwürdig zu sein. Die deutsche Intervention hat in einigen Fällen zu Unsicherheit und zur Änderung von Befehlen geführt; aber diese Schwierigkeiten sind mittlerweile beseitigt, und die Ansicht der Kommandos und der Truppen vor Ort hat sich schließlich durchsetzen können ${ }^{18}$. Besondere Aufmerksamkeit hat man den balkas gewidmet, die zum Don hinabführen; sie sind durch den Einsatz von Minen insbesondere gegen Panzer gesperrt worden.

Alles in allem wurde trotz der knappen verfügbaren Mittel viel gearbeitet, und obgleich die Verteidigungsstellung ihre endgültige Gestalt und auch ihre nötige $\mathrm{Fe}$ stigkeit noch nicht erlangt hat, legt sie gleichwohl Zeugnis von den Aktivitäten unserer Soldaten $a b$, die zweifellos jene übertreffen, die von anderen Truppen und in

$15 \mathrm{Zu}$ den Auseinandersetzungen zwischen den zuständigen italienischen Stellen und den deutschen Wehrwirtschaftsstäben vgl. den detaillierten Bericht des Generalstabs der Intendenza „Due battaglie invernali 1941/42-1942/43“; AUSSME, DS II 1557/8.

16 Nicht ermittelt.

17 Eine Übersichtskarte, die den Stand der Arbeiten wiedergibt und zeigt, daß diese letztlich nur im Bereich der vordersten Linie fortgeschritten waren, findet sich im AUSSME, L $14 / 86-1$.

18 Zur Auseinandersetzung über die Verteidigungsstrategie vgl. S. 61 f. des vorliegenden Bandes. 
anderen Abschnitten entfaltet worden sind. Auch von deutscher Seite werden diese Aktivitäten weithin anerkannt ${ }^{19}$.

\section{Die allgemeine taktische Lage}

Die Armee besetzt auch nach Durchführung der vorgesehenen Frontverkürzung - die im übrigen nicht mehr als $40 \mathrm{~km}$ ausmacht - im Verhältnis zu den verfügbaren Kräften einen sehr breiten Abschnitt, vor allem wenn man berücksichtigt, welche Bedeutung dieser mit Blick auf eine mögliche große sowjetische Operation in Richtung Rostow besitzt. Unseren Einheiten fehlt es an automatischen Waffen, abgesehen von denjenigen, die sich bereits seit langem in Rußland befinden und ihre Ausstattung mit erbeuteten Waffen vergrößert haben. Auch die Panzerabwehrbewaffnung ist unzulänglich. Die Artillerie befindet sich hingegen im Vergleich zu anderen Armeen in einem verhältnismäßig guten Zustand, doch mangelt es ihr vor allem bei den Alpinidivisionen ${ }^{20}$ an Reichweite, die eines längeren Arms bedürften, weil sie an sehr weitläufigen Front[abschnitt]en aufgestellt sind. Die Lage wird sich erheblich bessern, wenn die Verteidigungsstellung eine größere Festigkeit erlangt hat und die notwendigen Vorräte angelegt sind. Die Stimmungslage der Truppen scheint optimal zu sein. In den Verbänden des alten CSIR wartet man auf die Ablösung. Dringend erwünscht ist das Eintreffen der Pakete [aus der Heimat], womit die Unmöglichkeit ausgeglichen werden kann, im Land irgend etwas zu kaufen.

\section{Die Aktivitäten des Feindes}

Dic Sowjets entfalten eine intensive Aufklärungstätigkeit mit großen Patrouillen, die während der Nacht den Don zu überqueren versuchen und bisweilen unser Ufer erreichen, wobei sie fast immer Waffen und Gefangene in unseren Händen lassen. Tagsüber und insbesondere zur Dämmerung hin Störfeuer mit Artillerie und Granatwerfern der Infanterie. An einigen Stellen Aktionen von Scharfschützen. Der Feind tarnt seine Aktivitäten sorgfältig; Bewegungen und Arbeiten werden nachts oder im Schutz der ausgedehnten Waldgebiete durchgeführt.

Die sowjetische Luftwaffe ist tagsüber inaktiv; hingegen fliegt sie jede Nacht Angriffe gegen die wichtigsten Verkehrszentren und die vorgeschobenen Flugplätze der Luftwaffe, wobei sie mit kümmerlichen Ergebnissen wenige Bomben abwirft. Häufig ist das Absetzen von Flugblättern und Fallschirmspringern, die zum großen Teil gefangengenommen werden. Die Aktivitäten dieser Fallschirmspringer und der Partisanen im Armeeabschnitt haben bisher zu keinem Ergebnis geführt.

\section{Das deutsche Verbindungskommando}

Dieses verdient besondere Erwähnung, denn es steht unter dem Befehl eines Generals $^{21}$ [der Infanterie] und hat sich nach und nach dergestalt entwickelt, daß es einen aufdringlichen Charakter angenommen und Aufgaben übernommen hat, die weit

19 In Wahrheit fiel das Urteil der deutschen Beobachter recht zwiespältig aus, wie die regelmäBigen Berichte der Verbindungsoffiziere an den Deutschen General zeigen; BA-MA, MFB4 18276, Bl 461-506.

20 Die Artillerie der Alpinidivisionen bestand überwiegend aus Geschützen der Kaliber 7,5 und $10,5 \mathrm{~cm}$; lediglich das Korps verfügte über eine Abteilung mit zwölf Geschützen vom Kaliber $14,9 \mathrm{~cm}$; vgl. Operazioni delle unità italiane al fronte russo, S. $602 \mathrm{f}$.

21 In der Vorlage: „Generale di corpo d'armata“; dieser Rang entsprach dem eines Generals der Infanterie. 
über den gewöhnlichen Verbindung[sdienst] hinausgehen. Außer dem Chef des Kommandos gibt es einen Oberst i.G. als stellvertretenden Chef des Kommandos, einen weiteren Generalstabsoffizier, der den Titel Stabschef trägt, einen für die Artillerie zuständigen Offizier, einen Nachrichtenoffizier, einen Feindlageoffizier, einen Offizier zur besonderen Verwendung; wahrscheinlich gibt es noch weitere nachgeordnete Offiziere; zahlreich [sind] die Mannschaften und reichhaltig [ist] die zur Verfügung stehende Ausrüstung22.

Das Verbindungskommando verfügt über eine eigene Nachrichtenabteilung und eine eigene [Fernmelde-]Zentrale, über die alle Meldungen von und für unsere Armee laufen. Ich habe beim OKH interveniert, um eine direkte Verbindung der Armee mit meiner Dienststelle zu erhalten. Mir wurde erklärt, daß dieser Sachverhalt nicht bekannt sei und daß man davon ausgehe, daß es den direkten Kontakt schon gebe. Man kann deshalb vermuten, daß das Verbindungskommando eine echte Kontrolle ausüben und sich vielleicht auch das Vorrecht bei der Übermittlung der Lageberichte und anderer Nachrichten sichern möchte. So läßt sich zum Teil auch die Verzögerung erklären, die bei den Lagemeldungen der Armee aufgetreten ist.

Der Chef des Kommandos und seine Offiziere fahren im Sektor [der Armee] herum, der zuweilen auch von Offizieren der Heeresgruppe und von Offizieren des Oberkommandos des Heeres besucht wird. Alle geben ihrer Wertschätzung Ausdruck und äußern gelegentlich auch Bedenken. Insgesamt besteht der offenkundige Eindruck, daß das Verbindungskommando beabsichtigt, zunehmende Kontrollaktivitäten zu entwickeln. Man kann festhalten, daß, soweit bisher bekannt, keine der verbündeten Armeen einen Chef des [Verbindungs-]Kommandos im Rang eines Generals [der Infanterie] hat.

General von Tippelskirch, Chef des Verbindungskommandos bei unserer Armee, den ich seit langen Jahren kenne, war es wichtig, mir seine heikle und schwierige $\mathrm{Si}$ tuation darzulegen, wobei er mir sagte, daß seine Ernennung nicht nur der Tatsache geschuldet sei, daß er Italienisch könne (und das deutsche Heer verfügt nur über vier Generäle, die Italienisch können, inklusive von Rintelen ${ }^{23}$ ), sondern auch dem Faktum, daß der Umfang der Reserven, die das deutsche Oberkommando zu unserer Armee zu verschieben gedenke, die Anwesenheit eines sehr hochrangigen deutschen Offiziers verlange, der den Einsatz dieser Reserven zu koordinieren vermöge. Es lag ihm ferner daran hinzuzufügen, er wisse sehr wohl, daß einige seiner Einwände unsere empfindlichen Punkte berührt hätten, doch halte er es für notwendig, unserer Armee alle Erfahrungen des vergangenen Winterfeldzugs nahezubringen ${ }^{24}$. Ich antwortete ihm, wir würden es unsererseits immer begrüßen, über diese Lehren unterrichtet zu werden, während wir jegliches Gebaren mißbilligen würden, das auf eine Kontrolle schließen lasse. General von Tippelskirch erklärte mir, er wolle jede derartige Haltung absolut vermeiden, doch gegen Ende des Gesprächs fand er einen

22 Vgl. hierzu Dok. 1 und 2 sowie S. 55 ff. des vorliegenden Bandes.

23 Enno von Rintelen (1891-1971), General der Infanterie, Teilnahme am Ersten Weltkrieg, 1936-1943 deutscher Militärattaché in Rom und seit 1940 auch deutscher General im Hauptquartier der italienischen Streitkräfte.

${ }^{24}$ Kurt von Tippelskirch, der den ersten Winter des Krieges gegen die Sowjetunion als Kommandeur der 30. Infanteriedivision im Norden der Ostfront erlebt hatte, wurde nicht müde, diesen Punkt zu betonen; BA-MA, MFB4 41403, Bl. 1041 f., KTB des Deutschen Generals beim italienischen AOK 8, Eintrag vom 14. 10.1942. 
Weg, um zu sagen, er fühle sich seiner Verantwortung gegenüber dem deutschen Oberkommando und der gewissenhaften Ausführung seines Auftrags wegen verpflichtet, bei jeder Gelegenheit seiner Meinung Ausdruck zu geben. Ich bin deshalb zu dem Schluß gekommen, daß General von Tippelskirch besondere Anweisungen erhalten hat, die im wesentlichen zu einer zunehmenden Einmischung in die Aktivitäten der Armee führen müssen, zusätzlich zu derjenigen, die bereits ziemlich spürbar von der Heeresgruppe praktiziert wird.

\section{[Schlußfolgerungen]}

Dieser Besuch im Abschnitt der 8. Armee hat es mir erlaubt, mir noch einmal der Sorgen und der Bedürfnisse des Armeeoberkommandos hinsichtlich des Nachschubs und der Winterstellung bewußt zu werden, aber er hat mir auch ermöglicht festzustellen, wie eifrig seitens der Truppe gearbeitet worden ist, welche die gesamte verfügbare Zeit und alle Ressourcen vor Ort genutzt hat. Diese Betriebsamkeit und die hervorragende Moral der Verbände stellen ein höchst befriedigendes Ergebnis dar.

Die Aufgabe der Armee ist angesichts der großen Ausdehnung des ihr anvertrauten Abschnitts nicht einfach; die Lage wird sich mit dem weiteren Ausbau der Verteidigungsstellung verbessern, doch es ist unabdingbar, daß die Armee einen Teil unserer Divisionen in der zweiten Linie halten kann, um nötigenfalls mit eigenen Mitteln eingreifen zu können, ohne beim ersten möglichen Nachgeben der Front auf den militärischen Beistand der Deutschen zurückgreifen zu müssen. Diese Verfügbarkeit ist auch notwendig, um den Divisionen an der Front angemessene Ruhephasen garantieren zu können.

Die Einschränkungen, die unsere Armee im logistischen Bereich aufgrund der Fortdauer der Operationen gegen Stalingrad hinnehmen mußte, sind erheblich. Aber auch im operativen Bereich hat unsere Armee eine sehr wichtige Aufgabe erfüllt, da sie die in Stalingrad eingesetzten Armeen gedeckt hat. In Erfüllung dieser Aufgabe sind auch harte Gefechte geführt worden, und die vom XXXV. und vom II. Armeekorps erlittenen Verluste machen klar, welche Funktion die 8. Armee gehabt hat. Es ist notwendig, daß man jetzt von deutscher Seite - und dies ist dem OKH deurlich gemacht worden - alles mögliche unternimmt, um die von der Armee erbrachten Opfer zu kompensieren und es ihr zu ermöglichen, den verbliebenen Rest der trockenen Jahreszeit optimal zu nutzen. Man muß die schwerwiegenden allgemeinen Probleme des deutschen Heeres gebührend berücksichtigen, doch es ist unabdingbar, daß man die kürzlich versprochenen Züge und Betriebsstoffmengen unserer Armee regelmäßig zukommen läßt.

Der General und Chef der Mission (E.L. Marras)

AUSSME, L 13/48-3. 


\section{Dokument 17}

Aufzeichnungen Aldo Vidussonis ${ }^{25}$ für Benito Mussolini über eine Inspektionsreise an die Ostfront, einen Besuch im Führerhauptquartier und eine Reise nach München vom 20. September bis 8. Oktober 1942

Rom, 24. Oktober 1942-XX

\section{Notiz für den Duce}

\section{Die Reise (20.-29. September)}

Die Abfahrt aus Mailand erfolgte am 20. September um 20.10 Uhr, nachdem Faschisten und Zuschauer den langen Zug im Bahnhof hatten bewundern können, der aus ungefähr vierzig Güterwaggons und aus den Wagen für die Delegation und die Eskorte bestand. Während des zweistündigen Halts in Mailand habe ich mich zunächst mit den Familien der Gefallenen unterhalten und anschließend den Erfrischungsraum für die Soldaten besuchen können.

Bei der Abfahrt dieses Zuges, der ein wenig das Herz des faschistischen Mailand verkörperte, das den Soldaten in Rußland - und insbesondere denjenigen aus Mailand - seine innige Liebe durch ein faßbares Zeichen seiner Zuneigung übermitteln wollte, [herrschte] bei allen größter Enthusiasmus.

Die Delegation fuhr in einem normalen Wagen dritter Klasse, wo sie sich zum Schlafen ein aus kleinen Seegrasmatratzen bestehendes Lager eingerichtet hatte, das sich - getestet während unseres neuntägigen Aufenthalts - als trefflich erwies.

$\mathrm{Zu}$ der von mir geleiteten Delegation gehörten: der Vizesekretär der GUF $D^{\prime} \operatorname{sste}^{26}$, der Mailänder Federale 27 Ippolito ${ }^{28}$, der Mailänder Podestà 29 Gallarati Scotti ${ }^{30}$, der Präsident der Mailänder Kriegsversehrten Gorini ${ }^{31}$ und der [Präsident]

25 Aldo Vidussoni (1914-1982), faschistischer Politiker, 1936 Teilnahme am Spanischen Bürgerkrieg, kriegsversehrt, Sekretär der faschistischen Studentenorganisation „Gioventù universitaria fascista“ (GUF) in Triest, 1941 Sekretär der GUF, 1941-1943 Sekretär des PNF und Mitglied des faschistischen Großrats, nach dem 8. 9. 1943 Mitglied im Direktorium des PFR.

26 Antonio D'Este, 1935-1937 Sekretär der GUF in Triest, 1942/43 stellvertretender Sekretär der GUF, stellvertretender Sekretär des nationalen Instituts für faschistische Kultur, Mitglied im Direktorium des PNF.

27 Führer der faschistischen Partei auf Provinzebene.

28 Andrea Ippolito (geb. 1903), faschistischer Politiker, Sekretär der GUF in Mailand, Sekretär des PNF in Lucca, Littoria und Rom, Mitglied im Direktorium des PNF, Dezember 1940 November 1942 Sekretär des PNF in Mailand.

29 Als zentrales Element der faschistischen Kommunalverfassung stand der Podestà seit 1926 den Verwaltungen in den Städten und Gemeinden Italiens vor; vgl. Loreto Di Nucci, Podestà, in: de Grazia/Luzzatto (Hrsg.), Dizionario del fascismo, Bd. 2, S. 395-398.

30 Gian Giacomo Gallarati Scotti (1886-1983), Jurist, 1912 Eintritt in den diplomatischen Dienst, Karriere als Kolonialbeamter in Nordafrika, seit 1934 Senator des Königreichs Italien, 1938-1943 Bürgermeister von Mailand, nach dem Zweiten Weltkrieg Rückzug ins Privatleben.

31 Alessandro Gorini (geb. 1891), Buchhalter, Teilnahme am Ersten Weltkrieg und an den militärischen Aktionen in Nordafrika, kriegsversehrt, Mitglied der Abgeordnetenkammer, Präsident der Vereinigung der Kriegsversehrten für Mailand und die Lombardei, Direktor der Zeitschrift „La stampella“. 
der Frontkämpfer Rossi ${ }^{32}$, Hauptmann Navone ${ }^{33}$ von der Abteilung „ $\mathrm{P}^{434}$ des Generalstabs, der Chef meines persönlichen Sekretariats Gallo, der Inspekteur des Provinzialverbands Mailand Camagna, Hauptmann Wondrich vom Comando Supremo und mein Dolmetscher, der Journalist Ongaro und der Chef der Filmabteilung des PNF Moschioni.

In Verona stiegen die Eskorte mit dem Kommandanten des Zuges, Oberstleutnant Lanza, der Militärarzt und der für die Verpflegung zuständige Offizier zu.

Während der Fahrt auf italienischem Territorium wünschten die Honoratioren von Brescia, Verona und Bozen, mir den Gruß ihrer Städte und Provinzen zu überbringen.

Am Brenner, wo wir am 21. gegen zehn Uhr anlangten, erwartete uns die von der Nationalsozialistischen Partei gesandte Abordnung, die uns während der ganzen Reise durch Deutschland und die besetzten Gebiete begleiten sollte; sie setzte sich aus Oberbefehlsleiter Friedrichs ${ }^{35}$, Befehlsleiter Klopfer ${ }^{36}$ und dem Dolmetscher Bauer ${ }^{37}$ zusammen.

Auch im Groß[deutschen] Reich oder in den von ihm kontrollierten Gebieten erhielten wir an den einzelnen Bahnhöfen Besuche und Grüße von den höchsten Würdenträgern der Partei und der Streitkräfte des verbündeten Deutschland: so in Innsbruck, Halle, Litzmannstadt, Brest-Litowsk, Stolpce, Baranowicze, Minsk, Brobuisk, Charkow, um nur die längeren Aufenthalte zu erwähnen. In Halle wünschten sich auch Botschafter Alfieri ${ }^{38}$ mit Gattin und Kameraden des Berliner Fascio einzufinden; auch in anderen Orten wurde uns der willkommene Gruß der Vertreter der italienischen Gemeinden überbracht. Überall schließlich der Gruß der Kommandos und der Soldaten der Etappenkommandanturen.

Die in neun Tagen bewältigte Route war die nördliche, wobei oftmals Nebenstrecken benutzt wurden: nach dem Brenner kamen wir nach Innsbruck, Trudering (bei München), Nürnberg, Halle, Glogau, Lissa, Litzmannstadt, Warschau, BrestLitowsk, Minsk, Gomel, Charkow, Kupjansk, Waluiki ${ }^{39}$ und Millerowo. Aufgrund

32 Amilcare Rossi (geb. 1895), Rechtsanwalt, Teilnahme am Ersten Weltkrieg, Inhaber der goldenen Tapferkeitsmedaille, seit 1919 Mitglied des PNF, Mitglied der Abgeordnetenkammer, Präsident der Associazione Nazionale Combattenti, Luogotenente Generale der faschistischen Miliz.

$33 \mathrm{Zu}$ Navone und den im folgenden genannten Personen konnten keine Angaben ermittelt werden.

34 Die für Fragen der Propaganda zuständige Abteilung des Generalstabs.

35 Helmuth Friedrichs (geb. 1899), Funktionär der NSDAP, seit 1930 Geschäftsführer des Gaues Kurhessen, seit 1934 Leiter der Abteilung II (Parteiangelegenheiten) im Stab des "Stellvertreters des Führers" bzw. der Parteikanzlei der NSDAP.

36 Gerhard Klopfer (1905-1987), Jurist und Ministerialbeamter, 1941-1945 Leiter der Abteilung III (staatliche Angelegenheiten) in der Parteikanzlei der NSDAP, 1942 Teilnehmer an der Wannseekonferenz, nach 1945 interniert, 1949 im Spruchkammerverfahren für minderbelastet erklärt, seit 1956 Rechtsanwalt in Ulm.

37 Nicht ermittelt.

38 Dino Alfieri (1886-1966), faschistischer Politiker und Diplomat, 1929-1932 Staatssekretär im Ministerium für die Korporationen, 1935/36 Staatssekretär im Ministerium für Presse und Propaganda, 1936-1939 Minister für Presse und Propaganda bzw. für Volkskultur, 1939/40 Botschafter am Heiligen Sruhl, 1940-1943 Botschafter in Berlin, Mitglied des faschistischen Großrats, stimmte am 24./25. 7. 1943 gegen Mussolini, Flucht in die Schweiz, 1944 im Prozeß von Verona in Abwesenheit zum Tode verurteilt.

39 In der Vorlage: „Valniki“. 
der unsicheren Lage im Gebiet zwischen Brest-Litowsk und Gomel, das von Partisanen verseucht ist, wovon die zahlreichen entgleisten Waggons, Lokomotiven oder gar Eisenbahnzüge Zeugnis geben, hielt der Zug auf Befehl des Führerhauptquartiers nachts in den Bahnhöfen von Brest-Litowsk, Stolpce und Bobruisk. Während des Aufenthalts besichtigten wir in Brest-Litowsk die Stadt und die Zitadelle, in Minsk die Stadt und einige Gebäude (Oper, Volkshaus, Kirche, Verpflegungsstelle für die Zivilbevölkerung und Unterkünfte für die wolgadeutschen Flüchtlinge), wobei wir auch eine kurze Strecke auf der Autobahn nach Moskau gefahren sind, die zunächst von den Gebäuden des Polytechnikums und von Kasernen gesäumt wird; in Stolpce wie auch in Bobruisk wohnten wir der Vorführung deutscher Dokumentarfilme bei; ein Kurzbesuch in Charkow hat es uns erlaubt, die Physiognomie dieser großen, völlig stillosen, heute zum Großteil zerstörten Stadt kennenzulernen.

Die Ankunft in Millerowo erfolgte am 29. [September] um 11.30 Uhr. Am Bahnhof, der einfach und nur mit deutsch-italienischen Fahnen geschmückt war, erwarteten uns seine Exzellenz Gariboldi mit den höheren Offizieren des Armeeoberkommandos, viele Offiziere und eine Ehrenformation.

\section{Eindrücke}

Gegen die Organisation des Zuges ist nichts einzuwenden: sorgfältig hinsichtlich der Lagerung der Pakete, die ordentlich in die für sie bestimmten Waggons verladen wurden; ebenso sind auch die Waggons gekennzeichnet, die keine Pakete, sondern bestimmte Güter transportieren (Kognak- und Weinfässer, Zigaretten, Zitronen, Streichhölzer); auch für die Unterkunft und die Verpflegung der Delegation und ihrer Eskorte ist alles vorbereitet, indem ein Küchenkomplex beigefügt und ein halber Wagen der dritten Klasse als Mensa eingerichtet wurde. Die deutsche Abordnung - unser Gast, soweit es die Verpflegung betraf - hat stets in einem eigenen Waggon der Reichsbahn übernachtet. Wie Sie wissen, sind fünfzigtausend Pakete transportiert worden, abgesehen von den siebentausend persönlichen, die die Familien der Frontkämpfer geschickt haben.

Die persönlichen Pakete enthielten: eine Halbliterflasche Wein, einen Viertelliter Kognak, eine Dose Kondensmilch, ein Päckchen Marmelade, einen Sicherheitsrasierer aus Bakelit, ein Päckchen Rasierklingen, einen kleinen Panettone, eine kleines Medaillon der Madonnina, Trockentinte, Schreib- und Zeichenfeder, Bleistift, einen Bilderrahmen mit den Photographien des Königs ${ }^{40}$ und des Duce, einen Geldbeutel, Briefpapier und Propagandapostkarten, zwei Taschentücher, zwei Paar Strümpfe, einen Pullover, ein Handtuch. Der Zug transportierte ferner, außer mehreren Hundert Bildern des Duce mit russischen Schriftzeichen, einen Waggon voller Zitronen, zwei voller Zigaretten, einen voller Streichhölzer, viele Hektoliter offenen Weines und Kognaks, 500 Kisten mit unterschiedlichem Propagandamaterial für die Kommandos und überdies verschiedene charakteristische Gegenstände wie Grammophone, Gitarren, Photoapparate, Fußbälle, Spielkartenpäckchen usw. All diese Gegenstände sind den Soldaten sehr willkommen, die wiederholt und mit allen Mitteln darauf bedacht waren, uns ihre Erkenntlichkeit und ihren Dank zukommen zu las-

40 Viktor Emanuel III. von Savoyen (1869-1947), seit 1900 König von Italien, dankte im Mai $1946 \mathrm{ab}$, Tod im ägyptischen Exil. 


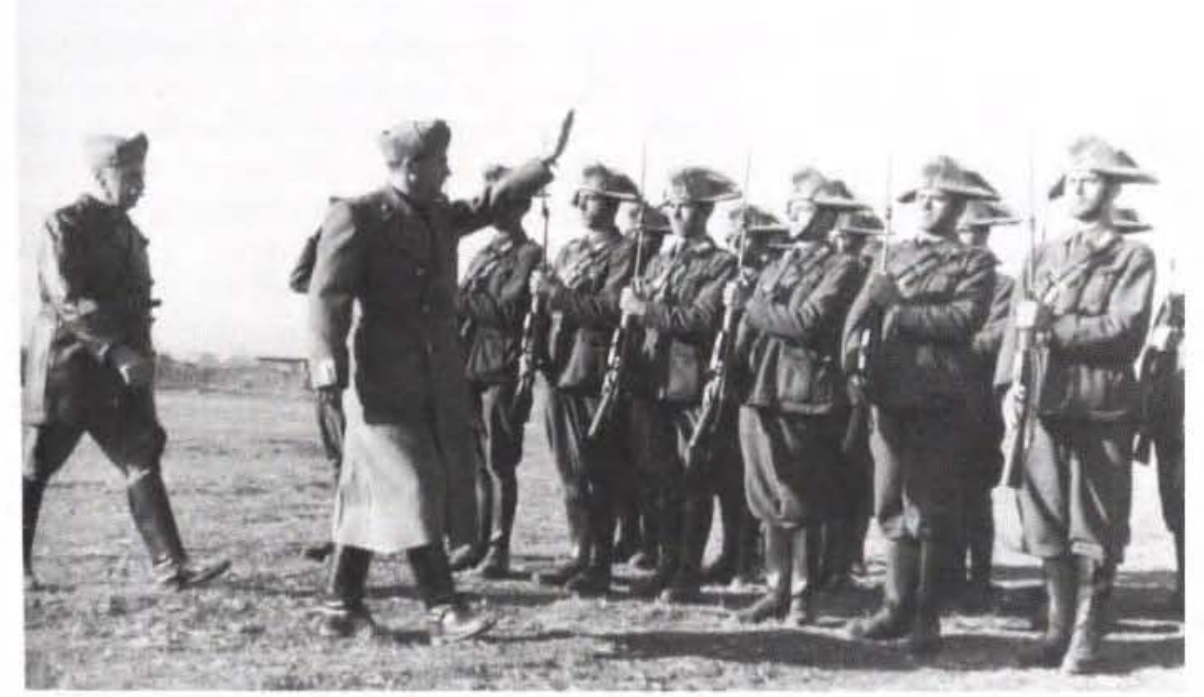

Abb. 11: Ostfront - Aldo Vidussoni und Generaloberst Gariboldi schreiten die Ehrenformation ab, Oktober 1942 (AUSSME, Photoarchiv).

sen: In diesen Tagen habe ich sogar zahlreiche Briefe von Offizieren und Soldaten erhalten, die das beste Zeugnis von diesen Gefühlen der Dankbarkeit ablegen.

Im Laufe der Reise und während der Aufenthalte richtete ich meine Aufmerksamkeit auf die Betreuung der Truppen und das Funktionieren der Etappenkommandos. Bezüglich des ersten Punktes habe ich festgestellt, daß wir den Deutschen in nichts nachstehen ${ }^{41}$ : Unsere Leute waren aufmerksam und zuvorkommend beim Austeilen von heißem Wein, Zigaretten, Zeitschriften, Postkarten, Bleistiften usw. und hatten für jeden Soldaten einen guten Wunsch, einen Gruß und ein freundliches Wort übrig. Aufgrund der gegebenen Verhältnisse war die deutsche Betreuung natürlich auch quantitativ sehr viel umfangreicher, da es eine stets bereite Küche, heißen Kaffee-Ersatz usw. gab, die auch unseren Soldaten nicht verweigert wurden. Was die Etappenkommandos und ihre Offiziere betrifft, stelle ich - soweit ich selbst habe beobachten können und aufgrund einiger Hinweise, die mir gegeben worden sind - fest, daß sie insgesamt gut funktionieren, das italienische Ansehen hochhalten und in bestem Einklang mit den deutschen Kameraden arbeiten.

Wie ich bereits gesagt habe, war der Empfang durch die politischen und militärischen deutschen Würdenträger großartig: Sobald der Zug in die verschiedenen Bezirke einfuhr, und kaum daß Zeit und Wetter es erlaubten, kamen die hohen Parteifunktionäre, die Repräsentanten des Staates, die hohen Offiziere, um uns zu

4I Tatsächlich wurde vor Ort rege Kritik an der Betreuung der Soldaten geübt; vgl. etwa ACS, MCP, Gabinetto, busta 140, fasc. "Ottava Armata - Compagnia di Propaganda “, sottofasc. 4: „Nucleo correspondenti di guerra presso l'ARMIR“, Bericht für den Minister für Volkskultur, Gaetano Polverelli, vom 13. 4. 1943. 
begrüßen; so stieg beispielsweise in Innsbruck der Gauleiter ${ }^{42}$ zu; in Halle kam zusammen mit unserem Botschafter der erste Bürgermeister von Berlinn3; in Litzmannstadt beehrte uns ein Vertreter des Gouverneurs Frank ${ }^{44}$. In den Gebieten unter Militärverwaltung haben uns die Streitkräfte begrüßt und uns zuweilen auch zusammen mit Honoratioren der Partei bei der Besichtigung von Objekten begleitet, die es verdienten, gesehen zu werden: so in Brest-Litowsk, Stolpce, Minsk, Bobruisk, Charkow. Überall wünschte man den Vertretern des faschistischen Italien zu sagen, daß sie willkommene Kameraden seien und daß das deutsche Volk stolz sei, an unserer Seite zu marschieren.

Kaum hat man den Brenner überquert, spürt man die enorme Anstrengung, die Deutschland für den Krieg unternommen hat: Den ersten Nachweis liefert der breite Einsatz von Frauen und Kindern für eine Unzahl von Dienstleistungen und Tärigkeiten, die zuvor zweifellos Vorrecht der Männer waren. Das Arbeitskräfteproblem, das engstens mit dem der Produktivität in den besetzten Gebieten und mit der Funktionsfähigkeit des Dienstleistungssektors verbunden ist, muß sehr stark zu spüren sein. Es gibt wenige und zumeist ältere Männer. Stark ist der Einsatz von Gefangenen - Russen, Franzosen, Belgiern, Polen -, die durch besondere Abzeichen kenntlich gemacht werden. Mit dem groß angelegten Einsatz von Frauen und Gefangenen versucht man, die Arbeitskraft den Erfordernissen der Produktion anzupassen und in Zukunft zu vermeiden, daß Ernten wie die des Getreides wegen entsprechender Probleme verlorengehen.

Der Boden erweist sich im übrigen als äußerst fruchtbar: Ausgedehnte Getreidefelder wechseln mit endlosen Sonnenblumen- und, vor allem in der Ukraine, Kartoffelpflanzungen ab. Die Produktion und ihre Nutzung hängen allerdings von der Arbeitskraft und vom Transportwesen ab, das bisher vor allem hinsichtlich des Transports mit Kraftfahrzeugen unzulänglich ist, wo man den Betriebsstoffmangel nachhaltig spürt.

Am meisten beeindrucken die Transporteinrichtungen, [und zwar] vor allem in den besetzten Gebieten, wo neben der Wiederinbetriebnahme der [Eisenbahn-]Linien die Spurweite vollkommen umgestellt worden ist und man die Modernisierung der Anlagen in den Bahnhöfen in Angriff genommen hat. Wie noch nie garantieren Ordnung und Disziplin einen Verkehr, der, wie es heißt, äußerst stark, aber auf die Minute genau reguliert ist.

42 Franz Hofer (1907-1972), Kaufmann, seit 1931 NSDAP-Mitglied, 1932 zum Gauleiter von Tirol ernannt, 1938-1945 Gauleiter von Tirol-Vorarlberg, seit 1940 auch Reichsstatthalter für Tirol-Vorarlberg, seit September 1943 Oberster Kommissar in der Operationszone Alpenvorland, 1945 verhaftet, 1948 Flucht aus der Haft, im Spruchkammerverfahren als Hauptschuldiger zu drei Jahren und fünf Monaten Arbeitslager verurteilt, 1949 in Österreich in Abwesenheit zum Tode verurteilt.

${ }^{43}$ Ludwig Steeg (1894-1945), Verwaltungsbeamter, seit 1933 NSDAP-Mitglied, 1937-1940 Bürgermeister, seit 1940 amtierender Oberbürgermeister und amtierender Stadtpräsident von Berlin, Februar - April 1945 Oberbürgermeister von Berlin, in sowjetischer Internierung verstorben.

44 Dr. jur. Hans Frank (1900-1946), Rechtsanwalt und nationalsozialistischer Politiker, 1933/34 bayerischer Justizminister, 1934-1945 Reichsminister ohne Geschäftsbereich, seit 1939 Generalgouverneur der nicht in das Deutsche Reich eingegliederten polnischen Gebiete, 1946 vom Internationalen Militärgerichtshof in Nürnberg zum Tode verurteilt und hingerichtet. 
Überall Gelassenheit. Die Bevölkerung in den besetzten Gebieten zeigt nicht allerorts identische Gefühle und Verhaltensweisen, obgleich man eine allgemeine Tendenz zum Ertragen und zur Passivität feststellt. Die deutschen Dienststellen werden respektiert, ich würde sagen, wegen ihrer Strenge in der Behandlung [der Zivilbevölkerung] und der Unduldsamkeit bei mangelnder Zusammenarbeit gefürchtet. Vor allem die ukrainische Bevölkerung kollaboriert.

Absolute Härte wird den Juden gegenüber demonstriert, die man unnachsichtig behandelt und jeglicher Art von Restriktion unterwirft, auch wenn es welche gibt, die arbeiten. Italiener, die in jenen Gebieten leben, und zuweilen auch zur Vertraulichkeit aufgelegte Deutsche haben mir erzählt, daß Erschießungen an der Tagesordnung sind und auch große Gruppen von Personen jeglichen Alters und Geschlechts betreffen. In der Oper von Minsk haben wir das dort aufgehäufte Zeug von tausenden und abertausenden ermordeten Juden gesehen, und es scheint, daß es an die Bevölkerung verteilt wird. Es heißt, es würden nur diejenigen ausgebeutet, die arbeiten können, und zwar bis zu ihrer materiellen Erschöpfung. Was die Italiener am meisten berührt hat, ist die Art der Tötung, mit der sich die Opfer im übrigen anscheinend abgefunden haben. Die Bevölkerung ganzer Städte und Dörfer wurde um bis zu einem Drittel oder bis zur Hälfte dezimiert, insbesondere aufgrund der Beseitigung der Juden.

Bei den Kurzbesuchen, die ich in einigen Städten oder Ortschaften machen konnte, habe ich die Trostlosigkeit des Lebens feststellen können, die die Zerstörungen des Krieges überdauert hat. Überall ist die einseitige Anstrengung zur Industrialisierung sichtbar, die der Bolschewismus auf Kosten aller anderen Bedürfnisse der Bevölkerung unternommen hat. Das Bauwesen beeindruckt tendenziell aufgrund der enormen Ausmaße der Gebäude. Allerdings versinkt es in einer Grobschlächtigkeit, die neben der konzeptionellen Nachlässigkeit das Fehlen von Bebauungsplänen und einer Architektur verrät, die sich als solche bezeichnen läßt. Die Straßen sind in schlechtem Zustand, die Häuser der Bevölkerung, die das niedrige soziale Niveau erkennen lassen, auf dem die Menschen lebten, sind kläglich, schmutzig. Die Geschäfte sind halbleer. Nichts kann man kaufen, auch wegen der ziemlich hohen Preise; im übrigen leben die Märkte beinahe vom System des Tauschhandels.

\section{Der Besuch bei der 8. Armee (29. September bis 7. Oktober)}

Am 29. September kamen wir um 11.30 Uhr in Millerowo an, wo sich das Oberkommando der Armee befindet, und wurden von Seiner Exzellenz Gariboldi und von anderen Offizieren empfangen. Am Sitz des Oberkommandos wünschte General Gariboldi, der Delegation den Salut der 8. Armee zu überbringen. Ich antwortete, ich würde mich stolz und geehrt fühlen, daß ich von Ihnen den Auftrag erhalten habe, Ihren herzlichen Gruß den Soldaten zu überbringen, die auf dem Boden Rußlands kämpfen und denen das Vaterland und die Partei wie auch ihre Familien ständig nahe sind.

Ich wollte mit der Verteilung der Geschenkpakete gerade bei denjenigen beginnen, die sich als erste die Anerkennung des Vaterlands verdient haben: bei den Verwundeten. Am Dienstagnachmittag in Millerowo, am Mittwoch in Woroschilowgrad habe ich insgesamt ungefähr ein Dutzend Lazarette besucht, die über zweitausend Patienten beherbergen. Das Zusammentreffen mit den Verwundeten war 
besonders bewegend: alle Italiener müßten sehen können, welch hoher Geist diese unsere Tapferen beseelt! Die Pakete wurden in den Lazaretten ohne Ansehen der Nationalität an alle verwundeten Patienten verteilt, und es sind deutsche, rumänische, slowakische, ukrainische und sogar russische Kameraden in ihren Genuß gekommen.

Von Donnerstag, den 1. Oktober, bis einschließlich dem 6. besuchte ich von Millerowo aus noch einmal mit dem Flugzeug, dann mit dem Wagen unsere verschiedenen Divisionen, wobei ich mich nicht nur auf die Kommandos der Armeekorps oder Divisionen beschränkt habe, sondern auch zu den Kommandos der Kompanien und - sofern es möglich war - fast immer zu den weiter vorgeschobenen Stellungen, in die Beobachtungsstände, gegangen bin, so daß ich bis auf wenige hundert Meter an den Don herangekommen bin. Überall nahm ich direkten Kontakt mit den Offizieren und den Soldaten auf und war stolz darauf, aus ihrem eigenen Mund höchste Worte der Vaterlandsliebe, des Glaubens, der Siegesgewißheit zu vernehmen.

Am 1. [Oktober] besuchte ich die Division Celere, am 2. die Divisionen „Pasubio", "Sforzesca", "Tridentina" und die Schwarzhemden der [Legion] "Tagliamento"; am 3. die Divisionen "Cosseria" und "Ravenna" und die Schwarzhemden der XXIII. Brigade45; am 4. die Division "Torino“, am 5. die Alpini der "Cuneense", am 6. die der "Julia". Da ich in Rossosch übernachtet hatte, habe ich am 5. auch die beiden Lazarette an diesem Ort besucht, so wie ich mich am 6 . in das Feldlazarett von Saprina begeben wollte. Auf dem dortigen Friedhof ruht der am 3. gefallene Oberleutnant Cellanova ${ }^{46}$, Sekretär der GUF von Pavia.

Überall, bei den Truppen und bei den aufmarschierten Abordnungen oder bei den Einheiten wünschte ich immer, Ihren Gruß, Duce, und den des Vaterlands zu überbringen, wobei ich den Soldaten versicherte, daß die Partei mobilisiert werde, um den Frontkämpfern und ihren Familien auf jede Weise beizustehen und ihnen zu helfen; ich sagte den Soldaten, wie sehr ihre Taten in Italien bekannt seien und bewundert würden. Ich erklärte ihnen, welche Bedeutung diesem Beweis der Solidarität und Zuneigung der Stadt Mailand zukomme. Die Alpini habe ich gemäß Ihres Befehls noch ermuntert, nicht die Hoffnung zu verlieren, bald im Gebirge eingesetzt werden zu können ${ }^{47}$, sondern sich zu erinnern, daß ihre Väter sich bereits in Libyen gut zu behaupten wußten ${ }^{48}$, denn die Alpini blieben überall dieselben, wo immer sie auch kämpften. Ich habe mich dann während meiner Besuche an hunderte und aberhunderte Soldaten gewandt und daraus die klare Überzeugung von

45 In der Vorlage wörtlich: „raggruppamento“. Hier ist wohl die dem II. Armeekorps unterstellte Schwarzhemden-Brigade „23 Marzo “ gemeint.

46 Domingo Cellanova (1914-1942), Oberleutnant im 8. Alpiniregiment der Division "Julia“.

47 Die drei Alpinidivisionen "Julia", "Tridentina" und "Cuneense" sollten zunächst zusammen mit deutschen Gebirgsjägern im Kaukasus eingesetzt werden, wurden dann jedoch ebenfalls an den Don verlegt (vgl. Operazioni delle unità italiane al fronte russo, S. 305-308). Die Aussicht, in ungewohntem Gelände kämpfen zu müssen, warf einen Schatten auf die Moral der Truppe, ohne sie jedoch zu erschüttern (AUSSME, DS II 974, KTB Alpinikorps, September/ Oktober 1942, Anlage 129: Bericht des Alpinikorps über die Moral der Truppe und die Haltung der Zivilbevölkerung im Monat September 1942).

48 Die Alpini hatten zwischen 1911 und 1915 auch im italienisch-türkischen Krieg um Libyen und in der sich anschließenden Kampagne zur Unterwerfung der Zivilbevölkerung gekämpft; vgl. Oliva, Storia degli Alpini, S. 90-93. 
einer hervorragenden Moral gewonnen, die alle momentanen Entbehrungen zu überwinden hilft.

\section{Eindrücke}

Ich habe eine wirklich hervorragende Sanitätsausstattung vorgefunden ${ }^{49}$. Zufriedenstellende Verhältnisse in den Räumlichkeiten, die von unserem Sanitätsdienst sorgfältig und mit Bedacht eingerichtet wurden, auch um dem Winter begegnen zu können; Material in Fülle; hervorragende Ärzte, vor allem im chirurgischen Zentrum der Armee in Woroschilowgrad, wo die Professoren Fabiani ${ }^{50}$, Uffreduzzi ${ }^{51}$ und Dogliotti ${ }^{52}$ arbeiten. Die Zahl der Rotkreuzschwestern, die mindestens um 50 Prozent erhöht werden müßte, ist hingegen bescheiden, obgleich sie leidenschaftlich und aufopferungsvoll die zahllosen Anforderungen des Dienstes auf sich nehmen. In den Lazaretten ruft man vor allem nach Radios und vielen, vielen Zeitschriften, Zeitungen und Büchern.

Hinsichtlich der Kommandos von Armee und Armeekorps habe ich festgestellt, daß sie zu stark mit Offizieren aufgebläht sind: 240 z. B. in dem der Armee, 100 in dem des Alpinikorps. Sehr viele Offiziere jeden Dienstgrads haben vorher noch nie an Kriegen oder Feldzügen teilgenommen. Die Organisation der Abteilungen „P $\mathrm{P}^{4}$ ist unzulänglich, worüber ich zahlreiche Klagen gehört habe. Wahrscheinlich ist der Chef der Situation nicht gewachsen, wie auch der Chef der Kriegsberichterstatter, die sich darüber beschweren, im Gegensatz zu den wenigen, die arbeiten können, weil sie autonom sind, ihren Dienst nicht gut versehen zu können ${ }^{53}$. Die Kommandos sind oftmals Dutzende Kilometer von den Linien entfernt. Bei den Kommandos der Bataillone und Kompanien dagegen überall ein hervorragender Eindruck.

Die Moral der Verwundeten ist hoch. Niemand beklagt sich, nicht einmal in den schmerzhaftesten Augenblicken: Alle sind stolz, ihr Blut für die Sache gegeben zu haben, und wünschen, bald zu ihren Einheiten zurückkehren zu können. Man verspürt eine gewisse Beschämung unter den Kranken, die sich unbehaglich fühlen angesichts derjenigen, deren Körper zerschunden war. Sie alle sind dankbar für das, was man für sie tut. Einen besonderen Eindruck hat ein Unteroffizier der Alpini mit einer Brustverletzung auf mich gemacht, der einem General, der ihm zur Verleihung

49 Zur Organisation des Sanitätsdiensts der 8. Armee allgemein und zum im folgenden erwähnten chirurgischen Zentrum in Woroschilowgrad vgl. Servizi logistici, S. 48-51. Mängel und Probleme wie Transportschwierigkeiten oder das Fehlen bestimmter Sanitätsgüter wurden dem propagandistischen Zweck der Reise gemäß - offensichtlich nicht thematisiert. Dazu auch AUSSME, L 14/87-2, Intendenza der 8. Armee: Bericht über den Einsatz der logistischen Dienste von Dezember 1942 - März 1943, S. 9-17.

50 Nicht ermittelt.

51 Ottorino Uffreduzzi (1885-1943), Chirurg, Direktor der chirurgischen Universitätsklinik in Turin, Verfasser von Lehrbüchern über Chirurgie im Krieg.

52 Achille Mario Dogliotti (1897-1966), Chirurg, seit 1937 Professor für klinische Chirurgie in Catania, auf eigenen Antrag der 8. Armee zugewiesen, nach seiner Rückkehr von der Ostfront im Sommer 1943 zum Direktor der chirurgischen Universitätsklinik in Turin berufen, Mitbegründer der modernen italienischen Kardiochirurgie.

$53 \mathrm{Zu}$ den Auseinandersetzungen um den Chef der Sektion Kriegsberichterstattung, Hauptmann Saverio Grana (geb. 1896, Beamter im Ministerium für Volkskultur), der von einigen italienischen Journalisten der Unfähigkeit geziehen und dann auch abberufen wurde, vgl. den Schriftwechsel im ACS, MCP, Gabinetto, busta 140, fasc. „Ottava Armata - Compagnia di Propaganda“, sottofasc. 4: "Nucleo correspondenti di guerra presso l'ARMIR“. 
der silbernen Tapferkeitsmedaille gratulierte, antwortete, er habe nichts Besonderes getan, um sich eine solche Auszeichnung zu verdienen.

Auch die Stimmung unter den Soldaten in den Einheiten ist großartig: Vor allem die Gebirgstruppen vermitteln den klaren Eindruck von Selbstbewußtsein, Verantwortungsgefühl und von der Ruhe, die sich aus dem Vertrauen in die eigene Tapferkeit ergibt. Das Herannahen der Winterzeit hält zum Bau der Unterstände und Unterkünfte an, die sinnvoll und den Erfordernissen entsprechend angelegt werden.

In der Regel klagen die Soldaten nicht über die Verpflegung: Zweifellos hätten diejenigen an der Front gerne reichhaltigere Rationen, anderthalbmal so viel wie die anderen, wenn möglich. Man bittet vor allem, daß das Brot besser wird (was anscheinend wegen der Zubereitung und des Wassers nicht immer möglich ist) und daß der Soldat jeden Tag seine Ration Wein oder Kognak haben kann, die heute normalerweise auf drei- bis viermal in der Woche beschränkt ist. Ferner bittet man um eine Erhöhung der Zigarettenration, wobei betont wird, daß die fünf momentan verteilten unzureichend sind. Wünsche, denen es besondere Beachtung zu schenken gilt, wenn man bedenkt, daß das Land nur wenig bieten kann, abgesehen von den Lebensmitteln, die allerdings ebenfalls schwer zu erwerben sind, weil sie von den Deutschen kontrolliert werden oder weil es unmöglich ist, die Eigentümer zufriedenzustellen, die kein Geld wollen, bei dem sie im übrigen ihrer Mentalität entsprechend keinen Unterschied machen (tatsächlich wird nicht $\mathrm{zwischen} \mathrm{Rubel,} \mathrm{Lira} \mathrm{und}$ Mark unterschieden, und das, was man z. B. für ein Päckchen Zigaretten erhalten kann, ist Dutzende von Mark wert). Dies wird durch die Tatsache bestätigt, daß der Soldat nichts ausgibt und die Summe zur Verbesserung der Verpflegung einbehalten wird. Man hat mich überdies darauf aufmerksam gemacht, daß bei der Verteilung der Beihilfen ein Mißverhältnis zwischen den Verbänden an der Front und den Verbänden in der Heimat bestehe, die davon in einem höheren Maße profitierten.

Die Beziehungen zu den deutschen Kameraden sind nicht gerade herzlich - aus unterschiedlichen Motiven, nicht zuletzt wegen des Gefühls, von den Deutschen kontrolliert und beiseite geschoben zu werden, wenn es darum geht, die Ressourcen des Landes zu nutzen.

Die Rußlandveteranen - die des alten CSIR - sehnen nachdrücklich ihre Ablösung herbei. Sie sind wirklich müde (und die Truppen erschöpft). Nachhaltig auf ihre Moral haben sich die bisweilen bestätigten, dann wieder nicht bestätigten Nachrichten über eine bevorstehende Heimkehr ausgewirkt, und eine klare Aussage von maßgeblicher Stelle dazu wäre opportun.

Es besteht ein Konflikt zwischen Gariboldi und Messe, der durch die Überzeugung des letzteren provoziert wird, geopfert worden zu sein ${ }^{54}$. Man munkelt auch, daß Gariboldi etwas zu nachgiebig gegenüber den Deutschen sei55.

54 Zu den Konflikten zwischen Gariboldi und Messe, die Auseinandersetzungen in Sachfragen ebenso beinhalteten wie persönliche Verletzungen und die letztlich zu Messes Entschluß führten, im September 1942 um seine Ablösung zu bitten, vgl. Orlandi, Giovanni Messe, in: Grazia/Pasimeni/Urgesi (Hrsg.), Maresciallo d'Italia Giovanni Messe, S. 100-105; vgl. auch den Schriftwechsel im AUSSME, Fondo Messe, busta A.

55 Dies bestätigt etwa ACS, MIn, DGPS - Divisione Polizia politica, busta 215, fasc. 2: Corpo di Spedizione Militare Italiano in Russia, Bericht aus Verona vom 10. 12. 1942. Messe kultivierte den Ruf, hart und entschlossen mit den deutschen Verbündeten umzugehen (vgl. 
Faschistischer Geist unter den Soldaten verbreitet, aber nicht in gleichem Maße unter den Offizieren. Auf jeden Fall stellt man fest, daß die unmittelbare Erfahrung der Methoden und Lebensbedingungen der Russen (die in ihrer Politik alles der Propaganda, der Erziehung, den Kriegsvorbereitungen geopfert haben) geholfen hat, mehr als eine Meinung zu ändern. Unter diesem Gesichtspunkt ist es wichtig, die $\mathrm{P}$ [ropaganda-]Offiziere richtig auszuwählen, die bei den Verbänden hervorragende faschistische Propagandaarbeit leisten können.

Die Winterstellung ist auch aufgrund der zahlreichen Truppenverschiebungen in jüngster Zeit noch nicht fertig. Insgesamt besteht auch aufgrund von Nachforschungen, die bei der Intendenza angestellt wurden, die Überzeugung, daß für die Truppe alles vorbereitet ist, daß aber nicht alles zur rechten Zeit eintreffen kann wegen des Mangels an Betriebsstoff und wegen der Aussicht, daß das Einsetzen des Regens den Verkehr mit Kraftfahrzeugen für eine gewisse Zeit blockiert, während der Transport mit Zugtieren ziemlich unzulänglich ausfällt, weil Tiere fehlen, die alle von den Deutschen requiriert worden sind. Die Unterkünfte sind im Bau; die Baracken sind bereits angekommen. Allerdings fehlen noch die Öfen, während für bestimmte Gebiete die Frage des Brennstoffs ein schwerwiegendes Problem sein wird, da die italienischen Stellungen heute weit entfernt sind vom Kohlerevier um Stalino und man nicht auf die Eisenbahn rechnen kann, die auf vielen Strecken überlastet, auf anderen noch nicht instand gesetzt ist.

\section{Besuch beim Führer und in München (7. und 8. Oktober)}

Nachdem ich beim Armeeoberkommando an der Feldmesse mit der Mailänder Madonnina teilgenommen und einen Major der Luftwaffe mit der auf dem Schlachtfeld [erworbenen] silbernen Tapferkeitsmedaille ausgezeichnet hatte, startete ich im viermotorigen Flugzeug des Führers zu dessen Hauptquartier und landete um 11.20 Uhr auf dem Flughafen von Winniza.

Um 13.30 Uhr wurde ich vom Führer empfangen, wobei Feldmarschall Keitel ${ }^{56}$, Reichsleiter Bormann ${ }^{57}$, der Dolmetscher und der persönliche Sekretär ${ }^{58}$ Hitlers anwesend waren. Das außerordentlich herzliche Gespräch dauerte eine Stunde: Der Führer fragte nach meinen Eindrücken von der Front, äußerte sich zur politischmilitärischen Lage, wobei er sich optimistischer zeigte als in der Vergangenheit, wollte mir Erklärungen bezüglich des Einsatzes der Alpini geben (nebenbei merke ich an, daß mit Skiern ausgerüstete Bataillone sehr nützlich und erwünscht wären;

Ciano, Diario, S. 627, Eintrag vom 4.6. 1942), bei denen er aber dennoch als zuverlässiger Partner galt (vgl. Distler, Verbindungsoffizier, S. 16).

56 Wilhelm Keitel (1882-1946), Generalfeldmarschall, Teilnahme am Ersten Weltkrieg, 1919 Übernahme in die Reichswehr, seit 1935 Chef des Wehrmachtsamts im Reichskriegsministerium, 1938-1945 Chef des OKW, 1946 vom Internationalen Militärgerichtshof in Nürnberg zum Tode verurteilt und hingerichtet.

57 Martin Bormann (1900-1945), nationalsozialistischer Politiker, seit 1933 Leiter des Stabes des "Stellvertreters des Führers", seit 1941 Leiter der Parteikanzlei der NSDAP im Range eines Reichsministers, 1943 zum "Sekretär des Führers" ernannt, während des Kampfes um Berlin ums Leben gekommen.

58 Hier eventuell gemeint: Philipp Boubler (1899-1945), Funktionär der NSDAP, 1934-1945 Leiter der "Kanzlei des Führers" im Range eines Reichsleiters der NSDAP, beging im Mai 1945 Selbstmord. 
sie ließen sich während des Winters am Don zweckmäßig und gewinnbringend einsetzen), die auch in Anbetracht des Klimas in dem Abschnitt äußerst nützlich seien, in dem sie sich befinden, und schließlich sprach er ausführlich von seinem Wunsch, Euch, Duce, bald zu sehen, wobei er mich wiederholt beauftragt hat, Ihnen seine persönlichen Grüße zu überbringen.

Um 14.30 Uhr geruhte der Führer, die Personen aus meinem Gefolge zu empfangen: den Vizesekretär der GUF D'Este, den Chef meines persönlichen Sekretariats Gallo, den Pressereferenten des PNF Ongaro und den Dolmetscher Hauptmann Wondrich vom Comando Supremo, und er hat sich mit lebhafter Herzlichkeit verabschiedet. Im Hauptquartier hatte ich Gelegenheit, außer Feldmarschall Keitel und Reichsleiter Bormann noch Polizeichef Himmler ${ }^{59}$, Pressechef Dietrich ${ }^{60}$ und weitere Beamte, Parteifunktionäre und Offiziere kennenzulernen.

Erneut mit dem Flugzeug des Führers startete ich nach München, wo ich um 19 Uhr ankam und von Persönlichkeiten der Partei, des Staates und der Streitkräfte empfangen wurde. Am Abend gab der Gauleiter ${ }^{61}$ einen Empfang; er hieß mich im Namen der Braunhemden herzlichst in der Stadt willkommen, die die Geburt der nationalsozialistischen Bewegung gesehen hat. Am nächsten Tag erwies ich den ersten Gefallenen der nationalsozialistischen Revolution die letzte Ehre, besichtigte den Verwaltungsbau [der NSDAP], das Braune Haus und den Führerbau.

\section{Eindrücke}

Aus dem Gespräch mit dem Führer habe ich den Eindruck gewonnen, daß die Oberkommandos und insbesondere Adolf Hitler - der keine Gelegenheit ausgelassen hat, mir seine lebhafteste Freundschaft und Bewunderung für Sie zu zeigen den Beitrag der italienischen Armee im Rußlandfeldzug unter sachlicher Beurteilung unserer Anstrengungen sehr zu schätzen wissen. Äußerste Höflichkeit pflegte man uns gegenüber sowohl im Hauptquartier als auch in München, wo ich insbesondere mit dem Reichsschatzmeister ${ }^{62}$ einen interessanten Meinungsaustausch über die Verwaltungsorganisation der Partei gehabt habe, die in München konzentriert ist, wie die drei enormen Karteien für zehn Millionen Parteimitglieder beweisen. Es wurde mir bestätigt, daß es auch in Deutschland eine Aufnahmesperre gibt, ja daß man zu einer Säuberung neigt, damit nur diejenigen in der Partei bleiben, die ihrer würdig sind.

59 Heinrich Himmler (1900-1945), 1929-1945 Reichsführer SS, seit 1936 auch Chef der deutschen Polizei, seit 1939 Reichskommissar für die Festigung des deutschen Volkstums, 1943-1945 Reichsinnenminister, 1944/45 Oberbefehlshaber des Ersatzheeres und Chef der Heeresrüstung, nach seinem Angebot einer Teilkapitulation im Westen von Hitler im April 1945 aller Ämter enthoben, beging in britischer Kriegsgefangenschaft Selbstmord.

60 Otto Dietrich (1897-1952), Journalist, seit 1931 Reichspressechef der NSDAP, 1937-1945 Staatssekretär im Reichsministerium für Volksaufklärung und Propaganda und Pressechef der Reichsregierung, 1945 verhaftet, 1949 in Nümberg zu sieben Jahren Haft venurteilt, 1950 entlassen.

61 Adolf Wagner (1890-1944), nationalsozialistischer Politiker, seit 1923 NSDAP-Mitglied, Teilnehmer am Hitler-Putsch, 1929-1944 Gauleiter des Gaues München-Oberbayern, 1933-1944 bayerischer Innenminister und stellvertretender Ministerpräsident, seit 1936 auch bayerischer Kultusminister.

62 Franz Xaver Schwarz (1875-1947), Beamter, seit 1925 Reichsschatzmeister der NSDAP, 1945-1947 interniert, 1948 nach seinem Tod von der Spruchkammer als Hauptschuldiger eingestuft und zu Vermögenseinzug verurteilt. 
Überall und immer das sichere Gefühl, daß die Partei in Deutschland alles ist; nichts gegen die Partei, alles für die Partei. Die Partei redet in allen Bereichen mit und gibt den Ton an. Die hohen Parteifunktionäre werden respektiert und nehmen die Ehrenplätze ein. Groß sind die ihnen vorbehaltenen Vergünstigungen, bestens die Gehälter (wurde mir vom Schatzmeister gesagt). Man gesteht ihnen, wie ich es auch in Wien habe feststellen können, in allem ein gewisses Privileg zu. Die hohen Parteifunktionäre wohnen in einem Vorort (München-Pullach) in Häusern, die der Partei gehören.

Gut sind die Beziehungen zu den Kameraden des Münchener Fascio, dessen Sekretär ${ }^{63}$ ein vortreffliches Element ist. Aus Zeitgründen konnte ich nicht bei der italienischen Gemeinde verweilen. Ich habe Kontakt zu Mitgliedern der Leitung des Fascio aufgenommen und einen Besuch versprochen. Immerhin habe ich erfahren, daß sich die Gemeinde gut verhält und von den Deutschen hoch geschätzt wird.

P.S. - Beim Armeeoberkommando in Millerowo werden 80 Kosaken unter dem Befehl eines ehemaligen zaristischen Obersten ausgebildet ${ }^{64}$.

In München hat der Schatzmeister der nationalsozialistischen Partei, Franz Schwarz, um die Ehre gebeten, von Ihnen eine Photographie mit Autogramm zu erhalten.

N.B. Die Eindrücke, die in diesem chronologischen Ereignisbericht zusammengestellt sind, beanspruchen nicht, definitiv und allgemeingültig zu sein. Tatsächlich sind sie zwar Ergebnis einer aufmerksamen Beobachtung, doch auch immer im räumlichen wie im zeitlichen Rahmen beschränkt und dementsprechend nicht gänzlich verallgemeinerbar.

ACS, SPD-CR 1922-1943, 50/fasc. Aldo Vidussoni.

\section{Dokument 18}

\section{Memorandum zur Lage der 8. italienischen Armee vom Beginn der sowjetischen Offensive bis zum Rückzug}

Die Dislozierung der Divisionen im Sektor der 8. Armee - ein Sektor mit einer Frontbreite von ungefähr $250 \mathrm{~km}$ - entsprach zum Zeitpunkt des russischen Angriffs - grosso modo - der folgenden groben Skizze: [...] $]^{65}$

Der russische Angriff erfolgte anfangs mit einer beträchtlichen Menge Infanterie - ungefähr 30 Divisionen -, die insbesondere in Richtung der Divisionen „Cosseria" und "Ravenna" entlang des Tals von Petropalowka drängten. Gegen unsere bei-

63 Nicht ermittelt.

${ }^{64} \mathrm{Zu}$ den vor Ort rekrutierten Kavalierieeinheiten, die nicht zuletzt mit der Bekämpfung von Partisanen betraut waren, vgl. die Dokumente im AUSSME, DS II 1551/7 und L 14/93-8. Die Reste dieser Einheiten wurden 1943 nach Italien verlegt und sollten nach ihrer Reorganisation in Albanien eingesetzt werden.

65 Hier folgt eine Skizze zur Dislozierung der italienischen und deutschen Großverbände im Frontabschnitt der ARMIR. Insgesamt enthält das Dokument sieben Lageskizzen, auf deren Reproduktion verzichtet wurde. 
den Divisionen rückten nicht weniger als acht russische Infanteriedivisionen vor, d. h. 72 Bataillone. Ein ähnlich starker russischer Angriff erfolgte gleichzeitig im rumänischen Sektor ${ }^{66}$. [...]

Unsere beiden Divisionen leisteten - am 9., 10., 11., 12., 13., 14., 15. und 16. Dezember - verbissen Widerstand gegen den mit einer großen Zahl von Bataillonen geführten russischen Angriff; diese Bataillone wurden aufgehalten und dezimiert. Die Division "Ravenna“, wo der Druck am stärksten war, hielt dem Angriff stand, allerdings mit wechselndem Geschick.

Der rumänische Abschnitt gab dem Druck des Gegners nach, so daß die deutsche Führung - um den Einbruch abzuriegeln - die Reserven und die deutsche Division des XXIX. deutschen Armeekorps aus dem italienischen Abschnitt abzog, die durch unsere Division Celere ersetzt wurde ${ }^{67}$. [...]

Dergestalt blieb der Sektor der 8. Armee - nach den ersten Gefechten - ohne Reserven. Unser Armeeoberkommando wies die deursche Führung darauf hin, daß es in einer solchen Situation angebrachter sei, die gesamte Armee zurückzuziehen. Dieser Vorschlag wurde nicht angenommen, weil „der Führer will, daß man bis zum Äußersten Widerstand leistet"; hinsichtlich der Reserven würde sich die deutsche Führung darum kümmern, andere Großverbände, auch gepanzerte, heranzuführen.

Am Morgen des 17. Dezember - d. h. nach acht Tagen ebenso anhaltender wie ergebnisloser Angriffe der russischen Infanterie - wurde die Division "Ravenna“, die am stärksten geschwächt war und folglich am stärksten wankte, von zwei russischen Panzerbrigaden angegriffen (ungefähr 200 Panzer), die in die Tiefe vorstießen und die Stellungen unseres Abschnitts nach Osten und Westen umgingen. Die Reste der "Ravenna", denen sich auch die der "Cosseria" anschlossen, wichen nach Süden aus. Diese Divisionen waren - mit den ihnen zur Verfügung stehenden Mitteln nicht in der Lage, einen Panzerangriff zum Stehen zu bringen, auch weil - nach acht Tagen harter Kämpfe - die Munition, insbesondere die der Artillerie, fast aufgebraucht war. [...]

Um der Bedrohung zu begegnen, bezog die kroatische Legion mit Front nach Westen Stellung, und die Alpinidivision "Julia“, die durch die Division "Vicenza“ ersetzt wurde, postierte sich mit Front nach Osten rechts von der ${ }_{n}$ Cuneense ${ }^{4}$. [...]

Den Deutschen gelang es indessen nicht, die im rumänischen Abschnitt entstandenen Einbrüche abzuriegeln. Deshalb stießen die russischen Panzereinheiten entweder ungefähr $50 \mathrm{~km}$ tief vor oder umgingen die rumänische Aufstellung in Richtung Osten. [...]

66 Vgl. hierzu die Dok. 8-10 und S. 62-69 des vorliegenden Bandes.

67 Dieses Manöver erfolgte allerdings - das Dokument gibt die Chronologie der Ereignisse nicht immer korrekt wieder - bereits im November, während die Angriffe der Roten Armee gegen die ARMIR erst am 11. Dezember begannen. Abgezogen wurden die an der Front des XXIX. Armeekorps eingesetzte 62. Infanteriedivision sowie die 22. Panzerdivision und die 294. Infanteriedivision, die als Reserve vorgesehen waren. Vgl. 8a Armata Italiana nella seconda battaglia difensiva del Don, S. 8 ff. Die 3. Division Celere löste die 62. Infanteriedivision am 20.11. 1942 ab und übernahm einen rund $52 \mathrm{~km}$ langen Frontabschnitt auf dem rechten Flügel der Armee. AUSSME, DS II 1556/9, zusammenfassender Bericht über den Einsatz der 3. Division Celere zwischen Dezember 1942 und Februar 1943. 
Die russischen Panzereinheiten, die im Abschnitt unserer Division "Ravenna“ durchgebrochen waren und im Rücken unserer Aufstellung nach Westen vorrückten, wurden von den Divisionen "Cuneense" und "Julia zum Stehen gebracht, während diejenigen, die gegen Osten vorrückten und ihr Umgehungsmanöver fortsetzten, die rückwärtigen Gebiete der Divisionen „Pasubio“, "Torino“, Celere und "Sforzesca“ erreichten, diese Divisionen von hinten angriffen und in der Rückwärtsbewegung aufrieben, die von diesem Moment an durch die Aktion des Feindes, die Überraschung und die in der Etappe ausgelöste Konfusion und Panik chaotische Züge annahm. Einigen Teilen dieser Divisionen gelang es, sich zusammen mit den Resten der "Cosseria" und "Ravenna" einen Weg durch die russischen Einheiten zu bahnen und zu Fuß bis Tschertkowo ${ }^{68}$ zu gelangen, wobei sie die gesamte Artillerie, Munition, vielerlei Material, die Versorgungslager der Divisionen und Armeekorps, Kraftfahrzeuge, Feldlazarette usw. in die Hand des Feindes fallen lieBen.

In dieser kritischen Situation hatte unser Armeeoberkommando das Oberkommando der deutschen Heeresgruppe ersucht, den Rückzug des - bis dahin intakten und noch nicht von den Russen angegriffenen - Alpinikorps zu befehlen, um zu vermeiden, $\mathrm{da} ß$ es von diesem gefährlichen Vorstoß der gegnerischen Einheiten in Mitleidenschaft gezogen würde. Aber auch in diesem Fall vergebens: „Der Führer will, daß man bis zum Äußersten Widerstand leistet!“

Ich glaube (aber das ist ein rein persönliches Urteil), daß die deutsche Führung mit Blick auf den Widerstand der deutschen Armee in Stalingrad zum Widerstand bis zum Äußersten verleitet wurde von: der Hoffnung auf eine - wie im vergangenen Winter - schnelle Erschöpfung der russischen Offensive, der Annahme, diesen gegnerischen Einbruch sehr bald abzuriegeln, und schließlich von den gefährlichen Konsequenzen, die sich für alle im Donbogen dislozierten deutschen und verbündeten Einheiten aus einer Rückverlegung dieses wichtigen Abschnitts ergeben konnten - eine Rückverlegung, die die Abschnürung des Bogens bewirkt hätte.

So ging es bis zum 14. Januar, als neue russische Panzereinheiten - unbemerkt zwischen den Stellungen der "Julia“ und Tschertkowo durchstießen. Ein Teil dieser Einheiten griff den letztgenannten Ort an, wo sie unsere dort versammelten Einheiten einschlossen, und ein Teil stieß im Rücken unseres Alpinikorps in Richtung Rossosch vor. Zugleich wurden im Norden die ungarischen Stellungen zerschlagen. [...]

Die "Julia" und die „Cuneense", die bereits an der Front bedrängt worden waren, wurden im Zuge dieser unerwarteten Einkreisung überrannt und fast völlig vernichtet (von jeder Division blieben zwischen 2000 und 4000 Mann übrig). Der „Tridentina" und einem Teil der "Vicenza“ gelang es hingegen, dem gegnerischen Zangenangriff zu entkommen, indem sie sich nach Westen zurückzogen, während die Versorgungslager der rückwärtigen Gebiete, die Artillerie, allerhand Material und die Kraftfahrzeuge in der Hand des Feindes blieben.

\section{Rückzug}

So kam es zum Rückzug, wenn man ihn so nennen kann, aller Divisionen, und zwar mit einer derartigen Schnelligkeit, daß das Armeeoberkommando in Millerowo

68 In der Vorlage (wie auch weiter unten): „Scherkovo“; vgl. dazu auch Dok. 22 und 23. 
plötzlich zur Nachhut und somit gezwungen wurde, die ihm zur Verfügung stehenden Carabinieri und Soldaten der [rückwärtigen] Dienste zur Verteidigung einzusetzen.

Einige Verbände, die weniger erschöpft oder noch in der Hand energischer Kommandeure waren, führten aufeinanderfolgende, harte Gefechte, um sich einen Weg durch die ständigen Sperren des Gegners zu bahnen. Die "Tridentina" beispielsweise führte insgesamt nicht weniger als 14 solcher Gefechte. Die Masse [der Truppe] hatte ein zersplittertes, chaotisches, erschreckendes Aussehen angenommen, wobei aus dem Offizier leider nur ein von der Strömung mitgerissener Automat geworden war. Es handelte sich um eine Flut von 100000 und mehr Soldaten aller Waffengattungen und Verbände ohne den geringsten inneren Zusammenhang und ohne Disziplin, die von Panik durchdrungen, von Kälte und Hunger erschöpft über schneebedeckte Felder und Wälder nach Westen, nach Süden und Südwesten zog, auf bis zum Äußersten mit Karren, Schlitten, Kraftfahrzeugen, Zivilisten vollgestopften Straßen, ständig bedrängt, angegriffen und weiter zersplittert, eingekreist und herumgestoßen von Panzern, motorisierten Kräften und Kavallerie des Feindes. Unsere Soldaten befreiten sich von Waffen, Munition, Handgranaten, um den Marsch weniger beschwerlich zu machen.

Die überall herumliegenden Handgranaten explodierten beim Vorbeiziehen dieses menschlichen Gewimmels und forderten Opfer, die zu den nicht weniger zahlreichen hinzukamen, die der Feind, die große Kälte und die Erschöpfung verursachten. Man erlebte Mitleid erregende Szenen: erfrierende Soldaten, die sich am Ende ihrer Kräfte niederknieten, beteten, das Haupt senkten und im selben Augenblick starben. Selbstmorde und Fälle von Wahnsinn unter den Offizieren vervollständigten das traurige Bild. Die Erfrierungen hielten an, so daß die Opfer, die es nicht mehr schafften weiterzugehen, den Korridor des Rückzugs säumten. Und der Strom dünnte sich aus, blieb aber stattlich und wälzte sich fort, überflutete die Dörfer, wo die Isbas ${ }^{69}$ von italienischen, deutschen, rumänischen und ungarischen Soldaten überquollen, die sich ausruhen und aufwärmen wollten. Um sich einen warmen Platz zu erobern, kam es - auch zu bewaffneten - Handgreiflichkeiten. In dem Durcheinander gerieten viele Isbas in Brand, wobei ein Großteil der hier untergebrachten Soldaten verbrannte, weil das Gedränge sie daran hinderte, sich zu retten. Bei diesen Ruhepausen stießen andere, der Gefangenschaft entkommene Soldaten - einige von ihnen ohne Mantel, andere ohne Rock und nicht wenige ohne Schuhe, die ihnen der Feind genommen hatte, um sie an der Flucht zu hindern, und mit strohumwickelten Füßen - zu dieser menschlichen Flut und versuchten, den Marsch mit ihr fortzusetzen.

Während sie sich vom Feinddruck lösten, verloren die Soldaten jedes militärische Aussehen: Hosen, Kopfbedeckungen, Jacken der ukrainischen Bevölkerung ersetzten die zerlumpten Uniformen, Filzstiefel die zerfetzten Schuhe. So zogen sie von Haus zu Haus, von Dorf zu Dorf, wo ihnen die Bevölkerung der Ukraine - mehr aus Sympathie oder Dankbarkeit als, wie viele behaupten, wegen einer Anordnung der russischen Stellen, die auch in Form von Flugblättern aus Flugzeugen abgewor-

69 Einfache Wohnhäuser der Landbevölkerung in Rußland und der Ukraine. 
fen wurde - Zuwendung, Aufmerksamkeit und Freundlichkeit entgegenbrachte und ihnen Essen, Kleidung und Ruhemöglichkeiten bot.

Einige, die aus der Gefangenschaft entkommen sind, behaupten überdies, daß ihnen selbst die russischen Soldaten und sogar die Partisanen dieselbe Behandlung hätren zu Teil werden lassen, während sie alle deutschen Gefangenen erschossen hätten. Einige andere hätten allerdings das Gegenteil behauptet, doch weiß ich nicht, ob diese Behauptung der Wahrheit entspricht oder ob sie geäußert worden ist, um die Geschichte von der überstandenen Gefahr zu dramatisieren ${ }^{70}$. Die erste Vermutung wird von der Mehrheit bestätigt, und man kann sie für glaubwürdig halten, weil sie von offensichtlichen Absichten politischer Natur inspiriert worden sein kann, die darauf zielten, die Italiener und die Deutschen auseinander zu bringen, die in dieser mißlichen Situation wirklich in tadelnswerter Weise gehandelt haben.

\section{Verhalten der Deutschen gegenüber den Italienern ${ }^{71}$}

Tatsächlich zögert kein Italiener vom General bis zum letzten Soldaten damit, das Verhalten der Deutschen gegenüber unseren Kommandos und unseren Soldaten im allgemeinen zu beklagen - ein Verhalten, das wegen des krassen Kontrastes zu der fast liebevollen Haltung der russischen Bevölkerung und zu der Humanität und Korrektheit, die, wie bereits angedeutet, einige Teile des feindlichen Heeres ihnen gegenüber zeigten, um so stärker hervortrat. Im einzelnen:

a) ließ und läßt man unser Armeeoberkommando weiterhin über die Kriegsereignisse ebenso im Unklaren wie über die Lage in den angrenzenden Abschnitten;

b) wurden die vom Oberkommando unserer Armee gemachten Vorschläge entweder nicht angenommen oder aber, falls sie angenommen wurden, von untergeordneten deutschen Kommandos in ihrer praktischen Umsetzung behindert. Für die nicht angenommenen Vorschläge ist niemals irgendeine Begründung gegeben worden;

c) wurde den diversen Forderungen unseres Armeeoberkommandos oder der Intendenza nicht stattgegeben, insbesondere hinsichtlich des Treibstoffs. Dieser wurde im übrigen von den Depots ohne Ermächtigungen nur nach der Abgabe von Wein und Lebensmitteln oder im Tausch gegen Gefälligkeiten jeglicher Art ausgegeben;

d) verhöhnten, verlachten und verschmähten die Deutschen auf Lastwagen oder in Zügen während des Rückzugs unsere Soldaten, die sich unter den elenden Bedingungen, die ich beschrieben habe, zu Fuß dahinschleppten. Und wenn jemand versuchte, auf die Lastwagen oder in die Züge zu steigen - oftmals halbleer oder voll von zuweilen wertlosen Gegenständen - wurde er mit dem Gewehrkolben geschlagen und gezwungen, unten zu bleiben;

e) durften unsere Soldaten - immer noch während des Rückzugs - die Isbas nicht betreten, in denen sich bereits deutsche Soldaten befanden, und selbst aus den

70 Zur gefährlichen Situation der Gefangennahme vgl. Giusti, Prigionieri, S. 33-37, die auch Berichte italienischer Kriegsgefangener über die Tötung ihrer Kameraden zitiert.

71 Der Abschnitt "Comportamento tedesco durante la battaglia“ in: $8^{2}$ Armata Italiana nella seconda battaglia difensiva del Don, S. 60-66, lehnt sich eng an diesen Abschnitt des hier abgedruckten Dokuments an. 
[von ihnen belegten] Isbas wurden unsere Soldaten mit der Waffe in der Hand vertrieben, um den deutschen Platz zu machen;

f) wurden Lastwagen, die von den Unsrigen wegen des Mangels an Treibstoff aufgegeben worden waren, von den Deutschen aufgetankt und für die eigenen Bedürfnisse eingesetzt;

g) wurden unsere Lastwagen, die auf der Straße zurückgelassen worden waren, weil sich der Fahrer vorübergehend entfernt hatte, unbefugt von den Deutschen übernommen und weggebracht, so wie - und das ist noch schlimmer - nicht wenige von unseren Kraftfahrern von den Deutschen unter Androhung von Waffengewalt gezwungen wurden, ihnen das Fahrzeug für ihre eigenen Dienste zu überlassen;

h) zwang man unsere Soldaten, auch die Verwundeten, unsere Kraftfahrzeuge zu verlassen, um Platz für die deutschen Soldaten zu machen;

i) wurden von den mit unseren Verwundeten belegten Zügen die Lokomotiven abgehängt, um sie an die deutschen Eisenbahnzüge zu hängen;

1) wurden verwundete und von Erfrierungen betroffene Italiener auf die Flachwagen gelegt, wo einige während der Fahrt wegen der Kälte gestorben sind, während sich die - nicht verwundeten - deutschen Soldaten in den geschlossenen Eisenbahnwagen niederließen, wo sie unbekümmert aßen und rauchten, während unsere Soldaten seit vielen Tagen hungerten;

m) wurde unseren Soldaten, wenn sie auf deutsche Versorgungseinheiten stießen, die mit Lebensmitteln einschließlich Brot ausgestattet waren, nichts oder bloß ein wenig Hirse und drei rohe Kartoffeln gegeben;

n) wurden einige Versorgungslager der Armee, für deren Räumung die Transportmittel verweigert worden waren, von den deutschen Truppen geplündert, so daß der Verdacht aufkam, der Grund für die Absage habe in der Absicht gelegen, sich der Lebensmittel und des Materials zu bemächtigen.

All diese Episoden und andere, die mir entfallen sind, haben bei allen Italienern der ARMIR eine entschieden deutschfeindliche Stimmung erzeugt. Denn die Italiener spüren, daß sie eine derartige Behandlung nicht verdienen, weil sie sich bewußt sind, daß sie ihre Pflicht bis zum äußersten Widerstand vollkommen erfüllt und ungefähr 70 Prozent ihrer Infanterie geopfert haben, um einem an Ausrüstung und Soldaten überlegenen Feind acht Tage lang die Stirn zu bieten. Dieser Widerstand hat es den deutschen Truppen erlaubt, sich in aller Ruhe zurückzuziehen und in aller Ruhe ihr gesamtes Material herauszuziehen. Wenn sich die italienischen Truppen in jener ungeordneten Weise zurückgezogen haben, ist dies vor allem der unhaltbaren Situation geschuldet, in der sie die deutsche Führung gelassen hatte: ohne Reserven, mit einer mehr als breiten Front, ohne adäquate Mittel zur Panzerabwehr, ohne Befehle, um einen geordneten Rückzug durchführen zu können, ohne Treibstoff. Die Deutschen schreiben die Niederlage jedoch mehr oder weniger offen dem Nachgeben der Front bei unserer Armee zu. Das ist nicht richtig. Bei einer solchen Behauptung kann es sich nur um eine politische Spekulation handeln. Bedauerlich ist deshalb die Bemerkung, die ein deutscher Offizier gemacht haben soll, als ihn einer unserer höheren Offiziere fragte, warum er einen seiner Vorgesetzten aus dem italienischen Heer nicht grüße: „Wir Deutsche haben am Don gesehen, was die Italiener wert sind! ${ }^{\prime}$ 


\section{Derzeitige Lage}

Der Strom von Versprengten erreichte den Donez und überquerte ihn teilweise; von hier aus gelang es dem Oberkommando unserer Armee unter unerhörten Mühen, Transportmittel zu erlangen, einen Teil der Versprengten mit Lastwagen und einigen Zügen schneller und weniger chaotisch in Richtung Dnjepr zu verfrachten, sie mit Lebensmitteln zu versorgen und einige Depots der Intendenza zu räumen. Erst am Ende des vergangenen Monats Februar war es möglich, einen Teil der Truppen am Dnjepr zu versammeln, und zwar verteilt wie folgt: ungefähr 12000 in Dnjepropetrowsk und Umgebung; ungefähr 5000 in Lemberg und Umgebung; ungefähr 70000 im Gebiet von Gomel - Neshin - insgesamt rund 87000 Mann, zu denen etwa 34000 hinzuzuzählen sind, die sich in Krankenheilstätten befinden und bereits heimgekehrt sind. Die Stärke der Armee belief sich zu Beginn des russischen Angriffs einschließlich des Ersatzes auf 235000 Mann.

Allerdings ist zu berücksichtigen, daß es im Raum Dnjepropetrowsk - Lemberg - Gomel - Neshin und in den leeren Gebieten zwischen den vorrückenden feindlichen Kolonnen viele weitere Soldaten gibt, die sich in den Isbas versteckt halten und nach einer angemessenen Rast und nachdem sie sich vergewissert haben, daß die Gefahr vorbei ist, gruppenweise zurückkehren. Nicht wenige Soldaten haben die Transporte mit Verwundeten und von Erfrierungen Betroffenen genutzt, um sich unter diese zu mischen und ohne Wissen ihrer Kommandos heimzukehren, ebenso wie die Verwundeten und die Soldaten mit Erfrierungen ohne Wissen ihrer Kommandos mit den Transporten in Pflegeanstalten eingeliefert worden sind. Man kann also davon ausgehen, daß immer noch ungefähr 100000 Mann über ein ungefähr $350 \mathrm{~km}$ breites und über $200 \mathrm{~km}$ tiefes Gebiet verstreut sind, locker in bunt zusammengewürfelten Formationen zusammengefaßt, mit ausgesprochen wenigen Offizieren, vereinzelten Regimentskommandeuren und einigen Divisionskommandeuren, ohne Verbindungen und ohne Mittel, eine Razzia durchzuführen, die sich im übrigen ziemlich schwierig gestalten würde.

Angesichts dieser Situation ist es dem Armeeoberkommando fast unmöglich, die Verluste genau festzustellen, auch weil zum Zeitpunkt des russischen Angriffs eine Ersatzabteilung, die noch nicht bei den Verbänden geführt wurde, in Richtung des Sektors der Armee marschierte, und eine weitere Abteilung Abgelöster ${ }^{72}$, die bereits aus den Stärkemeldungen der Verbände gestrichen worden waren, ins rückwärtige Gebiet aufbrach. Diese beiden Abteilungen wurden - mit den entsprechenden Konsequenzen - in die Schlacht verwickelt.

Das Armeeoberkommando hat für die Zusammenstellung [der Verluste] angeordnet: Listen mit den Namen derer, die präsent sind, unter Angabe der Einheit, der sie angehören - diesen Listen werden die Namen der Versprengten hinzugefügt, sobald sie sich melden; eine Liste der bisher ermittelten und noch zu ermittelnden Toten. Nur hinsichtlich der Generäle ist festgestellt worden, daß alle präsent oder krankheitshalber im Lazarett sind, abgesehen von den folgenden: General Tarnassi ${ }^{73}$, bei einem Luftangriff getötet; General Martinat, im Kampf gefallen; General

72 Handschriftlich korrigiert; ursprünglich: „complementi“, also Ersatz.

73 Paolo Tarnassi (1890-1942), Brigadegeneral, 1942 als General z.b.V. im Stab des II. Armeekorps, Befehlshaber des rückwärtigen Korpsgebiets und des Militärbezirks Kantemirowka, 
Perrod ${ }^{74}$, vermißt; General Pezzi1 ${ }^{75}$, vermißt; General Ricagno, in Gefangenschaft; General Battisti, in Gefangenschaft; General Pascolini76, in Gefangenschaft.

Gegenwärtige Situation der Divisionskommandos

[...]

Im Laufe der Operationen verlorenes Material

Im großen und ganzen ging der Armee folgendes Material verloren ${ }^{77}$ : die gesamte Artillerie (abgesehen von zwei $75 \mathrm{~mm}-\mathrm{Kanonen);} \mathrm{die} \mathrm{gesamte} \mathrm{Munition;} 12000$ Kraftfahrzeuge von 16000 [ursprünglich] vorhandenen; fast alle Feldlazarette (abgesehen von einem oder zweien); alle Lebensmittel- und Bekleidungsdepots der $\mathrm{Di}$ visionen und Armeekorps; ein Drittel (nach General Biglino) der diversen Güter, der Lebensmittel und der Kleidung aus den Lagern der Intendenza. Die Magazine von Woroschilowgrad, Debalzewo, Charkow sollen geräumt worden sein. Die Räumung der Magazine von Rykowo und Stalino ist immer noch im Gange, da der Feind diese beiden Städte noch nicht besetzt hat, obgleich er bereits über die beiden Orte hinaus nach Westen vorgerückt ist ${ }^{78}$.

Von den Deutschen und den Verbündeten im Zuge dieser Offensive allein im südlichen Abschnitt erlittene Gesamtverluste

Eine italienische Armee; eine ungarische Armee; zwei rumänische Armeen; anderthalb deutsche Armeen. Die Offensive ist noch nicht zum Stehen gebracht worden. Nur im südlichen Abschnitt verfährt die deutsche Führung [nach dem Prinzip] der elastischen Verteidigung und wirft den feindlichen Marschkolonnen aus Frankreich kommende Divisionen entgegen. Auf diese Weise hat sie ein ausgedehntes Territorium bis zum Donez wiederbesetzt und vor allem vermieden, daß die Russen bei Dnjepropetrowsk den Dnjepr erreichen. Dies hätte die südlich dieses Gebiets stehenden deutschen und verbündeten Truppen in eine kritische Lage gebracht. Westlich von Kursk und Orel hält die russische Offensive noch an und greift nach Westen aus. Von den Russen sind [amerikanische] Panzer und viele amerikanische

im Dezember 1942 bei einem Bombenangriff auf Mitrofanowka gefallen, im Oktober 1944 von der Sowjetunion bezichtigt, die Erschießung von Zivilisten befohlen zu haben.

74 Adriano Perrod (1889-1942), Brigadegeneral, seit Oktober 1942 Artillerieführer des XXXV. Armeekorps.

75 Enrico Pezzi (1897-1942), Brigadegeneral der Luftwaffe, 1918 Teilnahme am Ersten Weltkrieg als Leutnant bei der Artillerie, seit 1924 bei der Luftwaffe, Einsätze in Nord- und Ostafrika sowie im spanischen Bürgerkrieg, 1937 zum Oberst befördert, nach Italiens Eintritt in den Zweiten Weltkrieg Einsätze gegen Malta und in Nordafrika, 1942 zum Brigadegeneral befördert und Kommandeur der italienischen Luftstreitkräfte an der Ostfront, am 29. 12. 1942 von einem Flug ins eingeschlossene Tschertkowo nicht zurückgekehrt.

76 Etelvoldo Pascolini (1884-1956), Brigadegeneral, Teilnahme am Ersten Weltkrieg sowie an den Kriegen gegen Abessinien und Griechenland, im November 1942 zunächst Kommandeur des rückwärtigen Armeegebiets der 8. Armee, übernahm dann im Dezember 1942 das Kommando über die Division "Vicenza“, geriet am 24. 1. $1943 \mathrm{im}$ Raum Waluiki in sowjetische Gefangenschaft, 1950 nach Italien entlassen.

77 Genauere Angaben finden sich in: Operazioni delle unità italiane al fronte russo, S. 464 f.

78 Die Rote Armee war bis Februar 1943 im Bereich der Heeresgruppe B nördlich von Rykowo und Stalino bereits bis in die Nähe von Dnjepropetrowsk vorgestoßen, während sich die Verbände der Heeresgruppe Don am Mius hatten halten können. Vgl. Wegner, Krieg gegen die Sowjetunion, in: DRZW 6, Karte nach S. 1060. 
Lastwagen eingesetzt worden. Im südlichen Abschnitt ist von den Deutschen bis auf die Höhe von Gomel keine echte Widerstandslinie aufgebaut worden, doch, wie ich gesagt habe, werden frische Divisionen gegen die feindlichen Kolonnen geworfen, sobald sie ankommen.

So bilden sich leere Räume von beträchtlicher Ausdehnung, von denen einige wie die in der Gegend von Kiew und Gomel wegen der äußerst aktiven Partisanen auch gefährlich sind: Durch den Einsatz von Minen, die während des Transits der Eisenbahnzüge explodieren, beschädigen oder zerstören sie rollendes Material, [und zwar] insbesondere Lokomotiven, deren spürbaren Mangel die Deutschen beklagen. Sie greifen Dörfer an und bemächtigen sich ihrer auch unter Einsatz von Artillerie; sie geben den vorrückenden russischen Verbänden Signale; sie stören die Fahrzeugkolonnen; sie töten einzelne Soldaten.

Der Dnjepr, der ein wirksames Hindernis darstellen könnte, um Widerstand zu leisten, ist zum Teil noch gefroren. Doch die Deutschen haben an den taktisch wichtigsten Abschnitten mit Minen breite Furchen ausgehoben, die aufgrund der Eisdicke (auch mehr als ein Meter) richtiggehende Panzergräben bilden.

Gründe für die deutsche Niederlage im südlichen Abschnitt [der Ostfront] und für den chaotischen Rückzug der 8. italienischen Armee

\section{Von deutscher Seite:}

1. Das Beharren, eine Verteidigungslinie beizubehalten, die sich wegen der Breite und Tiefe der beiden Frontbögen nach Stalingrad und zum Kaukasus als gefährlich, wenig solide und folglich als anfällig dafür erwies, überrollt zu werden;

2. die Unkenntnis über den Umfang des Angriffs und die Vorgehensweise des Feindes bzw. die irrtümliche Annahme, [den Angriff] zerschlagen, aufhalten und, wie im vorausgegangenen Winter, dessen Auswirkungen zunichte machen zu können;

3. die Organisation der Verteidigung ohne ein solides, tiefgestaffeltes Stellungssystem; der rasche Zerfall dieser unzureichend vorbereiteten [Verteidigungslinie], weil man bei dem Versuch, die verschiedenen Löcher zu stopfen, die im Sektor [unserer Armee] entstanden waren, die Reserven sofort einsetzen mußte; der Abschnitt unserer Armee hätte als der heikelste und für die Sicherheit des gesamten Stalingrader Bogens wichtigste eingestuft werden müssen;

4. der Befehl, bis zum Äußersten Widerstand zu leisten, der angesichts der Wucht und des Nachdrucks des gegnerischen Angriffs, die im Vergleich mit unseren schwachen Stellungen bereits überdeutlich geworden waren, nur zu enormen Opfern an Menschen und vor allem an wertvollem Material führen konnte. Es fehlten eine klare Vorstellung und eine genaue Beurteilung der Lage, die das deutsche Oberkommando zweifellos dazu gebracht hätten, [den Truppen an] der Abwehr[-Front] - wenn schon nicht mit dem Herannahen des Winters, so doch zumindest nach den ersten Tagen eines ebenso ergebnislosen wie sinnlosen $W_{1}$ derstands - zu befehlen, schnell einen "Sprung zurück " zu machen, wie ihn im übrigen der Gegner während der deutschen Offensive im letzten Sommer in sehr opportuner Weise gemacht hatte;

5. eine zu weit vorgeschobene Dislozierung der verschiedenen Versorgungslager und Depors, die sich angesichts des herankommenden Winters und folglich in der 
Gewißheit einer russischen Offensive (die im übrigen von Gewährsmännern und von den Russen selbst über in den Schützengräben postierte Lautsprecher angekündigt worden war) weiter hinten hätten befinden müssen;

6. die ausgebliebene Zuteilung von Treibstoff, an dem es dem Oberkommando der 8. Armee trotz beständiger Anforderungen seit ungefähr vier Monaten mangelte, was unsere Großverbände dazu gezwungen hat, die Artillerie, die Munition, die Kraftfahrzeuge, die Lebensmittel, die Bekleidung vor Ort zurückzulassen.

Von italienischer Seite:

1. fehlender Nachdruck ${ }^{79}$ seitens unseres Comando Supremo gegenüber dem deutschen Oberkommando, um die Vorschläge operativer Natur und die verschiedenen Anträge zu unterstützen, die die ARMIR an die vorgesetzten deutschen Stellen gerichtet hat;

2. eine energischere Haltung des Oberkommandos der 8. Armee gegenüber den zuständigen deutschen Stellen, um zu erhalten, was unsere Großverbände benötigten;

3. Ausbleiben von Befehlen und Dispositionen seitens aller Kommandos - insbesondere der gehobenen - für einen geordneteren Rückzug;

4. qualitative Mängel der Truppenführer, insbesondere der subalternen, von denen freilich etliche höhere Offiziere und einige Generäle ebensowenig frei waren. Die Offiziere waren sich der schweren Verantwortung eines Rückzugs nicht vollständig bewußt und folglich auch nicht der Notwendigkeit, nahe bei der Truppe zu sein, die Geschlossenheit der eigenen Einheit um jeden Preis, mit allen Mitteln und mit größter Energie zu wahren, die Initiative zu ergreifen, wie es die besondere Situation erforderte, um die Probleme anzugehen und zu lösen. Die ausbleibenden Befehle von oben und die übertriebene Sorge, in Gefangenschaft zu geraten, führten bei vielen dazu, daß sie den Gleichmut, die Ruhe und jeden Anschein eines befehlshabenden Offiziers verloren. Richtig ist, daß die besten Kommandeure während der ersten Abwehrkämpfe fielen oder verwundet wurden und daß folglich nicht alle Regimenter und Bataillone ihren Kommandeur hatten; dies rechtfertigt jedoch keineswegs das beklagenswerte Verhalten der restlichen Offiziere.

Die innere Struktur der Einheiten war unzulänglich: Subalternoffiziere, die es verstehen - wie mir Seine Exzellenz Gariboldi sagte -, sich töten zu lassen, aber weder die Fähigkeit noch die Tatkraft dazu haben, Kommandos zu geben; höhere Offiziere der Reserve oder im aktiven Dienst, die der Altersgrenze nahe sind und das Kommando über ein Bataillon im Krieg als Rettungsanker betrachten, weil sie darauf hoffen, aufgrund von Verdiensten auf dem Schlachtfeld gnädig befördert zu werden; zu viele - körperlich und intellektuell geeignete - höhere aktive Offiziere, die nicht dem Generalstab angehören, dienen angesichts der Tatsache, daß dieser Dienst für sie im Rahmen ihrer Laufbahn als Truppenkommando gewertet wird, in den mobilisierten Kommandos von Großverbänden, so daß etliche den Rang eines Obersten erreichen, ohne jemals ein Bataillon gesehen zu haben, weder im Frieden noch im Krieg; auch mancher Offizier im Generalsrang ließ wegen Unfähigkeit und Kleinmut zu wünschen übrig;

79 In der Vorlage ursprünglich: „assistenza“; handschriftlich korrigiert in: „insistenza“. 
5. die bezüglich von Taktik und Disziplin mangelhafte Standfestigkeit des Ersatzes, einschließlich derjenigen, die an die Front geschickt worden waren, um sich zu bewähren. Diese letztgenannten waren der Aufgabe angesichts der zahlenmäßigen und waffentechnischen Überlegenheit, die der Feind besaß, nicht gewachsen, um dann während des Rückzugs in die ungebührlichste Disziplinlosigkeit zu verfallen;

6. die Erschöpfung der noch nicht abgelösten Soldaten, die den zweiten Winter in Rußland verbracht haben;

7. die offensichtliche Unterlegenheit unserer Bewaffnung gegenüber den überaus beeindruckenden Möglichkeiten des Feindes. Diese Unterlegenheit hat den Mut und die Zähigkeit unserer Soldaten ziemlich untergraben, die nicht in der Lage waren, sich gegen die zahlreichen Panzer zu verteidigen, die ihre Stellungen überrollten.

Schwierigkeiten bei der Umsetzung einiger Anordnungen zur Neuordnung der

8. Armee

a) Versammlungsraum

Wie ich gesagt habe, sollen sich die Reste der 8. Armee auf Anordnung des Oberkommandos der deutschen Heeresgruppe im Raum Gomel sammeln. Dieses Gebiet ist aus folgenden Gründen nicht besonders geeignet:

1. es kann jederzeit zum Schlachtfeld werden, mit allen Konsequenzen für die Masse der Frontsoldaten, die von der inneren Struktur [der Einheiten], der Disziplin und der moralischen Verfassung her nicht in der Lage ist, Gefechte zu bestehen;

2. es handelt sich um Malariagebiet, vor allem aber ist es von einer beachtlichen Zahl höchst aktiver Partisanen verseucht und stellt folglich ein Territorium dar, das nicht die notwendige Ruhe bietet, die ein Unternehmen wie die Neuordnung eines Großverbands verlangt;

3. Gomel wird fast täglich von russischen Flugzeugen bombardiert. Wir haben bereits Tote und Verletzte als Opfer zu beklagen;

4. es fehlt an Unterkünften, so daß diese Masse, die aus über 100000 Mann besteht, auf ein Gebiet von mindestens $150-200 \mathrm{~km}$ verteilt werden muß. Diese Situation begünstigt die Neuordnung der Verbände nicht.

Es erweist sich deshalb als notwendig: entweder die Zurückverlegung des Versammlungsraums zumindest bis auf die Höhe von Lemberg, oder die schnelle Repatriierung aller.

Seine Exzellenz Gariboldi hat dem deutschen Oberkommando diese Situation dargelegt und erklärt, "den Befehl nicht auszuführen", die Armee in Gomel zu versammeln. Da das Gesuch negativ beschieden wurde, hat er eine Intervention unseres Comando Supremo erbeten, das ihm geantwortet habe, es solle „sich an die $\mathrm{Be}$ fehle der deutschen Stellen halten“.

b) Aufstellung des II. Armeekorps

Auf Befehl des Comando Supremo - im Einvernehmen mit dem deutschen [Oberkommando] - sollen aus dieser Masse von ungefähr 100000 Mann die besten Elemente ausgewählt werden, um das II. Armeekorps mit zwei Divisionen wiederaufzubauen: der "Cosseria“ und der "Ravenna“. Diesem Korps sollen Polizeiaufgaben 
übertragen werden. Obgleich diese Aufgaben leicht zu sein scheinen, sind alle der Meinung - und nicht zu Unrecht - daß alle Reste der 8. Armee, wirklich alle, vom Kommandeur bis zum letzten Soldaten, aus folgenden Gründen in die Heimat verlegt werden müssen:

1. alle stehen noch unter dem Eindruck, dem Feind an Zahl und Ausrüstung weit unterlegen zu sein, und [glauben] deshalb, daß sie sich umsonst opfern würden;

2. alle leiden unter dem Zusammenbruch, den dieser ungeordnete, mühselige und belastende Rückzug bewirkt hat; deshalb sind alle erschöpft und, was die Moral betrifft, niedergeschlagen;

3. die besten Elemente, die zum Aufbau des II. Korps ausgewählt werden sollen, sind diejenigen, die sich in den früheren Gefechten hervorgetan haben und im allgemeinen diejenigen, die mit der ersten Expedition des CSIR an die russische Front gekommen sind. Nach zwei Jahren sind sie zwangsläufig ausgelaugt und würden sich zweifellos gedemütigt fühlen, wenn sie eines Tages ihre nach ihnen [an die Ostfront] gekommenen Kameraden heimkehren sähen. Kurzum, mit einer solchen Maßnahme würde man die weniger Verdienstvollen bevorzugt behandeln.

4. Es ist nicht einfach, aus den verbliebenen 100000 Mann ungefähr 50000 für das II. Korps auszuwählen, es sei denn, man nimmt auch die weniger Tauglichen. Ferner ist zu berücksichtigen, daß diese 50000 Bekleidung, Waffen und Ausrüstung benötigen, [Dinge], die sie heute nicht haben oder die sich in einem erbärmlichen Zustand befinden. Artillerie, automatische Waffen und Munition fehlen. Den Offizieren, die ihre Kisten verloren haben, fehlt die Ausstattung.

5. Die große Mehrheit hegt (zu Recht oder zu Unrecht) einen wilden Groll gegen die deutschen Verbündeten und erklären daher offen, daß ssie es vorziehen, mit den Russen zu kämpfen statt an der Seite der Deutschen, und es vorziehen, den Krieg zu verlieren, um nicht mehr an der Seite der Deutschen kämpfen zu müssen“. Es mag sich dabei um Verrücktheiten handeln, aber so sieht ihre Stimmungslage wirklich aus, was ich sowohl während meines Aufenthalts als auch während der Reise feststellen konnte.

6. Man muß dem II. Korps einen neuen Kommandeur zuweisen, weil der jetzige sich seinem Amt nicht gewachsen gezeigt har ${ }^{80}$ und Seine Exzellenz Zingales die Ernennung zum designierten Armee[general] ${ }^{81}$ herbeisehnt, wofür er - nach eigener Aussage - bereits für geeignet erklärt worden ist. Er fühlt sich überdies gedemütigt, weil er an der russischen Front aufgrund der [spezifischen] Erfordernisse des Sektors praktisch nur die Division „Pasubio“ befehligt hat, was ihm

80 Generaloberst Gariboldi hatte dem Comando Supremo Ende Februar 1943 mitgeteilt, er halte den Kommandierenden General des II. Armeekorps, Giovanni Zanghieri, nicht für geeignet, dieses Kommando weiterhin zu führen (AUSSME, DS II 1489, Anlage zum KTB des Comando Supremo für Februar 1943: Funkspruch des AOK 8 an das Comando Supremo vom 21. 2. 1943). Nachdem es General Zingales, der Kommandierende General des XXXV. Armeekorps, abgelehnt hatte, dieses Kommando zu übernehmen, wurde Zanghieri im März 1943 durch General Arnaldo Forgiero ersetzt. Zu Zingales vgl. auch seinen eigenen Bericht in Dok. 20.

81 Zingales hoffte wohl, zum Generale designato d'Armata befördert zu werden, eine Rangstufe, die es in der Wehrmacht nicht gab und die zwischen dem Rang eines Generals der Infanterie etc. und dem eines Generalobersten angesiedelt war. 
hinsichtlich des umgehenden Vollzugs der von ihm erwarteten Beförderung geschadet habe, die er virtuell bereits zu besitzen glaubt.

c) Repatriierung der Überzähligen

Von den für den Personalbestand des II. Korps überzähligen [Soldaten] dürfen nicht mehr als 1000 täglich heimkehren, weil es die für die Quarantäne vorgesehenen Einrichtungen nicht erlauben, pro Tag eine größere Zahl zu repatriieren. Bei dieser geringen Menge würde die Heimkehr der Überzähligen ungefähr zwei Monate in Anspruch nehmen. Wie ich schon gesagt habe, gibt es zu viele offensichtliche und augenfällige Gründe, die dazu zwingen, das für eine geordnete Auffrischung des II. Korps [vorgesehene] Gebiet zügig zu räumen und so schnell wie möglich eine Masse von Individuen zu entfernen, die sich und anderen schaden und ein wenig erbauliches Schauspiel bieten. Seine Exzellenz Gariboldi ersucht, dafür Sorge zu tragen, nach weiteren Orten zu suchen, wo die Quarantäne vollzogen werden kann, um die tägliche Menge der Heimkehrer zumindest zu verdoppeln.

d) Heimkehr des Armeeoberkommandos

Es wäre erwünscht, daß vom Comando Supremo die Abfolge und damit das Datum für die Repatriierung des Oberkommandos der 8. Armee festgesetzt würde. Das Armeeoberkommando schlägt folgenden Ablauf vor: Alpinikorps; Truppen und Dienste der Armee; Armeeoberkommando; XXXV. Armeekorps; Intendenza. Es wäre auch erwünscht, daß man sich um den Transport Seiner Exzellenz Gariboldi und seines Generalstabs auf dem Luftweg kümmert.

e) Gepäckverlust der Offiziere

[...]

\section{Verschiedenes}

Deutsche Generäle haben unseren Generälen zu verstehen gegeben, daß man in Deutschland einen Separatfrieden Italiens fürchtet.

$[\ldots]$

Seine Exzellenz Gariboldi hat mich ermächtigt zu berichten, er habe mit Bedauern festgestellt, daß die im Operationsgebiet mit dem Kommando über eine Division betrauten Brigadegeneräle, die er für einen höheren Rang geeignet hält, bei der Beförderung von Kollegen überrundet würden, die immer im Büro gewesen seien. Dies - hat Seine Exzellenz hinzugefügt - rufe eine gewisse Unzufriedenheit hervor. Gleiches gelte für die Beförderung und den Aufstieg der subalternen und höheren Offiziere sowie der Generäle aufgrund von Verdiensten im Kriege und ebenso für den Wechsel der Oberstleutnante in das Generalstabskorps, die bei Verbänden im Operationsgebiet dienen und sich von den anderen, in Rom residierenden Kollegen überrundet sehen.

Es geht das Gerücht, einige Soldaten hätten, um sich Lebensmittel zu verschaffen, Waffen an die Partisanen abgegeben. Nachforschungen hätten gezeigt, daß dieses Gerücht jeglicher Grundlage entbehrt ${ }^{82}$.

82 General Zanghieri nahm diese immer wieder auftretenden Vorwürfe so ernst, daß er Gegenmaßnahmen anordnete und Untersuchungen einleiten ließ. AUSSME, DS II 1204, KTB II. Armeekorps, März/April 1943, Anlage 6: General Zanghieri an die unterstellten Truppenteile (Nr. 733/02 di prot.) vom 5. 3. 1943. 
Es ist auf die Unmöglichkeit hingewiesen worden, den Adressaten die Korrespondenz aus Italien zuzustellen; die Korrespondenz ist an verschiedenen Orten gelagert. Mit Ausnahme der Einschreiben wird sie vernichtet.

AUSSME, L 14/92-13.

\section{Dokument 19}

\section{Bericht von Major Achille Mazzi ${ }^{83}$ (italienisches Verbindungskommando zur Heeresgruppe B) für General Umberto Utili über das Verhältnis zwischen den Verbündeten vom Mai $1943^{84}$}

Der Sektor, den man der 8. italienischen Armee am Don zugewiesen hatte, war von der deutschen Führung bereits seit September 1942 als besonders heikel eingestuft worden und sollte in Zukunft mit besonderer Aufmerksamkeit beobachtet werden. In diesem Sinne äußerte sich Marschall von Weichs, der Oberbefehlshaber der Heeresgruppe B, Anfang September 1942 im Beisein des Unterzeichneten gegenüber General Marras, wobei er die Versicherung hinzufügte, er wolle sein möglichstes tun, um die Reihen der 8 . Armee zu verstärken ${ }^{85}$.

Das Armeeoberkommando selbst mußte die deutsche Seite wiederholt auf das bestehende Mißverhältnis zwischen den verfügbaren Mitteln und der Breite des Abschnitts sowie auf das Fehlen ausreichender Reserven hinweisen, die es angefordert hatte. Gleichzeitig wurden sowohl vom Armeeoberkommando, das sich des deutschen Verbindungskommandos bediente, als auch vom Unterzeichneten als dem Chef des italienischen Verbindungskommandos wiederholt Panzerabwehrkanonen und Maschinengewehre beantragt, wobei soweit wie möglich auch auf funktionstüchtiges Kriegsmaterial aus Beutebeständen zurückgegriffen werden sollte. Die deutsche Seite kam diesen Forderungen entgegen, indem sie festlegte, die Division Celere, die Division ${ }_{n}$ Sforzesca“, die 294. Infanteriedivision und die 22. Panzerdivision in einer zweiten Linie aufzustellen. All diese Großverbände sollten nach einer

${ }^{83}$ Keine weiteren Angaben ermittelt.

84 Dem Bericht geht eine von Major Mazzi gezeichnete kurze Vormerkung für Umberto Utili voraus: „Ihrer Aufforderung gemäß werde ich im vorliegenden Bericht zusammenfassend einige Aspekte und Tatsachen darlegen, die auf persönliche Erfahrungen, Befragungen von Soldaten und Einsichten zurückgehen, die ich in der Zeit meiner direkten Zusammenarbeit mit deutschen militärischen Dienststellen gewonnen habe. Es handelt sich um Aspekte und Tatsachen, die hoffentlich unter anderem dazu beitragen können, die Bedingungen, unter denen die 8 . Armee auf russischem Territorium operieren mußte, objektiv zu bewerten, insbesondere soweit ein Zusammenhang mit den Beziehungen zu den Verbündeten besteht."

85 Hier bezieht sich Mazzi offensichtlich auf das Gespräch zwischen Marras und von Weichs am 4. 10. 1942 in Starobelsk. Der italienischen Aufzeichnung (AUSSME, DS II 1333 a) zufolge führte der Oberbefehlshaber der Heeresgruppe B aus: „Der Führer betrachter den Sektor der 8. Armee als strategisch äußerst heiklen Punkt besonders aufmerksam. - Wenn wir die Russen wären, würden wir diesen Sektor als für eine Aktion gegen unsere Aufstellung ausnehmend geeignet ansehen." Die im folgenden angesprochenen Probleme (Panzerabwehr- und automatische Waffen, Zuteilung von Beutewaffen) wurden laut dieser Aufzeichnung ebenfalls behandelt. 
Verkürzung des von der Armee gehaltenen Sektors, die sich aus der Eingliederung der 3. rumänischen Armee an der rechten Flanke ergeben sollte, verfügbar werden. In Wirklichkeit konnte diese Schlachtordnung nicht eingenommen werden, weil:

- die 3. rumänische Armee, die nicht über ausreichende Kräfte verfügte, um den eigenen Abschnitt zu besetzen, die Division "Sforzesca“ dazu zwang, an der Front zu bleiben;

- der von den Russen gegen Ende November erzielte Durchbruch im Abschnitt der 3. rumänischen Armee die deutsche Führung dazu zwang, die 294. deutsche Division und die 22. Panzerdivision in jenem Sektor einzusetzen ${ }^{86}$, während die Division Celere den bisher von der 62. Division gehaltenen breiten Abschnitt übernehmen mußte, die bei dieser Gelegenheit ebenfalls in die Bresche geworfen wurde, welche die Russen bei der 3. rumänischen Armee geschlagen hatten.

Dergestalt ergab sich für die 8. Armee eine lineare Aufstellung in einem breiten Frontabschnitt ohne Verbände in zweiter Linie. Der italienischen Armee blieb nur das Versprechen, das die Heeresgruppe B über den General des deutschen Verbindungskommandos [Kurt von Tippelskirch] gegeben hatte, daß mit von hinten herankommenden deutschen Großverbänden (385. Division, 6. und 11. Panzerdivision) eine angemessene Reserve geschaffen werde. Von diesen Großverbänden traf die 385. Division mit Verspätung ein; die 6. und die 11. Panzerdivision kamen rechtzeitig, doch auch sie wurden eilig in den Sektor der 3. rumänischen Armee umgeleitet $^{87}$.

Die Forderung nach Panzerabwehrkanonen bewirkte trotz meines wiederholten Drängens bei der Heeresgruppe B wenig88. Etwas wurde bewilligt, doch sehr wenig im Vergleich zu den wirklichen Erfordernissen, die ein so breiter und heikler Abschnitt mit sich brachte, zumal sich der Don auch außerhalb der Frostperiode an verschiedenen Stellen leicht von Panzern überqueren ließ. Bezüglich der Maschinengewehre antwortete die deutsche Seite, daß man nicht über Kriegsbeute verfüge und ein entsprechender Antrag an das OKH gerichtet worden sei. Erst gegen Ende November wurde mir von deutscher Seite mitgeteilt, daß der Antrag zum größten Teil bewilligt worden sei und die Waffen in den Rüstungsfabriken und Depots in Deutschland vorbereitet würden, um anschließend an die Front geschickt zu werden.

86 Zwei graphische Darstellungen zur Dislozierung der Großverbände im Bereich der 8. Armee zum 1. 11. (mit der Division "Sforzesca ${ }^{\alpha}$ an der Front, der 294. Infanteriedivision als Reserve im Sektor des Alpinikorps sowie der 22. Panzerdivision und der 3. Division Celere als Reserven hinter der Front des II. und XXXV. Korps) und zum 10. 12. 1942 (62. und 294. Infanteriedivision sowie 22. Panzerdivision abgezogen, 3. Division Celere als Ersatz für die 62. Infanteriedivision an der Front, 27. Panzerdivision als Eingreifreserve im Abschnitt des II. Korps) finden sich in: Operazioni delle unità italiane al fronte russo, Abbildungen 33 und 34.

87 Die Panzerdivisionen wurden schließlich am Tschir (11.) und zum Entsatz Stalingrads (6.) eingesetzt. Zu den deutschen Verbänden im Sektor der ARMIR vgl. S. 60 und S. 62 f. dieses Bandes, zu den auch die 8. Armee betreffenden Truppenbewegungen im November/Dezember 1942 vgl. Kehrig, Stalingrad, S. 101, S. 132 und S. 160.

88 Neben den sechs Pak vom Kaliber $7,5 \mathrm{~cm}$, die das OKH jeder italienischen Division zugeteilt hatte (vgl. Förster, Ruolo, in: Italiani sul fronte russo, S. 237 f.), wies die Heeresgruppe B der 8. Armee Anfang Dezember auch 4,5 cm Pak zu, die man von der Roten Armee erbeutet hatte (BA-MA, MFB4 18276, Bl. 572, Nachricht des Deutschen Generals beim italienischen $A O K 8(Q u / W u G)$ vom 6. 12.1942). 
In wenigen Worten: Am 11. Dezember mußte die 8. Armee dem Ansturm übermächtiger russischer Kräfte standhalten

- mit einer linearen Aufstellung in einem sehr breiten Frontabschnitt;

- ohne Großverbände in zweiter Linie, ausgenommen die in letzter Minute eingetroffene 27. Panzerdivision, die allerdings nur über 47 Panzer verfügte ${ }^{89}$;

- mit einer Ausstattung an Panzerabwehrwaffen, die völlig unzureichend war, um der Masse von russischen Panzern die Stirn bieten zu können;

- mit einem Rückgrat an Feuerkraft (Maschinengewehre), das im Verhältnis zur Breite des Verteidigungsabschnitts zu schwach war.

Dem muß noch der Treibstoffmangel hinzugefügt werden, der auf der an sich schon komplexen und schwierigen Aufgabe unserer Intendenza stets wie ein Alptraum lastete. Dieser Mangel wirkte sich nicht nur negativ auf die Transporte aus, weil er die Intendenza notgedrungen dazu zwang, auf einen konkreten und verläßlichen Transportplan zu verzichten und die Entscheidungen von Tag zu Tag zu treffen, sondern verhinderte auch die Bildung selbst der kleinsten Reserve, die für die Verlegung von Truppen und Gerät im taktischen Bereich, vor allem aber für die Manöver unserer Artillerie während des Rückzugs unabdingbar gewesen wäre. Die Masse unserer Artillerie konnte sich aufgrund des Treibstoffmangels dem Zugriff [des Feindes] nicht entziehen.

Aus persönlichen Beobachtungen und Erklärungen unserer Soldaten geht hervor, daß auf deutscher Seite sehr viel Personal und Gerät gerettet werden konnte, weil die Fronteinheiten über Treibstoff verfügten. Noch zum Thema der Verfügbarkeit von Treibstoff auf deutscher Seite: Es scheint, daß die Deutschen in mehreren Orten der frontnahen Etappe während des Rückzugs im letzten Moment einige ihrer Treibstofflager in die Luft gesprengt haben ${ }^{90}$. Im rückwärtigen Gebiet schließlich fiel der auch in Zeiten operativer Ruhe durchweg erhebliche Verkehr von Kraftfahrzeugen auf, mit denen deutsche Unteroffiziere und Soldaten in aller Bequemlichkeit unterwegs waren.

Die wirkliche Lage, in der sich die 8. italienische Armee zu Beginn des Winters befand, mußte dem Oberkommando der Heeresgruppe B bekannt gewesen sein, weil sie das Armeeoberkommando selbst durch den General des deutschen Verbindungskommandos wiederholt zum Vortrag gebracht hat und weil sich das deutsche Oberkommando seinerseits für jede operative Frage, die die 8. Armee betraf, gerne dieses Generals bediente. Man kann sicher nicht behaupten, dieser General sei bei der Ausübung seines Amtes von dem Willen beseelt gewesen, die Armee aus einem gesunden Verständnis für ihre wirklichen Bedürfnisse heraus zu unterstützen und ihr zu helfen, und er habe sich bei der Heeresgruppe dafür eingesetzt, Schwierigkei-

89 Diese Zahl wird auch kolportiert in Operazioni delle unità italiane al fronte russo, S. 327. Tatsächlich zählte die dringend auffrischungsbedürftige Division mehr gepanzerte Gefechtsfahrzeuge. Nach einer Meldung des Deutschen Generals an das AOK 8 vom 9.12. 1942 (BA-MA, MFB4 18276, Bl. 249) verfügte die 27. Panzerdivision unmittelbar vor den ersten Angriffen der Roten Armee über 47 Panzer, acht Pak vom Kaliber 7,5 cm auf Selbstfahrlafette sowie eine Sturmgeschützabteilung mit 22 Sturmgeschützen, von denen allerdings erst 16 eingetroffen waren. 12 weitere Pak vom Kaliber $7,62 \mathrm{~cm}$ auf Selbstfahrlafette und 17 Panzer vom Typ III sollten der Division so schnell wie möglich zugeführt werden (BA-MA, MFB4 18276, Bl. 222, Fernschreiben Nr. 6168 vom 9. 12. 1942, geheim).

90 Bei Ostrogoschsk etwa mußte das zentrale Treibstofflager der 2. ungarischen Armee gesprengt werden; vgl. Wimpffen, Zweite ungarische Armee, S. 90. 
ten zu beseitigen und der Armee ihre Aufgaben zu erleichtern. Seine vorrangige Funktion schien meiner Meinung nach weniger im Verbindungsdienst als in der indirekten Kontrolle des Wirkens der Armee zu bestehen, wobei sich die Tendenz abzeichnete, in die eigentlichen Kompetenzen des Armeeoberkommandos einzugreifen, wenn sich die Gelegenheit dazu bot. Seine Aktivitäten erschienen als entschieden einseitig, d.h. allein der deutschen Seite verpflichtet ${ }^{91}$.

Ich bin nicht in der Lage, das Verhalten zu beurteilen, das die Offiziere des Oberkommandos der Heeresgruppe B während der entscheidenden Phase der russischen Offensive im Sektor der 8. Armee uns gegenüber an den Tag gelegt haben, weil ich von Mitte Dezember bis Ende Januar nicht beim [Verbindungs-]Kommando gewesen bin. Ich kann jedoch sagen, daß ich Ende Januar, als ich den Kontakt zum erwähnten deutschen Kommando wiederaufnahm, eine offen zur Schau gestellte Kälte und bei einigen Generalstabsoffizieren auch Unduldsamkeit im Umgang mit dem italienischen Verbindungskommando feststellen mußte.

Tatsächlich enthielt sich die deutsche Seite zwar jeglicher Andeutung oder jeden Kommentars über das Geschehene ${ }^{92}$, doch die Probleme, die die Armee insbesondere im logistischen Bereich weiterhin betrafen (Zuteilung von Treibstoff, Zuweisung von Zügen für Evakuierungen, Zuteilung von Lebensmitteln entlang der für die Truppenbewegungen zu Fuß [vorgesehenen] Marschroute), fanden kein geneigtes Interesse mehr. Im Februar wurden nur wenige der vielen Anforderungen logistischer Natur bewilligt, die das italienische Verbindungskommando eingereicht und erörtert hatte.

Von deutscher Seite wurden gegen jeden unserer Anträge umfassende Einwände vorgebracht; die Abwälzung von Verantwortlichkeiten führte uns von einem Kommando zum anderen, wobei ein jedes erklärte, für die Behandlung des Themas nicht zuständig zu sein. Oftmals versprachen sie schließlich etwas, was sie dann nicht immer oder nur teilweise gewährten. Für den Bereich des Sanitätswesens muß ich hingegen anerkennen, daß die Sanitätsoffiziere, denen die Leitung dieses Dienstes im Rahmen der Heeresgruppe B oblag, sehr viel Verständnis zeigten und den dringenden Erfordernissen bei der Evakuierung und Unterbringung der Verwundeten und der Soldaten mit Erfrierungen (insbesondere ankommende Alpini und Soldaten [anderer Waffengattungen] sowie Bettlägerige in Charkow) mit einem ausgeprägten Opfersinn und Kameradschaftsgeist begegnet sind.

Insgesamt hatte ich mit anderen hohen Offizieren des [Verbindungs-]Kommandos den Eindruck, daß sich die deutsche Führung nach den bekannten Ereignissen kaum mehr um das Schicksal der Truppen gekümmert hat, die nicht sofort für Kampfzwecke wiederverwendet werden konnten, sondern es ihnen selbst überlassen hat, soweit wie möglich mit eigenen Mitteln für den Unterhalt und das Erreichen des jeweiligen Auffrischungsraums Sorge zu tragen (dies gilt auch für die ungarischen Truppen).

91 Auch Generaloberst Gariboldi beklagte sich bitter über von Tippelskirch, der "keinerlei Sympathie für unser Heer" hege, und sprach sich dagegen aus, ihn auszuzeichnen; AUSSME, L 13/48-5, Italo Gariboldi an das Comando Supremo (Nr. 08/1598) vom 11.3. 1943.

92 Dies entsprach nach einer Absprache mit General Marras auch dem Willen des deutschen Oberkommandos; ADAP, Reihe E, Bd. 5, S. 435 f.: Aufzeichnung des Botschafters z.b.V. Ritter vom 20. 3. 1943. 
Es fehlte nicht an unerfreulichen und auch ernsteren Zusammenstößen zwischen Italienern und Deutschen. Zumeist handelte es sich um Übergriffe unterschiedlicher Art seitens deutscher Soldaten gegen die Italiener, die sich auf dem Rückzug befanden und durch die Etappe zogen oder dort Halt machten. Im allgemeinen waren es Gruppen von deutschen Soldaten - dabei oftmals auch Unteroffiziere und Subalternoffiziere -, die sich ebenfalls auf dem Rückzug befanden und mit dem Ziel, so schnell wie möglich und unter geringeren Strapazen die Etappe zu erreichen, Kraftfahrer, Maultier- und Schlittenführer mit der Waffe in der Hand bedrohten, um sich des Transportmittels zu bemächtigen, wobei sie die Erschöpfung unserer Soldaten ausnutzten (siehe einige Fälle in der beiliegenden, vom italienischen Bahnhofskommandanten in Poltawa erhaltenen Abschrift eines Phonogramms) ${ }^{93}$.

Major Estrafallaces ${ }^{94}$ vom Oberkommando der 8. Armee, der einigen Alpinieinheiten östlich von Charkow entgegengeschickt worden war, berichtete, er habe energisch und mit Gewalt eingreifen müssen, als sich einige Deutsche, ich glaube Agrarexperten, beim Vorbeimarsch isolierter, müder und erschöpfter Gebirgstruppen den Treibern genähert hätten, um sich der Maultiere zu bemächtigen, die die tapferen Alpini noch mit sich führten. Major Estrafallaces behauptete, auf diese Weise sechs oder acht Maultiere gerettet zu haben.

Dem Armeeoberkommando und der Intendenza sind viele andere Übergriffe und Drohungen bekannt, und ich nehme an, daß sie davon eine gut dokumentierte Sammlung angelegt haben. Dem italienischen Verbindungskommando selbst sind, aus Charkow kommend, während seines kurzen Aufenthalts in Poltawa die in Anhang 2 [beschriebenen] Vorfälle widerfahren ${ }^{95}$. Ein Teil der Gewaltakte wurde auch von deutschen Soldaten, insbesondere SS-Einheiten, verübt, die aus dem rückwärtigen Gebiet an die Front unterwegs waren.

Anscheinend hatte sich insbesondere bei den deutschen Verbänden, die in der Etappe Halt machten oder die von hinten an die Front zogen, die Überzeugung verfestigt, die Italiener hätten das Schlachtfeld vorschnell verlassen, sich übereilt zurückgezogen und es so den Deutschen überlassen, die Lage zu bereinigen. Meiner Meinung nach ist diese falsche Überzeugung als Folge des unterschiedlichen Anblicks entstanden und gereift, den der italienische Rückzug dem beiwohnenden deutschen Soldaten verglichen mit dem Rückzug der deutschen Verbände bot. Tatsächlich war der Rückzug der deutschen Verbände nicht so auffällig und hart wie der italienische; deshalb konnte er den Augenzeugen in der Etappe größtenteils entgehen. Die Masse der deutschen Truppen hatte die Möglichkeit, Lastwagen, Schlitten und diverse Fahrzeuge der Trosse zu nutzen. Insgesamt waren im Vergleich zu den Italienern sehr wenige [deutsche] Truppen zu Fußmärschen ge-

93 Costamiles Poltawa (gez. Hauptmann Bertegani) an Detachement UTIC (für General Biglino) vom 8. 2. 1943; auf die Wiedergabe dieser Anlage wurde verzichtet. Von zahlreichen ähnlich gelagerten Fällen wird in Dok. 24 berichtet.

94 Major Ugo Estrafallaces war schon am 23. 12. 1942 vom AOK 8 als Verbindungsoffizier zum Alpinikorps entsandt worden; AUSSME, DS II 1126, KTB Alpinikorps, November/ Dezember 1942.

95 Auf die Wiedergabe dieser Aufstellung über drei Zwischenfälle vom 13.-16. 2. 1943 in Poltawa wurde verzichter; in Dok. 24 werden zahlreiche vergleichbare Fälle referiert. 
zwungen. Die körperliche Verfassung und die Uniformen der italienischen Truppen, die über mehrere Wochen - oft vom Feind bedrängt - lange Strecken zu Fuß zurücklegen mußten, zeigten dagegen manifeste Spuren von Strapazen und Entbehrungen.

Der Major im Generalstabsdienst (Achille Mazzi)

AUSSME, DS II 1551/5.

\section{Dokument 20}

Bericht des Kommandierenden Generals des XXXV. italienischen Armeekorps, Francesco Zingales, über das Verhalten der deutschen Verbündeten am Beginn und während des Rückzugs vom Don, März $1943^{96}$ [...]

V. Feindselige Haltung deutscher Offiziere und Soldaten gegenüber den Italienern von Werchne Makejewka bis Morosowskaja (21.-30. Dezember)

Von den ersten Kontakten mit den Deutschen in Werchne Makejewka an war es unverkennbar, daß sie einen kaum verhüllten Groll gegenüber den Italienern hegten, die als die Hauptverantwortlichen für den Rückzug angesehen wurden. Offenkundige Anzeichen einer solchen Haltung bemerkte man während des weiteren Rückzugs, den das Generalkommando des XXXV. mit dem XXIX. deutschen Armeekorps zwischen dem 24. und dem 30. Dezember von Kijewskoje bis Morosowskaja vollzog ${ }^{97}$, bei zahlreichen Anlässen. Von diesen Anzeichen werden die wesentlichsten im folgenden aufgezählt:

1. Offiziere und Mannschaften trugen eine ostentative Gleichgültigkeit zur Schau oder verhielten sich offen feindselig, indem sie vortäuschten, die höheren Dienstgrade unseres Heeres nicht zu erkennen, und es systematisch unterließen, sie zu grüßen. Außerdem antworteten sie undiszipliniert und grob auf Fragen, die Offiziere an sie richteten.

2. Es war häufig möglich, Fetzen von Gesprächen in deutscher Sprache zwischen Offizieren und Soldaten aufzuschnappen, die hinsichtlich unserer Haltung während der Schlacht am Don beleidigend waren und versteckte Drohungen für die Zukunft enthielten.

96 Im AUSSME, DS II 1555/1, findet sich ein 79 Seiten umfassender, auf den Januar 1943 datierter Bericht des XXXV. Armeekorps (Ufficio Operazioni) über die Ereignisse vom 25. 11.-31. 12. 1942, der von General Zingales gezeichnet ist. Darüber hinaus hielt es Zingales offenbar für nötig, einen auf März 1943 datierten Sonderbericht (Comando XXXV Corpo d'Armata - Ufficio Operazioni: „Relazione sul contegno degli alleati tedeschi all'inizio e durante il ripiegamento ") anzufertigen, der noch einmal 37 Seiten und einige Anlagen umfaßt und von dem hier die letzten beiden Kapitel abgedruckt werden.

97 Vgl. dazu - aus deutscher Sicht - Dok. 10 sowie die kommentierenden Anmerkungen zu diesem Dokument. 
3. In den täglichen Besprechungen zwischen Offizieren des Generalkommandos des XXXV. Armeekorps und deutschen Offizieren zu dienstlichen Zwecken (Bewegungen, Feindlage, Nachschub, Vorstellungen über den weiteren Gang der Operationen usw.) war ein systematischer Widerwille festzustellen, uns auch nur in der geringsten Weise zu unterstützen, obgleich unsere zwingenden Bedürfnisse bekannt waren.

4. Das deutsche Kommando hat ständig versucht, den Kontakt mit uns zu vermeiden, um uns über seine wirklichen Absichten bezüglich der nächsten Etappe im Dunkeln zu lassen.

5. Das willentliche und vollständige Desinteresse am Schicksal unserer höheren Offiziere, die aufgrund eiserner Notwendigkeit (Umfüllen von Benzin aus einem Kraftfahrzeug in ein anderes) ohne Transportmittel geblieben waren, ist in unanfechtbarer Weise deutlich geworden: Man verweigerte unseren Offizieren einen Platz in den Mannschaftstransportern, obgleich einige zur Verfügung standen und obgleich man wußte, daß eine Strecke von 55 Kilometern zu Fuß zu bewältigen war. Die unfreundliche Form der Verweigerung [unserer Bitte] ist der beste Beweis dafür, daß man einen wirklichen Groll gegen uns hegte, der bei jeder Gelegenheit zum Ausdruck kam.

6. Auch hinsichtlich des Transports unserer Verwundeten in deutschen Krankenwagen legte man uns Hindernisse jeglicher Art in den Weg.

Kurzum, die unfreundliche, bisweilen unfaire Form des täglichen Umgangs, aber auch das systematische Infragestellen all unserer Bedürfnisse mußten als Anzeichen für eine weit verbreitete feindselige Stimmung gelten. Die Ursache für eine solche Stimmung liegt in der grundlosen Überzeugung, daß die gesamte Verantwortung für den Rückzug aus den Stellungen am Don aufgrund ihres dürftigen Widerstands den italienischen Truppen zugeschrieben werden müsse. Die Vermutung, daß diese Stimmung künstlich aufrechterhalten wird, um die Moral und die Widerstandskraft der deutschen Truppen zu stärken, ist überaus glaubhaft.

Am 24. Dezember hatte ich eine lange Unterredung mit dem Kommandeur des XXIX, deutschen Armeekorps [Hans von Obstfelder], mit dem ich folgende Fragen besprochen habe:

a) Haltung der Deutschen gegenüber den Italienern;

b) Unterstellung des XXXV. Korps unter das XXIX.;

c) Erkundung von Perwomajskoje.

Hinsichtlich dieser Fragen führte ich aus:

a) Der Rückzug von der Front am Don hatte sich [im Abschnitt] von Werch. Mamon bis Weschenskaja vollzogen, wo italienische, rumänische und deutsche $\mathrm{Di}$ visionen eingesetzt waren ${ }^{98}$. Die versprengten Soldaten der letztgenannten hatten - von Nowo Astachoff [kommend] - Annenskij erreicht (61. und 62. deutsche Division ${ }^{99}$ ). Deshalb war es nicht angebracht, nur von italienischen Versprengten zu sprechen. Die Gründe für den Rückzug lagen in den allgemeinen Dispositio-

98 Es handelte sich um Divisionen des II. und XXXV. italienischen Armeekorps, des XXIX. deutschen Armeekorps und der Gruppe Hollidt.

99 Hier liegt ein Irrtum vor; die 61. Infanteriedivision stand bei der Heeresgruppe Nord im Raum Leningrad. 
nen für die Verteidigung und im wesentlichen in der linearen Besetzung [der Front] ohne Eingreiftruppen und Reserven.

b) Der Frontabschnitt des II. Armeekorps, wo sich die Lücke aufgetan hatte, wurde nicht nur von zwei italienischen Divisionen, sondern auch von zwei deutschen Divisionen verteidigt ${ }^{100}$. Eine weitere Lücke ergab sich bei den Divisionen Celere und „Sforzesca“: beide Divisionen unterstanden dem XXIX. deutschen Armeekorps. Die einzigen Divisionen, die ihre Positionen gehalten haben: die „Pasubio“, die vom Feind heftig angegriffen wurde und deren Stärke in zehn Kampftagen auf unter 25 Prozent gesunken war ${ }^{101}$, außerdem die beiden vom Feind nicht angegriffenen Divisionen, d.h. die "Torino" und die 298. deutsche Division. Deshalb war das Verhalten der Deutschen gegenüber den Italienern als den [angeblichen] Verantwortlichen der Katastrophe unberechtigt, schädlich und verbrecherisch.

c) Das XXXV. Korps hatte aufgrund des tapferen Widerstands, den es am Don geleistet hatte, und infolge der vor dem Rückzug erhaltenen Befehle (anderes Unterstellungsverhältnis der 298. Division, Aufgabe der Artillerie wegen Mangels an Betriebsstoff, Wechsel des von den vorgesetzten Stellen angeordneten Marschziels) an Kampfstärke verloren.

d) Der Befehl zur Erkundung von Perwomajskoje hatte nur einen Zweck ${ }^{102}$ : das Wort „italienische Versprengte ${ }^{\alpha}$ in einen Befehl einzubauen, wobei man nicht umhin konnte zu spezifizieren „die dem XXIX. deutschen Armeekorps unterstanden“, wenn man schon nicht „rumänische und deutsche“ hinzufügen wollte. Die Unterredung zeigte Wirkung: Es wurde bestätigt, daß die Führungsoffiziere des XXXV. Korps und der „Pasubio“ dazu eingesetzt werden sollten, die Versprengten zu sammeln und diese zu einem der Division „Sforzesca“ unterstehenden Regiment zu formieren; das Generalkommando des XXXV. Korps sollte eine eigene Gruppe im Gefolge des [Generalkommandos] des XXIX. bilden und wie dieses bereit sein, im Falle einer möglichen Gefangennahme die äußersten Konsequenzen zu ziehen; am Weihnachtstag wurden mit einer warmen deutschen Mahlzeit zum ersten Mal Lebensmittel ausgegeben ${ }^{103}$.

100 Neben dem Grenadierregiment 318 der 213. Sicherungsdivision waren hier die 27. Panzerdivision und die 385. Infanteriedivision eingesetzt.

101 Die Division „Pasubio" hatte zwar keinen Durchbruch zugelassen, aber den Donbogen von Ogolew aufgeben und sich bis zum 19.12.1942 auf eine Sehnenstellung zurückziehen müssen. Die Verluste der Division vom 1. 12.-19. 12. wurden mit 1900 Gefallenen und Vermißten und 5600 Verwundeten, Erkrankten und von Erfrierungen Betroffenen angegeben. $\mathrm{Vgl}$. $8^{\text {a }}$ Armata Italiana nella seconda battaglia difensiva del Don, S. 18 und S. 26 ff. Von deutscher Seite wurde die Lage bei der "Pasubio" nach den ersten Gefechten als bedrohlich und die Widerstandskraft der Division als gering eingeschätzt; BA-MA, MFB4 41403, Bl. 1074 und Bl. 1080, KTB des Deutschen Generals beim italienischen AOK 8, Einträge vom 16. 12. und 17. 12. 1942.

102 Nach der Schilderung im Sonderbericht des XXXV. Korps: „Relazione sul contegno degli alleati tedeschi all'inizio e durante il ripiegamento“ (AUSSME, DS II 1555/2) war der von der Führung des XXIX. Armeekorps wiederholt vorgebrachte Vorschlag, im mehr als 40 km vom aktuellen Standort entfernten Perwomajskoje versprengte italienische Truppen zu sammeln, für die Offiziere des XXXV. Korps deshalb ein solcher Affront, weil sie dieses Unternehmen angesichts der aktuellen Lage für ein ebenso sinnloses wie selbstmörderisches Himmelfahrtskommando hielten, das nur dem Ziel dienen konnte, sie loszuwerden.

103 Eine kurze Schilderung dieser Aussprache findet sich auch im Bericht des XXXV. Korps 
Die deutschen Verbindungsoffiziere berichteten ferner, daß der Kommandeur des [XXIX.] Korps ${ }^{104}$ die deutschen Offiziere am 29. Dezember versammelt und ihnen gesagt habe: „Die Rumänen und Italiener haben ihre Pflicht vollständig erfüllt und müssen deshalb so behandelt werden wie die Deutschen behandelt werden." Dies geschah [ $\mathrm{zwar}$ ] nicht genau so, aber der Satz beweist, daß es vor dem 29. nicht geschehen war ${ }^{105}$.

\section{Schlußfolgerung}

I. Schon vor dem Rückzug kam es aufgrund fehlender Kooperationsbereitschaft zweier deutscher Großverbände - der 298. Division und des XXIX. Armeekorps - gegenüber zwei italienischen Großverbänden - dem XXXV. Armeekorps und der Division „Pasubio“ -, die mit allen Kräften in der Verteidigungsschlacht am Don engagiert waren, zu Zwischenfällen. Dieser Mangel an Kooperationsbereitschaft hatte negative Auswirkungen auf den Rückzug des XXXV. Armeekorps, da die Division "Pasubio" und die dem XXXV. Armeekorps direkt unterstehenden Truppen von den deutschen Großverbänden auf den Flügeln überhaupt nicht unterstützt wurden und sich völlig dabei verschlissen, den Durchbruch am [Don-]Bogen von Ogolew zu verhindern, wobei sich die Verluste vom 1. bis zum 19. Dezember auf ganze 11000 Mann beliefen ${ }^{106}$.

Die Infanterie zahlte den höchsten Preis, so daß nicht mehr als 3000 Infanteristen des XXXV. [Armeekorps] die Verteidigungsstellungen hielten, als der Befehl zum Rückzug kam. Diese Sachlage wurde erschwert durch die von der deutschen Führung gewollte Ausdehnung des Sektors der 298. deutschen Division auf die halbe Front der "Pasubio" mit der daraus folgenden teilweisen Unterstellung der Infanterie des XXXV. [Armeekorps] (ungefähr ein Drittel) unter diese Division ${ }^{107}$. Da sich diese Teile aufgrund der folgenden Ereignisse nicht wieder mit dem Armeekorps vereinigen konnten, ergab es sich, daß das XXXV. [Armeekorps] zu Beginn des Rückzugs insgesamt über 2000 Infanteristen verfügte, die den unterschiedlichsten Verbänden angehörten (I./79. [Infanterieregiment], 80. Infanterie[regiment], Brigade $n 3$ Gennaio “, 4. Baubataillon, Eingreif-

(Ufficio Operazioni) über die Ereignisse vom 25.11.-31. 12. 1942 (AUSSME, DS II 1555/1). Die Deutschen hätten sich daraufhin zumindest formal korrekter verhalten, auch wenn es noch vereinzelt zu $Z$ wischenfällen gekommen sei.

104 In der Vorlage: „XXXV ${ }^{\circ}$ Corpo “. Da der Kommandierende General des XXXV. Armeekorps jedoch Zingales selbst war, kann hier nur das XXIX. deutsche Armeekorps gemeint sein.

105 Der italienische Satz "ciò precisamente non avvenne " läßt zwei Lesarten zu und bedeutet entweder, daß die Anordnung des deutschen Generals nicht vollständig ausgeführt worden sei, oder aber, daß man sie überbaupt nicht vollzogen habe. Der Kontext legt jedoch die erstere Variante nahe.

106 Auch der Bericht des XXXV. Armeekorps (Ufficio Operazioni) über die Ereignisse vom 25. 11.-31. 12. 1942 (AUSSME, DS II 1555/1) gibt die ungefähre Höhe der Verluste der italienischen Truppen des XXXV. Korps vom 1. 12.-19. 12. 1942 mit 11100 an, davon knapp 2300 Tote und Vermißte.

107 Diese Entscheidung, die mit einer kurzzeitigen Unterstellung der 298. Infanteriedivision unter das II. Korps einherging, traf das AOK 8 angeblich auf höhere Weisung am 18. 12. 1942; General Zingales war darüber deshalb so erbost, weil er damit praktisch ausgeschaltet wurde. AUSSME, DS II 1555/1, Bericht des XXXV. Armeekorps (Ufficio Operazioni gez. Francesco Zingales) über die Ereignisse vom 25. 11.-31. 12. 1942. 
bataillon Pioniere, 16. Gaskompanie, 15. Sturmpionierbataillon, Stabsquartier Division „Pasubio“, 1. Kradschützenkompanie) und wegen des Verschleißes im Zuge der langen Kämpfe am Don in ihrer Kampfkraft geschwächt waren.

II. Die willkürliche Abänderung der Rückzugsbefehle der 8. Armee durch das XXIX. Armeekorps führte

- für das XXXV. Armeekorps zum Verlust des einzigen intakten Verbands, der ihm geblieben war, die 298. deutsche Division, so daß dem auf die bloßen Reste der "Pasubio" und der Korpstruppen reduzierten Armeekorps nach menschlichem Ermessen jede Möglichkeit genommen wurde, den Bewegungskrieg anzunehmen, den die Lage erzwang, wie sie sich in der Nacht zum 20. Dezember herausgebildet hatte;

- zu einer Verlängerung des Rückzugsweges des Armeekorps ${ }^{108}$, was aufgrund der beschränkten Verfügbarkeit von Betriebsstoff zum Verlust des größten Teils der Artillerie des XXXV. [Armeekorps] führte und eine weitere entscheidende Reduzierung der Kampfkraft des Armeekorps bedingte.

III. So wie das XXXV. Armeekorps vor allem aufgrund der Entschlossenheit seines Kommandeurs die ihm anvertraute Linie am Don um jeden Preis verteidigt und damit den Durchbruch überlegener Feindkräfte verhindert hatte, erreichte es trotz der schwierigen Bedingungen auch dieses Mal das ihm zugewiesene Ziel, von dem man annahm, es sei vom Oberkommando der 8. Armee vorgegeben worden. Und am Morgen des 20. Dezember befand sich das Generalkommando des XXXV. [Armeekorps] mit den Kräften, die es unmittelbar mit sich hatte führen können, am Ziel: im Raum Awakusch.

IV. Von diesem Moment nahm der Mangel an Kooperationsbereitschaft und Kameradschaftsgeist der deutschen Großverbände und insbesondere des Generalkommandos des XXIX. Armeekorps ein solches Ausmaß an, daß man glauben konnte, man wolle das Generalkommando des XXXV. [Armeekorps] bewußt in Schwierigkeiten bringen: Ein erstes Mal, als man die kleine Kolonne des XXXV. [Armeekorps] (1200 Italiener und Deutsche) am 20. Dezember in Schapiloff in einer äußerst schwierigen Lage ohne Beistand ließ, obgleich es bei der rund 35000 Mann zählenden Masse, die in Popowka konzentriert war und dem XXIX. Armeekorps unterstand, ein leichtes gewesen wäre, sich einen Weg zu bahnen, um ihr zu Hilfe zu eilen. Ein zweites Mal am 21. Dezember in Werchne Makejewka, als man die Kolonne des XXXV. [Armeekorps] in der von jeder Verteidigung entblößten Ortschaft zurückzulassen versuchte, nachdem man dieser Kolonne alle deutschen Kräfte, die mit den einzigen Panzerabwehrkano-

108 Die 298. Infanteriedivision wurde am 19.12.1942 dem XXIX. deutschen Armeekorps unterstellt, wodurch das XXXV. italienische Armeekorps außer den Korpstruppen nur noch über die Reste der Division "Pasubio“ verfügte. Ursprünglich war vorgesehen gewesen, das XXXV. Korps mit der Division "Pasubio" in eine neue Verteidigungsstellung an der Tichaja zurückzunehmen, dann erhielt das Korps jedoch über das deutsche XXIX. Armeekorps den Befehl, sich weiter nach Nordwesten zurückzuziehen, um die linke Flanke der TichajaStellung zu decken. Aufgrund der geringen Treibstoffvorräte war es jedoch unmöglich, dieses wesentlich weiter entfernte Ziel mit der Masse der Fahrzeuge und Geschütze zu erreichen. AUSSME, DS II 1555/1, Bericht des XXXV. Armeekorps (Ufficio Operazioni) über die Ereignisse vom 25. 11.-31. 12. 1942. 
nen bewaffnet waren, die sie besaß, entzogen hatte. Das dritte Mal, als man am 22. und 23. Dezember dem Generalkommando des XXXV. [Armeekorps] die Verlegung - zunächst allein, dann mit einer Eskorte von 120 Mann und zwei Geschützen 75/27 - in den Raum Perwomajskoje, wo von Tausenden Partisanen unterstützte russische Panzer gemeldet worden waren, aufzuzwingen versuchte, um einen hypothetischen Sammelpunkt für versprengte Italiener einzurichten.

V. Und als hätte all dies noch nicht gereicht, führte man unter den deutschen Truppen des XXIX. Armeekorps eine heimtückische und unverschämte Verleumdungskampagne, die darauf zielte, die Schuld am unglücklichen Ausgang der Schlacht am Don allein den Italienern zuzuschreiben. Während des gemeinsamen Rückzugs, der sich zwischen dem 22. und 30. Dezember im Gefolge der Kolonne des XXIX. [Armeekorps] vollzog, gab es zahlreiche Hinweise darauf, daß eine solche Propaganda existierte.

Der italienische Soldat mit seiner lebhaften intuitiven Intelligenz sieht den Dissens zwischen der deutschen und der italienischen Militärführung deutlich und beurteilt den hochmütigen Stolz, den unnachgiebigen Egoismus und die spärliche Bereitschaft der Deutschen zur militärischen Zusammenarbeit mit den Italienern in ihrer ganzen Tragweite. Sein edler Geist veranlaßt ihn, im höchsten Interesse viel zu verzeihen. Allerdings verzeiht er nicht, daß der Deutsche angesichts des großmütigen Opfers vieler Italiener herausstreicht, wie bedeutsam die Unterstützung (wenn er sie nicht verweigert) durch seine überlegene Bewaffnung ist - im wesentlichen durch Panzer und Sturmgeschütze, welche die Waffen sind, die man zum Sieg an dieser Front benötigt. Deshalb besteht ein Gefühl des Grolls, das sich zunächst auf die hohen Offiziere beschränkte, jetzt aber - als Folge der Erfahrungen und Beobachtungen aus der letzten Schlacht - auch bei den unteren Dienstgraden und bei den Mannschaften verbreitet ist.

Der gegenwärtige Kampf entscheidet über Leben und Tod der beiden verbündeten Völker. Es ist deshalb nötig, daß sie sich während der Schlacht in spontaner Großmut und ohne Hochmut oder Ausdruck von Dominanz zu einem Amalgam verbinden, nur den Sieg als einziges Ziel verfolgen und ein jeder großzügig und ohne Aufrechnung gibt, was er kann. Hierbei handelt es sich um ein grundsätzliches Problem, das vollständig gelöst werden muß, ohne Ausflüchte und ohne Zögern, vor allem aber ohne Kompromisse. Nur so kann das Amalgam zwischen den beiden Völkern zu einem entscheidenden Faktor für Stärke und Sieg werden.

Deshalb ist es nicht nur sinnvoll, sondern erscheint geradezu als Pflicht, genau über die Tatsachen zu berichten, die Meinungsverschiedenheiten präzise darzulegen und deren Gründe herauszuarbeiten. Nur so gelangt man zu jenem tätigen Kameradschaftsgeist als wertvollem Beitrag und unabdingbarem Element des Sieges, der nicht nur auf Worten beruht, sondern von Taten geheiligt wird und von spontaner, auf Gegenseitigkeit beruhender Großmut inspiriert ist. Der Krieg muß von den Deutschen und den Italienern gewonnen werden. Die Deutschen werden ihn alleine nie gewinnen, und die Italiener werden ihn alleine nie gewinnen können.

Der Kommandierende General des Armeekorps (Francesco Zingales) 


\section{Dokument 21}

Bericht des Kommandierenden Generals des II. italienischen Armeekorps, Giovanni Zanghieri, über den Einsatz in der Sowjetunion 1942/43 vom 30. April 1943109

\section{$[\ldots]$}

Verhalten der Deutschen uns gegenüber während des Feldzugs an der Ostfront 1942-1943

Man kann ehrlicherweise nicht sagen, daß das Verhalten, das die deutschen Streitkräfte unseren Truppen gegenüber in Rußland mehrheitlich gezeigt haben - von einigen besonderen Anlässen abgesehen -, besonders entgegenkommend gewesen ist. Unverständnis, Übergriffe, Unhöflichkeiten und Gewaltakte gab es zuhauf, und darüber haben schon andere berichtet. Diese Haltung löste bei den Unsrigen, die jedoch durch entschlossenes Auftreten und Gewaltandrohungen ihrerseits rasch wieder für Parität gesorgt haben, zunächst Überraschung und Unmut aus. Allerdings ist nicht daran zu zweifeln, daß die Rußlandheimkehrer - zumindest was die Streitkräfte des Verbündeten angeht - nicht deutschfreundlich sind.

Dieses [den Italienern gegenüber ablehnende] Verhalten rührt insbesondere bei den einfachen deutschen Soldaten von der ihnen eingeimpften Überzeugung her, daß der deutsche Soldat der beste und am besten bewaffnete der Welt sei, und deshalb betrachteten sie die Italiener, Ungarn und Rumänen als "Hilfstruppen “. Nach den ersten Rückschlägen hat sich die Haltung insbesondere bei den njungen Soldaten" natürlich geändert, aber nur für kurze Zeit. Auf jeden Fall ist der deutsche Soldat ein guter, disziplinierter und kaltblütiger Kämpfer, der auf sich selbst und seine Führer vertraut, der gut ausgerüstet und ausgezeichnet bewaffnet ist (viele deutsche und russische automatische Waffen; wenige Gewehre, viele Panzerabwehrwaffen etc. pp.). Er wird von erfahrenen, gedrillten und angesehenen Unteroffizieren gut geführt, die indirekt auch jenen Reserveoffizieren Autorität verleihen, die ohne sie nicht den notwendigen Einfluß hätten.

Es ist ein großer Vorzug der vom Feind angegriffenen Verbände, daß sie sich (wie soll man sagen?) "nicht im Stich gelassen fühlen“, d.h., daß sie sich von den Russen ruhig umgehen und umzingeln lassen, ohne die Stellungen aufzugeben. Es sei hinzugefügt, daß der Russe dem „leeren Raum" gegenüber bisher sehr unentschlossen gewesen ist, und daß er erst in letzter Zeit vom Gegner lernt, „die Kessel auszuräumen “. Sind [die angegriffenen Verbände] abgeschnitten, vermögen sie, den Entsatz abzuwarten, und sie sind geschickt darin, sich gewaltsam einen Weg zurück zu bahnen.

Ein weiterer Grund für dieses Überlegenheitsgefühl des deutschen Soldaten und für die beschriebene Einschätzung der anderen als „Hilfstruppen“ liegt darin, daß der deutsche Soldat (abgesehen von den Pionieren) „kämpft, aber nicht arbeitet“. Alle Schanz- und Befestigungsarbeiten, der Ausbau von Unterkünften, die Straßen-

109 Der Bericht General Zanghieris "Il II Corpo d'Armata italiano al fronte russo (1942-1943) - relazione sintetica" umfaßt mit Anlagen rund 40 Seiten und ist in sieben Kapitel gegliedert, von denen hier das letzte wiedergegeben ist. 
arbeiten etc. pp. werden (entgegen den internationalen Konventionen) von den Gefangenen und der Zivilbevölkerung durchgeführt. Auch die Organisation Todt im rückwärtigen Gebiet dirigiert und überwacht, setzt aber [bei der Durchführung von Arbeiten] auf dieselben Methoden. Ich habe am Don (bei der mir unterstellten 294. deutschen Division) gesehen, wie die Gefangenen in Sichtweite der russischen Kameraden, die auf sie schossen, unter der Aufsicht eines einzigen deutschen Unteroffiziers arbeiteten 110 und wie die von zwei gefangenen russischen Ingenieuren (Unteroffizieren) geleiteten Arbeiten zur Verlegung des Divisionskommandos unter die Erde allein von russischen Soldaten als Arbeitskräfte und gänzlich ohne Aufsicht vorangebracht wurden"11.

Ich habe verschiedene deutsche Divisionen befehligt, auch im Gefecht. Abgesehen von der 294. [Infanteriedivision], die von Anfang an viel Kameradschaftsgeist und perfekte Unterordnung bewiesen hat, neigten die anderen vor allem anfänglich dazu, auf eigene Faust Krieg zu führen. Nach einem energischen Vorstoß beim Kommandeur und beim jeweiligen deutschen Verbindungsoffizier (normalerweise ein Oberst i.G.) hat sich alles eingerenkt. Gute Mannschaften, gute Kommandeure, aber alle mit der Neigung, die härtesten Aufgaben den italienischen Kameraden zu überlassen, um dann zur "Rettung der Lage“ hinzustoßen zu können, nachdem sich die Verbündeten bis zum letzten Heller verausgabt hatten. Mit mir konnten sie dieses Spiel beim [II.] Armeekorps freilich nie spielen. Im größeren Rahmen ist leider, wie bekannt, niemand gekommen, um die Lage zu retten, nachdem auch der letzte Heller ausgegeben worden war.

Oftmals kamen Offiziere des deutschen Oberkommandos und der Heeresgruppe „zu Besuch" an die Front und zögerten zunächst nicht, unnötige Ratschläge zu erteilen, die im übrigen bewiesen, welch geringe Meinung sie von den italienischen

110 Die 294. Infanteriedivision wurde dem II. Armeekorps unterstellt, das am 16.8.1942 den Befehl über einen Frontabschnitt am Don übernahm; am 20. 9. 1942 trat die Division unter den Befehl des Alpinikorps. AUSSME, DS II 785, KTB II. Armeekorps, Juli/August 1942, Anlage 121: Comando $\mathrm{II}^{\circ}$ Corpo d'Armata (Ufficio Operazioni) an die unterstellten und benachbarten Verbände vom 16. 8. 1942 (Nr. 2156/02 di prot.), und DS II 974, KTB Alpinikorps, September/Oktober 1942, Anlage: Befehl der 294. Infanteriedivision (Abt. Ia 840/42 geh.) für die Ablösung der Division vom 18. 9. 1942.

111 Während der Arbeitseinsatz von Kriegsgefangenen an der Front im Bereich des II. Korps ausdrücklich untersagt worden war (AUSSME, DS II 787, KTB Division "Ravenna", Juli/ August 1942, Anlage 302: Anweisung des Kommandos der Division "Ravenna" (Ufficio Operazioni e Servizi - Nr. 912/Op. di prot. segreto) vom 24. 8. 1942), wurden sie im Bereich des XXXV. Korps zur Anlage von Befestigungen herangezogen (DS II 876, KTB Division "Pasubio", Juli/August 1942, Anlage 232: Anweisung des Kommandos der Division "Pasu-

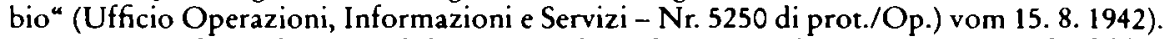
Der Kommandierende General des XXIX. deutschen Armeekorps, Hans von Obstfelder, ließ die italienischen Divisionen in seinem Befehlsbereich wissen, man müsse alle Kriegsgefangenen und alle Zivilisten zum Arbeitseinsatz in der vorderen Linie heranziehen. In diesem Zusammenhang wurde er mit den Worten zitiert: „Man muß nicht allzu zimperlich mit den Gefangenen und Zivilisten umgehen. “ DS II 976, KTB Division „Pasubio“, September/ Oktober 1942, Anlage: "Argomenti trattati nel rapporto tenuto dall'Eccellenza il Comandante il XXIX Corpo d'Armata germanico il giorno 26 ottobre 1942 in località Getreide". Zum Arbeitseinsatz von Kriegsgefangenen und Zivilisten bei den Fronttruppen der Wehrmacht vgl. Rass, Menschenmaterial, S. 360-378. 
Kommandos und Generalstäben hatten ${ }^{112}$. Angesichts unserer Reaktionen und der Feststellung der Tatsachen hat sich dies aber anschließend völlig gewandelt.

Gleichgeblieben ist aufgrund der atavistischen deutschen Tendenz, an einst guten Ideen festzuhalten (auch wenn sie wegen der veränderten Lage heute nicht mehr zeitgemäß sind), dies: alle Truppen auf einer überbreiten Front in die Kampflinie zu beordern, ohne sich allerdings um strategische Reserven in der Tiefe zu kümmern; an der im wesentlichen inaktiven (von mir gegenüber den Emissären der deutschen Oberkommandos wiederholt mißbilligten) Verteidigung [der Positionen] am Don festzuhalten, auch als er kein Hindernis mehr darstellte, und weiterhin zu glauben, die Russen würden nicht angreifen, obgleich sie Truppen zusammenzogen (unglaublich, aber wahr), und sich im Kampf wie letztes Jahr verhalten, ohne irgend etwas vom Feind gelernt zu haben.

Ich glaube, daß sich einige dieser Emissäre noch nicht bewußt sind, daß, wenn das II. Armeekorps (wenn auch mit deutschem Beistand) das Wunder vollbringen konnte, fast eine Woche lang Widerstand zu leisten, dies [nur möglich] war, weil ich eine wenn auch nur minimale Tiefe[nstaffelung] beibehalten hatte, indem ich meine bescheidenen, aus Sturmtruppen (Schwarzhemden „ $\mathbf{M}^{* 113}$ ) bestehenden Reserven nicht an die Front beordert und den Divisionen erlaubt hatte, eine verkleinerte Divisionsreserve zu behalten.

Bei den unteren Rängen und bei den Komponenten [der deutschen] Landwirtschafts- und Wirtschaftsorganisation Tendenz, immer den Unsrigen die Schuld an verschiedenen $Z$ wischenfällen (Übergriffe, Diebstähle, Brände usw.) zu geben, die jedoch nach sofortigen Ermittlungen größtenteils auf die Deutschen, die ukrainische Polizei oder auf die Bevölkerung zurückfiel114.

Auf einer sehr viel höheren Ebene Tendenz (wie es während der letzten Großoffensive geschah), den Verbündeten die Schuld an den Rückschlägen zuzuschreiben. So habe ich anfänglich wiederholt sagen hören, daß der Grund für den Verlust von Stalingrad vor allem bei den Rumänen, ferner bei den Italienern und schließlich bei den Ungarn [zu suchen] sei, als ob es nichts mit ihnen [den Deutschen] zu tun gehabt hätte, daß die Flanke auch nach heftigen Angriffen ([3.] rumänische Armee und Teil der 8. [Armee]) und trotz des Zusammenziehens zusätzlicher Kräfte weiterhin

112 Als Beispiel für die bei den höheren italienischen Offizieren geradezu verhaßten deutschen Empfehlungen als Ergebnis von Truppenbesuchen vgl. BA-MA, MFB4 18035, Bl. 284-288, Memorandum des Deutschen Verbindungsstabs an das AOK 8 vom 2. 9. 1942. Am 17. 9. 1942 vermerkte das Kriegstagebuch des Deutschen Generals (MFB4 41403, Bl. 1031): „Aus weiteren Äußerungen des [Stabs-]Chefs [der 8. Armee] geht hervor, daß die Italiener den Austausch von taktischen Erfahrungen als unerwünschte Belehrung betrachten."

11? Dem II. Korps unterstand als Reserve die Schwarzhemden-Brigade "23 Marzo" mit sechs Bataillonen; vgl. Operazioni delle unità italiane al fronte russo, S. 607. Der Buchstabe $M$ stand für Mussolini und bezeichnete die für Kampfeinsätze vorgesehene Elite der faschistischen Miliz.

$114 \mathrm{Zu}$ diesem Konflikt $z$ wischen den Verbündeten und den damit verbundenen Anschuldigungen und Rechtfertigungen vgl. das Material in: BA-MA, MFB4 41403, Bl. 110-207; General Zanghieri war hier wie auch an anderen Stellen sichtlich darum bemüht, das Verhalten seiner Soldaten und sein eigenes Handeln im bestmöglichen Licht erscheinen zu lassen. Ein Soldat der zum II. Korps gehörenden Division "Ravenna" hielt in seinen Aufzeichnungen fest, seine Kameraden hätten auf dem Weg zum Don eine Spur der Verwüstung hinterlassen. Sobald die typischen grün-grauen italienischen Uniformen aufgetaucht seien, hätten die $\mathrm{Zi}$ vilisten ihr Eigentum versteckt und ihre Häuser verriegelt. Vgl. Rattenni, Tornerai, S. 65. 
von einer dünnen Linie ohne Reserven gedeckt wurde. Verbreitet die schäbige Tendenz, jede Gelegenheit zu nutzen, um zu erklären, daß die Verbündeten „davongelaufen" seien.

Ich übergehe die ungerechten Klagen über die "Sforzesca", weil die Division immer außerhalb des Armeekorps [eingesetzt] war und weil es [bereits] jemandem gelungen ist, für sie Genugtuung zu erhalten ${ }^{115}$. [Dagegen] verweile ich bei der anfangs (nicht nur von den Deutschen) angestellten ${ }_{n}$ Spekulation “ über die Panik, die am 19. Dezember aufgrund eines Vorstoßes russischer Panzer nach Kantemirowka eingetreten ist - ein Vorfall, der zunächst als Flucht des II. Armeekorps, dann anderer [Verbände] von der Front (!) gedeutet wurde ${ }^{116}$. In dieser Ortschaft, die im rückwärtigen Gebiet (60-80 km hinter der Kampflinie) im Territorium der Intendenza hinter dem Sektor des XXXV. Armeekorps (außerhalb des Gebiets des II. Armeekorps) lag, versammelten sich wegen der Kälte (-30 Grad), die in der Nacht den sicheren Tod bedeutet hätte, zusammen mit den Truppen der Intendenza (ungefähr 4000 Mann) im wesentlichen Unterstützungstruppen und Artillerie zu Fuß des II. (ungefähr $4300 \mathrm{Mann}$ ) und XXXV. Armeekorps (ungefähr $1000 \mathrm{Mann}$ ) sowie der Division Celere (ungefähr 300 Mann), weil sie den Befehl zum Rückzug erhalten und in ihren Territorien keine Einquartierungsmöglichkeiten gefunden hatten. Ein Vorstoß russischer Panzer, der von einem Partisanenaufstand unterstützt wurde, rief aufgrund des Mangels an jeglicher Voraussicht seitens des Ortskommandanten ${ }^{117}$ eine große Panik hervor, die eine Flucht der Lastwagen sowohl der Intendenza als auch der anderen Verbände und der Deutschen in Richtung Starobelsk zur Folge hatte (der erste, der von der Panik ergriffen wurde, scheint eben der Kommandeur des Logistikzentrums gewesen zu sein), wo sie vom Oberkommando unserer Armee angehalten, neu geordnet und nach Woroschilowgrad geschickt wurden.

Nun wurde dieser schmerzliche und ungerechtfertigte, aber erklärbare Vorfall in der Etappe zunächst in eine Art Flucht des Armeekorps umgedeutet, ohne zu be-

${ }^{115}$ Hier wird auf die Auseinandersetzungen um die Rolle der Division ${ }_{n}$ Sforzesca“ während der ersten Verteidigungsschlacht am Don angespielt; vgl. dazu S. $53 \mathrm{ff}$. dieses Bandes. Der von Zanghieri angesprochene ,jemand " war kein geringerer als Giovanni Messe.

116 Kantemirowka hatte dem II. Korps bis Ende Oktober 1942 als Hauptquartier gedient und beherbergte auch später Teile der rückwärtigen Dienste und Versorgungseinheiten des II. Korps. Aufgrund seiner verkehrsgünstigen Lage an der Bahnlinie Millerowo - Rossosch und der Straße nach Bogutschar hatte die Intendenza der 8. Armee hier einen der zentralen logistischen Stützpunkte errichtet, von denen aus die Divisionen an der Front versorgt wurden. Die chaotische Flucht der hier konzentrierten Einheiten und Dienststellen zog Untersuchungen und Rechtfertigungen nach sich; entsprechende Berichte finden sich etwa im AUSSME, DS II 1330, DS II 1563/10 und DS II 1557/1; letzterer Faszikel enthält den ausführlichen Augenzeugenbericht des Stabschefs der Intendenza, Oberstleutnant Luigi De Micheli, für General Biglino vom 25. 12. 1942, wo es heißt: „Aber plötzlich, kurz vor acht Uhr, verschärfte sich die Lage dramatisch: Als einige russische Panzer auf den umliegenden Hügeln auftauchten, breitete sich blitzartig eine unbeschreibliche allgemeine Panik aus. Ein Haufen von etwa 6000 Mann stürzte mit deutlichen Anzeichen kollektiven Wahnsinns in Richtung der Straße, die nach Belowodsk führt, wobei Waffen und Ausrüstung weggeworfen und die vorbeifahrenden Lastwagen gestürmt wurden. Aus den Häusern schossen vereinzelt Partisanen mit Gewehren, und die Masse der Fliehenden wurde zu einer Lawine, die alles fortriß.“

117 Francesco Pinzi, Oberst, Chef des für Kantemirowka zuständigen Comando Tappa Speciale 302. 
denken, daß es sich um Truppen handelte, die sich ordnungsgemäß ins rückwärtige Gebiet zurückgezogen hatten, die sich vor allem aus Unterstützungstruppen und Artillerie ohne Geschütze zusammensetzten und zahlenmäßig nur einen minimalen Teil (weniger als ein Fünftel) der Überlebenden des II. Armeekorps ausmachten, dann in eine Flucht der Intendenza (wegen des Verhaltens des Kommandeurs des Logistikzentrums), schließlich [auch in eine Flucht] des XXXV. Armeekorps. Die Wiederholung des Vorfalls unter fast analogen Umständen in Millerowo und die anschließende Flucht auch der Deutschen (die zum Teil am Donez von italienischen Truppen gesammelt wurden, unter denen sich als Ironie des Schicksals auch die aus Kantemirowka befanden) stutzte den $Z$ wischenfall auf angemessene Proportionen zurück und [ließ ihn] in günstigerem Liche [erscheinen].

Wenn richtig ist, was mir berichtet wurde, [haben] die Deutschen den Rumänen und Ungarn gegenüber ein ähnliches, aber noch schärferes Verhalten [an den Tag gelegt]. Dies erleichtert natürlich nicht die Aufgabe derjenigen, die den Soldaten den Umständen entsprechend davon überzeugen müssen, daß es für uns absolut notwendig ist, mit unserem Alliierten aufs engste verbunden zu sein und bis zum Sieg und darüber hinaus einen Block zu bilden.

General Giovanni Zanghieri

Kommandeur II. Armeekorps - Feldpost Nr. 20

AUSSME, DS II 1552/5.

\section{Dokument 22}

Bericht des Kommandeurs der Infanteriedivision "Torino“, General Roberto Lerici, über das Verhalten der deutschen Verbündeten vom 14. Mai 1943

An das

Dronero, 14. Mai 1943

Kommando des XXXV. Armeekorps (CSIR) - Führungsabteilung

Feldpost Nr. 88

Betreff: Haltung der deutschen Verbündeten

Aufgrund postalischer Probleme erreichte mich die Sendung dieses Kommandos mit den Schreiben 643/Op. und 662/Op. vom 15. bzw. 20. März ${ }^{118}$ erst gestern, am 13. Mai, und ich antworte daher mit Verspätung auf die an mich gerichteten Fragen.

$\mathrm{Zu}$ Beginn des Rückzugs unterstand die Division "Torino“ dem XXIX. deutschen Armeekorps. Dieses Unterstellungsverhältnis bestand seit ungefähr fünf Monaten ${ }^{119}$, in deren Verlauf unsere Beziehungen zu den Verbündeten immer von Herzlichkeit und Kameradschaft gekennzeichnet waren.

118 Nicht ermittelt.

119 Die Division „Torino“ übernahm am 9.8. einen Verteidigungsabschnitt am Don und unterstand seit dem 13. 8. 1942 dem XXIX. deutschen Armeekorps; AUSSME, DS II 788, KTB IR 82 (Division "Torino“), Juli/August 1942, Anlage 47: Tagesbefehl des Infanterieregiments 82 vom 10. 8. 1942, und DS II 785, KTB II. Armeekorps, Juli/August 1942, Anlage 
Kurz nachdem ich die Befehle zum Rückzug erhalten hatte (19. Dezember 1942) ${ }^{120}$, wurde jede Verbindung zum Kommando des XXIX. Armeekorps unterbrochen, und die Division "Torino " mußte auf eigene Faust handeln. Zur Erklärung dieses möglicherweise befremdlich erscheinenden Umstands gebe ich die $\mathrm{Be}$ merkungen aus meinem Tagebuchbericht wieder, den ich dem Oberkommando der 8. Armee am 28. Januar dieses Jahres übermittelt habe ${ }^{121}: \ldots$... Um 24 Uhr hört die Telephonzentrale von Meschkoff, die die Verbindung zum Kommando des XXIX. Armeekorps ermöglicht hatte, zu funktionieren auf. Von diesem Zeitpunkt an verliert die Division ,Torino' die Verbindung zum eigenen Armeekorps, weil sich das einzige Funkgerät, das eine solche Verbindung hätte aufrechterhalten können, im Besitz des deutschen Verbindungskommandos befand und am Morgen des 19. auf Befehl von Oberleutnant Böhm ${ }^{122}$, dem Chef des Kommandos, zerstört worden war, als dieser erfahren hatte, daß sich die Russen in Kalmykoff befanden. Diese vollkommen willkürliche Entscheidung, die getroffen worden war, ohne vorher das Divisionskommando zu hören, sollte später gravierende Auswirkungen auf den Verlauf der weiteren Operationen haben."

Bezüglich des deutschen Verbindungskommandos mache ich auf eine kuriose Geschichte aufmerksam, die meiner Division widerfahren ist. Als wir im Donezbecken in Verteidigungsstellung lagen, $d . h$. in einer relativ ruhigen operativen Lage, verfügte die "Torino" über ein beachtliches und perfektes deutsches Verbindungskommando, das reichlich mit Nachrichtengerät ausgestattet war und, was wichtiger ist, von einem kultivierten und fähigen Hauptmann befehligt wurde, der dem ehemaligen österreichischen Heer entstammte ${ }^{123}$. Zu Beginn des Vormarsches vom Donez zum Don wurde das besagte Kommando aufgelöst und so gut es ging durch neue Kräfte ersetzt, die schlecht ausgestattet waren, wenig Erfahrung hatten und nicht aufeinander eingespielt waren. So wurde die Situation gerade dann kritisch, als es nötig war, mit den deutschen Verbänden, die mit uns operierten, täglichen Kontakt zu halten.

102: AOK 8 (Prot. Nr. 02/2345 - gez. Bruno Malaguti) an die Korpskommandos, die Division „Cosseria“ und die Intendenza vom 10. 8. 1942.

120 Am 19. 12. 1942 mittags wies das XXIX. Korps die Division "Torino“ an, den Rückzug hinter die Tichaja einzuleiten (Funkspruch des XXIX. Armeekorps an die Division "Torino" vom 19. 12. 1942, 13 Uhr, abgedruckt in: Bedeschi (Hrsg.), Fronte russo, Bd. 1, S. 44 f.); aufgrund des raschen Vormarsches der sowjetischen Truppen widerrief das Korps diesen Befehl jedoch wenige Stunden später und ordnete den allgemeinen Rückzug in südwestlicher Richtung an. AUSSME, DS II 1555/9, Comando Divisione fanteria at. „Torino“, gez. Roberto Lerici: „Relazione sul ciclo operativo 19 dicembre 1942 - 17 gennaio $1943^{\text {“, }, ~ S . ~} 2$ f.; abgedruckt in: ebenda, S. 22-44.

121 AUSSME, DS II 1555/9, Comando Divisione fanteria at. "Torino“, gez. Roberto Lerici: „Relazione sul ciclo operativo 19 dicembre 1942 - 17 gennaio $1943^{4}$, S. 3; das hier wiedergegebene Zitat weicht geringfügig von der von Lerici angesprochenen Vorlage ab.

122 In der Vorlage: „Bomm“. Oberleutnant Böhm befehligte das DVK, da sich dessen Chef, Hauptmann Schlubeck, im Urlaub befand. Nach dem Gefechtsbericht des DVK zur Division "Torino" (BA-MA, RH 31 IX/35, Bl. 19-31) wurde die Funkstelle am Abend des 19. 12. 1942 zerstört, nachdem Böhm erfahren hatte, daß die "Torino" fast vollständig eingeschlossen war.

123 Die Zusammensetzung des DVK bei der Division "Torino“ in diesen Monaten war nicht zu ermitteln. 
Nach Beginn des Rückzugs mußte ich Kontakt zur deutschen Panzergruppe des Majors Hoffmann ${ }^{124}$ und zur 298. deutschen Division aufnehmen, die wie wir in den Raum Popowka marschiert waren. Die Beziehungen zu Major Hoffmann waren von Anfang an gut ${ }^{125}$, und es war einfach, sich in dem Sinne zu einigen, daß die "Torino“ der Panzergruppe folgen sollte, um durch die von ihr geschlagene Bresche zu entkommen. Allerdings sollte sie tausend Liter Treibstoff beisteuern, die den Zugmaschinen unserer Artillerie abgezapft wurden. Weniger angenehm waren die Beziehungen zur 298. Division (die sich wie wir die von der Panzergruppe geschlagene Bresche zunutze machen sollte), deren provisorischer Kommandeur ${ }^{126}$, wie ich mich erinnere, immer sehr beschäftigt war, wenn wir Kontakt aufnehmen mußten. Dieser Mangel an Verbindlichkeit in unseren Beziehungen hat sich nach und nach verstärkt, als die Schwierigkeiten während des Rückzugs zunahmen, und wäre in einen offenen Konflikt umgeschlagen, wenn die Verhältnisse, in denen wir uns fatalerweise befanden, nicht ein besonnenes Verhalten unsererseits nahegelegt hätten.

Genaue und detaillierte Angaben zu machen, fällt mir vor allem deshalb nicht leicht, weil der größte Teil derjenigen, die Übergriffe und Gewaltakte gesehen oder erlitten haben, nicht mehr unter uns (die "Torino" hat um die 90 Prozent ihrer Iststärke verloren ${ }^{127}$ ) oder jedenfalls nicht in meiner Nähe ist. Wenn man sich auf Episoden beschränkt, wäre es meines Erachtens nützlich, in den Lazaretten oder in den Zentren der Mobilmachung Nachrichten zu sammeln, wo die Rückkehrer von der russischen Front eingetroffen sind.

Es ist jedoch eine Tatsache, daß man die Feindseligkeit der deutschen Verbündeten uns gegenüber mit den Händen greifen konnte: Es war klar, daß die Deutschen uns die Schuld für das Geschehene zuschrieben und die verantwortlichen Kommandos, soweit ich weiß, nichts taten, um bei den Untergebenen eine solch willkürliche Interpretation der Ereignisse zu entkräften. Daraus ergab sich insbesondere seitens der einfachen deutschen Soldaten eine Reihe von Übergriffen, Anmaßungen und Gewaltakten, die noch dadurch verschärft wurden, daß die 298. Di-

124 Nicht ermittelt.

125 Trotz Differenzen, die es sowohl mit Major Hoffmann (Oberstleutnant Turrini, der Stabschef der Division "Torino" berichtete etwa, dieser habe den Kolonnen der Division bei Makarow mit einer "unerhörten Arroganz" die Durchfahrt verweigert; AUSSME, DS II 1555/11, Umberto Turrini: „Relazione circa l'attività svolta alla Divisione di fanteria ,To-

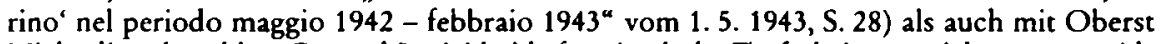
Michaelis gab, schlug General Lerici beide für eine hohe Tapferkeitsauszeichnung vor. Als General und Soldat könne er nicht anders, als die Professionalität und den Wagemut der beiden Offiziere herauszustreichen. AUSSME, DS II 1555/9, Comando Divisione fanteria at. "Torino“, gez. Roberto Lerici, an Italo Gariboldi vom 28. 1. 1943; abgedruckt in: Bedeschi (Hrsg.), Fronte russo, Bd. 1, S. $46 \mathrm{ff}$.

126 Herbert Michaelis (geb. 1897), Generalmajor, am 27. 12.1942 als Oberst mit der Führung der 298. Infanteriedivision beaufragt, 1944 Kommandeur der 95. Infanteriedivision, 1944-1955 sowjetische Kriegsgefangenschaft.

127 Nach den Angaben von Umberto Turrini (AUSSME, DS II 1555/11, „Relazione circa l'attività svolta alla Divisione di fanteria "Torino“ nel periodo maggio 1942 - febbraio $1943^{\circ}$ vom 1. 5. 1943, S. 44), zählte die „Torino“ zu Beginn des Rückzugs rund 11000 Mann, von denen nur etwa 1200 das sichere Starobelsk erreicht hätten. Das Ufficio Storico des italienischen Heeresgeneralstabs bezifferte die Verluste der "Torino" an Toten und Vermißten mit rund 5000; Operazioni delle unità italiane al fronte russo, S. 491. 
vision vorwiegend aus Sachsen ${ }^{128}$ (auch unter den Deutschen selbst für ihre Härte berüchtigt) bestand, außergewöhnlichste Bedingungen herrschten und sich die Unsrigen leider in einem Zustand befanden, daß sie kaum zu reagieren vermochten. Zu den größten Konflikten kam es über die Belegung der Isbas und die Nutzung der Transportmittel. Ich erinnere mich beispielsweise an die Schwierigkeiten, auf die ich in Arbusow 129 stieß (21.-23. Dezember), um vom deutschen Kommando eine Unterkunft für unsere Verwundeten zu erhalten; ich erinnere mich daran, daß jede nennenswerte Unterstützung mit Lebensmitteln für uns ausblieb, während sie [die Deutschen] warme Verpflegung verzehren konnten; ich erinnere mich an die Brutalität, mit der die Deutschen die Unsrigen zurückstießen, die am Ende ihrer Kräfte waren und versuchten, sich an ihre Schlitten anzuhängen - und all dies bei einer Temperatur von 30-40 Grad unter Null! Ich könnte in diesem Zusammenhang konkrete Episoden nennen. Ich werde davon Abstand nehmen, weil ich denke, daß das traurige Phänomen, von dem hier die Rede ist, unabhängig von der notgedrungen emotional aufgeladenen Stimmung des Einzelfalls betrachtet werden muß. D. h. man muß sich - immer meinem Dafürhalten nach - die Bedingungen in Erinnerung rufen, unter denen es zu diesen Ereignissen kam. Ich werde sie kurz ansprechen:

Allgemeine Rahmenbedingungen: vergleichbar mit denen in einem brennenden Theater oder einem sinkenden Schiff.

Mitwirkende: Italiener, Deutsche und Russen. Italiener: sehr zahlreich (zwischen fünfundzwanzig- und dreißigtausend in Popowka), schlecht ausgerüstet, aus Mangel an Benzin ohne Artillerie und Logistik, kaum Munition; zahlreiche Truppenteile bereits in Auflösung; Gesamteindruck [ließ auf] geringe Kampfkraft [schlieBen].

Deutsche: weniger zahlreich (acht- bis zehntausend in Popowka); gut ausgerüstet (gefütterte Tarnanzüge, Schuhwerk russischer Machart); Artillerie und Versorgungsdienste einsatzfähig, weil bespannt; Truppenteile in guter Ordnung; Gesamteindruck [ließ auf] gediegene Kampfkraft [schließen], die durch die Präsenz der Panzergruppe noch verstärkt wurde. Russen: durch die erzielten Erfolge wagemutig geworden; gut ausgerüstet; reichlich mit automatischen Waffen, Artillerie und Panzern versehen; beharrlich in ihren Angriffen, insbesondere von hinten und an den Flanken. Es ist klar, daß die Italiener unter diesen Bedingungen nur den kürzeren ziehen konnten.

Zum Abschluß dieser Bemerkungen zitiere ich, was ich diesbezüglich in meinem oben erwähnten Tagebuchbericht geschrieben habe: „... Im konkreten Fall war der

128 Die 298. Infanteriedivision war 1940 im Wehrkreis VIII (Breslau), also in Schlesien, aufgestellt worden.

129 Die Kolonne, die vor allem aus den Resten der Division "Torino“ und der 298. Infanteriedivision bestand, wurde am 21. 12. 1942 südwestlich des Flusses Tichaja in Arbusow eingeschlossen und konnte sich erst nach harten Kämpfen, unter schwersten Verlusten und der Zurücklassung aller nicht transportfähigen Verwundeten den Weg nach Westen freikämpfen. Wie Nikolajewka so hat auch Arbusow - das "Tal des Todes" - einen festen Platz in der kollektiven Erinnerung an die Campagna di Russia. AUSSME, DS II 1555/9, Comando Divisione fanteria at. "Torino", gez. Roberto Lerici: „Relazione sul ciclo operativo 19 dicembre 1942 - 17 gennaio 1943“, S. 8; L 13/202, Oberstleutnant Archimede Palazzo: Olocausto. Il "ripiegamento“ della Divisione "Torino“ nell'eco dei caduti e nella voce dei superstiti, S. 5. 
Schaden, den der rasche Zusammenbruch des inneren Zusammenhalts [der Einheiten und Verbände] verursacht hat, sehr schwer. Unter anderem hat der in der Tat wenig erbauliche Anblick unserer Truppenteile das Verhalten der Soldaten der 298. deutschen Division uns gegenüber noch mehr verhärtet, die - wenn auch unberechtigterweise - nicht umhin konnten, in uns eher eine Last denn eine Hilfe zu sehen. Von daher die Neigung [der Deutschen], uns unter dem Vorwand zurückzulassen, ihre tatsächlich sehr geordneten Bewegungen nicht zu behindern, während es in Wirklichkeit darum ging, uns stets die Nachhut bilden zu lassen, wodurch ihre Verluste begrenzt, unsere aber beträchtlich erhöht wurden. Es bedurfte der Tage von Tschertkowo ${ }^{130}$, damit die Deutschen der 298. [Infanteriedivision] zumindest teilweise ihre Meinung über die Qualitäten unserer Soldaten im Krieg änderten. ${ }^{* 131}$

Und weiter ${ }^{132}$ : „Während der Nacht (Arbusow 22.-23. Dezember) drängen die Russen von allen Seiten heran und konzentrieren das Feuer der automatischen Waffen, Granatwerfer, ,Katjuschas' und Kanonen auf die Masse unserer Männer, die ein leichtes Ziel darstellen, da sie gezwungen sind, im Freien zu bleiben, weil alle Häuser von den zuerst hier eingetroffenen deutschen Truppenteilen besetzt worden sind. Auch der Kommandeur der Division ,Torino' ist mit den Resten seines Kommandos gezwungen, draußen zu übernachten... Ohne mich zu befragen, läßt das deutsche Kommando gewaltsam die Tanks der wenigen noch zur Verfügung stehenden italienischen Kraftfahrzeuge leeren. Man braucht den Treibstoff für die Panzer. Ich protestiere gegen die Vorgehensweise..."

Es ist die unbarmherzige Wahrheit, daß in Ausnahmesituationen das Recht immer beim Stärkeren liegt. Damit will ich das Verhalten der Deutschen in dieser für unsere Streitkräfte dramatischen und außerordentlich harten Begebenheit keineswegs rechtfertigen. Wie es mir andererseits nicht im Traum einfallen würde, eine Person zu verteidigen, die Frauen und Kinder niedertrampelt, um sich vor den Flammen des brennenden Theaters zu retten. Ich möchte nur sagen, daß solche

130 In Tschertkowo, einem wichtigen logistischen Knoten an der Eisenbahnlinie von Millerowo nach Rossosch, hielt sich vom 20.12.1942-15.1.1943 ein von deutschen und italienischen Soldaten verteidigter Stützpunkt. Die Kolonne mit den Resten der "Torino“ und der 298. Infanteriedivision erreichte den Ort in der Nacht vom 25. auf den 26. 12. Lerici beschönigte hier die tatsächliche Lage. Nach dem Gefechtsbericht von Oberst Göller (BA-MA, MFB4 1835, Bl. 405-410) sei die Mehrzahl der Italiener unbewaffnet und damit keine große Hilfe gewesen. Die italienischen Quellen, auch der Gefechtsbericht Lericis für die Zeit vom 19. 12. 1942-17. 1. 1943 (hier S. 10-14) selbst (AUSSME, DS II 1555/9), geben ein zwiespältiges Bild von kämpfenden Freiwilligen und waffenlosen Verzweifelten; vgl. AUSSME, L 13/202, Console Italo Vianini (Schwarzhemden-Gruppe „Montebello“): Bericht über die Kampfhandlungen am 8./9.1. 1943 in Tschertkowo vom 15.2. 1943, die Erinnerungen (Epopea dei Carabinieri della "Torino") von Leutnant Attilio Boldoni (66. Sektion Carabinieri), in: Bedeschi (Hrsg.), Fronte russo, Bd. 1, S. 55-72, hier S. 66 ff., sowie Dok. 23.

131 Dieses Zitat ist nicht Lericis Gefechtsbericht selbst, sondern einer gesonderten Notiz entnommen, die er General Gariboldi am 28. 1. 1948 zusammen mit dem Bericht und einem persönlichen Schreiben zukommen ließ; AUSSME, DS II 1555/9. Die Notiz ist abgedruckt in: Bedeschi (Hrsg.), Fronte russo, Bd. 1, S. 48-52. Das hier wiedergegebene Zitat weicht geringfügig vom Original ab.

132 Dieses Zitat stammt wiederum aus Lericis Gefechtsbericht für die Zeit vom 19.12. 1942-17. 1. 1943, S. 6f. (AUSSME, DS II 1555/9), und weist im Vergleich mit dem Original leichte Abweichungen auf. 
Dinge geschehen, daß sie immer schon geschehen sind und auch in Zukunft immer geschehen werden. Wesentlich ist, alles uns Mögliche zu tun, damit wir nicht in eine [bedrohliche] Lage geraten, deren Folgen wir zu tragen haben.

Der Divisionsgeneral gez. Roberto Lerici

AUSSME, DS II 1555/9.

\section{Dokument 23}

Bericht über den Einsatz der Carabinieri der Division „Torino“ während des Rückzugs von Makarow nach Belowodsk vom 4. April 1943

Lage der 56. und 66. Sektion CC.RR. am 4. Dezember 1942 (Datum der Ankunft des Ersatzes)

Im Gebiet unter der Jurisdiktion der Division "Torino“ bestanden 13 Militärkommandanturen, um die Angelegenheiten der Zivilbevölkerung zu regeln ${ }^{133}$. Bei jeder Ortskommandantur war eine Carabinieristation - ein Mannschaftsgrad und zwei Carabinieri - mit den polizeilichen Aufgaben des Kampfes gegen die Partisanen und der Suppression der von Zivil- und Militärpersonen begangenen Straftaten errichtet worden ${ }^{134}$. Den wichtigsten Stationen der Sektionen (66. in Makaroff, Sitz des taktischen Kommandos der Division; 56. in Medowa, Sitz des Stabsquartiers und der Versorgungsdienste der Division) war das übrige Personal zugeteilt, darunter Fahrer, Kradfahrer usw.

Von der 56. Sektion eingerichtete Stationen: Bogomoloff - Sitz des Kommandos des 82. Infanterieregiments; Medowa - Sitz des Stabsquartiers, des Kraftwagentrupps, des [Feld-]Postamts, der Zahlmeisterei, der Leitung des Sanitätsdienstes mit Feldlazarett, des Kriegsgefangenenlagers; Kriniza - Sitz der 243. schweren Kraftwagentransportabteilung, eines aktiven und eines inaktiven Feldlazaretts; Karasejew Sitz der Nachschubeinheit, der Verwaltung, des Bäckereitrupps, eines inaktiven Feldlazaretts und des für die Ablösung zuständigen Etappenkommandos (diese Station wurde aus einem Unteroffizier und zehn Carabinieri gebildet); Krawzoff - Sitz einer Kommandantur im rückwärtigen Gebiet; Liman - desgleichen; Batowka desgleichen;

Von der 66. Sektion eingerichtete Stationen: Makaroff - Sitz des taktischen Kommandos der Division und des Kommandos der CC.RR.; Michajloff - Sitz des Kom-

133 Zur Organisation des rückwärtigen Gebiets der Division „Torino“ haben sich keine Dokumente erhalten. Zur Dislozierung der Division am 15.12. 1942 vgl. die von Umberto Turrini gezeichnete Aufstellung, die seinem Gefechtsbericht für die Zeit vom Mai 1942 bis zum Februar 1943 (AUSSME, 1555/11) beigefügt ist.

134 Nach den Erinnerungen von Boldoni, Epopea dei Carabinieri, in: Bedeschi (Hrsg.), Fronte russo, Bd. 1, S. 56, verfügte die 56. Sektion CC.RR. (mot.) unter der Führung eines Subalternoffiziers über acht Unteroffiziere und 57 Mann, die 66. Sektion CC.RR. (mot.), ebenfalls unter der Führung eines Subalternoffiziers, über sieben Unteroffiziere und 60 Mann. Koordiniert wurde die Tätigkeit der Carabinieri von einem bei der Division angesiedelten Kommando unter dem Befehl eines Hauptmanns. 
mandos des 52. Artillerieregiments; Ssuchoj Log - Sitz des Kommandos der Divisionsinfanterie; SSwch[?] - Sitz des Kommandos des 81. Infanterieregiments; Popowka - Sitz der Verteilungsstelle für Pioniermaterial; Klibnji - Sitz der 183. leichten Kraftwagentransportabteilung und des Treibstoff- und Schmiermittellagers.

Kraftfahrzeuge der Sektionen: Die bei den Kommandos der Sektionen gesammelten $\mathrm{Kraftfahrzeuge} \mathrm{befanden} \mathrm{sich} \mathrm{größtenteils} \mathrm{in} \mathrm{schlechtem} \mathrm{Zustand,} \mathrm{weil} \mathrm{sie} \mathrm{durch}$ den langen Gebrauch verschlissen waren. Die Lastwagen: abgenutzt, aber funktionstüchtig; die Personenkraftwagen: nicht betriebsbereit, weil defekt; die Krafträder: mit Ausnahme von dreien der 66. Sektion nicht betriebsbereit.

\section{Bericht}

\section{Lage vom 19. Dezember 1942 bis zum 17. Januar 1943}

Am 19. Dezember besetzten russische Panzer die Standorte Kriniza und Klibnji. Alarmbereitschaft und Verteidigungszustand in den anderen Standorten der Division. In Makaroff und Medowa wurde unter Einsatz von Carabinieri und Schreibern der Verteidigungsplan in Kraft gesetzt. Am Vormittag zogen sich das Kommando und das Hauptquartier des XXXV. Armeekorps sowie das Kommando der Division „Pasubio“ nach Medowa zurück, wo sie bis zum Abend blieben ${ }^{135}$. Um 17 Uhr des genannten 19. erreichte das Kommando der Division „Torino“ der Befehl des Kommandos des XXIX. deutschen Armeekorps, dem sie hinsichtlich des Einsatzes unterstellt war, auf neue Positionen südwestlich des Flusses Tichaja zurückzugehen ${ }^{136}$. Einige Stunden später machte der deutsche Verbindungsoffizier eigenmächtig das Funkgerät unbrauchbar [und zerstörte so] die einzige Verbindungsmöglichkeit mit dem XXIX. deutschen Armeekorps.

Den Kommandos der Stationen der CC.RR. wurde befohlen, sich mit den Ortskommandanturen zurückzuzichen. Dic Stationen von Krawzoff 137, Liman und Batowka erhielten keinen Rückzugsbefehl, weil diese Standorte noch nicht an das Telephonnetz angeschlossen waren. Das Divisionskommando ordnete den Rückzug in zwei Kolonnen an, die sich wie folgt zusammensetzten ${ }^{138}$ :

- Kommando und Versorgungsdienste der Division, 82. Infanterieregiment mit seinen Artilleriegruppen, Kommando des 52. Artillerieregiments;

- Infanteriekommando der Division, 81. Infanterieregiment mit seinen Artilleriegruppen.

Auf der Route des Divisionskommandos begannen aber am 19. bei Einbruch der Dunkelheit nicht enden wollende Kolonnen von Soldaten und Kraftfahrzeugen des Hauptquartiers des XXXV. Armeekorps, der Kommandos und Truppenteile der Division „Pasubio“, der Division „Ravenna“, der Schwarzhemden-Gruppen „Montebello“ und „Tagliamento “ und der 298. deutschen Division, gefolgt von der Panzergruppe Hoffmann, vorüberzuziehen. Auf dieser Straße (Karasejew - Maka-

135 AUSSME, DS II 1555/1, Bericht des XXXV. Armeekorps (Ufficio Operazioni-gez. Francesco Zingales) über die Ereignisse vom 25. 11.-31. 12. 1942, S. 45.

136 Vgl. dazu Dok. 22 mit Anm. 120.

137 In der Vorlage: "Kranzow“.

138 So auch Brigadegeneral Cesare Rossi, der stellvertretende Kommandeur der Division „Torino", in seinem Gefechtsbericht (hier S. 6) für die Monate Oktober 1942 bis Januar 1943 (AUSSME, DS II 1555/10). 
roff - Michajloff), einer einfachen Durchgangsstraße, verursachten die versprengten Soldaten auf dem Rückzug ein großes Durcheinander, und die Kraftfahrzeuge verursachten Staus, weil sie plötzlich wegen Motorschadens oder Benzinmangels ausfielen oder weil die Räder wegen fehlender Schneeketten durchdrehten. Dank des Einsatzes aller Offiziere der CC.RR. der Division (Leutnant Mantineo Francesco ${ }^{139}$ war am Abend des 19. mit der eigenen Sektion und nur zwei Lastwagen in Makaroff angekommen) und der verfügbaren Soldaten der Sektionen schaffte man es, obwohl man die ganze Nacht arbeitete, erst um 12 Uhr des 20., die Straße frei zu machen, und bot damit der Kolonne der Division "Torino" die Möglichkeit, nach Michajloff zurückzugehen.

Bevor man Makaroff verließ, wurden auf Befehl des Divisionskommandos die Korrespondenz und die Geheimdokumente sowie das gesamte Material vernichtet, das aus Mangel an Kraftfahrzeugen und Treibstoff nicht mitgeführt werden konnte. Die Sektionen begannen den Rückzug so nur mit jeweils zwei Lastwagen und drei Krafträdern. Ein Lastwagen, der sich versehentlich der Wagenkolonne des Kommandos des XXXV. Armeekorps angeschlossen hatte, brach am Abend des 19. auf und hatte das Glück, der Einkreisung zu entgehen; so wurden die Schreibstube und einige Soldaten der 66. Sektion in Sicherheit gebracht. Die übrigen Kraftfahrzeuge wurden während des Marsches vom 20. zum 21. [Dezember] aufgrund von Schäden, die man nicht sofort beheben konnte, zurückgelassen und zerstört.

Während eines kurzen Halts in Michajloff meldeten sich 35 Unteroffiziere und Carabinieri der Sektionen des XXXV. Armeekorps beim Kommando der CC.RR. der Division, die im Laufe der Nacht von den Russen angegriffen und gefangengenommen worden waren, als sie mit der Wagenkolonne des Hauptquartiers auf dem Rückzug waren. Nachdem die genannten Soldaten den ganzen Tag herumgeirrt waren, trafen sie zufällig auf die Kolonne der „Torino“; man gab ihnen zu essen, vervollständigte ihre Bewaffnung und Ausstattung und wies sie den Sektionen der Division zu. Bei dieser Gelegenheit berichteten einige Unteroffiziere, sie hätten im Morgengrauen der Gefangennahme des Herrn Major D'Ambrogi ${ }^{140}$ und des Herrn Hauptmann Boccuccilit beigewohnt; sie behaupteten, sie hätten gesehen, wie sie mit einer Gefangenenkolonne ins rückwärtige Gebiet der Russen abmarschiert seien.

Bei Einbruch der Dunkelheit brach die Kolonne der Division nach Popowka auf. Während dieses Transfers wurde der einzige Lastwagen der 66. Sektion, auf dem der Herr Leutnant Boldoni Attilio 142 fuhr, nach einem Motorschaden verbrannt, und die Soldaten zogen zu Fuß weiter. Der Lastwagen war mit dem Gepäck der Offiziere, den Lebensmitteln und der Munitionsreserve beladen. In Popowka waren in unbeschreiblicher Unordnung die versprengten Truppen der Divisionen „Pasubio“, "Ravenna“ sowie der beiden Schwarzhemden-Gruppen „Montebello" und "Tagliamento", die des Hauptquartiers des XXXV. Armeekorps und die Lastwagen zusammengedrängt, die während der Nacht dem russischen Angriff entkommen wa-

139 Nicht ermittelt.

140 Nicht ermittelt.

141 Möglicherweise Mario Boccucci (geb. 1907, gilt als gefallen bzw. in Gefangenschaft verstorben), Hauptmann im Generalkommando XXXV.

142 Attilio Boldoni, Leutnant, 1942/43 Chef der 66. Sektion (mot.) CC.RR. der Division „Torino". 
ren. In dieser Ortschaft vereinigten sich die beiden Kolonnen der Division „Torino“ wieder, und der Herr kommandierende General [Roberto Lerici] verfügte folgende Marschordnung: Panzergruppe Hoffmann, 298. deutsche Division, Division "Torino", Versprengte der anderen Großverbände ${ }^{143}$.

Entlang der Kolonne wurde die Artillerie verteils, und die Fußtruppen mußten an den Straßenrändern marschieren, um die Fahrzeugkolonnen zu schützen. Nach einem kurzen Kampf zwischen deutschen und russischen Panzern begann der Marsch, der von Vorhutgefechten mehrfach unterbrochen wurde und sich bis zum Morgengrauen hinzog. Während der Nacht und insbesondere während der Marschpausen überholten die versprengten Truppenteile nach und nach die Division „Torino" und brachten ihre Verbände durcheinander. Als man im Morgengrauen des 21. den Fluß Tichaja erreicht hatte und sich die Möglichkeit eines heftigen russischen Angriffs abzeichnete, war aus der Division "Torino" eine ungeordnete Kolonne geworden, die sich aus Soldaten aller Waffengattungen und Verbände zusammensetzte.

Es war also dringlich notwendig, die Truppen der Division zu sammeln, und die Aufgabe wurde vom Herrn General an Herrn Hauptmann Fazzi Enrico ${ }^{144}$ übertragen, der fast alle Soldaten der unterstellten Sektionen zusammenzog und den äußerst schwierigen Auftrag in Angriff nahm. Nach einigen Stunden harter Anstrengungen, die daraus resultierten, daß man in einer unorganisierten Masse von ungefähr 30000 Männern und inmitten eines Gewirrs von Schlitten und Kraftfahrzeugen arbeiten mußte, war die Aufgabe fast bewältigt, als die Soldaten aufgrund eines plötzlichen russischen Angriffs und des Abzugs der gepanzerten deutschen Kolonne von Panik ergriffen wurden und erneut auseinandersprengten. Die Kommandeure der Verbände der "Torino" begegneten dem feindlichen Angriff mit den Männern, die sie zu halten vermochten.

Hauptmann Fazzi stellte sich mit cinigen Carabinieri sofort an die Spitze der Kolonne der Versprengten und versuchte vergeblich, sie mit Waffengewalt aufzuhalten, um das zurückgelassene Gerät wiederaufnehmen zu lassen (Lastwagen und Artillerie). In der Zwischenzeit hatte sich Leutnant Mantineo mit den eigenen Soldaten an den Gegenangriffen beteiligt, die es möglich machten, mehrere Lastwagen, auf die man die Verwundeten geladen hatte, und einige Zugmaschinen mit Artilleriegeschützen in Marsch zu setzen. Ein Teil unserer angreifenden Truppen, alle Nach-

143 Am 20. 12. 1942 war in einer Lagebesprechung vereinbart worden, die Marschbewegungen der deutschen und italienischen Truppen zu koordinieren. Den Panzerfahrzeugen der Gruppe Hoffmann - nach einem deutschen Gefechtsbericht nur noch zwei Panzer und zwei Sturmgeschütze - kam dabei die Aufgabe zu, einerseits den Durchbruch zu erzwingen, andererseits die Marschkolonne gegen Panzerangriffe zu schützen. $\mathrm{Da}$ die Panzer und Sturmgeschütze jedoch nicht mehr über genügend Treibstoff verfügten, stellte die "Torino" 1000 Liter zur Verfügung, weshalb zahlreiche Fahrzeuge und Geschütze der Division zurückgelassen werden mußten. Den am 20.12. getroffenen Absprachen gemäß übernahm die "Torino" die Nachhut. BA-MA, RH 31 IX/35, Bl. 19-31, Bericht des Sonderführers Hamann über den Einsatz des DVK bei der Division "Torino" vom 17. 12. 1942-16. 1. 1943. General Lerici schilderte den Hergang der Ereignisse, nicht aber die Ergebnisse der Besprechungen, etwas anders; AUSSME, DS II 1555/9, Comando Divisione fanteria at. "Torino", gez. Roberto Lerici: „Relazione sul ciclo operativo 19 dicembre 1942 - 17 gennaio $1943^{4}$, S. 4.

144 Enrico Fazzi, Hauptmann, 1942/43 Chef der Carabinieri der Division „Torino“. 
zügler, die noch von der Straße aus Popowka herbeiströmten, viele Artilleriegeschütze und eine bedeutende Anzahl von Lastwagen mit Lebensmitteln, Munition und weiterem Material fielen in die Hand der Russen. In den Nachhutgefechten wurden einige Carabinieri - Feldwebel Masci ${ }^{145}$ und Leutnant Mantineo - verletzt, die man auf Lastwagen verlud.

Nach weiteren Angriffen, die man während des Marsches zu erleiden hatte, und nach Überwindung des heftigen Widerstandes in Ssmirnowskij traf die bereits beträchtlich dezimierte Kolonne in der Nacht vom 21. auf den 22. [Dezember] in Arbusow ein, wo sie eingeschlossen wurde. Als sich dort am Morgen des 22. zeigte, $\mathrm{da} ß$ die gepanzerten deutschen Truppenteile nicht ausreichten, um den konzentrischen Angriff der Russen abzuwehren, folgten die italienischen Soldaten dem Beispiel und Ansporn der Offiziere und setzten zu einem alles mitreißenden Sturmangriff mit dem Bajonett an, mit dem sie den Feind zwangen, sich überstürzt hinter die umliegenden Höhenzüge zurückzuziehen. Obgleich die italienischen Soldaten hungrig und müde waren, lösten sich den ganzen Tag über Angriffe, Gegenangriffe und Gegenstöße mit dem Bajonett ab und verursachten blutige Verluste.

Auch die Offiziere der CC.RR. der Division "Torino" (Leutnant Mantineo war nicht in Arbusow eingetroffen) nahmen an der Spitze von Abteilungen aus Carabinieri und Soldaten an den Kämpfen des Tages teil, machten viele Gefangene und erbeuteten viele Waffen. Im Laufe des Tages wurde Leutnant Boldoni von einem Granatsplitter am Fuß verletzt und viele Carabinieri fielen oder wurden verwundet. Während der Kämpfe vollbrachten die Carabinieri, die den Soldaten jederzeit zum Vorbild gereichten, zahllose tapfere Taten.

Unter anderem griff eine Gruppe von Carabinieri unter der Führung des Vicebrigadiere ${ }^{146}$ Antonelli Gino ${ }^{147}$ bzw., nachdem dieser verwundet worden war, des $\mathrm{Ca}_{\text {- }}$ rabiniere Capati Antonio 148 mit Handgranaten ein starkes feindliches $W_{1}$ derstandsnest an, wobei sie ein schweres Maschinengewehr erbeutete und einige Gefangene machte. Als überdies ein namentlich nicht bekannter Carabiniere sah, daß eine große Gruppe von Soldaten auf der Rechten der von Hauptmann Fazzi befehligten Abteilung unter dem heftigen feindlichen Feuer zurückwich, sprang er spontan auf ein in der Nähe herumstreifendes verschrecktes Pferd, warf sich mit wehender Trikolore und unter dem Ruf "Savoia“ im Galopp gegen den Feind, preschte dabei mitten durch die Gruppe und riß sie mit sich zum Gegenangriff. Wenige Augenblicke später fiel der heldenhafte Carabiniere vor den feindlichen Linien ${ }^{149}$.

Am Nachmittag des 22., nachdem sich die Verteidigungslinie in gewisser Weise stabilisiert hatte, befanden sich unsere Truppen aufgrund fehlender Munition in großen Schwierigkeiten. Als Hauptmann Fazzi dies sah, organisierte er den Munitionsnachschub, wobei er von den Carabinieri aus eigener Initiative unterstützt wurde. Unter heftigem feindlichen Beschuß sammelte er die Munition derer ein, die wegen Verwundungen oder Erfrierungen kampfunfähig waren, und verteilte sie auf

145 Umberto Masci (geb. 1905, gilt als gefallen bzw. in Gefangenschaft verstorben), Feldwebel in der 56. Sektion CC.RR. (mot.) der Division "Torino“.

146 Unteroffiziersdienstgrad der Carabinieri.

147 Gino Antonelli (geb. 1910, gilt als gefallen bzw. in Gefangenschaft verstorben), Angehöriger der 56. Sektion CC.RR. (mot.) der Division "Torino".

148 Nicht ermittelt.

$149 \mathrm{Vgl}$. S. $1 \mathrm{f}$. des vorliegenden Bandes. 
die verschiedenen Abschnitte der Kampflinie. Nachdem er diese Aufgabe bei Einbruch der Dunkelheit erledigt hatte, erreichte er das Divisionskommando und organisierte mit den verbliebenen Carabinieri den nächtlichen Wach- und Sicherheitsdienst für dieses Kommando.

Am nächsten Morgen, dem 23. [Dezember], ging der Feind zu einem äußerst heftigen Bombardement über. Da der Herr Divisionskommandeur deshalb einen neuen Großangriff der russischen Infanterie befürchtete, erstattete er den Offizieren Bericht. Nachdem er die ziemlich prekäre Lage erläutert hatte, ordnete er den Aufbau von Hundertschaften an, die sich jeweils aus Soldaten und Offizieren derselben Einheit zusammensetzen sollten; Ziel war es, die Verteidigungsanstrengungen zweckmäßig und wirksam zu gestalten. Auch die Carabinieri der verschiedenen Sektionen wurden vereinigt und halfen den Offizieren beim Aufbau der erwähnten Hundertschaften, die sich im Verlauf des Tages als äußerst nützlich erwiesen.

Am 23. Dezember bot das Tal von Arbusow einen schmerzlichen Anblick: der Boden war mit Leichen übersät, in der Nähe der Häuser, die als medizinische Versorgungsstellen vorgesehen waren, lagen Tausende von Verwundeten, dem Beschuß ausgesetzt, auf dem verschneiten Boden. Die wenigen Häuser der Gegend quollen vor Verwundeten über. Die Ärzte, denen es an chirurgischem Gerät, Medikamenten und Verbandsmaterial fehlte, versorgten die schwersten Verletzungen mit Behelfsmitteln (Rasierklingen eines Sicherheitsrasierers, Taschenmesser usw.) auf der Türschwelle. Die hungrigen Soldaten aßen das rohe Fleisch der Maultiere, die dem Bombardement zum Opfer gefallen waren, und stillten ihren Durst mit Schnee, während die deutschen Truppen regelmäßig ihre Ration verzehrten, die in den fahrbaren Küchen zubereitet wurde. Im Laufe des Tages blieben alle Last- und Personenkraftwagen liegen, obgleich sie voll mit Verwundenten waren, weil das deutsche Kommando den Treibstoff in den Tanks beschlagnahmte, um die Panzer und die Sturmgeschütze am Laufen zu halten ${ }^{150}$. Nachdem der Einschlicßungsring gesprengt war, nahm die italienisch-deutsche Kolonne am 23. Dezember um 22.30 Uhr den Rückmarsch wieder auf, wobei sie alle Verletzten zurückließ, die nicht zu Fuß zu gehen vermochten.

Eine Gruppe von ungefähr 3000 italienischen Soldaten, die in einem benachbarten kleinen Tal im Freien lagerten und auf Befehle warteten, wurde nicht von der Bewegung benachrichtigt und bemerkte erst gegen Mitternacht, daß die Kolonne abgezogen war. Sobald sich Hauptmann Fazzi, der sich bei der Gruppe befand, der Lage bewußt wurde, beschloß er aufzubrechen, und am 24. um ein Uhr wandte er sich unter Zuhilfenahme des Kompasses nach Norden, wobei er, gefolgt von den Carabinieri und einigen Hundert Soldaten, ein enges Tal durchquerte. Nach einigen Stunden Marsch bog die kleine Kolonne nach Westen ab und konnte sich glücklicherweise wieder mit der Hauptkolonne vereinigen. Das intensive Feuer aus Gewehren und automatischen Waffen wie auch die lauten Schreie, die wenige Minuten nach dem Abrücken zu hören waren und aus dem kleinen Tal kamen, lassen vermuten, daß der Feind diejenigen angegriffen hat, die noch unschlüssig vor Ort geblieben waren.

Der Marsch der deutsch-italienischen Kolonne ging ununterbrochen bis Tschertkowo weiter, wo sie am Morgen des 26. Dezember ankam. Am Abend des 24. wur- 
den die marschierenden Truppen jedoch von einem Schneesturm und einem starken Absinken der Temperatur (ungefähr 38 Grad unter Null) überrascht, was insofern bedeutende Verluste verursachte, als eine große Zahl von Soldaten, die von den Verletzungen, dem langen, aufreibenden Marsch und vom Hunger erschöpft waren, den Erfrierungstod starben. Außerdem erlitt das Ende der Kolonne durch die häufigen Partisanenangriffe andauernd Verluste.

In den ersten Stunden des 26. Dezember in Tschertkowo angekommen, erhielt die Truppe (insgesamt ungefähr 6000 Mann) den Befehl, in Privathäusern Quartier zu nehmen, doch die Soldaten blieben auf der Straße, weil sie ein eventuelles Abrücken der Kolonne fürchteten; sie schufen auf diese Weise ein unbeschreibliches Durcheinander, das nicht nur die Verpflegung und medizinische Versorgung der unzähligen Verwundeten und Soldaten mit Erfrierungen lähmte, sondern den Russen auch die Möglichkeit eröffnete, von den Truppenbewegungen Notiz zu nehmen und die Gegend unter heftigen, mehrere Tage dauernden Beschuß zu nehmen.

Hauptmann Fazzi, der alle Angehörigen der Carabinieri (siehe beigefügte $\mathrm{Li}$ ste $\left.{ }^{151}\right)$ zu einer ad hoc-Formation zusammengefaßt hatte, kaum daß er in Tschertkowo angekommen war, erhielt sofort den Auftrag, unter der Truppe Ordnung zu schaffen; in diesem Sinne wurde allen befohlen, in den Privatwohnungen unterzuziehen und diese nicht mehr zu verlassen. Die Aufgabe erwies sich nicht nur wegen der Vielzahl der Soldaten als ausgesprochen schwierig, sondern auch deshalb, weil viele jegliche Disziplin verloren hatten, nicht gehorchten und sich sehr häufig mit der Waffe in der Hand gegen die Carabinieri wandten.

In den folgenden Tagen entdeckten die Soldaten die italienischen Depots und plünderten sie, wobei sie Lebensmittel und Kleidung mitnahmen und auf diese Weise das italienische Kommando in Schwierigkeiten brachten, das mit diesen Gütern die Versorgung der Truppe sicherstellen sollte. Da die Wachmannschaften der Depots die Plünderung nicht zu verhindern vermochten, erhielt Hauptmann Fazzi auch in diesem Fall den Auftrag, die Lage um jeden Preis zu bereinigen. Leutnant Boldoni, der zwar bei Arbusow leicht verwundet worden war, aber langsam wieder diensttauglich wurde, unterstützte den genannten Offizier nachhaltigst, dem es am 3. Januar trotz des anhaltenden feindlichen Beschusses, der durchdringenden Kälte und des bewaffneten Widerstands rebellierender Soldaten mit seinen Männern gelang, die Ordnung wieder vollkommen herzustellen; damit wurde es dem italienischen Kommando, das den Befehl erhalten hatte, sich auf eine lange Verteidigung einzurichten ${ }^{152}$, ermöglicht, mit der regulären Verpflegung der Truppe und der Reorganisation der Verbände zu beginnen.

Während des Aufenthalts in Tschertkowo - 26. Dezember 1942 bis 15. Januar 1943 - verrichteten die Carabinieri neben den oben näher bezeichneten Aktionen

151 Auf die Wiedergabe des "Elenco dei Sigg. ufficiali, dei sottufficiali e militari di truppa facenti parte della $66^{2}$ Sezione di formazione" wurde verzichtet.

152 Nachdem es sich als unmöglich erwiesen hatte, Tschertkowo zu entsetzen oder wenigstens einen Korridor zur Versorgung mit Nachschubgütern und zum Abtransport der Verwundeten zu öffnen, wurde der Besatzung des Stützpunkts am 14.1.1943 befohlen, sich nach Westen durchzuschlagen. BA-MA, MFB4 1835, Bl. 405-410 (hier Bl. 409), Gefechtsbericht von Oberst Göller „über Kampfeinsatz und Stützpunkt Tschertkowo“, Dezember 1942 und Januar 1943. 
ununterbrochen und unter ständigem feindlichen Feuer Wach- und Sicherheitsdienste am Sitz des Divisionskommandos und führten Tag und Nacht Patrouillen in dem von italienischen Soldaten belegten Stadteil durch, um Unruhen und Raubüberfällen vorzubeugen bzw. diese zu bekämpfen und um das Einsickern von Partisanen zu melden bzw. dagegen vorzugehen. Außerdem eskortierten die Carabinieri die Herren Generäle und leisteten Wach- und Ordnungsdienste bei den Verpflegungslagern. In diesem Zeitraum opferten sich alle Carabinieri trotz der Verwundungen und der Entbehrungen, die sie erdulden mußten, bei der Erledigung dieser Aufgaben, die nachts besonders beschwerlich waren, in lobenswerter Weise auf. In Tschertkowo fielen in Erfüllung ihrer Pflicht zwei Carabinieri, während ein Appuntato $^{153}$ von Granatsplittern getroffen wurde.

Nach Tschertkowo kamen auch Hauptmann Blundo Carmelo und Oberleutnant Maci Osvaldo ${ }^{154}$. Hauptmann Blundo, der im Laufe des jüngsten Rückzugsmarsches von einem italienischen Soldaten schwer am Brustkorb verletzt worden war, wurde nach einigen Tagen mit anderen Schwerverwundeten in ein deutsches Flugzeug verladen, dem es gelungen war zu landen. Oberleutnant Maci Osvaldo, der Erfrierungen ersten Grades an den Zehen erlitten hatte und nicht mehr diensttauglich war, wurde ins Lazarett eingewiesen.

Auch der Aufenthalt in Tschertkowo war von einem Mangel an Arzneimitteln, chirurgischem Gerät und Verbandsmaterial geprägt. Die Verwundeten und Soldaten mit Erfrierungen, rund 2000 an der Zahl ${ }^{155}$, wurden in einem geräumigen Gebäude untergebracht und auf Strohsäcke gelegt. Die Ärzte opferten sich in jeder Hinsicht auf, was soweit ging, daß sie brandige Gliedmaßen mit Behelfsmitteln amputierten und Kognak als Desinfizierungsmittel benutzten. Die Nachschubgüter, die von einigen italienischen Flugzeugen abgeworfen wurden, reichten nicht aus und wurden fast immer unbrauchbar, sobald sie am Boden aufschlugen.

Dic diensttauglichen Soldaten wurden zunächst Haus für Haus gezählt, dann in Abschnitten, die mehrere Häuser umfaßten, organisiert und schließlich je Regiment in Hundertschaften zusammengefaßt; sie wurden zu Befestigungsarbeiten und Kampfeinsätzen zur Verteidigung des Stützpunkts herangezogen.

Am 15. Januar gab das Kommando gegen 16 Uhr den Befehl zum Abrücken und die Anweisung zur Formierung der Kolonnen durch, die um 21 Uhr beginnen sollte. Sofort setzten die Vorbereitungen zum Aufbruch ein, wobei alle verfügbaren Schlitten ausgerüstet wurden, und zur festgelegten Stunde begann die Kolonnenbildung nach Großverbänden. Erneut ließ man die ins Lazarett eingelieferten Verwundeten und Soldaten mit Erfrierungen zurück, wenn sie nicht in der Lage waren, zu Fuß zu gehen. Hauptmann Fazzi ließ jedoch Oberleutnant Maci aus dem Lazarett holen und auf den einzigen Lastwagen verladen, über den die italienischen Truppen verfügten. Leider blieb der Lastwagen nach einigen Kilometern im Schnee stecken,

153 Dem Rang des Obergefreiten entsprechender Mannschaftsdienstgrad der Carabinieri.

154 Weder zu Carmelo Blundo noch zu Osvaldo Maci wurden weitere Angaben ermittelt.

155 Nach Angaben von General Lerici lag die Zahl der verwundeten und an Erfrierungen leidenden italienischen Soldaten mit 3850 fast doppelt so hoch. Von diesen seien mehr als 1000 nicht mehr in der Lage gewesen, sich aus eigener Kraft auf den Weg zu machen, und da man nur etwa 100 habe transportieren können, habe man den Rest in Tschertkowo zurücklassen müssen. Vgl. hierzu und zum folgenden den Gefechtsbericht von General Lerici (AUSSME, DS II 1555/9, S. 14 ff.) mit z.T. anderen Zeitangaben. 
so daß der genannte Offizier gezwungen war, zu Fuß weiterzugehen; es gelang ihm, der Kolonne bis zu ihrem Bestimmungsort zu folgen. Nachdem die Patienten im Lazarett vom Abrücken Wind bekommen hatten, obgleich ihnen dies auf Befehl des deurschen Kommandos verheimlicht worden war, wurden sie von Panik ergriffen; die meisten verließen [das provisorische Lazarett] und schleppten sich hinter der Kolonne her. Weil sie Schwierigkeiten beim Gehen hatten, blieben sie auf dem Weg zurück.

Nachdem die Russen in der Zwischenzeit auf unsere Bewegungen aufmerksam geworden waren, begannen sie mit einem heftigen Bombardement und führten zahlreiche Angriffe gegen die Kolonne. Der Marsch ging so bis Strelzowka weiter, wo wir am 16. Januar um ungefähr 18 Uhr eintrafen; die Kolonne wurde dabei von den Russen dauernd mit Maschinengewehren, Granatwerfern und Artillerie unter Beschuß genommen. Außerdem wurde die Kolonne ständig von Panzern bedrängt, die ihr immer wieder den Weg versperrten, und von der feindlichen Luftwaffe mit Maschinengewehren und Splitterbomben angegriffen. Auch wurde die Kolonne während des Marsches durch einen russischen Angriff aufgespalten. Einige hundert italienische Soldaten, die das Ende dieser Kolonne bildeten, wurden so gefangengenommen.

Auch auf diesem Marsch waren die Carabinieri größten Anstrengungen ausgesetzt, weil sie den Auftrag hatten, Ordnung und Disziplin unter den Soldaten aufrechtzuerhalten; diese neigten nämlich dazu, sich an der Spitze der Kolonne zu massieren, so daß sie vor allem der feindlichen Luftwaffe ein sehr verwundbares Ziel boten. In Strelzowka traf die Kolonne endlich auf den ersten deutschen Stützpunkt, wo man die italienischen Truppen kühl empfing und in das circa $25 \mathrm{~km}$ entfernte Belowodsk weiterleitete, ohne den Verwundeten und den Soldaten mit Erfrierungen auch nur die geringste Hilfe zu gewähren. Dieser letzte Abschnitt des Marsches war am beschwerlichsten, weil die Temperatur in der Nacht auf ungefähr $30 \mathrm{Grad}$ unter Null sank. Glücklicherweise begannen gegen Mitternacht italienisch-deutsche Kranken- und Lastwagen den Weg abzufahren, den die Kolonne genommen hatte, und all diejenigen aufzusammeln, die zu Boden gesunken waren, weil es ihnen unmöglich war weiterzugehen.

In Belowodsk setzte sich das italienische Etappenkommando auf jede erdenkliche Art dafür ein, die Truppe zu stärken und die Verwundeten und die Soldaten mit Erfrierungen ärztlich zu versorgen; diese wurden anschließend mit Krankenwagen ins Feldlazarett von Starobelsk gebracht. Auch die Truppe wurde mit Lastwagen dorthin befördert. In Starobelsk lieferte man Hauptmann Fazzi ins Lazarett cin, so daß er nicht in der Lage war, die Zahl der übriggebliebenen Soldaten der Carabinieri-Sektion festzustellen.

\section{Anhang}

Die italienisch-deutschen Beziehungen während des Rückzugs

Die italienisch-deutschen Beziehungen während des Rückzugs waren von großer Kälte und großer Verachtung der deutschen Truppen gegenüber den italienischen Offizieren und Soldaten gekennzeichnet. Die deutschen Soldaten grüßten die italienischen Offiziere nicht und nahmen keinerlei Rücksicht auf die von ihnen beklei- 
deten Ränge ${ }^{156}$; man behandelte sie wie gemeine Soldaten, verweigerte ihnen den Gehorsam und gebrauchte Gewalt. Anstatt einzugreifen, billigten die deutschen Offiziere das Handeln ihrer Untergebenen, und sehr selten traten sie an die italienischen Offiziere heran - nur an die hohen Ranges -, wobei sie Kälte und Hochmut zeigten.

Auf dem Marsch oder im Falle der Einschließung, boten sie den italienischen Soldaten nicht die geringste Hilfe an. Während unsere Soldaten tatsächlich aufgrund des Fehlens von Lebensmitteln hungerten, bereiteten die deutschen Truppenteile die Verpflegung regulär in den mitgeführten Küchen zu. Das deutsche Kommando requirierte überdies die Lebensmittel in den Ortschaften, die man durchquerte, erlaubte es dem italienischen Kommando aber nicht, genauso vorzugehen, und hürete sich davor, einen Teil der requirierten Lebensmittel an die Italiener abzugeben ${ }^{157}$. Wenn sich ein italienischer Soldat einer deutschen Küche näherte und um ein wenig Essen oder Wasser bat, wurde er mit Pistolenschüssen empfangen ${ }^{158}$.

Die deutschen Soldaten machten den Italienern gegenüber bei jeder Gelegenheit von der Schußwaffe Gebrauch, wenn diese nicht sofort den in deutscher Sprache erteilten Befehlen nachkamen.

Das deutsche Kommando, das sich wegen der Panzer und der Artillerie auf Selbstfahrlafetten der eigenen Überlegenheit bewußt war, tendierte außerdem stets dazu, sich von den italienischen Truppen abzusetzen; [die Deutschen] entfernten sich, als diese in ein Gefecht verwickelt waren wie am Fluß Tichaja ${ }^{159}$, oder versuchten, einen Einschließungsring aufzubrechen, wobei sie das italienische Kommando erst wenige Minuten vor der Befehlsausgabe benachrichtigten, wie es in Arbusow geschah ${ }^{160}$.

156 Wie verschieden die Erfahrungen sein konnten, zeigen die Erinnerungen eines Oberleutnants im Infanterieregiment 81 der Division "Torino ${ }^{*}$, der noch vierzig Jahre später berichtete, wie überrascht er war, als ein deutscher Unteroffizier salutierend Haltung annahm, während er in Tschertkowo den Gefechtsstand eines deutschen Regiments betreten habe. Die italienischen Soldaten dagegen hätten während des gesamten Rückzugs nicht einmal die Generäle gegrüßt. Auch an anderen Stellen läßt er das Verhältnis von Deutschen und Italienern in besserem Licht erscheinen, als dies im hier abgedruckten Dokument der Fall ist. Vgl. Giuseppe Longo, Dal Don a Karkov, in: Bedeschi (Hrsg.), Fronte russo, Bd. 1, S. 79-87, hier insbesondere S. $85 \mathrm{f}$.

157 Piero Guarducci, Gefreiter im Artilleriedepot der 8. Armee, erinnerte sich daran (Nella sacca di Cerkovo, in: ebenda, S. 103-117, hier S. 112), daß vor dem Ausbruch aus Tschertkowo der Befehl gegeben worden sei, so viele Schlitten und Pferde zu requirieren wie irgend möglich. Aber überall habe man auf die italienischen Bitten und Drohungen geantwortet, es seien schon die Deutschen da gewesen und hätten alles mitgenommen.

158 Die Tatsache, daß es den Deutschen gelungen war, trotz des Chaos Feldküchen zu retten, machte ebenso Eindruck auf die italienischen Offiziere und Mannschaften wie die unerwartete Erfahrung, daß die Verbündeten offensichtlich nicht bereit waren zu teilen. Vgl. den Gefechtsbericht von Oberstleutnant Turrini (AUSSME, DS II 1555/11, S. 37) oder Riccardo Richebuono, In Ritirata, in: Bedeschi (Hrsg.), Fronte russo, Bd. 1, S. 485-495, hier S. 488. Allerdings war die Bandbreite der Verhaltensweisen und Erfahrungen wiederum groß, wie die Erinnerungen von Giulio Casamenti, Soldat im Infanterieregiment 38 der Division "Ravenna“, zeigen (Fronte russo, in: ebenda, S. 495 ff., hier S. 496), der während der Kämpfe in Arbusow bei deutschen Soldaten Verpflegung und Unterkunft fand.

159 In der Vorlage: "Tukaja“.

160 Nach dem Gefechtsbericht Lericis für die Zeit vom 19.12. 1942-17.1. 1943, hier S. 8, (AUSSME, DS II 1555/9) wurde der Befehl zum Ausbruch aus Arbusow am 23. 12. gegen 
Während des Rückzugs trug es sich ferner zu, daß die deutschen Panzertruppen keine gepanzerten Abteilungen als Nachhut abstellten, um die gesamte Kolonne zu verteidigen, sondern nur an der Spitze und am Ende der deutschen Kolonne marschierten, die der italienischen vorausging, und diese so auf Gnade und Ungnade den fortdauernden Angriffen des Feindes überließ. Als man Tschertkowo verließ, sollte sich beispielsweise ein deutsches Bataillon zuletzt aus dem Ort absetzen und die Nachhut der gesamten Kolonne bilden ${ }^{161}$. Dagegen hängte sich dieses Bataillon an die deutsche Vorhut an und lieferte die nachfolgende italienische Kolonne, die keine automatischen Waffen und keine Munition besaß, dem Feind aus.

Dann waren Rücksichtslosigkeit und Raub an der Tagesordnung. Die deutschen Soldaten stellten zu mehreren und mit der Waffe in der Hand einzelne italienische Soldaten, um ihnen die Pistole bzw. die Uhr zu rauben oder das Maultier wegzunehmen, das sie in Obhut hatten. Als einige italienische Flugzeuge Arzneimittel mit dem Fallschirm abwarfen, war es nicht möglich, die Übergabe der von den deutschen Soldaten aufgenommenen Pakete zu erreichen. Als man verschiedentlich eingeschlossen war, erschossen die Deutschen schließlich erbarmungslos alle russischen Gefangenen, die ihnen nach und nach in die Hände fielen. Dieser Umstand provozierte eine Reaktion des Feindes, der mit den deutschen und italienischen Gefangenen ebenso verfuhr. In Arbusow wurden beispielsweise einige hundert gefangengenommene russische Soldaten von den Deutschen kaltblütig erschossen ${ }^{162}$, und man nimmt deshalb an, daß der Feind aus Rache Tausende italienische Verwundete getötet hat, die man vor Ort zurückließ, weil sie nicht transportiert werden konnten.

In Tschertkowo bemächtigte sich das deutsche Kommando 163 , das einige Tage nach dem Abzug der italienischen Garnison eintraf, all der gut ausgestatteten italienischen Versorgungslager. Und als die italienischen Truppen bei ihrem Rückzug dort ankamen, weigerte sich das deutsche Kommando, diese Versorgungslager zurückzugeben, so daß die italienischen Soldaten für einige Tage ohne Lebensmittel

20.30 übermittelt. Angesichts der Geschwindigkeit, mit der sich die deutsche Marschkolonne formiert habe, habe man den Eindruck gewinnen können, die deutschen Truppen seien bereits vorab informiert gewesen.

161 Umberto Turrini bemerkte in seinem Gefechtsbericht (AUSSME, DS II 1555/11, S. 42), als Nachhut sei ein deutsches Bataillon vorgesehen gewesen, in der Praxis hätten jedoch italienische Soldaten diese Aufgabe übernommen, allerdings unterstützt von deutschen Panzerfahrzeugen.

162 Daß den deutschen und italienischen Soldaten während der Kämpfe um Arbusow neben sowjetischem Kriegsmaterial zahlreiche Gefangene in die Hände fielen, ist auch anderweitig bezeugt. Umberto Turrini berichtete (AUSSME, DS II 1555/11, S. 34) daß man die Beute an Waffen und Munition behalten, die Gefangenen aber an die Deutschen übergeben habe, ohne sie je wiederzusehen. Angesichts der Tatsache, daß sowohl die Deutschen als auch die Italiener nicht einmal all ihre Schwerverwundeten abtransportieren konnten, erscheint es nicht unwahrscheinlich, daß man sich der Gefangenen tatsächlich entledigte, wobei sich nichts über Entscheidungsprozesse und Verantwortlichkeiten aussagen läßt.

163 Tschertkowo lag eigentlich im nückwärtigen Gebiet der 8. Armee und stand unter der Verwaltung des Comando Tappa Speciale 300. Nach dem sowjetischen Durchbruch hatten die italienischen Logistikeinheiten Tschertkowo verlassen, und seit dem 20.12. 1942 führte Oberst Wilhelm Göller vom Festungspionierstab 30 das Kommando über die Verteidiger. BA-MA, MFB4 41403, Bl. 1090, KTB des Deutschen Generals beim italienischen AOK 8, Eintrag vom 20. 12. 1942. 
blieben ${ }^{164}$. Angesichts der beharrlichen Proteste des italienischen Kommandos gab [das deutsche Kommando] die Depots später zurück, nachdem ihnen mit sorgfältiger Genauigkeit alle Genußmittel wie Butter, Marmelade, Mehl, Liköre, Schokolade, Zucker, Öl etc. pp. entnommen worden waren ${ }^{165}$. Während des Rückzugs gab es wegen der deutschen Haltung viele Konflikte, die als Reaktion unserer Soldaten darauf entstanden sind.

Rom, 4. April 1943-XXI

Der Hauptmann und Chef der CC.RR. der Division "Torino ${ }^{* 166}$ Enrico Fazzi

AUSSME, L 13/202.

\section{Dokument 24}

Bericht von Oberst Francesco Polito ${ }^{167}$ an das Kommando der Infanteriedivision „Cosseria“ über das Verhalten deutscher Soldaten gegenüber ihren italienischen Kameraden vom 28. März 1943

Kommando des 90. Infanterieregiments

„Gewohnt zu siegen“

Nr. 05/260 di prot. R.P.

P.M. 42, 28. März 1943-XXI

Betreff: Informationen

An das Kommando der Infanteriedivision „Cosseria“

Feldpost Nr. 42

Mit Bezug auf die Anfrage aus dem Schreiben 1/467 vom 20. des laufenden Monats ${ }^{168}$ gebe ich im folgenden einige Vorfälle in Bezug auf fehlende Zusammenarbeit

164 Brigadegeneral Cesare Rossi, der stellvertretende Kommandeur der Division „Torino“ berichtete dagegen (AUSSME, DS II 1555/10, Gefechtsbericht für die Monate Oktober 1942 bis Januar 1943, S. 14), man sei in Tschertkowo gut aufgenommen und durch den bislang höchsten italienischen Offizier im Stützpunkt, einen Oberstleutnant der Bersaglieri, reichlich mit Lebensmitteln versorgt worden.

165. Die Magazine von Tschertkowo waren offenbar bereits im Zuge der Räumung der Stadt durch Plünderungen und Brände schwer in Mitleidenschaft gezogen worden (vgl. Guarducci, Sacca di Cerkovo, in: Bedeschi (Hrsg.), Fronte russo, Bd. 1, S. 104). Nach den Erinnerungen von Attilio Boldoni (Epopea dei Carabinieri, in: ebenda, S. 67) versuchten hungrige italienische Soldaten später auch, die Depots zu stürmen.

166 Dienstgrad und Dienststellung sind handschriftlich vermerkt.

167 Francesco Polito, Oberst, seit Anfang März 1943 Kommandeur des Infanterieregiments 90 der Division "Cosseria“.

168 Der Kommandeur der Division "Cosseria“, General Enrico Gazzale, teilte dem Infanterieund dem Pionierführer seiner Division, den Infanterieregimentern 89 und 90 sowie dem Artillerieregiment 108 am 20. 3.1942 in einem vertraulichen Schreiben $(\mathrm{Nr} .1 / 467$ di prot.; AUSSME, DS II 1551/5) folgendes mit: „Das Comando Supremo wünscht, genauestens 
und verweigerte Unterstützung unserer Truppen von deutscher Seite während der Kämpfe vom vergangenen Dezember und des darauf folgenden Rückzugs wieder, von denen mir Soldaten des Regiments schriftlich berichtet haben. Diese Vorfälle haben reinen Beispielcharakter und bieten keine vollständige Dokumentation über die feindselige, ungeschliffene, oftmals barbarische und viehische, immer abfällige und anmaßende Behandlung seitens der Kameraden des deutschen Heeres.

Viele weitere, auch schwerwiegendere Vorfälle dieser Art, werden hier nicht wiedergegeben, obwohl sie "gerüchteweise“ bekannt sind, weil die Soldaten, die darin verwickelt waren und die sie bezeugen könnten, nicht mehr beim Regiment weilen. Klar ist, daß sich diese Vorfälle sehr ungünstig auf die Moral der Truppe ausgewirkt haben, und zwar bis zu dem Punkt, daß sich ihre Einstellung gegenüber dem deutschen Verbündeten zutiefst gewandelt hat. Selbst eine beharrliche Einflußnahme auf die Moral zur Änderung dieses Zustands wird keine besonderen Ergebnisse zeitigen, denn die Offiziere, die die Einheiten führen, sind fast alle nicht anders behandelt worden, und in keinem Fall gab es auch nur die mindeste Andeutung von Ehrerbietung und Respekt ihrem Dienstgrad gegenüber.

A) Fehlende Kooperation im Gefecht

Am Abend des 6. Dezember [?] befahl Major Millino Teresio ${ }^{169}$, der erste Adjutant des Regiments, in Dubowikoff dem befehlshabenden Oberleutnant der Geschützkompanie des 318. deutschen Grenadierregiments, die dem 90 . Infanterie[regiment] unterstellt war, im Raum Deresowka zur Kampflinie am Don vorzurücken und dort seine Geschütze nach den Weisungen aufzustellen, die er vor Ort erhalten würde. Der deutsche Offizier weigerte sich entschieden und in ruppiger Form, den Befehl auszuführen, wobei er erklärte, er würde von einem italienischen Kommando keine Befehle entgegennehmen. Erst als es möglich war, telefonisch mit dem deutschen Regimentskommandeur [Oberst Mielke] in Verbindung zu treten, der den Befehl bestätigte, rückte der deutsche Offizier in den ihm angewiesenen Abschnitt vor. Es sei hervorgehoben, daß die damalige Lage eine sofortige Umsetzung der befohlenen Maßnahme verlangte.

B) Aneignung von Waffen und Material

1. Der Schütze Muzzin Antonio, Sohn von Giuseppe, von der 3. Kompanie wurde am 19. Dezember 1942 während des Rückmarsches, und zwar unmittelbar hinter Kantemirowka, wo sich deutsche Panzerjäger befanden, von deutschen Sol-

über das Verhalten unserer deutschen Verbündeten zu Beginn und während des Rückzugs unterrichtet zu werden, und zwar über Fälle fehlender Zusammenarbeit im Gefecht, über die Verweigerung von Unterstützung für unsere Truppen auf dem Rückzug, schließlich über die willkürliche Aneignung von italienischen Kraftfahrzeugen und Versorgungslagern. Ein vollständiger und erschöpfender Bericht mit den geprüften Einzelfällen wird umgehend erbeten. Die Angaben sollen so umfangreich wie möglich sein und in allen Einheiten wie auch bei den einzelnen Untergebenen gesammelt werden; sie müssen aber genau, ausführlich beschrieben und soweit wie möglich dokumentiert sein."

169 Major Millino bekleidete dieses Amt seit dem 1. 12. 1942 (AUSSME, DS II 1553/2, Anlage 1 zur chronologischen Übersicht über den Einsatz der Division „Cosseria“ an der Ostfront zwischen Juli 1942 und April 1943); weitere Angaben ließen sich nicht ermitteln. Daten zu den in diesem Dokument erwähnten Personen wurden nur in Ausnahmefällen erhoben, da es sich in der Regel um Subalternoffiziere, Unteroffiziere und einfache Soldaten handelt, deren Biographie keinen Erkenntnisgewinn verspricht. 
daten festgehalten und aufgefordert, ihnen Karabiner und Munition zu übergeben. Als Muzzin sich weigerte und seinen Marsch fortzusetzen versuchte, holten ihn dieselben deutschen Soldaten ein, hielten ihn fest und entwaffneten ihn; nachdem man ihm einen heftigen Stoß und einen Tritt ins Hinterteil versetzt hatte, wurde er wieder freigelassen und konnte weiterziehen.

2. Die Schützen Pasquali Marino und Mastrodomenico Michele von der 8. Kompanie trafen am 19. Dezember 1942 auf der Straße von Kantemirowka nach Tschertkowo auf ungefähr zwanzig Deutsche, von denen sie aufgefordert wurden, ihnen die Waffen zu überlassen. Als sie sich weigerten, gaben die deutschen Soldaten zur Einschüchterung einige Pistolenschüsse ab und zwangen sie, die Waffen auszuhändigen.

3. Die Schützen Bandirali Carlo und Maglio Ernesto wurden zusammen mit anderen Italienern von einer Gruppe von Deutschen, die zahlenmäßig mehr als doppelt so stark war, gewaltsam entwaffnet.

4. Der Schütze Maiani Gino beobachtete in Charkow fünf Deutsche, als sie versuchten, sich eines italienischen Autos zu bemächtigen, das am Straßenrand stand. Der Fahrer versuchte, sie mit angelegtem Gewehr fernzuhalten, doch die Deutschen griffen ihn an, und nur durch die glückliche Intervention einiger zufällig vorbeikommender italienischer Offiziere, welche die Deutschen zum Etappenkommando geleiteten, war es möglich, den Diebstahl des Fahrzeugs zu verhindern.

5. Am 19. Dezember 1942 nahmen während des Rückzugs drei Deutsche, darunter ein Offizier, dem Stabsgefreiten Ferrandi Silvio von der 4. Kompanie auf der Straße von Kantemirowka nach Belowodsk gewaltsam das Maschinengewehr ab, das er geborgen und auf den Schultern transportiert hatte.

6. Zur gleichen Zeit wurde etwas westlich des Donez der Schütze Consonni Pietro von der 4. Kompanie zusammen mit weiteren Kameraden entwaffnet, die mit einem italienischen Lastwagen unterwegs waren.

7. Der Schütze Lopeduso Giuseppe von der 4. Kompanie traf mit zwei Artilleristen auf einige Deutsche, die sie dazu zwangen, ihnen die Waffen auszuhändigen. $\mathrm{Da}$ sie sich weigerten, richtete einer der Verbündeten die Pistole auf sie, schoß und verletzte einen der Artilleristen am rechten Arm. Beide wurden entwaffnet. Dem Schützen Lopeduso gelang es, die Waffe durch Flucht in Sicherheit zu bringen.

8. Nachdem er das Lazarett von Kantemirowka verlassen hatte, wohin er aufgrund einer Verwundung gebracht worden war, hatte der Schütze Presenza Giacobbe von der 4. Kompanie auf einem Schlitten Platz gefunden, der von zwei italienischen Maultieren gezogen wurde. Nach ungefähr zwanzig $\mathrm{km}$ zwang eine Gruppe von Deutschen den Führer mit der Waffe in der Hand, Schlitten und Maultiere herauszugeben.

9. Der Schütze Biraghi Ernesto von der 1. Kompanie berichtet, er sei dabeigewesen, als zwei italienische Soldaten in Kantemirowka von zwei deutschen Unteroffizieren aufgehalten worden seien. Nachdem diese sie entwaffnet und hätten weitergehen lassen, hätten sie ihnen von hinten nachgeschossen, ohne daß es jedoch gelungen sei, sie zu treffen.

10. Am 22. Februar 1943 traf die Kraftfahrzeugkolonne, die Truppen der Division "Cosseria" transportierte und auf dem Weg nach Gomel war, am Stadtrand von 
Kiew ein. Da es wegen der schneidenden Kälte völlig unmöglich war, auf den offenen Fahrzeugen zu übernachten, versuchten einige Soldaten, in den nahen Wohnhäusern unterzukommen, obgleich sie durch die Bombardements stark beschädigt waren. Mit dem Versprechen, eine Unterkunft zu finden, führte eine deutsche Streife den Stabsgefreiten De Carli Pietro, den Schützen Carubini Ubaldo und den Schützen Fabbri Enrico von der 5. Kompanie zur eigenen Wacheinheit, wo diese plötzlich mit Waffen bedroht und entwaffnet wurden. Danach setzte man sie gewaltsam vor die Tür. Um die Waffen am nächsten Tag zurückzubekommen, war es notwendig, daß der Bataillonskommandeur Hauptmann Bianchi Evanzio ${ }^{170}$ bei den örtlichen deutschen Behörden einschritt.

11. Am 19. Dezember 1942 wurden in Kantemirowka der Unteroffizier Curcio Giuseppe, der Stabsgefreite Salvadori Silvio und die Schützen Gambino Calogero und Gendusa Francesco von der Stabskompanie des I. Bataillons ohne jeglichen Grund gewaltsam von deutschen Streifen entwaffnet.

12. Am 23. Februar 1943 führte eine deutsche Streife in Kiew die Schützen Pravatà Salvatore und Rinchiuso Calogero zusammen mit anderen Soldaten des Regiments unter Vorwänden in ein Haus und zwang sie dort mit angelegten Gewehren, ihre Waffen abzugeben.

C) Von Niedertracht zeugende Vorfälle

1. Während des Marsches von Rykowo nach Jassinowatoje ${ }^{171}$ fuhr ein deutsches Kraftfahrzeug willkürlich den Leutnant Montoneri Giuseppe von der 10. Kompanie an, so daß er mit einem gebrochenen Arm ins Lazarett eingeliefert werden mußte.

2. Während desselben Marsches fuhr ein anderes deutsches Kraftfahrzeug aus offenkundig niederträchtigen Beweggründen den Schützen Citrini Idrio von der 10. Kompanie an, so daß er mit einem Knie- und Armbruch ins Lazarett eingeliefert wurde.

3. Der Schütze Donati Ubaldo, der sich am 18. Februar dieses Jahres auf der Fahrt nach Krementschug befand, blieb plötzlich ohne Benzin liegen. Deshalb mußte er am Straßenrand halten und auf einen italienischen Wagen warten, um abgeschleppt zu werden. Zwischenzeitlich traf ein deutscher Major ein, der wie ein Besessener schrie und ihn aufforderte, von dort zu verschwinden, weil das Parken von Kraftfahrzeugen verboten sei. Auf höfliche Art und mit höchstem Respekt gab der genannte Schütze dem deutschen Offizier zu verstehen, daß er sich wegen Benzinmangels nicht fortbewegen könne, daß er aber sofort aufbrechen würde, sobald ein italienischer Wagen vorbeikäme, der in der Lage sei, ihn abzuschleppen. Der deutsche Offizier wollte nichts davon wissen und rief aus, nachdem er sich völlig deplaziert über den italienischen Soldaten aufgeregt hatte: „Hört endlich auf, Italiener!“ Und während er dies sagte, richtete er die Pistole auf ihn und forderte ihn auf zu verschwinden. Wahrscheinlich war es seine Absicht gewesen, sich des Kraftfahrzeugs zu bemächtigen.

170 Major Bianchi führte seit Mitte November 1942 das II. Bataillon des Infanterieregiments 90.

171 In der Vorlage: ${ }_{n}$ Jasinowataja“; im folgenden wurden diese und andere falsche Schreibweisen stillschweigend korrigiert. 
4. Als der Schütze Fortolan Luigi am 15. Januar dieses Jahres auf der Straße fuhr, die von Woroschilowgrad nach Millerowo führt, sah er, wie etwa fünf $\mathrm{km}$ von Woroschilowgrad entfernt ein deutscher Soldat auf einen italienischen Kradfahrer schoß, der, am Kopf getroffen, tot zu Boden fiel ${ }^{172}$. Der deutsche Soldat bemächtigte sich danach des Motorrads und entfernte sich schnell. Dies geschah in einer Distanz von nicht mehr als $50 \mathrm{~m}$ vom Schützen Fortolan, der nicht reagieren konnte, weil er unbewaffnet war.

5. Der Schütze Malegori Luigi befand sich am vergangenen 19. Dezember zusammen mit einem anderen Soldaten von den Pionieren, dessen Füße bereits erfroren waren, in Kantemirowka und fragte einen deutschen Soldaten, wohin er sich wenden könne, um dem Kameraden zu helfen. Der deutsche Soldat schlug mit einem verächtlichen Lachen vor, ihn mit einem Pistolenschuß zu töten, und als Malegori nicht locker ließ, antwortete er, indem er ihn zu Boden warf und ihm das Gewehr wegnahm.

6. Der Schütze Pesce Giacomo behauptet, einige Kilometer hinter Kantemirowka einen unserer Verwundeten auf einem Schlitten gesehen zu haben, der sich - von deutschen Soldaten mit einer Peitsche bedroht - geweigert habe abzusteigen. Daraufhin wurde der Verletzte von deutschen Infanteristen zu Boden geworfen und konnte wenig später von einem vorbeikommenden italienischen Lastwagen aufgenommen werden.

D) Von fehlender Unterstützung zeugende Vorfälle

1. 25. Februar 1943 in Bolriskaja. Mehrere italienische Soldaten, die wegen Schäden an den Lastwagen ohne Fahrzeug geblieben sind, versuchten in einen Zug einzusteigen, um Kiew, den Versammlungsraum der Division zu erreichen. Der Zug war voller Rumänen und Zivilisten, aber es gab noch Platz. Die italienischen Soldaten wurden von den deutschen Soldaten mit Verachtung vertrieben, wobei sie gegen die Widerspenstigsten mit aufgepflanztem Bajonett vorgingen. Dem Vorfall wohnten der Gefreite Corchia Antonio und die Schützen Boscaro Fortunato, Gazzano Paolo, Rossi Adorno, Fazzi Amato, Socci Giulio von der Stabskompanie des I. Bataillons bei.

2. 5. Februar 1943 in Dnjepropetrowsk. Der Gefreite Sallitto Giuseppe und die Schützen Cugerone Carlo und Sacchi Mario von der Stabskompanie des I. Bataillons saßen an den Tischen eines in der Nähe des Bahnhofs gelegenen deutschen Restaurants und warteten darauf, bedient zu werden. Mehrere deutsche Soldaten traten ein, die sich jedoch, da sie keinen Platz fanden, den italienischen Soldaten näherten und von ihnen verlangten aufzustehen, weil sie bereits gegessen hätten. Diese wandten ein, daß dem nicht so sei. Da hoben jene den Gefrei-

172 Angesichts der Schwere des Vorfalls und um die Identität des erschossenen italienischen Soldaten klären zu können, bat das Divisionskommando um nähere Informationen. Der Zeuge sagte daraufhin aus, er habe eine heftige Diskussion zwischen dem unbekannten italienischen Kameraden und dem deutschen Soldaten beobachtet, die sich offensichtlich darum gedreht habe, daß dieser auf das Motorrad aufsteigen wollte, und die damit geendet habe, daß der deutsche Soldat den italienischen Kradfahrer mit einer Pistole erschossen habe. AUSSME, DS II 1551/5, Comando $90^{\circ}$ Reggimento fanteria (Nr. 05/321 di prot. ris. pers. - gez. Francesco Polito) an Comando della Divisione fanteria "Cosseria“ vom 12. 4. 1943. 
ten zusammen mit dem Stuhl gewaltsam hoch, um ihn anschließend schwer auf den Boden stürzen zu lassen. Es war ihre offenbare Absicht, die Uniform des italienischen Soldaten lächerlich zu machen, und tatsächlich brach der ganze Saal, der voller deutscher Soldaten war, in schallendes Gelächter aus.

3. 19. Dezember 1942 bis 16 . Januar 1943, Flugplatz $85 \mathrm{~K}$, in der Nähe von Kantemirowka. Die italienischen Soldaten, die zusammen mit den Deutschen eingeschlossen wurden, weil sie den Flughafen verteidigten, wurden wie Gefangene behandelt: reduzierte Verpflegung, mit Bajonetten und Stockschlägen durchgesetzte Ausführung schwerster Arbeiten. Nichts galt es, daß man gemeinsam gekämpft und das Leben für ein und dasselbe Ziel riskiert hatte. Zugegen waren die Schützen Cugerone Carlo und Fassina Siro von der Stabskompanie des I. Bataillons.

4. 20. Dezember 1942 in der Nähe von Millerowo. In den ersten Tagen des Rückzugs wurden die Schützen Fazzi Amato und Lamioni Alcide von der Stabskompanie des I. Bataillons und viele andere von anderen Truppenteilen gewaltsam gezwungen, von einem leeren, fahrenden Lastwagen zu springen. Dasselbe passierte den Schützen Muzzi Antonio und Gazzola Rosalino von der Stabskompanie des I. Bataillons, wobei Stockhiebe und Fußtritte erschwerend hinzukamen.

5. 22. Dezember in Belowodsk. Der Schütze Passarella Giovanni von der Stabskompanie des I. Bataillons wird zusammen mit anderen Pionieren und einem Oberleutnant der Pioniere von einem deutschen Offizier beschimpft, der verlangt, daß sie an die Front zurückkehren, obgleich ihm der Rückzugsbefehl an die Division "Cosseria " nicht unbekannt sein kann. Feige überzieht er den italienischen Offizier und die Soldaten auf italienisch mit den Schimpfworten: Feiglinge, Verräter, Angsthasen usw. Der italienische Offizier, der unfähig war zu reagieren, verfiel in einen Weinkrampf.

6. Die Schützen Cantore Gildo und Cartasegna Filippo haben berichtet, sie hätten am 19. Dezember um acht Uhr während des Rückzugs von Kantemirowka versucht, auf einen fast leeren deutschen Lastwagen zu klettern, auf den sie an der Straße gestoßen waren: Sobald sie sich an die Bordwände des Lastwagens gehängt hatten, begannen die deutschen Soldaten, die sich darauf befanden, mit dem Gewehrkolben auf ihre Hände zu schlagen und sie so vom fahrenden Lastwagen zu werfen. Als sie zu Fuß weitergingen, sahen sie eine halbe Stunde nach diesem Vorfall, wie ein deutscher Mannschaftsdienstgrad die Maschinenpistole gegen einen von unseren Lastwagen richtete und ihn dadurch zum Stehen brachte. Danach zwang der Mannschaftsdienstgrad den Fahrer weiter mit der Waffe in der Hand, ihn und seine Männer aufsteigen zu lassen, obgleich der Lastwagen voll beladen war.

7. Am Morgen des vergangenen 17. Dezember zog Leutnant Ferrol Salvatore von den CC.RR. zusammen mit dem Schützen Cadu Carmine von der 355. Kompanie Kanonen 47/32 der Division und anderen Infanteristen die Straße von Orobinskji nach Krasnyj entlang. Als sie ein deutsches Kraftfahrzeug sahen, das in dieselbe Richtung fuhr, bat er die Insassen, ihn und seine Soldaten mitzunehmen, da genügend Platz vorhanden war. Als diese sich weigerten, ließ er nicht locker und versuchte den deutschen Verbündeten die Gefahr vor Augen zu führen, die von den feindlichen Panzern drohte, die bereits in Orobinskij ständen. 
Die Antwort gab der Anmaßendste unter ihnen, der seine Maschinenpistole lud, sie gegen die Brust des italienischen Offiziers richtete und ihn aufforderte, sich zu entfernen.

8. Derselbe Offizier schlief am Abend des 23. Januar 1943 in Jassinowatoje in Begleitung seines Burschen, des Schützen Cappelli Gaetano, und des Schützen Ferri Giuseppe von der 8. Kompanie seit einigen Stunden in einer Isba, als ein deutscher Offizier mit einem Unteroffizier und einer aus sechs bewaffneten Männern bestehenden Patrouille eindrang und verlangte, [die Isba] zu räumen und sich sofort zu entfernen. Auch maß er der Bitte um Erklärungen seitens des italienischen Offiziers keine Bedeutung bei, ja er würdigte ihn keiner Antwort.

9. Am selben Tag und am selben Ort suchten der Unteroffizier Morando Giovanni und der Stabsgefreite Mandelli Alfredo, beide von der 4. Kompanie, eine Unterkunft in einer Isba und wurden dabei von den Verbündeten mit der Waffe in der Hand empfangen.

10. In den ersten Januartagen wurden die Schützen Terni Mario und Ribani Luigi von der 4. Kompanie in Solonowka von einigen Deutschen, die mit Gewehr und aufgepflanztem Bajonett bewaffnet waren, aus einer Isba vertrieben, die sie belegt hatten.

11. Den Gefreiten Calleri Paolo und die Schützen Galli Paolo und Ingraffia Vito von der 4. Kompanie zwangen die Deutschen in der Nähe von Kiew mit angelegten Gewehren nicht nur, sich zu entfernen; damit nicht zufrieden, hetzten sie den drei Soldaten noch einen Wachhund hinterher.

12. Der Schütze Mascara von der 3. Kompanie stieg in der Nacht vom 17. zum 18. Dezember des vergangenen Jahres auf der Straße Taly - Kantemirowka auf einen halbleeren deutschen Lastwagen, weil ihn die Müdigkeit übermannt hatte. Bald aber bemerkten die deutschen Soldaten auf dem Lastwagen seine Gegenwart und zwangen ihn auf ungehobelte Art und Weise zum Absteigen, wobei sie auch die Pistole gegen ihn richteten.

13. Der Schütze Grassi Mario von der 3. Kompanie klopfte am Abend des 26. Januar in Jassinowatoje nach einem Marsch von ungefähr $40 \mathrm{~km}$ an einem russischen Haus an, wo er hoffte, ein wenig Wärme und Ruhe finden zu können. Ihm öffnete ein deutscher Soldat, der das Haus zusammen mit russischen Zivilpersonen bewohnte. Grassi grüßte ihn, wobei er ihn Kamerad nannte, und bat ihn höflich um ein wenig Platz zum Schlafen. Der deutsche Soldat antwortete ihm mit harten Worten: ${ }_{n}$ Hitler e Mussolini camerati, tedeschi ed italiani essere camerati solo al fronte, qui niente. ${ }^{173}$ Nachdem er dies gesagt hatte, versetzte er dem italienischen Soldaten einen Stoß und schlug ihm die Tür vor der Nase zu.

14. Am Morgen des 19. Dezember des vergangenen Jahres, als die Stadt Kantemirowka wegen des plötzlichen Auftauchens russischer Panzer geräumt wurde, nahm der Schütze Grosso Lorenzo von der 3. Kompanie auf einem halbleeren deutschen Lastwagen Platz, von wo ihn die Deutschen bald mit Gewalt abzusteigen zwangen; um ihn einzuschüchtern, richteten sie die Pistole auf ihn und versetzten ihm beim Absteigen einen heftigen Fußtritt gegen die Brust, so daß er unglücklich auf die Straße fiel.

173 "Hitler und Mussolini Kameraden, Deutsche und Italiener sein Kameraden nur an der Front, hier nicht." 
15. Auch der Schütze Destradis Cosimo von der 3. Kompanie erklärte, daß er von deutschen Soldaten mit dem Gewehrkolben auf die Hände geschlagen worden sei, als er versucht habe, auf einen vollkommen leeren Lastwagen zu steigen, und daß man ihn mit einem Fußtritt vor die Brust hinabgestoßen habe, so daß er bewußtlos auf die Straße gefallen sei.

16. Der Schütze Barbera Giuseppe von der 3. Kompanie wurde am Abend des 19. Januar während des Rückmarsches in Jassinowatoje von einem deutschen Soldaten, an den sich der Schütze gewandt hatte, um ein wenig Gastfreundschaft in der Isba zu finden, wo der Deutsche bequem schlief, mit der Pistole in der Hand bedroht.

17. Der Unterfeldwebel Malabarba Giovanni erklärte, er habe am Abend des 25. Januar, nachdem er mit einigen Maultieren in Jassinowatoje angekommen sei, einen vollkommen leeren Reitstall gefunden und einige deutsche Soldaten um Erlaubnis gebeten, sowohl die Führer als auch die Maultiere in jenem Raum übernachten zu lassen. Auf seine Anfrage hin gingen sie mit den Waffen auf ihn zu und zwangen ihn, sich zusammen mit den anderen Soldaten zu entfernen. Vier Maultiere erfroren im Laufe der Nacht, während die Soldaten in einem Zimmer ohne Fensterscheiben Unterschlupf suchten.

18. Am 19. Dezember 1942 blieb der Stabsgefreite Barbati Domenico, nachdem er mit zwei anderen Infanteristen, die wie er verwundet waren, das Lazarett verlassen hatte, in Kantemirowka bei einigen unbewachten italienischen Fahrzeugen stehen in der Hoffnung, sie könnten einen dieser Kraftwagen benutzen. Indes trafen einige deutsche Soldaten ein, denen es gelang, einen der Wagen in Gang zu setzen. Zwei der Verwundeten versuchten einzusteigen, doch die deutschen Soldaten vertrieben sie auf rüde Weise, wobei sie ihnen mit der Waffe drohten.

19. Als sich der Schütze Rubino Giovanni von der 9. Kompanie am 19. Dezember 1942 in Kantemirowka an einen deutschen Lastwagen geklammert hatte, richteten deutsche Soldaten eine Pistole auf ihn, um ihn zum Absteigen zu bewegen. Als der Schütze Rubino zögerte, dieser Aufforderung nachzukommen, schlug man ihm mit dem Gewehrkolben auf die Hände, so daß er vom Lastwagen fiel.

20. Der Unterfeldwebel Ecchia Walter von den CC.RR. berichtete: Nachdem ich für meinen Trupp, der sich aus 55 Mann der Division „Cosseria“ und mehrheitlich des 90. Infanterie[regiments] zusammensetzte, die Genehmigung zum Weitermarsch erhalten hatte, meldete ich mich am 23. Februar 1943 gegen 12 Uhr in Snamenka bei einem deutschen Oberfeldwebel, den ich unter Vorlage der Genehmigung bat, auf einige offene, mit verschiedenen deutschen $\mathrm{Kraftfahrzeugen}$ beladene Güterwaggons eines nach Kiew fahrenden Zuges steigen zu dürfen. Ich wies auch darauf hin, daß der Führer des Trupps, Oberfeldwebel Fatiganti Tommaso, Fieber hatte. Der deutsche Unteroffizier redete gestikulierend in seiner Sprache auf uns ein, wobei ich nur "Nicht Saizemen “ [sic!] verstand. Dann zog er seine Pistole aus dem Halfter und richtete sie auf die Infanteristen, die inzwischen begonnen hatten, sich auf den offenen Güterwaggons um die Kraftfahrzeuge herum niederzulassen, und während der Zug sich in Bewegung zu setzen begann, forderte er sie trotz der großen Verletzungsgefahr auf, auszusteigen. Es waren zugegen: Oberleutnant Kaplan Palmi Antonio, Unterfeldwebel Passalacqua Francesco, Unteroffizier Soldaini Francesco, Stabsgefreiter Scorza Carlo und andere vom 90. und 89. Infanterie[regiment]. 
21. Oberleutnant Lamanna Cesare berichtet, er sei am 8. Februar 1943 gegen 20.30 Uhr, das heißt am späten Abend, nach einem Marsch unter besonders widrigen klimatischen Bedingungen mit seinem Truppenteil in Jakno angelangt, wo er übernachten mußte. Fast alle Isbas seien bereits von Deutschen belegt gewesen, aber mit wenigen Männern je Isba; so hätte es genügend Möglichkeiten gegeben, auch die italienischen Soldaten unterzubringen, wenn man die Deutschen entweder in weniger Isbas zusammengezogen oder auf eine gemischte Unterbringung gesetzt hätte. Die Deutschen weigerten sich jedoch kategorisch, die Italiener zu beherbergen. Nachdem er auf der Suche nach leeren Isbas vergeblich durch den Ort gezogen war, beschloß er gegen 21.30 Uhr, um jeden Preis zu erreichen, daß die italienischen Soldaten untergebracht würden. Deshalb sandte er Oberleutnant Caluzzi Ettore zu einer Isba, die von einem deutschen Unteroffizier und drei seiner Soldaten belegt war, um sie zu bitten, doch einige unserer Soldaten aufzunehmen. Oberleutnant Caluzzi klopfte an die Tür, erhielt vom Unteroffizier aber nur eine ungehobelte Abfuhr und einen Stoß; anschließend wurde die Tür wieder geschlossen, was eine Reaktion des Offiziers verhinderte. Sie beschlossen deshalb, sich mit Gewalt durchzusetzen, und nachdem sie die Tür aufgebrochen hatten, sahen sie sich vier Deutschen gegenüber, die versuchten, Gewalt gegen unsere beiden Offiziere anzuwenden. Nur unter vorgehaltener Pistole stimmten die Deutschen widerwillig und grummelnd zu, einige unserer Soldaten aufzunehmen. Außer Oberleutnant Caluzzi befanden sich bei Oberleutnant Lamanna noch Oberleutnant Paolella Fernando, Leutnant Devia Angelo, Leutnant Zauli Goffredo und Stabsfeldwebel Morelli Bruno, die alle dem Truppenteil angehörten, der mit ihm marschierte.

22. Der Militärseelsorger des Regiments, Pater Palmi Antonio, berichtete, er habe in Kirowograd einige unserer Soldaten zum deutschen Verpflegungsposten begleitet. Dort seien sic jedoch wie unerwünschte Gäste behandelt worden und hätten deshalb keinerlei Beistand erhalten. Er selbst habe trotz der Abzeichen eines Militärseelsorgers keine respektvollere Behandlung erfahren ${ }^{174}$. In Snamenka ließ er die Soldaten auf einige offene Güterwaggons eines Zuges steigen, um mit diesem Transportmittel weiterzukommen. Mit gezogenen Pistolen und angelegten Gewehren ließ man alle wieder absitzen (er bestätigt damit den unter Nr. 20 erwähnten Vorfall).

23. Am 18. Dezember 1942 hatten der Unteroffizier Bugelli Ezio und der Schütze Rocchi Zenone von der 90. Granatwerferkompanie in der Ortschaft Zapkowo einen schwer verwundeten Infanteristen des Regiments mangels anderer Möglichkeiten auf einen deutschen Lastwagen verladen, der verwundete Deutsche transportierte. Die deutschen Krankenträger bemerkten dies nicht sofort, als sie aber darauf aufmerksam wurden, hoben sie den italienischen Verwundeten hoch und warfen ihn vom Lastwagen, so daß er auf ganz unglückliche Weise in den Schnee fiel.

174 Antonio Palmi schrieb am 23. 3. 1943 an das Kommando seines Regiments (AUSSME, DS II 1551/5), er könne in vollem Bewußtsein seiner Pflichten als Priester und Soldat behaupten, daß das Verhalten der Deutschen den Italienern gegenüber während des Rückzugs nicht nur nichts mit dem Verhalten zu tun gehabt hätte, das man von Verbündeten hätte erwarten können, sondern daß es im Gegenteil „des verhaßtesten Feindes würdig“ gewesen wäre. 
24. Der Stabsgefreite Manesso Igino von derselben Kompanie versuchte am Morgen des 19. Dezember 1942, als Kantemirowka von feindlichen Kräften angegriffen wurde, auf ein deutsches Kraftfahrzeug zu steigen, das mit nur drei deutschen Soldaten besetzt war und stadtauswärts fuhr. Um seinen Versuch zu vereiteln, lud einer der deutschen Soldaten das Gewehr und gab einen Warnschuß in der Nähe des Kopfes ab, nachdem er ihm wiederholt heftig auf die Hände geschlagen hatte, mit denen er sich an die hintere Bordwand des Lastwagens klammerte.

25. Der Gefreite Manca Nicolino und der Schütze Desortes Angelo, die beide ebenfalls der Granatwerferkomapnie angehörten, versuchten unter denselben Umständen, unter denen sich der vorhergehende Vorfall ereignete, auf einen fast leeren deutschen Lastwagen zu steigen, der stadtauswärts fuhr. Auf dem Lastwagen saßen einige deutsche Soldaten, die sich sofort anschickten, ihrem Versuch mit Gewalt entgegenzutreten. Der Schütze Desortes gab den deutschen Soldaten zu verstehen, daß sein Kamerad, der Gefreite Manca, wegen einer im Kampf erlittenen Verletzung nicht mehr zu Fuß weitergehen könne. Seine Worte zeigten jedoch keinerlei Wirkung, vielmehr richteten die deutschen Soldaten fest entschlossen ihre Pistolen und Gewehre auf sie, mit denen sie bewaffnet waren. Um Unannehmlichkeiten zu vermeiden, verließen die beiden Infanteristen das Fahrzeug.

26. Als dieselbe Einheit im Januar von Woroschilowgrad nach Bjelej verlegt wurde, erbat und erlangte der Unterfeldwebel Alvano Vincenzo von seinem Kommandanten die Genehmigung, sich eines beliebigen Transportmittels zu bedienen, weil er wegen eines verrenkten Fußes nicht weitergehen konnte. Er hielt einen deutschen Lastwagen an und bat unter Hinweis auf die Gründe höflich, ihn bis zum nächsten Ort mitzunehmen. Ein deutscher Unteroffizier, der sich auf dem Wagen befand, weigerte sich mit den Worten: „Italiani non buoni, nemà mascina, italiani caput ${ }^{* 175}$ und schloß damit, daß er als Zeichen der Verachtung auf den Boden spuckte.

27. Der Unteroffizier Puzzi Virginio und der Schütze Gavazzeni Angelo, beide von der Granatwerferkompanie, suchten am Abend des 23. Januar 1943, als ihre Einheit im Zuge des Transfers in Debalzewo angekommen war, auf Befehl des Kompaniechefs in einigen Isbas, die in dem Gebiet lagen, das der Einheit zugewiesen worden war, nach einer Unterkunft für die Nacht. Alle Häuser waren von deutschen Soldaten belegt, die jegliche Gastfreundschaft verweigerten. Eine Isba war nur von zwei deutschen Soldaten belegt, die mit Gesten und Worten zu verstehen gaben, daß sie die Anwesenheit der Italiener nicht wünschten, obgleich noch genügend Platz für zwei weitere Personen vorhanden war. Als diese nicht locker ließen, zogen sie ihre Pistolen, bedrohten damit die beiden Italiener und zwangen sie, sich zu entfernen.

28. Am 19. Dezember 1942 gelang es dem Unterfeldwebel Molinari Vincenzo von der 2. Kompanie, auf einen deutschen Schlitten zu steigen, der sich auf dem Rückmarsch von Kantemirowka befand. Er wurde von einem deutschen Offizier zu Boden geworfen, der ihm einen überraschenden heftigen Stoß in den Rücken versetzt und dabei gleichzeitig folgende Worte gesprochen hatte: „Ita-

175 Heißt wohl soviel wie „Italiener nicht gut, sogar ohne Wagen, Italiener kaputt." 
lianski a piedi“ ${ }^{176}$; der Unteroffizier fiel als Folge des Stoßes bäuchlings in den Schnee, während der Schlitten sich entfernte.

29. Dem Unterfeldwebel Oliva Oronzo von derselben Einheit war es gelungen, sich auf der Straße nach Taly von einem deutschen Lastwagen mitnehmen zu lassen, der mit italienischem Material beladen war (Mäntel mit Pelzen, Strümpfe, Handschuhe usw.). Nach einer gewissen Zeit hielt der Lastwagen an und ein deutscher Unteroffizier, der im Führerhaus gesessen hatte, gab dem Unterfeldwebel Oliva zu verstehen, daß er ihn nicht weiter auf dem Lastwagen würde mitfahren lassen, wenn er als Entschädigung nicht eine Pistole bekäme; auf die Weigerung des italienischen Unteroffiziers (der mit einem Karabiner bewaffnet war), irgendeine Waffe abzugeben, reagierte der Deutsche, indem er den Karabiner und den Stahlhelm, die der Unterfeldwebel Oliva bei sich hatte, hinabwarf und ihn dadurch zwang, den Lastwagen zu verlassen.

30. Der Stabsgefreite Speziano Giuseppe, auch er von der 2. Kompanie, sah während des Rückzugs von Tschertkowo von einem Lastwagen aus einige italienische Soldaten, die von einem unserer liegengebliebenen Lastwagen abgestiegen waren und sich an einen deutschen Küchenwagen geklammert hatten; ein deutscher Offizier forderte sie auf abzusteigen und gab aus der auf sie gerichteten Pistole drei Schüsse $\mathrm{ab}$, so daß die drei Soldaten hinfielen, und zwar zwei davon so schwer, daß Speziano selbst den Eindruck hatte, sie seien getroffen worden.

31. In Kantemirowka wurden der Schütze Vighi Giuseppe von derselben Kompanic und einige andere von einigen Deutschen gebeten, ihnen zu helfen, einen deutschen Lastwagen herauszuziehen, der in einem Graben steckengeblieben war, wobei man ihnen versprach, sie anschließend auf dem Lastwagen mitzunehmen. Als der Wagen wieder auf der Straße stand, fuhr er rasch ab und ließ die Italiener zurück.

32. Leutnant Arengi Salvatore suchte am Abend des 17. Februar 1943 Unterkunft in den Häusern einer Ortschaft, wo die Wagenkolonne, zu der er gehörte, angehalten hatte und an die er sich jetzt nicht mehr genau erinnert; da alle Häuser von den Deutschen belegt waren, bat er fünf deutsche Soldaten, die in einem Haus schliefen, das nicht so klein war wie die anderen, ihm und seinem Burschen ein wenig Platz zu überlassen. Obgleich er sich als Offizier zu erkennen gegeben hatte, weigerten sich die Deutschen schroff und nahmen eine drohende Haltung ein. Der Offizier, von soviel Disziplinlosigkeit und Ungeschliffenheit angewidert und irritiert, zwang einen von ihnen (einen Mannschaftsdienstgrad), ihn bei der Suche nach einem freien Haus, wo es möglich sein würde, die Nacht zu verbringen, ohne die Gefahr neuer Zwischenfälle mit deutschen Soldaten heraufzubeschwören, zu führen. Da der deutsche Mannschaftsdienstgrad sich dem nicht entziehen konnte, führte er den Befehl unter Protest aus, während die anderen unwürdig herumschrieen, als der Offizier das Haus verließ.

33. Dem Unterfeldwebel Del Bò Enzo von der 1 . Kompanie war es gelungen, unbemerkt auf einen fahrenden deutschen Kleinlaster zu steigen, und er wurde erst entdeckt, als der Wagen anhielt, um italienische Nachschubgüter zu laden. Man forderte ihn auf abzusteigen, und da er sich weigerte, wurde der Wagen auf eine

176 "Italianski zu Fuß“. 
einsame Rollbahn gelenkt und angehalten, wo ihn der Fahrer und sein Begleiter mit angelegtem Karabiner zwangen abzusteigen.

34. Hauptmann Asquasciati berichtet, daß sich am 19. Dezember 1942 in Taly eine Gruppe unserer Soldaten, und zwar der Unteroffizier Pecolato Maggiorino, die Stabsgefreiten Saccocci Giuseppe, Mangione Volante sowie die Schützen Stancapiano Salvatore, Bombaci Nunzio, Buzzigoli Ernesto, die alle der 1. Kompanie angehörten, nach Übernachtung in einer Isba zum Aufbruch anschickte, um ihre Einheit zu erreichen. Als eine deutsche Troßkolonne an ihnen vorbeizog, gab man ihnen in einer Mischung aus Deutsch und Russisch zu verstehen, daß es - da sie Italiener seien - ausschließlich ihre Schuld sei, wenn man einige Positionen verloren habe: Denn die Italiener hätten die Kampflinie aufgegeben, und durch das Verschulden der Italiener seien viele Deutsche umgekommen. Und weil ihnen ihre falschen und provokanten Behauptungen nicht genügten, wagten es vier Deutsche (aus dem erwähnten Troß) sogar, sie als Zeichen höchster Verachtung anzuspucken. Selbstverständlich ließen sich die Unsrigen das nicht gefallen, doch der Streit hatte wegen eines feindlichen Panzervorstoßes sofort ein Ende.

35. Außerdem berichtete er, daß die ordnungsgemäß von drei Offizieren (Hauptmann Asquasciati Luigi, Leutnant Messere Marcello, Leutnant Calcagno Nicolò) geführte 1. Kompanie am 19. Februar 1943 in Krementschug von der deutschen Bahnhofskommandantur eine vorschriftsmäßige Genehmigung erhalten habe, bis Kiew mit dem Zug zu fahren, aber von einem deutschen Soldaten des Zuges mit der Pistole in der Hand gezwungen worden sei, von den offenen Güterwaggons zu steigen, auf denen sie sich hätten niederlassen dürfen. Die genannten Offiziere wandten sich erneut an die deutsche Bahnhofskommandantur; und da diese Seite der deutschen Gastfreundschaft zwischenzeitlich nichts Außergewöhnliches mehr darstellte, baten sie um einen Sonderbeauftragten, der sie zum Zug begleiten sollte. Nur so war es der Einheit möglich, in einen Wagen der 3. Klasse zu steigen. Aber kaum hatte sich der deutsche Sonderbeauftragte nach Erledigung seiner Aufgabe entfernt, kam ein deutscher Truppenteil, dessen Führer die Italiener aufforderte, für sie Platz zu machen und dafür einen nicht beheizten Viehwaggon zu belegen. Die Aufforderung von deutscher Seite erfolgte mit diesen Worten: „Avanti Savoia, cikai!“ ${ }^{177}$

Über die erwähnten Vorfälle, die nur in der Form modifiziert worden sind, um in den Bericht eingefügt werden zu können, haben die einzelnen Soldaten eine Erklärung abgegeben und unterzeichnet, die bei diesem Kommando verwahrt wird ${ }^{178}$.

Der Oberst und Regimentskommandeur

(F. Polito)

AUSSME, DS II 1551/5.

177 Mit dem Ruf "Savoia“ zogen die Soldaten des königlichen Heeres in den Kampf. Nach der ersten Verteidigungsschlacht am Don wurde die Division "Sforzesca" nach dem russischen Wort für fliehen als Division "cikai" diffamiert; vgl. Valerio Sella, Il lungo dramma della Sforzesca, in: Bedeschi (Hrsg.), Fronte russo, Bd. 1, S. 389-393, hier S. 391.

178 Diese Dokumentation findet sich im AUSSME, DS II 1551/5. 


\section{Dokument 25}

Bericht des Stabschefs der Alpinidivision "Tridentina", Oberstleutnant Alessandro Ambrosiani, über den Einsatz in der Sowjetunion und das Verhältnis zwischen den Verbündeten 1942/43

Kommando der 2. Alpinidivision „Tridentina“

\section{Abteilung-Operationen}

Nr. 1139/Op. di prot.

P.M. 228, den 1. Juni 1943-XXI

Betreff: Bericht über die Aktivitäten der Alpinidivision „Tridentina“ in der Zeit vom August 1942 - Januar 1943-XXI an der Ostfront (Rußland)

An das Generalstabskommando - Büro des Chefs der Operationsabteilung Feldpost Nr. 9

Antwort auf Schreiben 102/S vom vergangenen 9. April; Fortsetzung Schreiben Nr. 1115/op. vom 25. Mai 1943-XXI ${ }^{179}$

$[\ldots]^{180}$

Verlegung der „Tridentina“ vom äußersten rechten auf den äußersten linken Flügel der Armee

Im Zuge des Einbaus einer rumänischen Armee zwischen der 8. italienischen Armee und der 6. deutschen Armee war die Aufstellung der ARMIR zahlreichen Änderungen unterworfen. Vom übergeordneten Kommando wurde befohlen, daß die "Tridentina " zum Alpinikorps auf der äußersten Linken der gesamten Armeeaufstellung stoßen sollte ${ }^{181}$. Als die Alpini sahen, daß ihr großer Wunsch in Erfüllung ging - nämlich die Zusammenführung mit den beiden Schwesterdivisionen -, fügten sie sich gelassen in die Notwendigkeit eines erneuten langen Transfers von über $400 \mathrm{~km}$ in einer Jahreszeit, in der das Thermometer nachts bereits unter Null Grad fiel. Die Truppenbewegungen unter diesen Umständen wurden teilweise dadurch erleichtert, daß täglich einige Eisenbahnwaggons auf der Linie Millerowo - Rossosch zur Verfügung standen, die von einigen Truppenteilen ohne Transportmittel genutzt

179 Nicht ermittelt.

180 Auf die Wiedergabe des ersten Teils, in dem Oberstleutnant Ambrosiani die Verlegung der Division an die Ostfront, die ersten Etappen auf dem Weg in den Kaukasus, den Marsch an den Don und die Kämpfe im Verband des XXXV. Armeekorps zur Abwehr der sowjetischen Offensive bzw. zur Stabilisierung der Front zwischen Ende August und Anfang Oktober 1942 beschrieb, wurde verzichtet. Eine erzählende, weitgehend unkritische Schilderung des Einsatzes der "Tridentina" an der Ostfront, die jedoch wertvolle Ausschnitte aus unveröffentlichten Quellen enthält, findet sich bei Rasero, Tridentina Avanti, S. 331-530.

181 Zur Eingliederung der 3. rumänischen Armee in die Front zwischen der 6. deutschen und der 8. italienischen Armee und den daraus resultierenden Konflikten vgl. auch Dok. 10 mit Anm. 144. Die Division „Tridentina“ wurde bis zum Morgen des 10. 10. 1942 von der 9. rumänischen Infanteriedivision abgelöst; AUSSME, DS II 680, KTB XXXV. Armeekorps, Einträge vom 7. 10.-11. 10.1942. 
werden konnten. Aber wenn diese Maßnahme einen günstigen Einfluß auf den physischen Zustand ${ }^{182}$ eines Teils der Alpini hatte, so erschwerte sie die Organisation der Logistik, denn es war notwendig, gleichzeitig für die Verpflegung der im Raum Podgornoje eintreffenden Gruppen, für die der Einheiten, die bei Millerowo und Tschertkowo auf den Eisenbahntransport warteten, und für die der auf normalem Wege marschierenden Kolonne Sorge zu tragen; diese setzte sich aus dem gesamten Gebirgsartillerieregiment und allen Lasttieren der Division zusammen.

Die sehr komplexen Truppenbewegungen wurden ordnungsgemäß ausgeführt, so daß die gesamte "Tridentina" im Raum Podgornoje versammelt und bereit war, die 23. ungarische Division an der Front abzulösen. Seine Exzellenz der Oberbefehlshaber der 8 . Armee, der die Verlegung aus nächster Nähe verfolgte, drückte in einem bewegenden Tagesbefehl seine lebhafte Genugtuung über die Disziplin und Widerstandskraft aus, welche die Einheiten in großartiger Manier unter Beweis gestellt hätten.

Ferner gilt es, gebührend zu berücksichtigen, daß die Einheiten einen Teil ihrer Märsche während der sogenannten Schlammperiode durchführten. Dieser ausgesprochen unangenehme Umstand hatte keinerlei Einfluß auf den Verlegungsplan, dessen Umsetzung erhebliche Opfer verlangte, die von allen mit einem herausragenden Sinn für Disziplin auf sich genommen wurden. Die am 10. Oktober im Gebiet von Gorbatowo begonnenen Truppenbewegungen kamen, wie bereits gesagt, Ende Oktober im Raum Podgornoje hinter dem Sektor zum Abschluß, den die Division in den nächsten Tagen übernehmen sollte.

Verteidigungsstellung am Don zwischen den Ortschaften Karbut und Bassowka (äußerster linker Flügel der Schlachtordnung der 8. Armee) - die Division als Teil des Alpinikorps

Am 6. November löst die "Tridentina" die 23. ungarische Division am Don ab und dehnt damit den Verteidigungsabschnitt des Alpinikorps, das mit den Divisionen "Cuneense" und "Julia" bereits seit über einem Monat in Stellung liegt, nach links aus ${ }^{183}$. Auch hier ist die Front über $25 \mathrm{~km}$ breit, so daß die heiklen Probleme wiederauftauchen, die sich aus dem Mißverhältnis zwischen den knappen verfügbaren Kräften und der übermäßigen Ausdehnung der zu verteidigenden Front ergeben. Und man kann nicht sagen, daß der Don ein wirksames Hindernis darstellt, denn der bevorstehende Frost wird seine die Defensive begünstigenden Eigenschaften abschwächen und am Ende völlig verschwinden lassen.

Auf jeden Fall wurden trotz der Notwendigkeit, den Verteidigungsstellungen die größtmögliche Festigkeit zu geben, zwei der sechs verfügbaren Bataillone für das $z$ weite Treffen bestimmt; anfangs behielt jedes Bataillon des ersten Treffens eine Reservekompanie, später wurden die Reserven - aufgrund strikter Befehle von oben, die größtmögliche Zahl an Waffen an die Front zu werfen - zwischen den Kompanien geteilt ${ }^{184}$. Die 40 Panzerabwehrgeschütze $47 \mathrm{~mm}$ (24 bei den Bataillonen und

182 In der Vorlage wörtlich: "sforzo fisico“.

183 Die Division "Tridentina" übernahm am 6.11. 1942 ihren Verteidigungsabschnitt an der Nahtstelle zwischen der 8 . italienischen und der 2. ungarischen Armee; AUSSME, DS II 1126, KTB Alpinikorps, November/Dezember 1942, Eintrag vom 6. 11. 1942.

184 Zur Kräfteverteilung im Bereich der Division "Tridentina" und zum - weitgehend positiven - Urteil der deutschen Verbindungsoffiziere vgl. BA-MA, MFB4 18276, Bl. 503-506, Be- 
16 bei den beiden [Panzerjäger-]Kompanien der Division) wurden gemäß dem Konzept, eine angemessene Tiefe der Aufstellung zu gewährleisten, günstig in den vier wahrscheinlich gefährdetsten Abschnitten ${ }^{185}$ positioniert. Den drei [Artillerie-] Gruppen der Division von ziemlich kurzer Reichweite wurde die Unterstützung einer Gruppe von 105/32 [Geschützen] des Armeekorps zugesichert, und für kurze Zeit operierten im Sektor der Division auch zwei Gruppen [Artillerie] zu Pferd mit 75/27 [Geschützen] sowie eine gemischte Gruppe mit deutschen 105 und $150 \mathrm{~mm}$ Haubitzen. Als jedoch besondere Vorkommnisse, die sich auf dem rechten Flügel des Abschnitts der "Tridentina" ergeben hatten, das Abrücken der Gruppen zu Pferd und der deutschen Gruppe notwendig machten, verließ man sich ausschließlich auf das Feuer der drei Gruppen der Division[sartillerie] und auf die wenigen Geschütze der Gruppe 105/32.

Zusammengenommen war die Artillerie in dieser zweiten Phase ziemlich dürftig für eine so breite Front, die es zu verteidigen galt. Doch ein sorgfältiges Studium der Batteriestellungen, genaue und detaillierte Vereinbarungen über das rechtzeitige Einsetzen des Feuers sowie eine umsichtige Festlegung der zu treffenden Ziele, der abzuriegelnden Stellen und der zu neutralisierenden Zonen ermöglichten es, daß man alle stets heftigen und überraschend geführten Angriffe des Feindes abwehren konnte. Die Arbeiten an einer Verteidigungsstellung, die Sicherheit bei feindlichen Vorstößen bieten und die Einheiten vor den Härten des Winters schützen sollte, wurden bereits vor dem Zeitpunkt, an dem die "Tridentina" die Verantwortung für den Abschnitt übernahm, eifrig vorangetrieben und nahmen imposante Ausmaße an. Die von den Ungarn übergebenen Stellungen konnte man als für den Sommer [genügend] ansehen; die Einheiten der "Tridentina" (am 10. November fiel das Thermometer bereits auf zehn Grad unter Null) mußten hingegen Unterkünfte schaffen, die sie vor dem unmittelbar bevorstehenden Frost zu schützen vermochten. Die Alpini arbeiteten Tag und Nacht unter dem Störfeuer des Gegners, wobei sie gleichzeitig die beschwerlichen Aufgaben des Patrouillierens und der Aufklärung über den Don bewältigten und erfolgreiche Handstreiche ins Zentrum der tückischen gegnerischen Stellungen unternahmen. Tausende von Panzerabwehrund Schützenminen wurden in den gefährdetsten Abschnitten ${ }^{186}$ verlegt, obgleich die Eisdecke auf dem Boden die Arbeit höchst schwierig und gefährlich machte. Ende November, nach einem Monat pausenloser und unermüdlicher Tätigkeit, bekam die Kampflinie eine vertrauenerweckende Festigkeit, was die Organisation eines soliden Widerstands zur Vereitelung aller gegnerischen Angriffe ermöglichte.

Parallel zu den Schanzarbeiten und den operativen Aktivitäten wurden jene auf dem Feld der Logistik fortgeführt, die auf russischem Boden neue Formen angenommen haben wie zum Beispiel die Ausbeutung der lokalen Ressourcen in eigener Regie, das Mahlen von Roggen oder Weizen, das Dreschen usw. ${ }^{187}$. Dazu kam überdies die schwierige Organisation des rückwärtigen Gebiets, die von der Zählung der

richt des Verbindungsoffiziers zur Division "Tridentina“, Hauptmann Kött, vom 29. 11. 1942 und die diesbezüglichen Bemerkungen von General Schlemmer vom 3. 12. 1942.

185 In der Vorlage wörtlich: „zone di facilitazione“.

186 In der Vorlage wörtlich: "zone di maggior facilitazione“.

187 Die Kriegstagebücher des Alpinikorps für September/Oktober und November/Dezember 1942 (AUSSME, DS II 974 und 1126) enthalten zahlreiche Informationen zu diesem Themenkomplex. 
Einwohner bis zur Organisation des Schneeräumens auf Fahrbahnen in einer Länge von Hunderten von Kilometern, zur Organisation des Kampfes gegen Fallschirmspringer und Partisanen und zum Eingraben von $500 \mathrm{Kraftfahrzeugen} \mathrm{der} \mathrm{Division}$ reichte.

Auch der Umstand verdient Erwähnung, daß die winterlichen Verhältnisse, die recht plötzlich auf das ziemlich milde Klima des Monats Oktober folgten, das Kommando zwangen, in der Transportorganisation sofortige, radikale Änderungen durchzuführen: der Lastwagen mußte eilends durch den Schlitten ersetzt werden. Fieberhafte Arbeit, um diese zu requirieren und zu bauen, weil das von den Ungarn bereits vollständig ausgebeutete Gebiet keine entsprechenden Bestände mehr aufwies.

Um die ersten Dezembertage bemerkt man im gegnerischen Lager etwas Neues, d. h. in den Nachtstunden verstärken sich die Kraftfahrzeugbewegungen. Insbesondere in der Ortschaft Pawlowsk ${ }^{188}$, die dem Zentrum der Aufstellung der Division gegenüberliegt, laufen die Bewegungen von Norden und Osten zusammen. Die Möglichkeit eines massiven Angriffs gegen die Stellungen der Division entgeht dem übergeordneten Kommando nicht, das den Sektor der Division mit einer Gruppe von gepanzerten Selbstfahrlafetten und einer gemischten Gruppe deutscher Artillerie (Kaliber 105 und 150) verstärkt. Doch das anschließende "Abgleiten“ der Truppenbewegungen nach Süden zu den Stellungen des II. Armeekorps lenkt die Aufmerksamkeit des höheren Kommandos auf den rechten Sektor des Alpinikorps, so daß gegen Mitte Dezember alle Verstärkungen von der "Tridentina a abgezogen und eiligst dorthin geschickt worden sind. Die Division verfügt damit wieder nur über ihre eigenen Kräfte, ja sogar über weniger, denn die Bataillone "Vestone" und "Morbegno" werden ins Zentrum der Aufstellung des Alpinikorps verlegt und taktisch der Infanteriedivision "Vicenza ${ }^{4}$ unterstellt; diese ersetzte an der Front die "Julia" 189 , die dringend in den Abschnitt des II. Armeekorps gerufen worden war, um den Vorkommnissen entgegenzutreten, die sich dort ereignet hatten.

\section{Rückzug der Division vom Don zum Donez ${ }^{190}$}

Die Lageentwicklung auf dem rechten Flügel der italienischen Armee, die seit Ende November dazu geführt hatte, daß die Kräfte aus der zweiten Linie des Alpinikorps (eine deutsche Division) in Richtung Millerowo abgezogen wurden, um der machtvollen Offensive zu begegnen, die der Gegner im Frontabschnitt der rumänischen Divisionen entfesselt hatte, sowie das eilige Abrücken der "Julia" aus ihren Stellungen am Don (zwischen der "Tridentina" und der "Cuneense") im Anschluß daran, um im Frontabschnitt des II. italienischen Armeekorps Hilfe zu leisten, ließen einige Zweifel an der Möglichkeit aufkommen, eine Offensive zum Stehen zu bringen, die der Gegner möglicherweise mit starken Kräften und der Unterstützung von

188 In der Vorlage: „Pawlowka“.

189 Der Befehl, die Division „Julia“ aus der Front des Alpinikorps herauszuziehen, um die vom Einsturz bedrohte Front des II. Armeekorps zu stützen, erging am 16. 12. 1942. Für die Alpini der "Julia", die in den folgenden Wochen zusammen mit den Verbänden des XXIV. Panzerkorps eine improvisierte Verteidigungsstellung am rechten Flügel des Alpinikorps hielten, wurde die Sicherungsdivision "Vicenza" an die Front geworfen. AUSSME, DS II 1126, KTB Alpinikorps, November/Dezember 1942, Einträge vom 16.-19. 12. 1942.

$190 \mathrm{Vgl}$. hierzu Dok. 11 und 12 des vorliegenden Bandes mit den entsprechenden Anmerkungen. 
Panzern, die aufmerksame Boden- und Luftaufklärung bereits seit längerem gemeldet hatten ${ }^{191}$, hätte starten können. Die Zweifel betrafen nicht so sehr die Front der Division und des Alpinikorps als den rechten Flügel des Armeekorps, wo die nJulia" eingesetzt war, die sich unter blutigen Opfern wirkungsvoll den blutigen Angriffen entgegenstellte, die der Feind wiederholt in Richtung Rossosch führte, um sich einen Weg in den Rücken des Alpinikorps zu bahnen.

Es war bekannt, daß der Gegner auch links von der Division (und folglich vom Alpinikorps) an der von der ungarischen Armee gehaltenen Front Kräfte konzentriert hatte, und die widersprüchlichen Nachrichten, die hinsichtlich der mehr oder weniger verhaltenen Angriffe zirkulierten, welche die Russen mit Panzerkräften auf Höhe des vom Don mit einer scharfen Wendung seines Laufs nach Westen gebildeten Knies führten, lenkten die Aufmerksamkeit auf diese Stelle. Trotz dieser heiklen Lage verharrten die Einheiten der "Tridentina " in ihren Stellungen und ließen sich nicht von den umlaufenden Gerüchten über die Präsenz feindlicher Panzer in der Etappe beeinflussen.

Am 15. Januar fahren in Rossosch (Sitz des Kommandos des Alpinikorps) ungefähr 15 russische Panzer herum; einen Tag später tauchen auch in Postojalyj ungefähr zehn Panzer auf, wo sie Teile des Korps angreifen, die sich bereits dorthin zurückgezogen hatten. Die Lage spitzt sich auch an der Front der ungarischen Armee zu. Am 17. Januar sind die Stellungen des Alpinikorps nicht mehr als ein nach Osten vorgeschobener Keil. Festzuhalten ist, daß die Bataillone „Edolo“, „Vestone und „Morbegno“ am 15. Januar noch von ihren Stellungen aus einen machtvollen Angriff des Gegners zurückschlagen; allein am Frontabschnitt eines der drei Bataillone werden über 700 feindliche Leichen gezählt.

Am frühen Nachmittag des 17. kommt der Rückzugsbefehl192. Er wird von allen mit lebhaftem Schmerz aufgenommen, und von den Einheiten an der Kampflinie auch mit einer gewissen Überraschung, weil sie nicht genau darüber im Bilde waren, wie sich die Lage auf den Flügeln der Schlachtordnung des Alpinikorps seit einigen Tagen tatsächlich entwickelt hatte. Doch dieser Schmerz, die mit großer Leidenschaft und unter immensen blutigen Opfern angelegte Verteidigungslinie aufgeben zu müssen, wird keinerlei Auswirkungen auf die Moral der Einheiten während des gesamten aufreibenden Marsches haben, der als „Rückzug “ bis zum 31. Januar einschließlich dauern, aber unter Strapazen und den Gefahren der Kälte noch viele Tage in der trostlosen Steppe weitergehen wird.

Zwischenzeitlich überstürzen sich die Ereignisse, und insbesondere auf dem linken Flügel vollzieht sich der Rückzug der Ungarn ziemlich phasenverschoben (d.h. vorzeitig); die Flanken des Alpinikorps werden damit praktisch entblößt; die Hoffnung, der Einkreisung noch rechtzeitig zu entkommen, hat nun keine Grundlage mehr. An die Stelle dieser Hoffnung tritt der entschiedene Wille, den Ring zu durchbrechen, den der Gegner zu schließen beginnt. Deshalb müssen die Truppenbewegungen entschieden nach Westen ausgerichtet werden, auf eine Linie hin, die zweifellos im Rücken aufgebaut wird. Aber wo würde diese Linie verlaufen? Diese

191 Vgl. hierzu die entsprechenden Anlagen zum Kriegstagebuch des Alpinikorps für November/Dezember 1942; AUSSME, DS II 1126.

192 AUSSME, DS II 1554/1, Anlage 8 zum Gefechtsbericht General Nascis für die Zeit vom 14.-31. 1. 1943: Befehl des Alpinikorps vom 17. 1. 1943, $12.30 \mathrm{Uhr}$. 
Unsicherheit konnte gewiß kein Grund dafür sein, die Bewegungen hinauszuzögern. Es war nötig, so schnell wie möglich nach Westen zu marschieren. Die Befehle, die das Kommando des Alpinikorps, das der "Tridentina“ folgte, am 17. Januar in Podgornoje ausgab, legten drei Rückzugsrichtungen für jede der einst an der

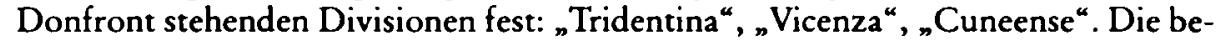
reits sehr erschöpfte Division "Julia" sollte der "Cuneense“ folgen.

Am 19. Januar setzt sich das Gros der Kolonne bei Tagesanbruch in Bewegung. Die Annahme, daß man sehr bald auf den Widerstand des Feindes treffen würde, war nicht falsch: In der Tat wird die am Nachmittag zuvor aufgebrochene Vorhut noch am 19. in Postojalyj in schwere Kämpfe verwickelt. Es besteht kein Zweifel mehr: Man muß sich mit ganzer Kraft den Weg bahnen. Eine detaillierte Schilderung aller Ereignisse und Gefechte, die zwischen dem 19. und 30. Januar entlang der Rückzugsstrecke stattgefunden haben, wäre zu weitschweifig. Ich halte es für richtiger, kurz einige Eindrücke wiederzugeben, welche die Entstehung dieser außerordentlich großen Kolonne betreffen, die mit der Eingliederung der Reste des XXIV. deutschen Armeekorps und des VII. ungarischen Armeekorps phantastische Ausmaße annahm.

Tatsächlich hatten sich die Kräfte des XXIV. deutschen Panzerkorps (zumeist Teile der Versorgungsdienste, die enorme, mit unterschiedlichem Material beladene Schlitten mit sich führten), am 16., 17., 18. und in der Nacht zum 19. aus dem Raum Rossosch nach Opyt zurückgezogen, und dies hatte Folgen für die Bewegungen der Division. Auch zahlreiche Ungarn waren am 19. in dieses Gebiet geströmt. Es handelte sich dabei zum größten Teil um Versprengte ohne Offiziere und Waffen, die zur 23. ungarischen Division gehörten; sie waren während des Rückzugs durch gegnerische Panzervorstöße abgeschnitten worden und versuchten, dem eisernen Griff des Feindes zu entkommen. Man kann sich leicht vorstellen, welche Schwierigkeiten diese führungslose, unkontrollierte Masse unter solchen Bedingungen bereitete; sie war nicht in der Lage, die Aktionen der "Tridentina" auch nur im geringsten zu unterstützen, die sich vollständig gerüstet und festgefügt in ihren Reihen anschickte, an der Spitze der Kolonne die Kämpfe auszufechten, die den Weg für alle bahnen sollten. Die einzigen aktiven Kräfte dieser Verbände der Verbündeten waren: eine Gruppe Artillerie mittleren Kalibers mit Kettenfahrzeugen (Major Fischer), vier Panzer, eine Batterie "Katjuschas ${ }^{\text {“ }}{ }^{193}$; diese Einheiten bildeten während des gesamten Rückzugs einen Teil der Vorhut.

Am 19. bietet das weite Becken von Opyt, wo neben den Fahrzeugen der Division auch ein Teil derjenigen des Alpinikorps und der Troß des XXIV. deutschen Armeekorps zusammengezogen worden sind, ein beeindruckendes Bild (Hunderte von Kraftfahrzeugen, Tausende von Schlitten und Tieren). Außerdem befanden sich folgende Kommandos dort: Alpinikorps, Division "Tridentina“, XXIV. deutsches Panzerkorps. Die Lage blieb weiterhin schwierig. Russische Einheiten von beträchtlicher Stärke stellten sich dem 5. Alpini[regiment] und den Bataillonen ${ }_{n} V e-$ stone" und "Val Chiese" des 6. [Regiments] auf der Linie Skororyb - Repjewka entgegen; auf dem rechten Flügel hatte das VI. ungarische Armeekorps aufgrund seines raschen Rückzugs die Flanke [des Alpinikorps] ungedeckt gelassen; von Osten war jederzeit das Auftauchen des Feindes zu erwarten. Angesichts dieser Situation war

193 Gemeint sind die Nebelwerfer des Artillerieregiments 387; vgl. dazu auch Dok. 11 Anm. 199. 
es notwendig, den Angriff auf die Ortschaft Postojalyj vorzubereiten, um der Kolonne einen Weg nach Westen zu bahnen. Zwischenzeitlich sorgte man im Laufe des 19. dafür, die übrigen Teile des 6. Alpini[regiments] in das Gebiet von Repjewka zu entsenden; dieses durch die bereits erwähnten deutschen Einheiten verstärkte Regiment sollte - bei Anbruch des folgenden Tages -, unterstützt durch eine Umfassungsaktion des 5. Alpini[regiments], an der linken Flanke Postojalyj angreifen. Man sorgte im Laufe des Tages auch dafür, eine oberflächliche Verteidigung der Ortschaft Opyt zu organisieren, und versuchte, die versprengten Ungarn zu ad hoc-Formationen zusammenzufassen.

Am 20. Januar um zwei Uhr griff der Feind mit Panzerunterstützung das Becken von Opyt aus nördlicher Richtung an: ein klarer Beweis dafür, daß die rechte Flanke völlig ungedeckt war. Es werden alle verfügbaren Einheiten eingesetzt, um den Feind zum Stehen zu bringen, der alle Kommandos zu vernichten oder gefangenzunehmen und die Division in zwei Teile aufzuspalten droht, die ihre beiden Alpiniregimenter und einen Teil ihrer [Artillerie-]Gruppen bereits nach Westen geworfen hat. Alle Einheiten aus dem Gebiet von Opyt vollbringen ein Wunder an Tapferkeit: Insbesondere zeichnen sich das Stabsquartier der Division und das II. Pionierbataillon aus, das bei der Durchführung eines Gegenangriffs 60 Prozent seiner Truppenstärke verliert und es durch dieses Opfer ermöglicht, daß der größte Teil der Kommandos und der in Opyt versammelten Verbände abziehen können. Indessen gelingt es dem 6. Alpini[regiment] in Postojalyj mit Unterstützung der Gruppen "Bergamo" und "Vicenza" und der deutschen Einheiten, den Feind nach einem heftigen Gefecht zu werfen und den Ort zu besetzen. So wurde am 20. gegen $13 \mathrm{Uhr}$ nach einem ereignisreichen Tag, an dem es zuweilen zu gleichsam verzweifelten $\mathrm{Si}$ tuationen kam, der erste Ring durchbrochen und der feindliche Versuch vereitelt, die "Tridentina" zu zerschlagen.

Alle chemals in Opyt aufmarschierten Kräfte, denen es gelang, sich im Raum Postojalyj dem Gros der Division anzuschließen, mußten - einschließlich der Kommandos - Lebensmittel, Gepäck und Transportmittel zurücklassen. Für sie begann der Leidensweg also sehr bald. Ich habe so ausführlich von den Ereignissen in Opyt gesprochen, weil ich glaube, daß das Opfer der Einheiten, die in diesem Gebiet mit unbändiger Tapferkeit kämpften, verhindert hat, daß der Gegner den bei Postojalyi in schwerem Kampf stehenden Bataillonen und [Artillerie-]Gruppen in den Rücken fiel. Das Kommando des Alpinikorps ist davon überzeugt, daß die feindlichen Angriffe weniger von hinten als vielmehr entlang der Marschwege erfolgen werden, um der riesenhaften Kolonne den Weg zu versperren, und befiehlt, daß zwei Alpinibataillone des 6. [Regiments] ("Vestone" und "Val Chiese"), zwei Gruppen des 2. Gebirgsartillerie[regiments] ("Bergamo“ und "Vicenza"), die vier deutschen Panzer und die Artilleriegruppe Fischer eine starke, schnelle Vorausabteilung bilden, die in der Lage sein soll, jeden Widerstand zu brechen und einen Weg nach Westen zu bahnen. Angesichts der Bedeutung der Aufgabe wird das Kommando der Vorausabteilung dem Kommandeur der Division "Tridentina“ [Luigi Reverberi] anvertraut. Indessen gingen recht unsichere Nachrichten über die Truppenbewegungen auf dem linken Flügel der Divisionen „Cuneense“, „Vicenza“ und „Julia“ ein, was daran liegt, daß fast alle Funkgeräte in den Kämpfen um Opyt zerstört worden sind.

Auf diese Weise geht am 20. der mühevolle Marsch nach Westen weiter. Alle zunächst von der Vorhut, dann von der ganzen Division bis zum 30 . Januar tapfer ge- 
führten Gefechte verdienten eine gesonderte Erörterung. Nowo Charkowa (in der Nacht zum 21. Januar), Lymoriwka (21. Januar), Scheljakino (22. Januar), Nikolajewka Ost (23. Januar), Malakejewa (24. Januar), Nikitowka (25. Januar), Arnautowo ${ }^{194}$ (26. Januar), Nikolajewka West (26. Januar) stellen die ruhmreichsten Etappen dieses mühseligen Weges dar. In jeder dieser Ortschaften hat ein blutiges $\mathrm{Ge}$ fecht stattgefunden, das jedesmal siegreich endete. In jeder hat die Division auch ihre Gefallenen im Eis der trostlosen Steppe zurückgelassen. Und dank der "Tri-

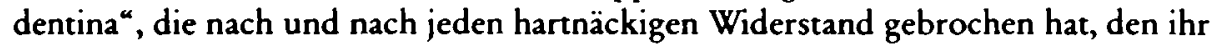
der Gegner auf dem Weg entgegenzusetzen suchte, ist es Tausenden von Alpini der drei Divisionen, von Infanteristen der Division „Vicenza“, von Deutschen und Ungarn gelungen, der Einkreisung zu entkommen.

Vor allem in den letzten Tagen des Rückzugs dünnte die große Kolonne empfindlich aus, weil insbesondere die Nachhut vom Gegner angegriffen wurde. In diesem Zusammenhang ist zu berücksichtigen, daß die Kolonne in Bewegung $40 \mathrm{~km}$ lang war, was einem zweitägigen Defilee ohne Unterbrechung gleichkommt (die Information stammt von einem deutschen Offizier, der einen Aufklärungsflug unternommen hatte). Da die Kräfte am Ende [der Kolonne] in der Regel durch eine bestimmte Ortschaft kamen, nachdem dort einen Tag zuvor die Vorhut operiert hatte, ist es wahrscheinlich, daß die zuletzt durchziehenden [Soldaten] dort zumeist eine andere Lage vorfanden, als sie von den an der Spirze der Kolonne marschierenden Einheiten geschaffen worden war. Und die strenge Kälte (es ging bis auf $40 \mathrm{Grad}$ unter Null), die Anstrengungen, Strapazen, Entbehrungen und Beschwernisse jeglicher Art haben dazu geführt, daß viele andere während des Marsches zurückblieben...

Ich habe bereits gesagt, daß jedes von der Division in den 15 Tagen des Rückzugs geführte Gefecht eine eigene Erörterung verdiente. Dies würde aber zuviel Platz in Anspruch nehmen. Das Gefecht um Nikolajewka am 26. Januar (das letzte, das die Division geführt hat) ist allerdings der besonderen Erwähnung wert, weil der Gegner hier am härtesten Widerstand leistete und die Division die größten Verluste erlitt ${ }^{195}$. Seit Tagesanbruch wurde der Abzug der Division aus Nikitowka von den Partisanen erheblich behindert. In der Nähe von Arnautowo wurde die Kolonne wenig später von starken feindlichen Kräften angegriffen, die dem Bataillon „Tirano" und der [Gruppe] "Valcamonica" schwer zusetzten; sie verfolgten dabei offensichtlich das Ziel, das Gros der Division von der Vorhut (6. Alpini[regiment]) zu trennen, die bereits am vorhergehenden Abend aus Sicherheitsgründen in das Gebiet von Arnautowo selbst geschickt worden war, um dort zu biwakieren. Der Feind wurde nach blutigen Kämpfen zurückgeschlagen. Zwischenzeitlich gelangten die Bataillone des 6. Alpini[regiments] in Sichtweite des Ortes Nikolajewka und begannen mit dem Angriff. Die Kampfkraft der Einheiten war aber wegen der überaus schweren Gefechte und der besonders ungünstigen Witterungsbedingungen, die

194 In der Vorlage: „Armankowo ; im folgenden stillschweigend korrigiert.

195 Die sogenannte Schlacht bei Nikolajewka hat einen festen Platz in der Erinnerungskultur der italienischen Streitkräfte. Es ist kein Zufall, daß die rund 680 Seiten dicke, von Giulio Bedeschi herausgegebene Sammlung von Erinnerungen über den Rückzug des Alpinikorps den Titel trägt: „Nikolajewka: c'ero anch'io“. 
große Lücken in ihre Reihen gerissen hatten, ziemlich geschwächt. Die Munition begann knapp zu werden ...

Der Feind, der die Ortschaft mit starken Kräften besetzt hält, leistet äußerst hartnäckigen Widerstand. Den wie die Löwen kämpfenden Bataillonen des 6. Alpini [regiments] gelingt es, die Böschung der erhöhten, am Rand der Ortschaft verlaufenden Bahnlinie zu überwinden, die eigens dazu gemacht scheint, dem Verteidiger einen Rückhalt zu geben; gegen elf Uhr befinden sie sich im Innern des Ortes, doch der an Männern und Material überlegene Feind zwingt sie, zu stoppen und sich hinter die Bahnlinie zurückzuziehen, von wo aus sie den Kontakt mit dem Feind aufrechterhalten. Gegen $12 \mathrm{Uhr}$ beginnt das Gros der Kolonne einzutreffen. Sofort wird die rasche Aufstellung der gesamten Artillerie angeordnet; es wird veranlaßt, daß die Einheiten des 5. Alpini[regiments] aufschließen, und befohlen, daß alle, die keine spezifische Aufgabe haben, Formationen unter dem Kommando von Offizieren bilden und sich in die Bataillone eingliedern. Indessen hat der Feind leichtes Spiel, sein eigenes Artillerie- und Granatwerferfeuer, das auch von Luftangriffen begleitet wird, zu konzentrieren. Nur zu gut kann man sich die Verluste unter dem anmarschierenden Haufen vorstellen, der vor allem aus Schlitten, Tieren und Kraftfahrzeugen besteht, die von Soldaten unterschiedlicher Nationalität und Sprache gelenkt werden. Der Angriff wird energisch wiederaufgenommen und von den deutschen Panzern vorangetrieben, die der Kommandeur der Division persönlich führt. Es gelingt, die Bahnlinie zu überwinden und in den Ort einzudringen. Der Gegner setzt seinen wütenden Widerstand insbesondere mit Artillerie- und Granatwerferfeuer auf die Truppen fort, die auf den Weitermarsch warten, so daß an einem bestimmten Punkt des Gefechts Zweifel an dem Erfolg der Aktion aufkommen. Gegen 15 Uhr treffen jedoch die Einheiten des 5 . Alpini[regiments] ein, die sich den Einheiten des 6. [Regiments] an die Seite stellen und mit ihnen den Angriff wiederaufnehmen, obgleich sic aufgrund der am Morgen in Arnautowo durchgeführten Aktion erschöpft sind. Es geht darum, die letzten Patronen klug zu nutzen... Vor diesem neuen, wuchtigen Ansturm weicht der Gegner zurück und läßt alle Waffen auf dem Schlachtfeld zurück. Somit endet der harte Tag des 26. Januar, der voll von glänzenden Heldentaten war, wie im Epos: Unter den Toten und Verwundeten sind mehr als 50 Offiziere (ein General stirbt und zwei Regimentskommandeure werden verwundet ${ }^{196}$ ). Die Verluste unter der Truppe sind nicht abzuschätzen.

Völlig erschöpft setzt sich die Kolonne bei Anbruch des folgenden Tages wieder in Bewegung. Als der Widerstand, den der Feind am Ortsausgang zu organisieren versucht, durch ein geschicktes Manöver überwunden ist, geht der Marsch weiter. Am 27. Januar werden Uspenka und Lutowinowo erreicht; am 28. Sslonowka; am 29. Bessarab; am 30. Bolsche Troitzkoje; am 31. Schebekino. Lange, mühsame Märsche durch die trostlose Steppe unter ausgesprochen widrigen klimatischen Bedingungen (die Temperatur schwankt immer zwischen 30-40 Grad unter Null). Die Schlitten sind überladen mit Verwundeten und Soldaten mit Erfrierungen, und

196 Nach dem Bericht von General Reverberi (AUSSME, DS II 1554/5, Relazione sulle azioni svolte dalla Divisione „Tridentina“ al fronte russo, S. 19) handelte es sich dabei um den Kommandeur des 5. Alpiniregiments, Oberst Giuseppe Adami, und um den Kommandeur des 2. Gebirgsartillerieregiments, Oberst Giuseppe Migliorati. Der Stabschef des Alpinikorps, Brigadegeneral Martinat, war gefallen. 
einige müssen leider für immer zurückbleiben. Überwältigt von den Strapazen brechen die Tiere zu Dutzenden zusammen. Die Artilleristen sind deshalb zu ihrem großen Leidwesen gezwungen, sich von ihren Geschützen zu trennen, für die sie allerdings auch keine Munition mehr haben.

Am 31. Januar endet der am 17. desselben Monats begonnene ruhmreiche Leidensweg ${ }^{197}$. Die Alpini der "Tridentina ${ }^{4}$, von den erduldeten Leiden schwer gezeichnet, schließen ihre gelichteten Reihen um die Fahnen, die sie mit soviel Glauben, Beharrlichkeit und Opfersinn verherrlicht haben, und schicken sich ruhigen Mutes an, den Marsch für weitere Tage wiederaufzunehmen, weil sie nicht mit der Bahn transportiert werden können.

\section{[Schlußfolgerungen]}

Die Division "Tridentina“, die im wesentlichen dank ihres Kommandeurs die Reihen während des zermürbenden Rückzugs geschlossen zu halten vermochte, ist mit all ihren regulären Bataillons-, Gruppen- und Regimentskommandos in die Heimat zurückgekehrt, auch wenn bei den unterstellten Einheiten so große, schmerzhafte Lücken entstanden sind. Aber obgleich die harten Tage des Rückzugs in der Erinnerung an die auf russischem Boden zugebrachte Zeit einen herausragenden Platz einnehmen (vielleicht gerade deshalb, weil es sich um die jüngsten Ereignisse handelt), dürfen die zuvor während der erschöpfenden Truppenbewegungen durchgestandenen Wochen ebensowenig vergessen werden wie die in den Verteidigungsstellungen am Don. Und ebensowenig dürfen die ruhmreichen Kämpfe vergessen werden, welche die Bataillone "Val Chiese" und "Vestone“ am 1. September unter dem Befehl des XXXV. Armeekorps (CSIR) bestanden haben ${ }^{198}$.

Der Zufall wollte es, daß die beiden von der Division "Tridentina" kontrollierten Verteidigungsabschnitte am Don immer den Flügeln der Aufstellung der 8. italienischen Armee entsprachen: dem rechten Flügel im September und in den ersten zehn Oktobertagen, dem linken Flügel im November, Dezember und in der ersten Januarhälfte. Notwendigerweise bestanden in der ersten Phase Beziehungen zu den Deutschen und in der zweiten zu den Ungarn. Die Beziehungen zu den Deutschen waren immer korrekt und herzlich. Wie bereits angemerkt, wurde der Division für ungefähr zwanzig Tage ein deutsches Infanterieregiment unterstellt ${ }^{199}$; keinerlei Beanstandungen bezüglich der Haltung der Truppe und der Präzision bei der Ausführung der Befehle.

197 Die aufgrund der angespannten Treibstoff- und Transportlage schwierige Verlegung der $A l$ pini aus dem Süden der Ostfront in den Bereich der Heeresgruppe Mitte ist dokumentiert in: AUSSME, L 14/87-2, Comando $8^{2}$ Armata, Ufficio Operazioni: La 2a battaglia difensiva del Don, Teil 3: L'avviamento delle Unità alla zona di riordinamento.

$198 \mathrm{Zu}$ dieser Aktion, deren Scheitern viel dazu beitrug, daß sich die seit dem sowjetischen Angriff ohnehin gespannten Beziehungen zwischen Deutschen und Italienern weiter verschlechterten, vgl. Operazioni delle unità italiane al fronte russo, S. 283 ff;; nach einer Aktennotiz für den Stabschef des Alpinikorps, General Martinat, vom 4. 9. 1942 (AUSSME, DS II 974, KTB Alpinikorps, September/Oktober 1942, Anlage 78) hatten die beiden Bataillone mindestens 81 Tote und 339 Verwundete zu beklagen; 166 Mann galten noch als vermißt.

199 Es handelte sich um das zur 298. Infanteriedivision gehörige Infanterieregiment 526, dessen Unterstellung unter den Befehl der "Tridentina" laut Kriegstagebuch des XXXV. Armeekorps (AUSSME, DS II 680) am 23. 9.1942 angekündigt wurde. 
Auch über die Ungarn gibt es nichts Besonderes zu berichten, doch hatte ich den Eindruck, daß ihre Aktivitäten vor allem dann, wenn sie die Beziehungen zu uns berührten, einen völlig anderen „Stil“ als die der Deutschen besaßen. Insbesondere als die Einheiten im Abschnitt der 23. ungarischen Division abgelöst wurden, legten einige Kommandos gewisse Verhaltensweisen an den Tag, die nicht immer korrekt waren und mit den Anordnungen zusammenhingen, die zu erlassen waren, um den Abtransport von Ressourcen jeder Art aus dem Gebiet zu unterbinden, das in die Zuständigkeit der „Tridentina“ überging. Tatsächlich wurden die Anordnungen eher zum Schein ausgegeben, als daß sie umgesetzt werden sollten, denn trotz aller Ermahnungen, Proteste und Befehle der höheren Kommandos fuhren die Ungarn fort, aus dem Sektor, der auf die „Tridentina“ übergegangen war, alle möglichen Güter wegzubringen, einschließlich des Holzes der Fußböden bestimmter Isbas, die von einigen unserer Kommandos belegt werden sollten.

Diese Umstände haben aber, ich möchte es noch einmal betonen, zu keinem Zeitpunkt die Beziehungen zwischen den Kommandos beeinträchtigt, die im wesentlichen immer herzlich geblieben sind. Was das Verhältnis zu den deutschen Truppen betrifft, die während des Rückzugs Teil der Marschkolonne waren, habe ich den Eindruck, daß recht verzerrte, wenn nicht gar unbegründete Nachrichten nach Italien gelangt sind. Ich schätze, daß sich der Anteil der deutschen Soldaten, die zur Kolonne gehörten, auf acht- bis zehntausend kaum geordnete Männer belief; es handelte sich dabei hauptsächlich um Teile der Versorgungsdienste des XXIV. Panzerkorps, die für den Troß und für enorme, mit jeder Art von Material überladene Schlitten zuständig waren, an deren Rettung sie insbesondere interessiert waren. Aber die militärische Ordnung dieses Haufens ließ zu wünschen übrig; ich erinnere mich, nur sehr wenige Offiziere gesehen zu haben. Es ist nicht ungewöhnlich, daß es während des mühevollen Marsches auf zuweilen sehr engen Pisten zu Zwischenfällen mit den Alpini gekommen ist, denn jeder, der zur Kolonne gehörtc, hatte nur ein Bestreben, nämlich nicht an Boden zu verlieren und sich vom Ende des Zuges fernzuhalten. Auch die Belegung der Isbas gab Anlaß zu zahlreichen Zwischenfällen bei dem Wettlauf, in den am Schluß einer Etappe alle Teile der Kolonne wegen der Angst eintraten, die Nacht im Freien verbringen zu müssen. Und da die Zahl der Isbas in den Orten, wo Station gemacht wurde, nicht ausreichte, um allen Schutz zu gewähren, wurde die Angst vor dem Erfrierungstod zu einer quälenden Sorge. Vorkommnisse von besonderer Schwere habe ich allerdings nicht beobachtet.

Zur Bewaffnung, Organisation und zum Ausbildungsstand des Führerkorps habe ich nicht viel zu sagen. Ich erwähne nur, daß mir das Maschinengewehr nicht hinreichend robust erschien, um bei so niedrigen Temperaturen eingesetzt zu werden, und daß sich das Geschütz 75/13 hinsichtlich Reichweite und Geschoßwirkung als nicht besonders geeignet erwiesen hat, um in so breiten Divisionsabschnitten verwendet zu werden, wie sie in Rußland zu besetzen waren. Bezüglich der Organisation betone ich, daß die Alpinidivision für den Einsatz im Gebirge geschaffen worden ist. Der Einsatz von Gebirgstruppen im russischen Flachland muß als Ausnahme gelten. Für Rußland schienen die 5000 Lasttiere der Division vielleicht zuviel zu sein, insbesondere angesichts der Tatsache, daß in der Winterperiode die Futtermittel vor Ort nicht ausreichten, so daß 50 Prozent davon tief in die Etappe verlegt werden mußten, oft 60 und mehr Kilometer von den Einheiten an der Front entfernt. Hinsichtlich des Führerkorps läßt sich sagen, daß jeder aus Italien gekom- 
mene Offizier mit seiner Einheit Tapferkeit und Geschick gezeigt und sich somit seiner Stellung als würdig erwiesen hat.

Hinsichtlich der logistischen Erfordernisse möchte ich an dieser Stelle bekräftigen, daß die von den höheren Kommandos unternommenen Anstrengungen, die Verpflegung auf jeden Fall - und auf die zweckmäßigste Weise - sicherzustellen, von den Soldaten selbst erkannt und geschätzt worden sind. Bei der Ausrüstung haben sich zwei wesentliche Mängel ergeben: Schuhwerk und Kopfbedeckung. Für Temperaturen, die von Dezember bis Februar zwischen 20 und 40 Grad unter Null schwanken, sind Lederschuhe nicht geeignet; das Oberleder wird spröde, biegt sich nicht und kann auch brechen. Sehr geeignet sind hingegen die sogenannten "Valenki ${ }^{\alpha}$, die von den Russen und den deutschen Truppen benutzt werden und bei denen es sich um nichts anderes als um große Stiefel aus Filz (gepreßte Wolle) handelt, die über den mit einem Wollstrumpf bekleideten Fuß gezogen werden; auf diese Weise ist die Gefahr von Erfrierungen fast vollständig gebannt. Auch die aus einem wollenen Kopfschützer bestehende Kopfbedeckung hat sich bei diesen rauhen Temperaturen als unzulänglich erwiesen, so daß man sagen kann, daß alle Soldaten das Bedürfnis verspürt haben, sich eine eigene Kopfbedeckung anzufertigen, die innen mit Kaninchen-, Hasen-, Schafsfell usw. gefüttert ist und auch ihre Ohren schützt. Solche Bekleidungsstücke haben sich in der Praxis als besonders zweckmäßig erwiesen und hätten auch die reguläre Art der Kopfbedeckung darstellen können.

Zum Schluß möchte ich noch kurz auf die Organisation [eines Aufgabenbereichs] eingehen, den ich als "Logistik und Zivilverwaltung" bezeichne und um den sich jede Division in ihrem Abschnitt zu kümmern hatte. Aus offensichtlichen Gründen mußte man in Rußland Agrarprodukte wie Schlachtvieh, Hafer, Futtermittel, Weizen und Roggen vor Ort requirieren, um einen Teil der logistischen Bedürfnisse der Verbände zu befriedigen. Da man aber sogar für das Mähen, Dreschen und Mahlen des Getreides sowie für das Schneiden des Heus sorgen mußte, ergab sich daraus eine komplexe Organisation des rückwärtigen Gebiets, die viele Offiziere und eine große Zahl von Soldaten band; außerdem verlangte sie vom Divisionskommando, logistische Funktionen wahrzunehmen, die über seine vorrangig operativen Aufgaben hinausgingen. Ähnliches gilt für alle Erfordernisse der Verteidigung des rückwärtigen Gebiets, der Zivilverwaltung, der Überwachung der "Kolchosen “ usw. Für den Fall, daß der Großverband "Division" aufgrund besonderer zufälliger Einsatzbedingungen in Territorien operieren muß, in denen es unabdingbar ist, die genannten Aufgaben zu übernehmen, halte ich es für angebracht zu vermeiden, das Divisionskommando von seinen vorrangig operativen Aufgaben abzulenken. Vielmehr sollte die gesamte Organisation von Zivilverwaltung und Logistik im rückwärtigen Gebiet einem eigens dafür vorgesehenen Organ des übergeordneten Großverbands übertragen werden.

Der Chef des Generalstabs Oberstleutnant A. Ambrosiani

AUSSME, DS II 1554/6. 


\section{Dokument 26}

Bericht des Armeepfarrers der 8. italienischen Armee, Don Arrigo Pintonello200, über die Moral der Truppe und das Verhältnis zwischen

Deutschen und Italienern an der Ostfront, undatiert

Die wilde Natur des Landes, die Ferne des Vaterlands, das häufige Ausbleiben der Post, das Leben in einer zweifach fremden Welt sind Faktoren, die zuweilen die Gefühlslage unseres Soldaten negativ zu beeinflussen vermochten - niemals jedoch so sehr, daß sie seine Moral geschwächt oder seinen [Kampf-]Geist untergraben hätten. Auch in den tragischsten Momenten hat unser Soldat auf russischem Boden immer seine natürliche gute Laune bewahrt, die Gelassenheit, die Zuversicht der Starken. Dies konnte ich bei meinen ständigen Fahrten von einem Ende des Sektors, der unseren Truppen zugewiesen worden war, zum anderen leicht ${ }^{201}$ feststellen; dies habe ich auch immer wieder den Berichten der Militärgeistlichen entnommen. Alle, auch der gemeinste Soldat, hatten das Gefühl, daß von unseren höheren Kommandos nichts unterlassen wurde, um für die Frontkämpfer die Verpflegung, die Ausrüstung, die Postzustellung... usw. sicherzustellen, während ihn die Übersendung von Kleidung und Geschenken aus der Heimat zutiefst berührte ${ }^{202}$.

Es läßt sich jedoch nicht leugnen, daß es zugleich andere Faktoren gab, die sich auf die Moral der Truppe ausgewirkt haben. In erster Linie beziehe ich mich hier darauf, daß der Mehrheit der Soldaten ein klares Bewußtsein von der Notwendigkeit des russischen Feldzugs fehlte: Sie betrachteten den antibolschewistischen Krieg eher als den Krieg des Verbündeten und nicht als ihren eigenen ${ }^{203}$.

Ferner hat sich die allgemeine Überzeugung, daß unser Soldat dem Feind bezüglich der Bewaffnung unterlegen sei, nicht wenig auf seine Gefühlslage ausgewirkt. In Erwartung des allgemeinen russischen Angriffs habe ich von Soldaten of die Antwort bekommen, daß sie bis zuletzt Widerstand leisten würden, daß man aber gegen die russischen Panzer und ihre „Parabellum " nichts auszurichten vermöge ${ }^{204}$. Die Furcht war weit verbreitet, daß es bei einer möglichen feindlichen Offensive an geeignetem Gerät fehlen würde, um Widerstand zu leisten.

Außerdem darf nicht verschwiegen werden, daß eine nachhaltige deutsche Propaganda im Soldaten die Vorstellung weckte, die Gefangenschaft sei mit dem Tod

200 Arrigo Pintonello (1908-2001), katholischer Priester, 1932 geweiht, 1941-1943 leitender Militärseelsorger des CSIR bzw. der 8. Armee, 1953 zum Bischof geweiht und zum Militärbischof der italienischen Streitkräfte ernannt, Titularbischof von Theodosiopolis in Arkadien, 1965-1967 apostolischer Administrator der Diözese Velletri, 1967-1971 Erzbischof der $\mathrm{Di}^{-}$ özese Latina-Terracina.

201 Handschriftlich eingefügt.

202 Tagebücher und Erinnerungen italienischer Soldaten der 8. Armee lassen diese Ausführungen stark geschönt und zweifelhaft erscheinen; vgl. etwa als berühmtes Beispiel Revelli, Mai tardi, S. $46 \mathrm{f}$.

$203 \mathrm{Vgl}$. Schlemmer, Erfahrung und Erinnerung.

204 Gemeint ist wohl die ebenso gefürchtete wie als Beutestück beliebte Infanteriewaffe mit der offiziellen Bezeichnung PPSh 1941, die ab 1942 in großer Stückzahl an die Truppe ausgeliefert wurde. 
selbst gleichzusetzen: von daher der Alptraum, die furchtbare Angst, in die Gefangenschaft des Feindes zu geraten. So etwas war weit davon entfernt, im Soldaten den Kampfgeist zu wecken, verstörte ihn vielmehr und machte ihn äußerst unruhig.

Mißverständnisse und kleine Unstimmigkeiten, die aufgrund von Sprachschwierigkeiten, von psychologischen, aber auch Religionsunterschieden unter Soldaten verschiedener Nationalität unvermeidlich sind, haben ferner dazu beigetragen, die Stimmung zu drücken und die Sehnsucht nach dem fernen Vaterland zu verstärken. Der sehr empfindsame italienische Soldat hatte erwartet, im deutschen Soldaten einen Kameraden zu finden, der ihm ebenso herzlich und großmütig entgegenkommen würde. Von all dem [war] jedoch nichts [zu spüren], und es hat nichts genutzt, $i \mathrm{hm}$ zu wiederholen, daß das deutsche Temperament dem unsrigen entgegengesetzt ist - kalt und der Freundschaft schwer zugänglich. Weit verbreitet war das Gefühl, der Deutsche schätze den italienischen Soldaten nicht. Und dieses Gefühl wurde durch das wenig disziplinierte Verhalten der deutschen Kraftfahrer - die ersten, die man kennenlernte, als man mit den Verbündeten in Kontakt kam - hervorgerufen, weil es sie reizte, sich mit ihren Fahrzeugen auf den Straßen als die Herren aufzuspielen; weil sie sich gewöhnlich weigerten, den Italiener zu Fuß aufzunehmen, wenn er darum bat, aufsitzen zu dürfen; weil die Deutschen es in ihrer großen Mehrheit unterließen, unsere Offiziere zu grüßen; wegen ihrer gering ausgeprägten Gastfreundschaft in den von ihnen bereits belegten Häusern oder - im Falle von Bahnfahrten - in den Zügen; weil sie sich absonderten und gleichsam den Kontakt mit uns zu vermeiden suchten... usw. Tatsächlich kam es mehr oder weniger überall $z u$ derartigen $Z$ wischenfällen.

Ich bin aber davon überzeugt, daß der wichtigste Grund in den Sprachschwierigkeiten liegt, die uns die Verständigung unmöglich machen. Sehr häufig konnte ich auf meinen Fahrten und im Rahmen meiner vielfältigen Beziehungen zu den deutschen Kommandos Äußerungen der lebhaftesten Bewunderung für den italienischen Soldaten, die Leistungsfähigkeit seines Kriegsgeräts und den Wert seines Beitrags zum Krieg ernten. Niemals wurde mir auf meinen unablässigen Fahrten kreuz und quer durch die Ukraine und durch Weißrußland von den deutschen Stellen etwas verweigert - die Bitte beispielsweise, mir einen Schlitten, einen Führer, Material aller Art zur Anlage von Soldatenfriedhöfen, ein Ersatzteil für den Wagen usw. zur Verfügung zu stellen. Und es muß betont werden, daß das zweifellos wenig freundschaftliche Verhalten der deutschen Kraftfahrer - und zuweilen auch des gewöhnlichen Deutschen - während der Fahrten oder im Alltagsleben auch gegenüber den eigenen Landsleuten nicht anders war. Nicht selten hörte man von den Deutschen, daß sie gewöhnlich nur von den italienischen Wagen und nicht von den deutschen aufgenommen wurden.

Während des Rückzugs drohte das Klima im Verhältnis zwischen Italienern und Deutschen freilich feindselig zu werden. Den Deutschen wird vorgeworfen, sie hätten Treibstoff und Kraftfahrzeuge nur sich selbst vorbehalten, unsere in der Steppe herumirrenden Soldaten von ihren Lastwagen weggedrängt und abgewiesen. Das ist häufig vorgekommen; es muß aber auch pflichtschuldig darauf verwiesen werden, daß die Orientierungs- und die Rücksichtslosigkeit, die den brutalen Instinkten des Menschen eigen sind, unter derartigen Umständen am Ende jeglichen Sinn für $\mathrm{Hu}-$ manität und Selbstlosigkeit ersticken. 
Zweifellos ging vom Gastgeber viel Unrecht aus; eines vor allem wird der italienische Soldat niemals vergessen können, daß man nämlich diejenigen, die dem feindlichen Einschließungsring entkommen waren, wochenlang bei unmöglichen Temperaturen auf offenen Waggons oder Flachwagen transportierte, während dem deutschen Soldaten immer zumindest ein Waggon der 3. Klasse vorbehalten war. Zweifellos aber wirkten hier Mißverständnisse und Übertreibungen zusammen, die insbesondere auf die Unmöglichkeit zurückzuführen sind, sich zu verständigen.

Der Armeepfarrer der 8. Armee

(Don Arrigo Pintonello)

AUSSME, DS II 1551/5.

\section{Dokument 27}

\section{Bericht von General Efisio Marras für das Comando Supremo vom 15. Januar 1943}

Italienische Militärmission

Berlin, 15. Januar 1943-XX

in Deutschland

Nr. 51/S

Betreff: Version der deutschen Führung von der Schlacht am Don

Antwort auf das Telegramm 2299/S.G. vom vergangenen 30. Dezember 205

An das

Comando Supremo

Feldpost Nr. 21

Als Antwort auf die an mich gerichtete Anfrage fasse ich zusammen, was sich diesbezüglich aus den Unterredungen sowohl beim OKW als auch beim OKH bzw. beim Oberkommando der Heeresgruppe B ergeben hat, aber auch aus den Gesprächen mit General von Tippelskirch und anderen Verbindungsoffizieren sowie mit deutschen Offizieren, die an den Operationen teilgenommen haben.

Die deutsche Version der Schlacht am Don interessiert nicht so sehr, um den genauen Verlauf der Operationen zu bestimmen, über die noch viele Einzelheiten fehlen, als vielmehr deshalb, weil sie die über diese Operationen abgegebenen Bewertungen vor allem hinsichtlich der Haltung unserer Truppen und letztendlich hinsichtlich der Gründe spiegelt, die den Rückzug bedingt haben.

Es ist vorauszuschicken, daß die feindliche Offensive gegen die 8. Armee die deutsche Führung zu einem Zeitpunkt überrascht hat, als man nach dem Rückschlag bei den rumänischen Armeen und der Isolierung der 6. Armee in Stalingrad die wenigen verfügbaren Reserven bereits eingesetzt hatte. Die deutsche Führung war sich des Ausmaßes der Bedrohung und des Ernstes der Gesamtlage im Südabschnitt anscheinend nicht bewußt, und es ist symptomatisch, daß einige Generalstabsoffiziere noch wenige Tage vor der Offensive der Meinung waren, daß das so- 
wjetische Oberkommando mit seiner Offensive gegen die rumänischen Armeen und gegen Stalingrad seine Offensivkraft für den Winter zum Großteil erschöpft habe 206 .

Soweit es möglich war, wurde die Schlacht vom OKH und vom Oberkommando der Heeresgruppe mit straffem Zügel geführt, und es ist deshalb natürlich, daß man von deutscher Seite über die Ausgangslage der Armee und über die Führung der Schlacht hinwegzugehen neigt. Man tendiert vielmehr dazu, den Mißerfolg der unzulänglichen Ausbildung unserer Truppen und den qualitativen Mängeln des Führerkorps zuzuschreiben, nicht ohne diskret und vage auf einige Fälle von unzureichendem Widerstand und einige Episoden von Panik hinzuweisen. Hierbei muß ich jedoch hinzufügen, daß sich diese Andeutungen nach einigen Tagen Zug um Zug abgeschwächt haben und sich hingegen die Zurückhaltung diesem Thema gegenüber verstärkt hat. Dies entspringt offensichtlich einer bewußt eingenommenen Haltung, aber auch der Tatsache, daß der Gesamtverlauf der Schlacht, die momentan zwischen [dem Sektor] unserer Armee und dem Kaukasus im Gange ist, die Ereignisse in einen größeren Rahmen und so in die richtigen Proportionen gestellt hat, da sich auch die deutschen Verbände zum Rückzug gezwungen sahen ${ }^{207}$.

Dies vorausgeschickt, gebe ich die Meinungen wieder, die mir gegenüber von verschiedenen Kommandeuren und in diversen Stäben geäußert worden sind. Der Generalstabschef des Heeres [Kurt Zeitzler] erklärte mir, er wolle von einer Prüfung der Geschehnisse Abstand nehmen, da die vorhersehbaren gegenseitigen Schuldzuweisungen zwischen deutschen Kommandos einerseits und italienischen Kommandos und Truppen andererseits zu nichts führen würden. Dennoch wies er bei der ersten Unterredung am 27. Dezember auf Fälle von Panik hin und sagte bei der zweiten Unterredung am 14. Januar, die im Zuge der Rückkehr von meiner Reise stattfand 208 , die Verteidigungsanlagen in unserem Sektor seien nach Aussagen von Kriegsgefangenen nicht so robust gewesen wie die in anderen Abschnitten, was nach General Zeitzler damit zusammenzuhängen scheine, daß unsere Abteilungen wenig gearbeitet hätten. Was die Anerkennung der Tapferkeit angeht, die unsere Truppen gezeigt haben, verlieh General Zeitzler, wie im allgemeinen alle deutschen Offiziere, seiner unbedingten Bewunderung für die Division "Julia“ Ausdruck ${ }^{209}$, während er sich hinsichtlich der anderen Verbände zurückhaltender gab.

206 Vgl. dazu S. 63 f. des vorliegenden Bandes.

207 Die weitreichendste Bewegung dieser Art vollzog sich mit dem Rückzug der Heeresgruppe A aus dem Kaukasus; vgl. Wegner, Krieg gegen die Sowjetunion, in: DRZW 6, S. 1064-1068. Zur panikartigen Flucht auch deutscher Einheiten und zur verheerenden moralischen Wirkung sowjetischer Panzerangriffe auf erstmals an der Ostfront eingesetzte deutsche Divisionen vgl. ebenda, S. 1012 mit Anm. 199 und S. 1019 f., sowie Gosztony, Hitlers fremde Heere, S. 324.

208 General Marras brach am 25. 12.1942 zur 8. Armee auf, wo er sich bis zum 10.1. 1943 aufhielt; sein Bericht an Generalstabschef Ugo Cavallero (Nr. 50/S) vom 14. 1. 1943 findet sich im AUSSME, L 13/48-4, und ist abgedruckt in: Ceva, Storia delle Forze Armate, S. 473-484.

209 Eine erzählende Darstellung der Kämpfe der Alpinidivision „Julia“ im Verband des XXIV. deutschen Panzerkorps findet sich bei Caruso, Tutti i vivi all'assalto, S. 69-112; vgl. auch Dok. 8, S. 114. 
General Jodl210 räumte unumwunden ein, daß die deutschen Reserven in unserem Abschnitt unzureichend gewesen seien, und er fügte hinzu, daß diese Blöße sowohl dem starken Verschleiß zugeschrieben werden müsse, den die Operationen gegen Stalingrad gefordert hätten, als auch dem Umstand, daß die ursprünglich im Abschnitt unserer Armee dislozierten Reserven von der Gruppe Hollidt vereinnahmt worden seien ${ }^{211}$. Auch General Jodl verwies auf Episoden von Panik, die sich in unserer Etappe ereignet hätten, und auf die Konfusion unserer in die Gegend von Woroschilowgrad strömenden Versprengten. Er hat mir allerdings auch berichtet, daß sich die Division "Cosseria" nach einer Aussage von General Fegelein dem Führer gegenüber in perfekter Ordnung zurückgezogen habe. Nach den widersprüchlichen Nachrichten, die das Führerhauptquartier während des Besuchs Seiner Exzellenz des Generalstabschefs erreicht hatten, war General Jodl sehr erfreut, mir dies mitzuteilen 212 .

General von Weichs, in dem ich einen loyalen Soldaten gefunden habe, erkannte ebenfalls an, daß Reserven fehlten, und sagte mir im Vertrauen, er habe in einigen Fragen, die ihm in der Vergangenheit vom Oberkommando der 8. Armee vorgetragen worden seien, und insbesondere in der Frage der überdehnten Front [dessen Position] persönlich geteilt, aber es sei ihm nicht möglich gewesen, die Zustimmung des Generalstabschefs des Heeres zu erlangen.

Bei der Führungsabteilung ${ }^{213}$ der Heeresgruppe ist mir gesagt worden, die Division „Ravenna“ habe sich einem Panzerangriff nicht gewachsen gezeigt. Des weiteren hieß es, man habe die Organisation der Panzerabwehr an der Front des II. Armeekorps nach der Zuführung deutscher Panzerjägerkompanien zur Verstärkung als die beste der gesamten Heeresgruppe betrachten müssen ${ }^{214}$. Auf meinen Einwand, daß diese Aufstellung den Vormarsch der Panzer nicht habe verhindern können, erwiderte man, die Panzerjäger seien nach dem Zusammenbruch der $W_{1}$ -

210 Alfred Jodl (1890-1946), Generaloberst, Teilnahme am Ersten Weltkrieg, 1919 in die Reichswehr übernommen, seit August 1939 Chef des Wehrmachtführungsamts bzw. des Wehrmachtführungsstabs, unterzeichnete am 7. 5. 1945 in Reims die Kapitulationsurkunde, Mitglied der Regierung Dönitz, 1946 vom Internationalen Militärgerichtshof in Nürnberg zum Tode verurteilt und hingerichtet.

211 Es handelte sich dabei um die 62. und 294. Infanteriedivision; die 22. Panzerdivision wurde zum XXXXVIII. Panzerkorps beordert; vgl. Wegner, Krieg gegen die Sowjetunion, in: DRZW 6, S. 1030.

212 Ugo Cavallero (1880-1943), Marschall von Italien, 1925-1928 Staatssekretär im Kriegsministerium, anschließend Spitzenpositionen bei Pirelli und Ansaldo, seit 1937 wieder aktiver Offizier, Dezember 1940-Februar 1943 Chef des Comando Supremo, im September 1943 unter ungeklärten Umständen ums Leben gekommen. Cavallero war am 16. 12. in Begleitung von Außenminister Ciano zu einem Meinungsaustausch mit Hitler aufgebrochen und am 22. 12. 1942 wieder nach Rom zurückgekehrt. Vgl. Cavallero, Diario, S. 616-631.

213 In der Vorlage wörtlich: „ufficio operazioni“.

214 Ende November 1942 verfügte das II. Armeekorps mit den Divisionen "Cosseria" und "Ravenna" über 78 Pak 47/32 und über 12 Pak vom Kaliber $7,5 \mathrm{~cm}$; dazu kamen drei auch zur Panzerabwehr geeignete Batterien des italienischen Artillerieregiments 201 mit zehn Geschützen vom Typ 75/32 im Abschnitt der Division "Ravenna“. BA-MA, MFB4 18276, Bl. 279, Fernschreiben des AOK 8 (Nr. 02/6530 - gez. Bruno Malaguti) an die Heeresgruppe B vom 30. 11. 1942. Kurz vor Beginn des sowjetischen Angriffs wurden auch deutsche Panzeriäger zum II. Armeekorps verlegt (vgl. hier S. 63). Akten zu den Versuchen, der 8. Armee praktisch im letzten Moment zusätzliche panzerbrechende Waffen zuzuteilen, finden sich auch im BA-MA, RH 32 IX/72. 
derstandslinie nicht in der Lage gewesen, sich der feindlichen Infanterie zu erwehren.

Es ist interessant festzustellen, daß nach Aussage dieser Dienststelle der sowjetische Vormarsch durch das von der Division Celere gehaltene Tichaja-Tal eine wichtige Rolle für den Rückzug gespielt hat. Das ist die einzige in diese Richtung gehende Behauptung. Man muß berücksichtigen, daß sich die Front der Division Celere über ungefähr $50 \mathrm{~km}$ erstreckte ${ }^{215}$. Dieselbe Dienststelle räumte mir gegenüber den Mangel an Reserven und den Umstand ein, daß die 385. deutsche Infanteriedivision zu Schlachtbeginn gerade anzurollen begann und daß die 27. Panzerdivision nur über 47 Panzer verfügte ${ }^{216}$. Man gab ferner zu, daß die Schlacht um Stalingrad bezüglich der Zuweisung von Material und Betriebsstoff auch auf die 8. Armee erhebliche Auswirkungen hatte. Die Leistungsfähigkeit der Verteidigungsorganisation wurde als gut bezeichnet; die Zahl der Panzerabwehrminen, die der Armee zur Verfügung standen, konnte man für ausreichend halten, doch es stellte sich heraus, daß ein großer Teil in Reserve gehalten worden war.

Ein Feindlageoffizier der Heeresgruppe sagte ausdrücklich, daß sich unsere Truppen gut geschlagen haben, und fügte hinzu, es sei ein schwerer Fehler gewesen, daß nach dem Zusammenbruch der rumänischen Armeen nicht der Befehl gegeben worden sei, die Front generell zurückzuverlegen. Ein in diese Richtung gehender Vorschlag des Generals von Weichs ist vom Oberkommando abgelehnt worden 217 .

General von Tippelskirch, Chef des Verbindungskommandos beim Armeeoberkommando, faßte sein Urteil über die Ereignisse dergestalt zusammen, daß die 8. Armee aufgrund des Ausbildungsstands nicht in der Lage gewesen sei, einem Großangriff mit Panzern zu begegnen. Ferner hat er betont, daß unser taktisches Vorgehen nicht den Notwendigkeiten der russischen Front entsprochen und er sich vergeblich dafür eingesetzt habe, die neuen deutschen Methoden, die auf den Lehren des vergangenen Winters beruhten, bei unseren Verbänden zu verbreiten. Die italienischen Verbände hätten an einer Staffelung von Truppen und Gerät festhalten wollen, was die Widerstandskraft der vordersten Linie geschwächt habe. Schließlich habe er die übermäßige Besatzung der Stützpunkte, die unzureichende Aufgliederung der Artillerie, den fehlerhaften Einsatz der Nachrichten[truppe] kritisiert und damit geschlossen, daß der Kampf von italienischer Seite mit einem zu hohen Aufwand an Menschen geführt werde ${ }^{218}$. Bezüglich des Kampfwerts unserer Truppen zeigte er sich sehr zurückhaltend. Über die Division nJulia“ äußerte er sich sehr positiv; er sagte [auch], daß sich die Artillerie gut geschlagen habe, wobei er insbesondere auf die Artillerie der Divisionen Celere und „Pasubio“ verwies, während hingegen einige Einheiten der Division "Pasubio" nicht genügend $W_{1}$ iderstand geleistet hätten. Ferner hob er die Folgen der Ablösung hervor.

215 Vgl. Dokument 18 mit Anm. 67.

216 Vgl. Dok. 19 mit Anm. 89.

217 Wegner, Krieg gegen die Sowjetunion, in: DRZW 6, S. 1026, berichtet lediglich von einem Vorstoß des zögernden Oberbefehlshabers der Heeresgruppe B vom 23. 11. 1942 zur $\mathrm{Zu}$ rïcknahme der 6. Armee.

218 Eine Zusammenfassung der Besprechung zwischen von Tippelskirch und Marras findet sich im BA-MA, MFB4 41403, Bl. 1107, KTB des Deutschen Generals beim italienischen AOK 8, Eintrag vom 5. 1. 1943. 
Festzuhalten ist, daß diese Urteile ein Echo dessen darstellten, was die einzelnen Verbindungsoffiziere - von denen einige auch niedrige Ränge bekleideten - berichtet hatten, und daß zum Zeitpunkt meiner Unterredung nicht alle Berichte eingegangen waren, so daß die Eindrücke zwangsläufig unvollständig blieben. Allerdings ändert dies nichts daran, daß diese umgehend an die vorgesetzten Kommandos gesandten Eindrücke an höherer Stelle zuweilen maßgebend werden.

Der Kommandeur der 298. Division ${ }^{219}$, die zwischen den Divisionen "Ravenna“ und "Pasubio" aufgestellt war und sich aufgrund eines direkten Befehls des Generals von Tippelskirch zusammen mit einigen Einheiten der Division "Pasubio" und der Division "Torino“ zurückgezogen hatte, legte unseren Truppen gegenüber einen gewissen Groll an den Tag. Er erzählte mir von einer in einem anderen Bericht wicdergegebenen Episode, wonach sich einer unserer Regimentskommandeure aus einer anderen Division geweigert habe, seine Befehle zu befolgen, die er auch im

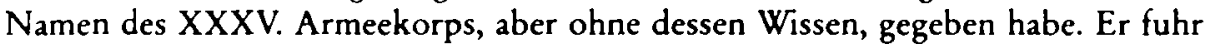
fort, er habe bei unseren Einheiten eine gewisse Trägheit festgestellt, wenn es ans Arbeiten gegangen sei. Er hat sich über den wenig ausgeprägten Kampfgeist einiger Elemente beklagt, die mit seiner Division nach Tschertkowo gelangt sind. Diese Kräfte sind in jener Ortschaft eingeschlossen, die der deutsche General im übrigen verlassen hat.

Schließlich teile ich mit, daß General Schlemmer, Verbindungs[-Offizier] beim Alpinikorps, mir gegenüber geäußert hat, keine Truppe habe dem sowjetischen Angriff widerstehen können, der mit einer neuen Taktik geführt worden sei. Auch er räumt ein, daß die Reserven eher hätten herangeführt werden müssen. Er sagte ferner, daß es sich beim 318. Infanterieregiment, das von der deutschen Führung an die wichtige Nahtstelle zwischen der "Cosseria“ und der "Ravenna“ beordert worden war, um ein minderwertiges Regiment gehandelt habe 220 .

219 Arnold Szelinski (1891-1943), Generalleutnant, Teilnahme am Ersten Weltkrieg, 1919 in die Reichswehr übernommen, bis 1933 zumeist als Kompaniechef verwendet, 1935 als Oberstleutnant Bataillonskommandeur, 1939-1942 als Oberst Regimentskommandeur, 1942 als Generalmajor Kommandeur der 298. Infanteriedivision, am 27. 12. 1942 abgelöst, seit April 1943 als Generalleutnant Kommandeur der 376. Infanteriedivision, im Dezember 1943 an der Ostfront gefallen.

220 Das Grenadierregiment 318, das zur im rückwärtigen Gebiet der Heeresgruppe B operierenden 213. Sicherungsdivision gehörte, wurde in der Nacht vom 7.12. auf den 8.12.1942 im Bercich des II. Armeekorps zwischen die Divisionen "Cosseria“ und "Ravenna“ eingeschoben, um einen Frontabschnitt zu verteidigen, der aufgrund der Beschaffenheit des Geländes als besonders gefährdet galt. Das Regiment, das rund 2900 Mann stark war, stellte cigentlich keine Kampf-, sondern eine Besatzungs- und Sicherungstruppe dar. Nur etwa die Hälfte der Soldaten waren kampferprobt; die 500 Mann, die das Regiment erst vor kurzem als Ersatz erhalten hatte, waren nach Angaben des Regimentskommandeurs über 40 Jahre alt und mangelhaft ausgebildet. Zum Einbau des Grenadierregiments 318 in die Front des II. Armeekorps und zu seinem Kampfauftrag vgl. AUSSME, DS II 1126 a, KTB II. Armeekorps, November/Dezember 1942, Anlage 297: Comando $11^{\circ}$ Corpo d'Armata, Ufficio Operazioni, an Comando Divisione "Cosseria" (Nr. 4695/02 di prot.) vom 4. 12. 1942, und DS II 1094, KTB Division "Cosseria“, November/Dezember 1942, Anlage 323: Grenadierregiment 318: Regimentsbefehl zur Verteidigung des Frontabschnitts am Don vom 7.12. 1942 (italienische Ubersetzung); zur Zusammensetzung des Regiments vgl. BA-MA, MFB4 18276, BI. 178, Notiz über einen Anruf des Kommandeurs des Grenadierregiments 318, Oberst Mielke, am 27.11. 1942; zu Kampf und Rückzug des Regiments zwischen Dezem- 
Abschließend scheint sich aus diesen verschiedenen Urteilen seitens deutscher Stäbe und Offiziere zu ergeben, daß

- einige gravierende Defizite der deutschen Seite - darunter vor allem das Fehlen von Reserven - im allgemeinen zugegeben werden;

- die Tapferkeit unserer Truppen in einigen Fällen anerkannt wird, man sich in dieser Hinsicht aber im allgemeinen sehr zurückhält, was wahrscheinlich jenem übertriebenen Bewußtsein der eigenen Tapferkeit zugeschrieben werden muß, das dazu führt, daß der deutsche Soldat ziemlich streng und nicht immer unvoreingenommen über andere urteilt;

- vage Andeutungen hinsichtlich einiger Fälle zu schwachen Widerstands und Panik gemacht worden sind;

- sich weitere Kritik gegen den insbesondere für den russischen Kriegsschauplatz [ungenügenden] Ausbildungsstand unserer Truppen richtete; gleichzeitig haben einige unser gutes Menschenmaterial im Bereich der Mannschaften und die qualitativen Mängel des Führerkorps hervorgehoben.

Abschließend kann ich den Eindruck wiedergeben, daß einige vorschnelle, in den ersten Tagen von der deutschen Seite über unsere Truppen gefällte Urteile, angesichts der Tatsache nach und nach abgeschwächt worden sind, daß sich die Schlacht immer mehr ausdehnte und zahlreiche weitere deutsche Verbände den Rückzug antreten mußten. Derartige Urteile mögen auf vereinzelten, noch zu klärenden Vorfällen beruhen, aber ich denke, daß unsere Verbündeten vor allem von den Anzeichen des Chaos im rückwärtigen Gebiet beeindruckt worden sind.

Chef der Mission

General Marras

AUSSME, L 13/48-4.

\section{Dokument 28}

Bericht von General Efisio Marras für das Comando Supremo vom 20. Februar 1943

Italienische Militärmission

in Deutschland

Betreff: Haltung des deutschen Oberkommandos gegenüber der 8. Armee

An das Comando Supremo (drei Ausfertigungen)

Feldpost Nr. 21

Das unglückliche Geschick, das der 8. italienischen Armee zuteil geworden ist, die trotz der von der Truppe unter Beweis gestellten verbissenen Tapferkeit - ein Zeugnis, das in Zukunft einen Grundpfeiler für den Ruhm unseres Heeres bilden wird ein umfassendes Rückzugsmanöver vollzogen und schwerste Verluste erlitten hat,

ber 1942 und Januar 1943 vgl. den ausführlichen Einsatzbericht vom 15. 2. 1943 im BA-MA, RH 22/129. 
läßt sich anscheinend zum größten Teil auf die Irrtümer und Defizite der deutschen Führung zurückführen. Diese Irrtümer und Defizite lassen sich in folgenden Punkten zusammenfassen:

- übermäßige Ausdehnung des der Armee zugewiesenen Sektors;

- ausgebliebene Zuweisung zusätzlicher Waffen und adäquaten Befestigungsmaterials, die notwendig gewesen wären, um den Sektor hinreichend auszubauen;

- ungenügende Zuweisung von Eisenbahntransporten und des benötigten Treibstoffs; der vollständige Verlust der Artillerie und der Verlust des größten Teils der Kraftfahrzeuge ist vor allem der chronisch unzureichenden Versorgung mit Treibstoff geschulder;

- Absenz von Großverbänden der zweiten Linie, die der Armee versprochen worden waren; auch sah sich das deutsche Oberkommando nicht in der Lage, rechtzeitig Reserven aus anderen Abschnitten heranzuführen;

- Beschränkungen jeglicher Art, die der Befehlsführung unserer Armee von der deutschen Führung auferlegt wurden.

Bekanntlich haben es sowohl das Oberkommando der 8. Armee und die ihm unterstellte Intendenza als auch diese Dienststelle in ihrer Funktion als Bindeglied zum deurschen Hauptquartier während des ganzen Sommers und des vergangenen Herbstes nicht unterlassen, wiederholt darauf zu bestehen, die notwendigen Voraussetzungen sicherzustellen, um es der Armee zu ermöglichen, einer großangelegten sowjetischen Offensive zu begegnen, die der Führer selbst von Anfang an vorausgesehen hatte ${ }^{221}$. Dieses Drängen zeigte zweifellos eine gewisse positive $W_{11}$ kung, führte aber insgesamt nicht dazu, die Situation grundlegend zu ändern, wie es notwendig gewesen wäre.

Die Argumente, auf die sich die verschiedenen Ebenen der deutschen Führung stützten, um das Ausbleiben der Vorkehrungen zu rechtfertigen, verwiesen im allgemeinen immer auf die schwerwiegenderen und dringlicheren Bedürfnisse, die sich aus den Operationen im Kaukasus und gegen Stalingrad ergaben. Aber abgesehen von der Verminderung unseres Bedarfs geschah es ständig, daß die versprochenen Transporte und Treibstofflieferungen noch weiter reduziert wurden und daß die deursche Seite bei vielen wichtigen Fragen versuchte, die Lösung hinauszuschieben ${ }^{222}$ bzw. die Fragen selbst aufgrund unterschiedlicher Kompetenzansprüche von Kommando zu Kommando weiterzugeben.

Ohne weiter auf diese aufreibende und gefährliche Situation einzugehen, die sich bereits vor dem Rückzug eingestellt hatte, muß man die Aufmerksamkeit jetzt auf die Haltung richten, die das deutsche Oberkommando während des Rückzugs der 8. Armee gegenüber eingenommen hat; diese führte zu neuen Verlusten unter unseren Truppen und brachte sie in eine materiell wie moralisch ausgesprochen schwie-

$221 \mathrm{Vgl}$. S. 60 des vorliegenden Bandes. Die ergriffenen Maßnahmen zur Sicherung der Donfront waren jedoch bestenfalls halbherzig, zumal die für die Feindlagebeurteilung zuständige Abteilung Fremde Heere Ost noch zwei Wochen vor der sowjetischen Offensive gegen die 6. Armee nicht mit einem Angriff im großen Don-Bogen gerechnet hatte. Vgl. Wegner, Krieg gegen die Sowjetunion, in: DRZW 6, S. 1012-1017.

222 So vertröstete etwa Freiherr von Weichs am 24. 8. 1942 (Ia Nr. 2633/42 geh. Kdos.) General Gariboldi, man werde der 8. Armee "nach Abschluß der Kampfhandlungen um Stalingrad“ ausreichende Kräfte zuführen; so lange müsse man mit dem auskommen, was zur Verfügung stehe. AUSSME, DS II 1551/1. 
rige Lage. Vor allem kann man sagen, daß die deutschen Kommandos nach Beginn des Rückzugs deutlich die Tendenz zeigten, sich nicht für die 8. Armee zu interessieren; sie überließen unsere Truppen sich selbst, auf daß sie sich mit eigenen Mitteln auf die bestmögliche Weise durchschlügen ${ }^{223}$. Das Hauptargument, mit dem man in den ersten Tagen des Rückzugs auf unser Drängen antwortete, war, daß man von deutscher Seite zwar das Möglichste tun würde, daß es aber der Ernst der Lage unbedingt verlangte, den Bedürfnissen der an der Front kämpfenden Verbände den Vorrang zu geben.

Diese Haltung erklärt die großen Verzögerungen und Defizite bei den deutschen Hilfsmaßnahmen, die nach all den Opfern, die unsere Truppen und insbesondere das Alpinikorps erbracht haben, um so gebotener gewesen wären; dieses war am weitesten von den wichtigen Nachschubwegen entfernt und hat am meisten gelitten. Dieser substantielle Mangel an Unterstützung wurde von den deutschen Stellen hinter der größtmöglichen formellen Höflichkeit versteckt, die immer von dem Versprechen begleitet war, uns soweit wie möglich entgegenzukommen. Die konkreten Ergebnisse blieben jedoch immer weit hinter den Versprechungen und vor allem hinter den wirklichen Bedürfnissen zurück.

Um die Defizite und Verzögerungen zu rechtfertigen, wurden und werden weiterhin unterschiedliche Verfahren angewandt. Häufig ist die Lösung unter verschiedenen Vorwänden in der Gewißheit verschoben worden, daß viele Probleme in der Zwischenzeit notwendigerweise - wenn auch unter schweren Opfern - aufgrund eigener Initiativen behoben, wenn nicht gar durch Feindeinwirkung gänzlich beseitigt würden. Dies ist z. B. bei der Räumung einiger Depots geschehen; erst stellte man dafür keine Transportmittel zur Verfügung, um freilich dann mit dem Hinweis auf die zur Eile drängende Lage deren Übergabe zu verlangen, als eine Zerstörung der Depots letztendlich gar nicht erforderlich war. Ein anderes Verfahren besteht darin, die Daten über unseren Bedarf zu verlangen und zu kontrollieren, was einen verhängnisvollen Zeitverlust mit sich bringt.

Noch häufiger ist die Methode, daß man von der vermeintlichen Nichtzuständigkeit des deutschen Kommandos ausgeht, an das der Antrag gerichtet war, und auf andere Instanzen verweist, die dann ihrerseits auf Anfrage erklären, daß sie aufgrund fehlender Befehle nicht handeln können. So ist es bezüglich der Transportfragen geschehen, die den wesentlichen Teil ausmachten. Was diese Fragen angeht, hat das OKH sehr oft geantwortet, daß sie in den Kompetenzbereich der Heeresgruppen oder besonderer Transportleitstellen fielen, wodurch unser Oberkommando bzw. unsere Intendenza - angesichts der außerordentlichen Streuung unserer Kräfte - gezwungen war, sich an die Heeresgruppe Don, die Heeresgruppe B, die Heeresgruppe Mitte oder an das Sonderkommissariat Transporte Süd zu wenden. Man muß hinzufügen, daß hinsichtlich der Organisation des Gebiets von Gomel auch die Zuständigkeiten des Kommandos für das rückwärtige Gebiet der Heeresgruppe Mitte und neuerdings auch die des Militärbefehlshabers im Generalgouvernement berührt sind. Daraus ist leicht zu ersehen, welche und wie viele Schwierigkeiten überwunden werden müssen, um diese Kontakte aufzunehmen, wobei das deutsche

223 Gegenüber dem Auswärtigen Amt gab man im OKW zu, daß die italienischen „Beschwerden und Wünsche bis zu einem gewissen Grade begründet" seien. ADAP, Reihe E, Bd. 5, S. 435 f.: Aufzeichnung des Botschafters z.b.V. Ritter vom 20. 3. 1943. 
Verbindungskommando beim Armeeoberkommando anscheinend keine große Hilfe ist. Vor allem aber muß hervorgehoben werden, daß aufgrund dieses Verschiebens von Kompetenzen und dieses Mangels an Befehlen immer wertvolle Zeit verlorengeht.

Andererseits fehlt es nicht an anderen Verhaltensweisen. Symptomatisch ist die Tatsache, an die General Biglino erinnert hat, daß sich Zugeständnisse häufig durch Geschenke an untergeordnete Dienststellen sehr viel schneller erreichen lassen; so erhielt man vor kurzem z. B. aufgrund eines Präsents von 40 Flaschen Kognak sofort einen Zug zu 40 Waggons.

Zu einer spürbaren Verbesserung der Situation kam es nach einer vom Duce befohlenen energischen Intervention, die beim deutschen Oberkommando durchaus einen gewissen Eindruck hinterlassen hat ${ }^{224}$. Marschall Keitel, General Zeitzler und der Generalquartiermeister ${ }^{225}$ gaben bei dieser Gelegenheit die umfassendsten Versicherungen ab, wobei sie, wie üblich, die Unzulänglichkeiten der Vergangenheit mit dem Ernst der Lage rechtfertigten. Trotzdem sind die Schwierigkeiten noch nicht überwunden. Die Gründe sind komplex. Einerseits muß eingeräumt werden, daß die deutsche Führung einer schweren Krise gegenübersteht, die es tatsächlich verlangt, daß man die Aufmerksamkeit und die [zur Verfügung stehenden] Mittel vor allem auf die an der Front kämpfenden Truppen und auf die Zuführung der Reserven konzentriert. Es besteht auch der Eindruck, daß die deutsche Führung weder in der Lage ist, die Situation vollständig zu kontrollieren noch Mißstände zu verhindern, die an der Peripherie auftreten.

Andererseits kann man in der deutschen Führung ein gewisses Unverständnis nicht ${ }^{226}$ verhehlen, das von der außerordentlichen formellen Höflichkeit kaum verdeckt wird. Dieses Unverständnis ist bei einigen peripheren Dienststellen noch ausgeprägter. So erklärt sich, daß die deutsche Führung noch zu oft allgemeine Versicherungen abgibt, aber konkreten Antworten ausweicht oder sic hinauszögert. Der Eindruck bleibt nicht aus, daß man - ist der aktuelle Anlaß einmal vorbei227 - an der zuvor gewählten Verfahrensweise festhält, um die im ersten Moment gezeigte gröBere Tatkraft und [das Interesse] an einer verstärkten Sorge um unsere Truppen verpuffen zu lassen.

Diese Haltung ist zu einem Zeitpunkt besonders besorgniserregend, wo die Unterkünfte für unsere Truppen noch so weit entfernt scheinen und wo große Teile un-

224 General Ambrosio forderte Marras am 6. 2.1943 im Namen Mussolinis auf (Fernschreiben Nr. 20481/Op. di prot.), energisch beim OKW zugunsten der 8. Armee zu intervenieren, um Transportraum und Treibstoff zur Verlegung der Reste der italienischen Verbände zu erhalten. Mussolini selbst bekräftigte diesen Auftrag am 7.2. 1943 (Fernschreiben Nr. 20484/Op. - PAPA di prot. an Marras). Über die Gespräche, die Marras im Zuge dieser Weisung im Führerhauptquartier vor allem mit Keitel führte, berichtete er am 10. 2. 1943 ausführlich nach Rom. Die hier zitierten Dokumente finden sich im AUSSME, L 13/48-4 und 48-6.

225 Eduard Wagner (1894-1944), General der Artillerie, Teilnahme am Ersten Weltkrieg, 1936-1940 Chef der Abteilung VI im Generalstab des Heeres, 1940-1944 Generalquartiermeister des Heeres, vereinbarte Richtlinien über die Zusammenarbeit von Wehrmacht und SS in Polen und in der Sowjetunion, Mitverschwörer des 20. Juli 1944, beging nach dem Scheitern des Attentats Selbstmord.

226 Handschriftlich eingefügt.

227 In der Vorlage wörtlich: "ssuperato il primo momento“. 
serer Verbände ungeheure Qualen erdulden. Da die deutsche Führung über die Eisenbahntransporte und die Treibstoffzuweisungen entscheidet, ist sie im wesentlichen dazu in der Lage, unser Oberkommando vollständig zu kontrollieren und in einen Zustand unbeschränkter Abhängigkeit zu versetzen, der zuweilen zur Ohnmacht gerät.

Aufgrund meiner Kenntnis des Milieus und der Personen betrachte ich es als notwendig, an einer klaren, korrekten und entschlossenen Linie festzuhalten, die allerdings von der Forderung begleitet werden muß, bei der Durchführung der deutschen Truppentransporte in Italien [das Gesetz] der Reziprozität in vollkommener Weise zu wahren. Auszuschließen sind alle Schritte, die als Vergeltungsmaßnahmen gedeutet werden können; sie sind auf jeden Fall zu vermeiden, doch es muß alles getan werden, um unser Recht auf mehr Rücksicht und angemessenere Behandlung durchzusetzen.

Der General und Chef der Mission (E. L. Marras)

AUSSME, L 13/48-4.

\section{Dokument 29}

Bericht über die Mission von Oberstleutnant Brunetto Paoli228 bei der 8. italienischen Armee vom 3. bis 15. Februar 1943

Generalstab des Königlichen Heeres

Abteilung Versorgungsdienste II

P.M. 9, den 16. Februar 1943-XXI

\section{$\underline{\text { Denkschrift }}$}

Betreff: Bericht über die Mission von Oberstleutnant Paoli bei der 8. Armee

1. Zweck der Mission: Kontaktaufnahme mit der 8 . Armee, um die angesichts der Lage wichtigsten Bedürfnisse - insbesondere in logistischer Hinsicht - kennenzulernen.

2. Zeitplan: Abfahrt aus Italien mit Militärtransport am 3. Februar und Rückkehr auf demselben Weg am 15. Vom 7. bis zum 11. Februar fünf Tage Aufenthalt im Sektor der 8. Armee. Kontakt aufgenommen mit: Seiner Exzellenz General Gariboldi, Oberbefehlshaber der 8 . Armee und seinem Generalstab in Borsna ${ }^{229}$;

228 Brunetto Paoli, Oberstleutnant i. G., Leiter der „Sezione Russia“ im Generalstab des italienischen Heeres.

229 Das AOK 8 befand sich bis zum 28. 2. 1943 in Borsna und wurde dann nach Gomel verlegt; AUSSME, L 14/87-2, Comando ${ }^{2}$ Armata, Ufficio Operazioni: La $2^{2}$ battaglia difensiva del Don, Teil 3: L'avviamento delle Unità alla zona di riordinamento, Anlage 29 III: Funkspruch (Nr. 02/1116) AOK 8 an die unterstellten Verbände vom 26. 2. 1943. 
Seiner Exzellenz General Zingales, Kommandeur des XXXV. Armeekorps ${ }^{230}$, der momentan mit dem Kommando des Auffrischungsraums in Neshin betraut ist; General Biglino, Quartiermeister der 8. Armee, und seinem Generalstab in Neshin und Kiew; General Baggi231, Kommandeur des rückwärtigen Gebiets Ost in Lemberg; der Inspektion des rückwärtigen Gebiets Nr. 2 (Kiew); verschiedenen Etappen[-Kommandos] entlang der Reiseroute; Besuch der Quarantänelager in Udine und Osoppo 232 .

3. Lage: taktische [und] strategische Lage bekannt, täglich neue Entwicklungen, so daß der Stand vom letzten Tag des Aufenthaltes im Sektor [der 8. Armee] bei der Rückkehr nach Italien bereits überholt ist. Zum Zeitpunkt, als sich der Unterzeichnete im Sektor [der 8. Armee] befand, konnte man davon ausgehen, daß die Armee in drei große Blöcke geteilt war, die keinen Feindkontakt mehr hatten ${ }^{233}$ : ungefähr 15000 Mann und etwa $100 \mathrm{Kraftfahrzeuge,} \mathrm{die} \mathrm{bereits} \mathrm{im} \mathrm{Raum} \mathrm{Nes-}$ hin angekommen waren; ungefähr 60000 Mann auf dem Rückzug (großteils zu Fuß, wie im folgenden genauer dargelegt wird) entlang der Marschroute Woroschilowgrad - Rykowo - Stalino - Dnjepropetrowsk - Neshin; ungefähr 20000 Alpini auf der Marschroute Achtyrka (Ankunft am 10. des laufenden Monats) - Gadjatsch - Romny - Bachmatsch (300 km nördlich der vorgenannten Marschroute). Alles in allem ungefähr $95000 \mathrm{Mann}$; es handelt sich dabei um einen groben Richtwert, denn es ist aufgrund der Entfernungen und fehlender Verbindungen bis heute nicht möglich, auch nur Näherungswerte zu erhalten. Von dieser Masse an Männern befinden sich, wie gesagt, noch etwa 80000 in Bewegung, und wenn diese, wie es scheint, weiterhin zu Fuß erfolgen muß, wird ein großer Teil der Soldaten aufgrund der Entbehrungen und Strapazen auf der Strecke bleiben. Die Straßen und Fahrbahnen sind mit Eis und Schnee bedeckt, was es während des Marsches schwierig macht, das Gleichgewicht zu halten. Die schon tagsüber rigide Temperatur erlaubt es, selbst wenn man über Decken, Wollkleidung und Pelze verfügt, auf keinen Fall, ohne ein angemessenes $\mathrm{Ob}$ dach, das zumindest vor dem Wind schützt, im Freien zu übernachten.

Für die Verpflegung ist bekanntlich ${ }^{234}$ die deutsche Seite zuständig, welche die deutsche Ration ausgibt, die nicht immer vollständig ist und viele Nahrungsmittel enthält, die nicht nach italienischem Geschmack sind, weil sie die von der 8. Armee vorgesehenen Lebensmittel nicht ausgeben kann. Tabakwaren fehlen fast vollständig, und Wein gibt es überhaupt nicht. Unabhängig davon, ob Lebensmittel zur Verfügung stehen, hat die italienische Intendenza keine Möglich-

230 In der Vorlage falsch: „XXXIV ${ }^{\circ}$ Corpo d'Armata ${ }^{“}$.

231 Carlo Baggi (geb. 1882), Generale di Divisione, 1942/43 Kommandeur des rückwärtigen Gebiets Ost.

232 In diesen Lagern verbrachten die von der Ostfront zurückkehrenden Soldaten die vorgeschriebene zweiwöchige Quarantäne; ACS, T-821/374, Bl. 5-8, Stato Maggiore del Regio Esercito (Nr. 135700/10900/R. di prot. - segreto) vom 23. 4. 1943: Rimpatrio del $\mathrm{II}^{\circ}$ Corpo d'Armata.

233 Von italienischer Seite zu diesem schwierigen Transfer zusammengestelltes Material findet sich im AUSSME, L 14/87-2, Comando 8 armata, Ufficio Operazioni: La $2^{a}$ battaglia difensiva del Don, Teil 3: Lavviamento delle Unità alla zona di riordinamento.

234 In der Vorlage handschriftlich gestrichen. Diese und andere Streichungen wurden jedoch offensichtlich nicht vom Autor des Berichts, sondern im Zuge einer späteren Bearbeitung vorgenommen und fanden bei der Übertragung des Dokuments daher keine Beachtung. 
keit einzugreifen, weil keine Verbindung zu den Truppen auf dem Marsch besteht, deren Bewegungen von deutscher Seite gesteuert werden, die, soweit verfügbar, Treibstoff und Eisenbahntransporte zur Verfügung stellen müßte. Um die Verpflegung der Truppen, die im Auffrischungsraum von Neshin angekommen sind, kümmert sich hingegen die italienische Intendenza in Übereinstimmung mit der deutschen Seite. Die Zubereitung der Mahlzeiten für die Truppen auf dem Marsch erfolgt fast immer behelfsmäßig235.

Zum Zeitpunkt, an dem ich den Sektor [der 8. Armee] verließ, ergab es sich, daß die deutsche Seite dem südlichen Block ${ }^{236}$ einige Züge zugestanden hatte, um dessen Marschbewegungen zu erleichtern. Der Quartiermeister hat seinerseits am 10. dieses Monats ${ }^{237}$ angeordnet, unabhängig von der Notwendigkeit, die Depots zurückzuverlegen, alle noch betriebsbereiten Kraftfahrzeuge zum Truppentransport einzusetzen, soweit es sich mit der Verfügbarkeit von Treibstoff vereinbaren läßt.

Für die Verlegung der Alpini wurde die deutsche Seite gebeten, wenigstens die Route unseres dreimal pro Woche angesetzten Transports von Neshin nach Gadjatsch zu verlängern, doch die Antwort fiel negativ aus, wobei man technische Gründe anführte. Es sei hervorgehoben, daß für die Fahrt beheizte Züge unentbehrlich sind; in den unbeheizten Güterwaggons sind die Erfrierungen überaus zahlreich; wer sich auf die offenen Waggons wagt, wie es zuweilen geschehen ist, ist endgültig dem absoluten Erfrierungstod ausgesetzt. Die überlebenden Alpini werden zwischen dem 20. und 25. dieses Monats im Raum Neshin ankommen; die Marschbewegungen der Gruppe Süd (60000 Mann) werden noch 30-40 Tage dauern. Entsprechend der letzten Anordnungen wird man dann weitermarschieren müssen, um aus dem Raum Neshin in den Raum Gomel zu gelangen $(200 \mathrm{~km})^{238}$.

Die Artillerie ist vollständig verloren, abgesehen von zwei Gruppen der Armce mit Flugabwehrkanonen 75/46, die sich noch auf dem Marsch befinden, und

${ }^{235}$ General Gariboldi beklagte sich am 14.2. 1943 in einem Funkspruch (Nr. 02/844) an das Comando Supremo in Rom, General Marras und den italienischen Verbindungsstab bei der Heeresguppe B (AUSSME, L 14/87-2, Comando $8^{2}$ Armata, Ufficio Operazioni: La 2a battaglia difensiva del Don, Teil 3: L'avviamento delle Unità alla zona di riordinamento, Anlage $28 \mathrm{~h}-\mathrm{III})$ : ,Auch Verpflegung unserer unglücklichen Truppen von deutscher Seite ist unzulänglich. Brot fehlt wegen Mangel an Brennholz. Heute, 14. [Februar], nur Kartoffeln ausgegeben. Zu den Entbehrungen [kommt] der Hunger."

236 Diese Kolonne, die den weitesten Weg zurückzulegen hatte, bestand vor allem aus den Resten des II. und des XXXV. Armeekorps; AUSSME, L 14/87-2, Comando $8^{\mathrm{a}}$ Armata, Ufficio Operazioni: La $2^{a}$ battaglia difensiva del Don, Teil 3: L'avviamento delle Unità alla zona di riordinamento, Anlage 16-III: Fernschreiben AOK 8 an das Comando Supremo, das Oberkommando des italienischen Heeres und an General Marras vom 1. 2. 1943.

237 An dieser Stelle handschriftlich vermerkt "Februar". Die hier angesprochene Anordnung wurde nicht ermittelt; das Kriegstagebuch der Intendenza für diese Monate ist nicht überliefert.

238 Das AOK 8 erfuhr am 8. 2. 1942 von der deutschen Entscheidung, die italienischen Truppen aus dem Raum Neshin in die Region Gomel zu verlegen; trotz des sofortigen Protests blieb es bei den deutschen Dispositionen. AUSSME, L 14/87-2, Comando $8^{2}$ Armata, Ufficio Operazioni: La 2a battaglia difensiva del Don, Teil 3: L'avviamento delle Unità alla zona di riordinamento, Anlage 26-III: Funkspruch (Nr. 02/703) AOK 8 an das Oberkommando der Heeresgruppe B vom 8. 2. 1943. 
einigen Geschützen, die in der zweiten Phase [der Kämpfe] der Division „Ravenna" für den Einsatz am Donez zur Verfügung gestellt worden sind ${ }^{239}$. Wie im folgenden genauer dargelegt wird, ist der Verlust der Artillerie zu einem groBen Teil dem Mangel an Treibstoff zuzuschreiben; die Division „Pasubio“ beispielsweise, die auf dem Rückzug sieben vollständige Gruppen mit sich führte, mußte nach $50 \mathrm{~km}$ alles aus Benzinmangel zurücklassen, weil die deutsche Seite trotz ständiger drängender Forderungen niemals den Treibstoff bewilligt hat, der nötig gewesen wäre, um bei den operierenden Einheiten Reserven anzulegen $^{240}$.

Aus Treibstoffmangel mußte man außer der Artillerie auch alles andere an der Front zurücklassen: Pioniermaterial, Ausrüstungsgegenstände, Lebensmittel, Bekleidung usw. Während des Rückzugs gingen auch die Kollektivwaffen (Maschinengewehre, Granatwerfer usw.) verloren; nicht selten wurden auch Gewehre und Karabiner zurückgelassen. Kurzum, bezüglich der Ausstattung der Kampfeinheiten muß alles erneuert werden, von der persönlichen Ausrüstung und jener der Einheiten bis zu den Waffen. Die verbliebenen Lasttiere werden auf ungefähr 5000 geschätzt; die Kraftfahrzeuge verschiedenen Typs auf ungefähr 3500; allerdings sind noch alle auf dem Marsch, so daß hinsichtlich ihrer endgültigen Bergung größte Vorbehalte bestehen; dies gilt insbesondere für die Kraftfahrzeuge, die ohne Wartung bis zum Äußersten beansprucht werden und für die es keine Reparaturmöglichkeiten gibt.

4. Ursachen des Rückzugs: Nach der Prüfung dessen, was von den höheren Kommandos der 8. Armee vor Ort zu erfahren war, und der Einzelheiten, die zahlreiche auf dem Transport, in den Unterkünften und Bahnhöfen befragte Soldaten untergeordneter Dienstgrade beschrieben haben, sieht der Unterzeichnete in folgenden [Faktoren] die wichtigsten Ursachen für den Rückzug:

a) Lineare Schlachtordnung ohne Tiefe, wobci man gemäß den präzisen Befehlen, die von deutscher Seite erteilt wurden, alles nach vorne geworfen hat, ohne Reserven zu bilden. Bekanntlich hat man aus dem Sektor der 8. Armee zwei deutsche Divisionen (die 62. und 294.) abgezogen ${ }^{241}$, nachdem die deutsch-rumänische Front bei Stalingrad durchbrochen worden war. Dementsprechend waren in einigen Abschnitten einer einzigen Gruppe Infanterie ungefähr 400 Meter Front anvertraut. Hervorgehoben sei, daß die gewundene Aufstellung genau dem langsamen Lauf des Don folgte, und dabei hatte der Fluß seit Einbruch des Winters jegliche Bedeutung als Hindernis verloren, weil er zugefroren war.

$239 \mathrm{Vgl}$. dazu Dok. 9 mit den entsprechenden Anmerkungen.

240 Von den Artillerieabteilungen, die der Division "Pasubio“ während der Abwehrkämpfe unterstellt waren, war eine von sowjetischen Truppen überrollt worden; weitere waren in der ersten Phase des Rückzugs aus Treibstoffmangel liegengeblieben. In Makarow, wo sich die Division sammelte, trafen vier Artillerieabteilungen ein. Aufgrund der Treibstofflage wurde beschlossen, alle Geschütze außer 11 zurückzulassen und deren Zugmaschinen mit Treibstoff für $40 \mathrm{~km}$ auszustatten. Am Ende konnten nur ein Geschütz und ein Fahrzeug gerettet werden. AUSSME, DS II 1556/1, Comando Divisione "Pasubio“ (gez. General Guido Boselli): „Relazione sulla difesa al Don e sul ripiegamento al Donez (dicembre 1942 - gennaio $1943)^{\prime \prime}$, S. 19, S. 22 und S. 28 f.

241 Diese beiden Divisionen wurden der Gruppe Hollidt unterstellt; vgl. S. 62 des vorliegenden Bandes. 
b) Große waffentechnische Überlegenheit des russischen Heeres, das mit zahlreichen schweren Panzern und vielen automatischen Gewehren „Parabellum" ausgestattet ist, aus denen die Individualbewaffnung einiger Einheiten besteht. Von großer Wirkung ist auch die "Katjuscha" ${ }^{242}$, ein Apparat auf einem Kraftfahrzeug, der den gleichzeitigen Abschuß von schweren Projektilen mit Raketenantrieb bis zu einer Entfernung von etwa sechs $\mathrm{km}$ erlaubt.

c) Befehl von deutscher Seite, an Ort und Stelle Widerstand zu leisten, obwohl es zu Einbrüchen gekommen war. Der Rückzugsbefehl kam erst, als die russischen Panzer bei der "Ravenna“ tief [in eigenes Gebiet] eingedrungen waren und aus dem Rücken der an der rechten Flanke der Armee stehenden deutsch-rumänischen Verbände noch effektiver [operierten]. Diese Panzer besetzten rasch alle Verkehrsknotenpunkte, und erstickten mit großer Beweglichkeit jeden Versuch unserer Verbände im Keim, Gegenmaßnahmen zu ergreifen. Auf einigen dieser Panzer waren zehn russische Soldaten aufgesessen, fünf auf jeder Seite, die mit sichtlich vernichtender Wirkung aus automatischen Karabinern auf Infanterie und Kraftfahrzeuge feuerten, denen sie auf ihrem Marsch begegneten.

d) Das Fehlen von Treibstoffreserven bei den italienischen Verbänden machte jedes weiträumige Manöver der Artillerie unmöglich, mit der man die in die Tiefe des Raumes vorgestoßenen Panzer hätte zerstören müssen.

e) Das Zurücklassen der Artillerie hat sich entschieden auf die Moral der Truppe ausgewirkt, und ihre Angst, in russische Gefangenschaft zu geraten, hat die Auflösungserscheinungen zunächst beschleunigt.

f) Schwächer ausgeprägte Fähigkeiten der Offiziere, insbesondere der unteren Ränge, bei Rückzugsoperationen.

g) Nachhaltiger Einfluß des Klimas auf die Truppe, die gezwungen war, Tag und Nacht ohne sorgfältig vorbereitete logistische Unterstützung in den vorgeschobenen Stellungen (Schützengräben, Schneelöcher und mit Öfen versehene Schutzräume, genügend Decken, Genußmittel usw.) im Freien zu kämpfen.

h) Befehlsführung nach Maßgabe der Dispositionen von deutscher Seite, die das Gesamtbild der operativen Lage nicht immer rechtzeitig weitergab. Die Division „Torino“ z.B., die dem XXIX. deutschen Armeekorps unterstellt war, wußte nicht um den Ernst der Situation und führte einen Angriff, um einige Stellungen wiederzugewinnen, während sich alle anderen Divisionen bereits auf dem Rückzug befanden.

Trotz all dieser Mängel hat sich der italienische Soldat tagelang mit der gewohnten Tapferkeit geschlagen. Alle Kommandeure erinnern sich mit Tränen in den Augen an die Aktionen der eigenen Truppen. Die Division "Ravenna“ widerstand sechs Tage lang dem Angriff starker gepanzerter Verbände (anscheinend rund 300 Panzer ${ }^{243}$. Die Division „Pasubio“, die von vier Divisionen und Einheiten zweier weiterer Divisionen angegriffen wurde, hielt bis zum Rückzugsbefehl durch und bahnte sich den Weg mit Hilfe von zwei deutschen Sturmgeschützen vom [Kali-

$242 \mathrm{Zu}$ "Parabellum“ und „Katjuscha“ bzw. „Stalinorgel“ vgl. Dok. 9 mit Anm. 113 und Dok. 26 mit Anm. 204.

243 Zur Kräfteverteilung und zur angeblichen Stärke der sowjetischen Panzertruppen vgl. Dok. 9 mit Anm. 112. 
ber] 88 , da sie eingeschlossen war ${ }^{244}$. Von der Division „Torino“ sind nur wenige Hundert Mann übrig, die sich unter dem Kommando ihres Generals [Roberto Lerici] nach dem epischen Widerstand von Tschertkowo den Weg zurück erkämpften $^{245}$. Das Alpinikorps hat die Bewunderung des Feindes und der Verbündeten erregt; überall spricht man mit Begeisterung von diesem großartigen Verband. Die Schwarzhemden haben sehr starke Verluste erlitten und zahlreiche Ruhmestaten vollbracht. Groß ist der Anteil der Offiziere aller Einheiten an den Gefallenen.

Zusammenfassend: Die Frontverbände haben sich hervorragend geschlagen und sind erst der erdrückenden Überlegenheit des Gegners und den außergewöhnlichen Witterungsverhältnissen gewichen. Im rückwärtigen Gebiet ist es stellenweise zu Panik gekommen; so in Kantemirowka ${ }^{246}$, wo die Deutschen die Szenen anscheinend gefilmt haben ${ }^{247}$. Der General Quartiermeister hat einige Kommandeure der vorgeschobenen Logistikzentren dem Kriegsgericht gemeldet, weil sie ihre Stellung zu früh aufgegeben haben.

5. Moral der Truppe:

a) Zweifellos ist die Moral der Truppen gegenwärtig sehr gedrückt. Sogleich sei aber betont, daß es bei diesen italienischen Soldaten nicht wegen der Kämpfe, sondern wegen der Entbehrungen und der mit den besonderen russischen Verhältnissen verbundenen Strapazen dazu gekommen ist. Ein großer Teil auch der bereits im Auffrischungsraum eingetroffenen und als einsatzbereit geltenden Soldaten leidet unter beginnenden Erfrierungen und Formen leichten Bronchialkatarrhs. Hoher Anteil von Erfrierungen mit schwerwiegenden Folgen; viele Todesfälle aufgrund von Erfrierungen, gepaart mit Herzschwäche, die den Entbehrungen und langen Märschen geschuldet war, oder mit Brandgeschwüren, die nicht rechtzeitig operiert werden konnten. Man kann sich leicht vorstellen, welche Verluste die noch auf dem Marsch befindliche Truppe erleiden wird. Hervorzuheben ist, daß die Etappen notgedrungen oberflächlich organisiert sind.

b) Ein anderer dominanter Aspekt, der die Soldaten aller Dienstgrade beeinflußt: die Beziehungen zur deutschen Seite. Das Unverständnis und gegenseitige Mißtrauen haben sich so zugespitzt, daß sie Anlaß zu allen möglichen Konsequenzen geben können. Das Thema verdient die besondere Aufmerksamkeit der höheren Dienststellen. Diese Notwendigkeit wurde dem Chef des Generalstabs der Armee [Bruno Malaguti], dem General Quartiermeister und dem Kommandierenden General des rückwärtigen Gebiets vor Augen geführt. Eine Erklärung der zentralen Dienststellen, die auf diese Notwendigkeit verweist, wäre zweifellos sehr opportun.

244 Vgl. Luoni, „Pasubio ${ }^{4}$ sul fronte russo, S. 267-298.

$245 \mathrm{Vgl}$. Dok. 22 und 23 mit den entsprechenden Anmerkungen.

246 Vgl. Dok. 21 mit Anm. 116.

247 Auf italienischer Seite nahm man diese Gerüchte so ernst, daß das Ministerium für Volkskultur den Botschafter in Berlin mit Nachforschungen betraute. Wie Dino Alfieri berichtete, hätten maßgebliche deutsche Stellen bestritten, daß das Chaos während des Rückzugs der ARMIR gefilmt worden sei, doch seien diese Dementis ebensowenig zu kontrollieren wie die Gerüchte selbst. ACS, MCP, Gabinetto, busta 137, fasc. „Corpo di Spedizione in Russia“, Telegramm des Ministeriums für Volkskultur, gez. Gaetano Polverelli, an Dino Alfieri vom 17.3. 1943 und dessen Antwort vom 21.4. 1943. 
Ursachen des Problems: Wie es in solchen Fällen immer geschieht, schreiben sich die Verbündeten gegenseitig die Verantwortung für den Rückzug zu. Die deutsche Seite gewährt Züge und Treibstoff nicht im geforderten Umfang, die nötig sind, um unsere Soldaten nach hinten zu verlegen, so daß sie Hunderte von Kilometern zu Fuß zurücklegen müssen und Tag für Tag höhere Verluste erleiden. Unsicherheit über den Auffrischungsraum der Armee, der sich ständig ändert; dadurch weitere Fußmärsche, Unmöglichkeit, Unterkünfte zu organisieren, Schwierigkeiten, Nachschub und Logistik zu gewährleisten usw. Sperrung der besseren Straßen wie der über Poltawa für den italienischen Verkehr. Verbot für italienische Verbände, die Städte Kiew und Dnjepropetrowsk zu betreten. Plünderung von Depots und insbesondere Raub von Kraftfahrzeugen, zum Teil auch mit der Waffe in der Hand und mit Schußwechseln, die bisher glücklicherweise folgenlos geblieben $\operatorname{sind}^{248}$. Zum gegenwärtigen Zeitpunkt nimmt sich die engmaschige deutsche Organisation in den rückwärtigen Gebieten wegen beschränkter Mittel nur der Deutschen und nicht der Italiener an, die sich oftmals im Stich gelassen fühlen. Die Unkenntnis der Sprache trifft denjenigen, der Hilfe nötig hat und nicht weiß, wie und an wen er sich wenden soll.

c) Wie bereits anfänglich gesagt, verstärkte die Angst, in russische Gefangenschaft zu geraten, die Auflösungserscheinungen und löste bei denen, die von ihrer Einheit getrennt wurden, das Verlangen aus, sich vor einer unmittelbar bevorstehenden Gefangennahme in Sicherheit zu bringen. Später jedoch verbreitete sich aufgrund einiger Begebenheiten die Nachricht, daß der Russe den italienischen Soldaten gut behandelt. Alpini der "Julia“, die nach zwei oder drei Tagen Gefangenschaft geflohen sind, erzählten, daß der russische Soldat die gefangenen italienischen Soldaten gut behandle, während die Deutschen entkleidet und umgebracht würden, und diese Gruppe von Soldaten berichtete mir, daß die Schuhe, die man den Deutschen weggenommen habe, an die italienischen Soldaten verteilt worden seien. Die Partisanen hingegen töten unterschiedslos alle Gefangenen. In einigen Fällen werden die gefangenen italienischen Offiziere anscheinend ohne Umschweife getötet, während man die gefangenen Mannschaften am Leben läßt ${ }^{249}$.

Dann bot die russische Bevölkerung all unseren Soldaten eingedenk der Behandlung, die sie in den besetzten Gebieten von unseren Truppen erfahren hat, im Verlauf des Rückzugs großzügige Hilfe an. Offensichtlich veranlaßte dies unsere bereits ermüdeten Soldaten dazu, in den Isbas zu bleiben, um den aufreibenden Rückzugsmärschen zu entgehen, die voller Risiken für denjenigen sind, der nicht mehr vollständig Herr seiner Kräfte ist.

Zusammenfassend: Im wesentlichen handelt es sich um ein physisches Tief, das sich auf den moralischen Zustand auswirkt. Starkes Verlangen, nach Italien zurückzukehren oder auf einen anderen Kriegsschauplatz versetzt zu werden, weil nur geringes Vertrauen in unsere Bewaffnung besteht, die ungeeignet ist, den Panzerkräften des russischen Heeres standzuhalten, und wegen der Furcht vor den Folgen des hiesigen Klimas im Falle eines Rückzugs aus ausgebauten Stellungen.

$248 \mathrm{Vgl}$. die Zusammenstellung von Zwischenfällen in Dok. 24.

$249 \mathrm{Zu}$ den widersprüchlichen Schilderungen vgl. auch Dok. 18 mit Anm. 70. 
6. Verluste und Möglichkeiten zur sofortigen $W_{1}$ ederverwendung von Personal:

a) Die ungefähr 215000 Mann starke Armee ist nunmehr auf ungefähr 95000 reduziert, ausgenommen diejenigen, die aus verschiedenen Gründen in die Reservelazarette und nach Italien gebracht worden sind ${ }^{250}$. Diese Zahlen müssen als grobe Näherungswerte verstanden werden. Die großen Entfernungen, die Zersplitterung und die fehlenden Verbindungen erlauben es nicht, die Verluste der einzelnen Verbände anzugeben, bevor nicht alle in einem einzigen Sektor versammelt sind.

b) Ebenso ist es momentan unmöglich, Kommandeure von Großverbänden und Generalstabsoffiziere für neue Verwendungen zu gewinnen (abgesehen von denen, die bereits wegen Verwundung oder Krankheit in die Heimat zurückgeschickt worden sind), weil das Führerkorps aus offenkundigen Gründen der Moral nicht von der Truppe auf dem Marsch abgezogen werden kann, auch wenn die Stärke der einzelnen Einheiten im Vergleich zum Soll beträchtlich reduziert ist.

Gegenwärtig könnte folgendes Personal gewonnen werden: Diejenigen, die ein Anrecht auf Ablösung haben; die Armee hat bereits die Befehle erlassen, um diese Soldaten nach Italien zu schicken, doch gibt es erhebliche Schwierigkeiten wegen des Mangels an Beförderungsmitteln. Truppen, Versorgungsdienste der Armee sowie Personal der Intendenza, die aufgrund der verbliebenen Gesamtstärke in der Operationszone nicht mehr benötigt werden. Leider gibt es jedoch für den Transport dieses Personals in die Heimat nur eine einzige Möglichkeit: den wertvollen, dreimal pro Woche angesetzten Transport, aber dieser genügt zumeist nicht einmal, um die Leichtverwundeten und Kranken zurückzuverlegen. Die Lazarettzüge reichen gerade für die Liegendkranken aus. Nötig wäre also eine größere Zahl von Zügen, die für die Beförderung von Personen ausgerüstet sind. Diese müßte man von der deutschen Seite einfordern, um die Kranken und Leichtverwundeten zurückzuverlegen und die verfügbaren [regulären] Transporte für das Personal freizuhalten, das heimkehren soll.

7. Neuordnung der verbliebenen Truppen: Bekanntlich wechselte der Auffrischungsraum für die verbliebenen Truppen mehrfach: zunächst Woroschilowgrad, anschließend Isjum, dann Neshin, schließlich Gomel. All diese aufeinanderfolgenden Änderungen haben bei der Truppe das Gefühl der Entmutigung erheblich verstärkt. Gravierende Auswirkungen hatte die Bergung des Materials aus den vorgeschobenen Logistikzentren und die Versendung bzw. Rückstellung von allem, was aus Italien kommt. Die Weiterleitung der Versorgungszüge mußte ausgesetzt werden, und ein Teil des Materials wurde nach Italien zurückgeschickt, weil die deutsche Seite nur zwei Lösungsmöglichkeiten zuließ: Entladung im Gebiet von Neshin oder Rücksendung der vollen Waggons in die Heimat. Für die Munition der Artillerie, die es nicht mehr gibt, und das schwere, nicht für den unmittelbaren Einsatz bestimmte Material blieb nur die Rücksendung in die Heimat.

Der Raum Neshin bot keinerlei Ressourcen, und das wenige Verfügbare war bereits von deutschen Kräften besetzt. Auch der größte den italienischen Truppen zugewiesene Entladebahnhof (Neshin) ist bis heute von Deutschen besetzt, die

$250 \mathrm{Zu}$ den Verlusten an Menschen und Material vgl. S. $74 \mathrm{f}$. des vorliegenden Bandes. 
auch die kleinste Aktion regeln; dem italienischen Militärkommando ist eine kleine, im wahrsten Sinne des Wortes schäbige Baracke vorbehalten. Man wird gezwungen sein, der Truppe, die nach Hunderten von Kilometern Fußmarsch auf eisigem Schnee in Neshin eintrifft, zu befehlen, nach Gomel weiterzumarschieren, das weitere $200 \mathrm{~km}$ entfernt ist.

Der neue Auffrischungsraum ist bekanntlich sumpfig, malariaverseucht, voll von organisierten Partisanen und ausnehmend knapp an logistischen Ressourcen. Wie dem auch sei, eines ist unbedingt notwendig: daß wir über ein ausschließlich für uns bestimmtes Gebiet verfügen, wo wir ohne deutsche Einmischung ein italienisches Milieu schaffen können, um unsere Soldaten physisch und moralisch wiederaufzurichten. Dieser von Seiner Exzellenz, dem Oberbefehlshaber der Armee, klar geäußerte Wunsch verdient die ganze Unterstützung der höheren Stellen. Seine Exzellenz Gariboldi hat überdies dem Wunsch Ausdruck gegeben, ihn zumindest bis zu dem Zeitpunkt, an dem der letzte Soldat das Neuaufstellungsgebiet erreicht hat, an seinem Platz zu belassen.

8. Eventuelle Neuaufstellung des II. Armeekorps: Momentan ist jedes Urteil darüber verfrüht ${ }^{251}$. Zunächst muß man wissen, wieviel insbesondere an Lasttieren und Kraftfahrzeugen im Auffrischungsraum gesammelt werden kann. Es gibt, wie gesagt, anscheinend noch $3500 \mathrm{Kraftfahrzeuge}$ und 5000 Lasttiere, die jedoch alle noch Hunderte von Kilometern von der Basis der Neuaufstellung entfernt sind. Keine Artillerie, wenige tragbare Kollektivwaffen. Die Reorganisation der Männer und ihre Einteilung in reguläre Einheiten beansprucht zweifellos viel Zeit. Die Überlebenden der Kampftruppen sind zum großen Teil leicht erkrankt oder leiden unter beginnenden Erfrierungen.

Es bleibt ein erheblicher [Bedar ${ }^{252}$ ] an Artillerie, Transportmitteln und diverser Ausrüstung, die Männer werden verschiedene Phasen durchlaufen müssen: Sammlung in einem bestimmten Gebiet, die vielleicht bis Ende März abgeschlossen ist; Selektion und Neugliederung in Einheiten; angemessen lange Ausbildung insbesondere für die Fachkräfte; die Ausbildung kann logischerweise erst beginnen, nachdem Waffen und Material herbeigeschafft und ausgegeben worden sind.

Infolgedessen wird der neue Großverband nicht vor Ende Juni einsatzbereit sein können, wenn die deutsche Seite liefert, was an Artillerie, Lasttieren und Kraftfahrzeugen nötig ist. In diesem Zusammenhang gilt es nach übereinstimmender Meinung aller höheren Stellen der 8. Armee und aufgrund der gemachten Erfahrungen zu bedenken, daß der neue Großverband reichlich mit Panzern und Sturmgeschützen vom [Kaliber] 88 oder 90 ausgestattet sein muß. Ohne diese Waffen kann man in Rußland nicht mehr kämpfen; andernfalls ist es um der nationalen Ehre willen besser, unsere Truppen zurückzuziehen. Angesichts der Tatsache, daß die deutsche Seite bereits indirekt mitgeteilt hat, sie könne das geforderte Gerät nicht stellen ${ }^{253}$, ist es sehr wahrscheinlich, daß man beabsich-

$251 \mathrm{Vgl}$. S. 75 des vorliegenden Bandes.

252 In der Vorlage wörtlich: „disponibilità “, was aber angesichts des Kontextes keinen Sinn ergibt.

253 Der Unwille, das königliche Heer mit deutschen Waffen auszurüsten, war auch bei Hitler spürbar; vgl. Heiber (Hrsg.), Lagebesprechungen, S. 81 f.; zu den divergierenden deutschen und italienischen Vorstellungen zu Ausrüstung und Einsatz des neuen Expeditionskorps 
tigt, die Reste der 8. Armee für den Kampf gegen die Partisanen einzusetzen und ihnen solche Aufgaben zu übertragen, wie sie den italienischen Hilfstruppen im Krieg 1915-1918 in Frankreich zugewiesen worden sind ${ }^{254}$. Auch diese Lösung würde der nationalen Ehre Italiens zweifellos nicht zum Vorteil gereichen.

Zusammenfassend scheint folgender Vorschlag der beste zu sein: Auffrischung der restlichen Truppen vor Ort, und wenn es nicht möglich sein sollte, eine angemessene Bewaffnung und einen eigenen Frontabschnitt zu erhalten, Rückkehr des Expeditionskorps nach Italien.

9. Logistische Organisation der 8. Armee: Die Intendenza bemüht sich mit allen Mitteln und unter Ausnutzung aller Möglichkeiten, die Situation zu meistern und zu retten, was zu retten ist. Der Quartiermeister, General Biglino, der sein gesamtes Personal fest in der Hand hat, begibt sich täglich per Flugzeug, Auto und Eisenbahn von einem Sektor in den anderen, um zu ermutigen und Maßnahmen zu ergreifen. Der Chef des Generalstabs, Oberstleutnant De Micheli ${ }^{255}$, der für den Widerstand gegen russische Panzer im von der kämpfenden Truppe bereits aufgegebenen vorgeschobenen Logistikzentrum Kantemirowka auf dem Schlachtfeld mit der silbernen Tapferkeitsmedaille ausgezeichnet worden ist, befindet sich nun im am weitesten vorgeschobenen Logistikzentrum in Charkow, der einzigen dort verbliebenen italienischen Einrichtung, um wertvolles Material zu bergen und zurückzuführen. Das übrige Personal ist über das gesamte Gebiet verteilt und versucht, die größtmögliche Menge an Material zu retten und unsere Truppen zu unterstützen.

Die Interventionen der Intendenza bei den deutschen Stellen, um Transportmittel, Treibstoff, Lebensmittel und Unterkünfte zu erhalten und zu verhindern, daß die Deutschen sich der Kraftfahrzeuge und logistischen Zentren bemächtigen, waren zweifellos sehr wirkungsvoll. Oftmals ist es zwischen den beiden Seiten zu sehr unerfreulichen Konflikten gekommen, doch muß auch bedacht werden, daß es der italienischen Seite darum geht, Tausende von unseren Soldaten und Materialien zu retten, die das Vaterland nicht ersetzen kann.

a) Räumung der Logistikzentren: In den vorgeschobenen Zentren einschließlich Kantemirowka und Tschertkowo ist die Gesamtheit des dort gelagerten Materials verlorengegangen - Unmengen von Lebensmitteln, Pelzbekleidung, Munition, Pionier-, Sanitäts-, chemisches usw. Material. Woroschilowgrad wurde mit Ausnahme des Brückenbaumaterials ganz geräumt. In Stalino und Rykowo wurden die Lazarette, die Fiat-Werkstätten, der 6. und 7. Kraftfahrzeugpark und der Apparat zur Ncukalibrierung von Patronenhülsen evakuiert, während sich die umfangreiche Ausrüstung verschiedener Dienste aufgrund des Fehlens von Transporimitteln noch dort befindet. Debalzewo wurde abgesehen von der

vgl. AUSSME, L 13/48-5, Bericht der italienischen Militärmission in Deutschland, gez. General Efisio Marras, an das Comando Supremo vom 15.3. 1943.

254 Neben dem 1917 an die Westfront entsandten, aus zwei Divisionen bestehenden II. italienischen Armeekorps unterstützte Italien die französischen Alliierten durch die Aufstellung eines Hilfskorps, das beim Bau von Feldbefestigungen, bei der Anlage von Feldflugplätzen, beim Bau oder der Instandhaltung von Straßen und Eisenbahnlinien im Operationsgebiet usw. eingesetzt wurde. Vgl. Bovio, Operazioni, in: Esercito italiano, S. 390 f.

255 Luigi De Micheli, Oberstleutnant, 1941-1943 Chef des Stabes der Intendenza des CSIR bzw. der 8. Armee. 
Munition fast vollständig geräumt. Kupjansk wurde abgesehen von den Barakken vollständig geräumt. Charkow: Räumung im Gange, aber durch das Fehlen von Transportmitteln behindert.

b) Verluste bei der Ausstattung der Intendenza: Zum gegenwärtigen Zeitpunkt ist die Intendenza nicht in der Lage, die Verluste an Material, Lasttieren und Transportmitteln auch nur annähernd anzugeben; [die Zahlen] werden so bald wie möglich präzisiert. Ein beträchtlicher Teil des aus den verschiedenen Zentren evakuierten Materials befindet sich in Eisenbahnwaggons, deren Rückführung in deutschen Händen liegt und davon abhängt, ob [Lokomotiven 256] zur Verfügung stehen. Man schätzt, daß ein Viertel des in der Gegend vorhandenen Eisenbahnmaterials verlorengegangen ist.

c) Ergriffene Maßnahmen: Rückführung der gesamten Artilleriemunition nach Italien. Rückführung des gesamten Materials zum rückwärtigen Sammelbahnhof (Skotschau ${ }^{257}$ bei Krakau), mit Ausnahme eines Teils der in Neshin benötigten Lebensmittel. Die normalen Versorgungsanforderungen für März wurden annulliert, abgesehen von einem Teil der Lebensmittel, die mit dem Nachschub für Februar geschickt werden.

Die Dienststelle wird auf Grundlage der mündlichen Absprachen mit dem General Quartiermeister die Anordnungen treffen, die sich aus den erwähnten Maßnahmen allgemeiner Natur ergeben. Keine Mängel wurden hinsichtlich dessen beklagt, was aus Italien geschickt worden ist oder sich auf dem Weg befindet. Alle erkennen gleichermaßen die Großzügigkeit an, mit der man sich um die Ausrüstung und die Versorgung der 8. Armee gekümmert hat.

Als der Angriff begann, hatten die Soldaten, die abgelöst werden sollten, keine pelzgefütterten Mäntel, von denen 50000 in den Depots des vorgeschobenen Zentrums von Kantemirowka lagerten. Gleiches gilt für die Schlafsäcke und weitere Sonderbekleidung. Einige Klagen über diese restriktiven Anordnungen bezüglich der Ausgabe von Bekleidung, deren Fehlen sich nun bei einem kleinen Teil der Soldaten auf dem Rückzug bemerkbar macht. Man muß jedoch anerkennen, daß diese Maßnahme logisch und opportun gewesen wäre, wenn nicht der unvorhersehbare Fall des Rückzugs eingetreten wäre ${ }^{258}$.

10. Organisation des rückwärtigen Gebiets: Das Kommando für das rückwärtige Gebiet Ost und das für Transporte zuständige italienische Verbindungskommando bemühten und bemühen sich unermüdlich darum, mit intelligenten Initiativen jede unvorhergesehene Zwangslage zu bewältigen. Das Lazarett in Lemberg hat Wunder vollbracht. Der Direktor, Oberstleutnant Palmieri259, verdient jedes Lob; durch dieses Hospital sind in kurzer Zeit ungefähr $8000 \mathrm{Kranke}$ und Verwundete gegangen, von denen viele aufgrund brandig gewordener Erfrierungen einer Amputation unterzogen werden mußten.

256 In der Vorlage wörtlich: „mezzi di trazione“.

257 In der Vorlage: „Schotscau“.

258 Das handschriftlich in diesen Satz eingefügte Wort ${ }_{n}$ auch" ergibt keinen rechten Sinn und wurde daher weggelassen.

259 Oberstleutnant Palmieri hatte die Leitung des Reservelazaretts Nr. 10 in Lemberg erst Ende Dezember 1942 übernommen; AUSSME, DS II 1204, KTB Comando delle Retrovie dell' Est, Dezember 1942/Januar 1943, Eintrag vom 22. 12. 1942. 
Sämtliche Etappenkommandos und die Militärkommandos an den Bahnhöfen versuchen mit allen Mitteln, die momentanen Schwierigkeiten zu meistern. Das Kommando für das rückwärtige Gebiet hat auch im Raum Neshin eingegriffen, wo es ein eigenes Etappen[kommando] positioniert hat, um auf die bestmögliche Weise mit der Intendenza zusammenzuarbeiten.

Hervorgehoben sei die hervorragende italienische Transportorganisation, die der deutschen, ungarischen und rumänischen weit überlegen ist. Dieser eigenständige italienische Apparat, der warme Speisen, beheizte Räumlichkeiten, Gesundheitsversorgung und Geldwechselmöglichkeiten bietet, wird von all denen aufgesucht, die mehrere Tage lang durch die unermeßlichen gefrorenen Ebenen Rußlands fahren müssen. Wer sich über die Transporte beklagt, hat offensichtlich kein Verständnis für die Probleme, die es zu überwinden gilt, ist noch nicht mit anderen Zügen in Rußland gefahren und will vor allem nicht das geringste Opfer für den Krieg auf sich nehmen.

Das gesamte Personal in der Etappe verdient Lob; allerdings wäre es angebracht, daß die Jüngeren möglichst bald durch Personal ersetzt würden, das in Rußland abgelöst worden ist. Wer den Frontkämpfern bei der Durchfahrt durch das rückwärtige Gebiet zu Diensten ist, sollte aus offensichtlichen Gründen der Moral zeigen können, daß er seine Pflicht an der Front bereits erfüllt hat.

11. Vorschläge zur logistischen Organisation: Die Lage ist noch zu unbeständig, um Programme logistischer Natur umsetzen zu können. Der Transport der gesamten Armee in den Raum Gomel verlangt Maßnahmen von großer Tragweite. Zunächst jedoch muß man in Erfahrung bringen: den Nachschubweg aus Italien, um die gesamte Organisation des rückwärtigen Gebiets entsprechend zu verlegen; die Möglichkeiten, das Material der Intendenza im Sektor [der Armee] zu lagern und in der 'Tiefe des Raums zu staffeln (fürs erste sind die Reservelazarette, Fiat-Werkstätten und Kraftfahrzeugparks in den Raum Lemberg geschickt worden, was zweifellos nicht der jüngsten Verschiebung [des Auffrischungsraums] nach Norden entspricht); die Route der dreimal pro Woche angesetzten Transporte, um einen Anhaltspunkt für die Dislozierung der Etappen[kommandos] zu haben; Truppen und Material, die nach Beendigung der laufenden Bewegungen in den Sektor [der Armee] verlegt werden sollen. Momentan ist alles ausgesetzt, und man wartet darauf, die genannten Angaben zu bekommen. 
